US Army Corps

of Engineers $s_{\circledast}$

Engineer Research and

Development Center

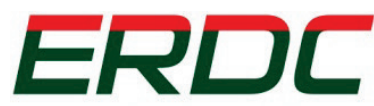

INNOVATIVE SOLUTIONS

for a safer, better world

Airfield Damage Repair Modernization Program

\title{
AM2 Brickwork Pattern Evaluation with Refurbished Matting
}

Lyan Garcia, Timothy W. Rushing, and Jeb S. Tingle

August 2015 
The U.S. Army Engineer Research and Development Center (ERDC) solves the nation's toughest engineering and environmental challenges. ERDC develops innovative solutions in civil and military engineering, geospatial sciences, water resources, and environmental sciences for the Army, the Department of Defense, civilian agencies, and our nation's public good. Find out more at www.erdc.usace.army.mil.

To search for other technical reports published by ERDC, visit the ERDC online library at http://acwc.sdp.sirsi.net/client/default. 


\section{AM2 Brickwork Pattern Evaluation with Refurbished Matting}

Lyan Garcia, Timothy W. Rushing, and Jeb S. Tingle

Geotechnical and Structures Laboratory

U.S. Army Engineer Research and Development Center

3909 Halls Ferry Road

Vicksburg, MS 39180-6199

Final report

Approved for public release; distribution is unlimited.

Prepared for Headquarters, Air Force Civil Engineer Center

Tyndall Air Force Base, FL 32403-5319 


\section{Abstract}

The U.S. Marine Corps established different lay patterns to assemble AM2 mat expanses that can be used to form aircraft operating surfaces. The brickwork configuration is the traditional installation pattern and has proven to provide improved load carrying capability of the system. For several years, the U.S. Army Engineer Research and Development Center conducted full-scale testing of the brickwork pattern using new AM2 Mod 5 matting acquired directly from the manufacturer. Several years ago, the Naval Air Systems Command (NAVAIR) implemented a refurbishment program to restore AM2 panels after these have been in service in an effort to reduce frequent large procurements of new AM2 Mod 5. Since AM2 is made from aluminum and has an indefinite service life, many earlier versions, such as two-piece and Mod 4, still remain in the fleet and can be found in refurbished bundles. The efforts of the test program discussed in this report focused on evaluating an AM2 surface that combined both new AM2 Mod 5 panels and AM2 refurbished panels to provide insight on the life expectancy of refurbished panels as compared to new panels. In addition, NAVAIR subgrade void criteria were tested to determine the effect a voided subgrade will have on the structural integrity of AM2. This report provides test results for each evaluation and discussions comparing their performance to previous tests conducted under similar conditions.

DISCLAIMER: The contents of this report are not to be used for advertising, publication, or promotional purposes. Citation of trade names does not constitute an official endorsement or approval of the use of such commercial products. All product names and trademarks cited are the property of their respective owners. The findings of this report are not to be construed as an official Department of the Army position unless so designated by other authorized documents. 


\section{Contents}

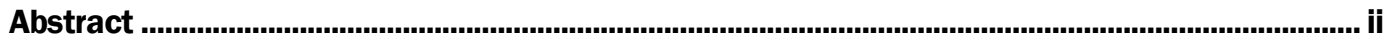

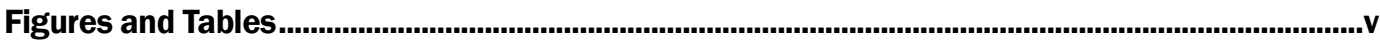

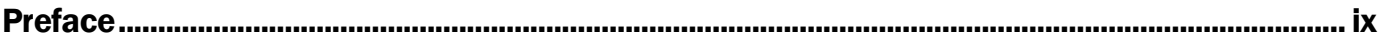

Unit Conversion Factors ........................................................................................................................

1 Introduction .............................................................................................................................. 1

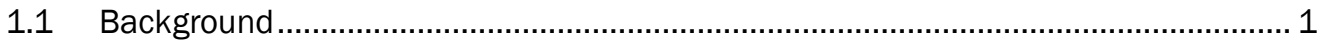

1.1.1 Naval Air Systems Command Dynamic Interface Model ...................................... 1

1.1.2 AM2 certified configuration lay patterns ............................................................ 1

1.1.3 AM2 brickwork lay pattern and NAVAIR void criteria ......................................... 3

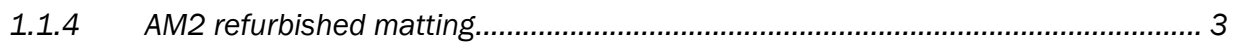

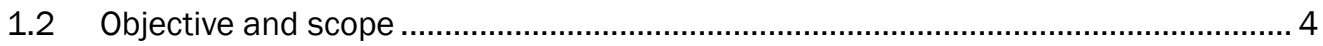

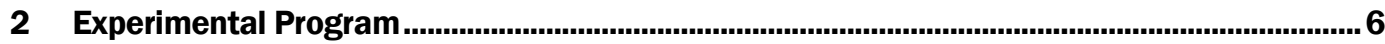

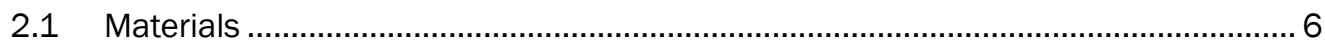

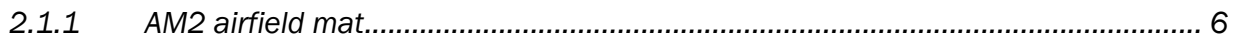

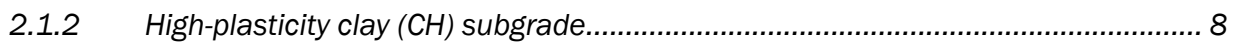

2.2 Test section general description .................................................................... 10

2.3 Test section construction ................................................................................. 13

2.3.1 Subgrade construction and posttest forensics ................................................ 14

2.3.2 Subgrade instrumentation........................................................................... 22

2.3.3 AM2 strain gauge instrumentation ................................................................. 24

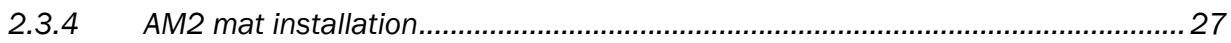

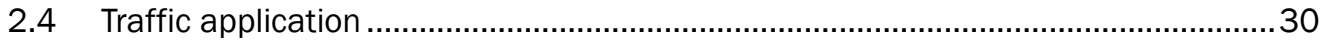

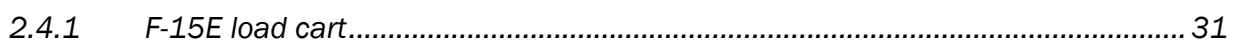

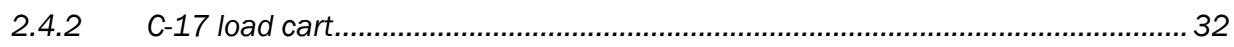

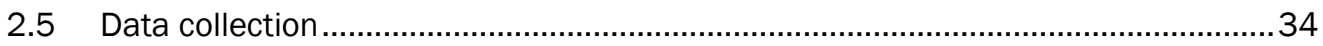

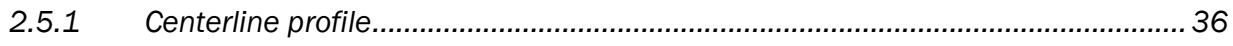

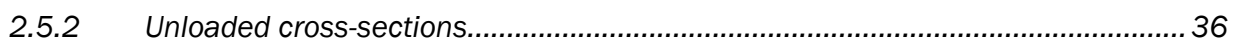

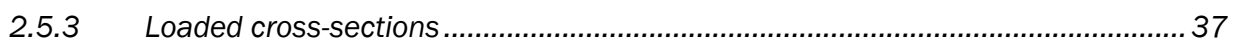

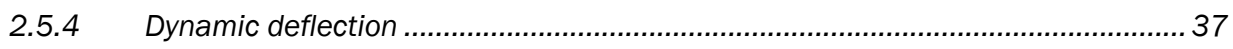

2.5.5 Earth pressure and strain measurements........................................................ 39

2.5.6 Borescope observation and depth measurement................................................ 39

2.6 Failure criteria ........................................................................................... 40

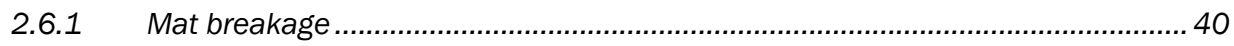

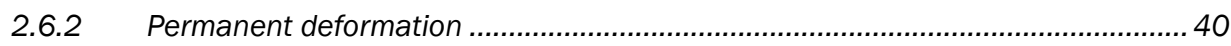

3 Test Results-Brickwork Pattern on Voided Subgrade............................................................42

3.1 Mat behavior under traffic (visual observations) ................................................42

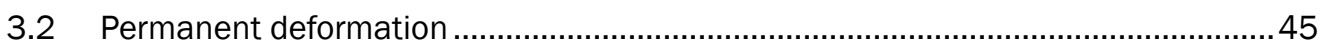




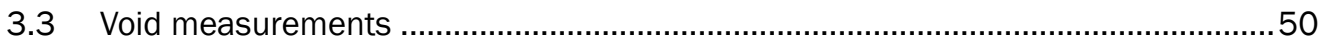

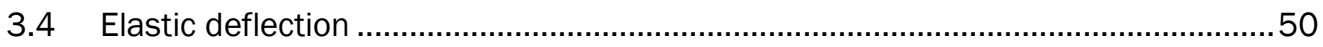

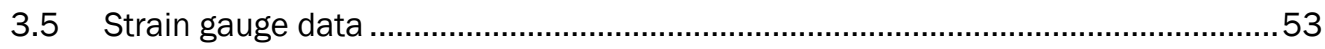

4 Test Results-Brickwork Pattern ...........................................................................................59

4.1 Mat behavior under traffic (visual observations) ...................................................59

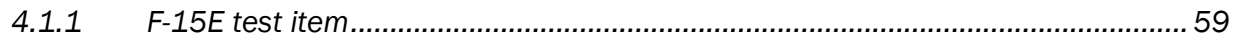

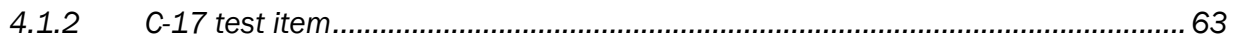

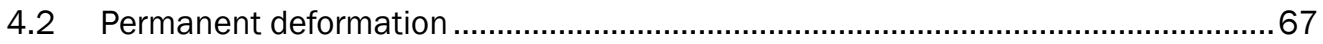

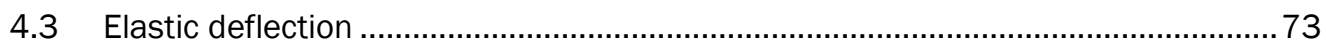

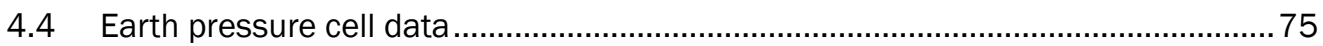

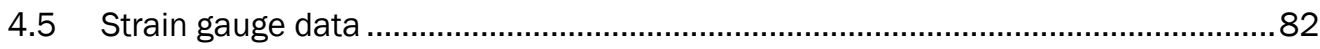

5 Analysis of Results-Brickwork Pattern on Voided Subgrade...................................................91

5.1 Mat breakage................................................................................................... 91

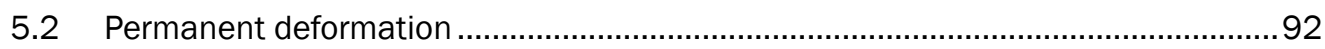

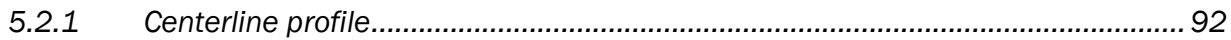

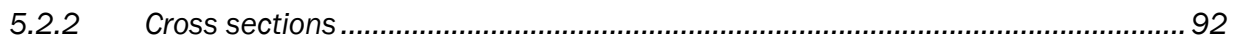

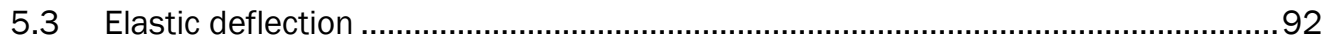

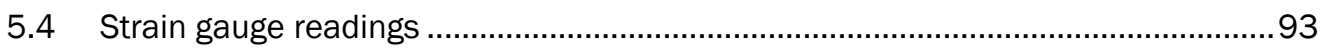

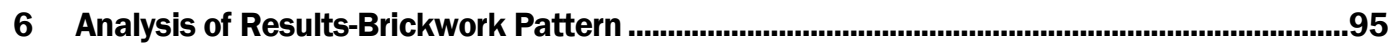

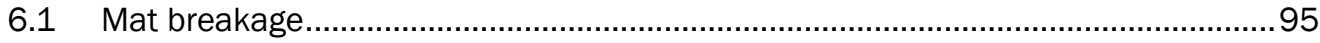

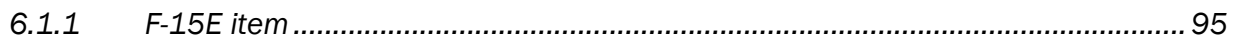

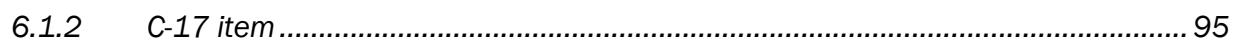

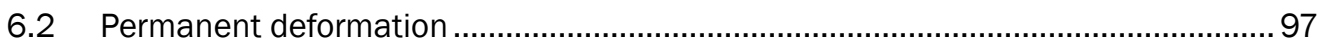

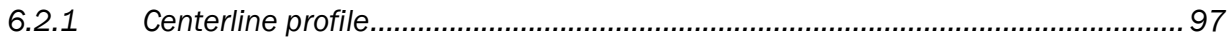

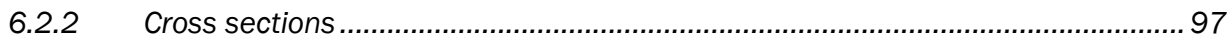

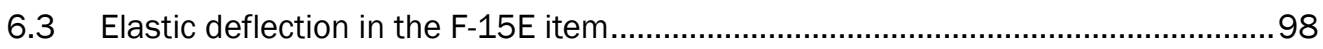

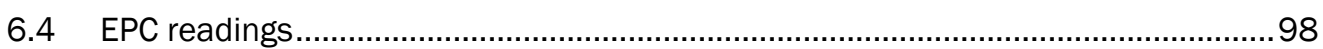

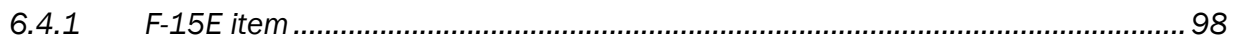

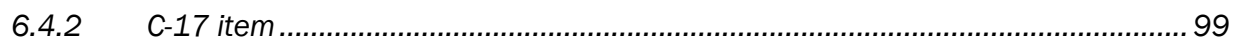

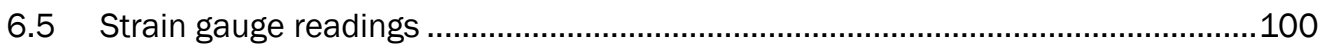

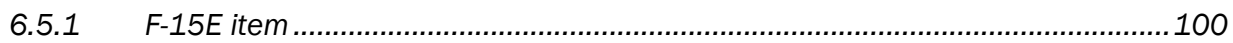

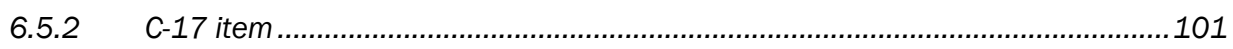

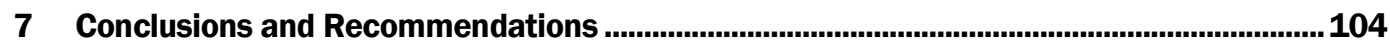

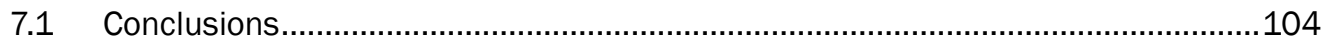

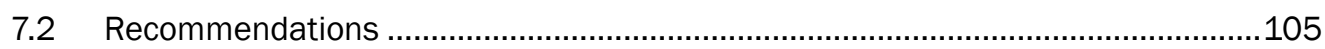

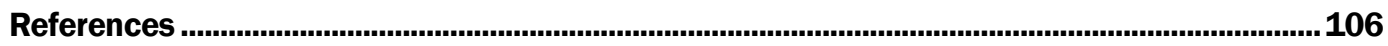

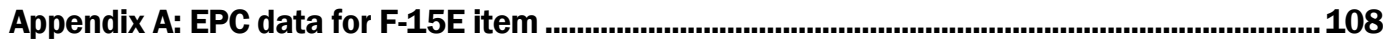

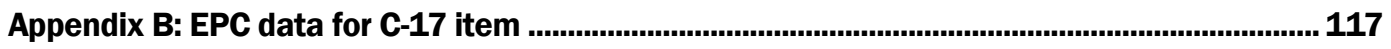

Report Documentation Page 


\section{Figures and Tables}

\section{Figures}

Figure 1. F71 (left) and F72 (right) mat packages.......................................................................

Figure 2. Damage noted on refurbished AM2 panel before applying traffic. .......................................

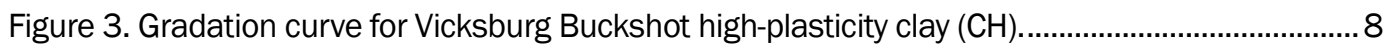

Figure 4. Dry density vs. moisture content for $\mathrm{CH}$ subgrade material. ................................................. 9

Figure 5. CBR vs. moisture content for $\mathrm{CH}$ subgrade material. ...........................................................

Figure 6. Test section profile.................................................................................................................10

Figure 7. AM2 brickwork pattern on voided subgrade panel layout....................................................11

Figure 8. AM2 brickwork pattern panel layout. ……………..............................................................12

Figure 9. Test section excavation. ...............................................................................................14

Figure 10. Test pit lined with impervious sheeting. ........................................................................15

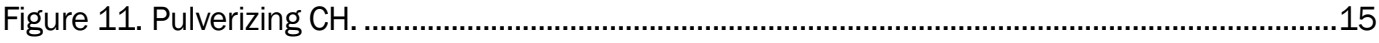

Figure 12. Addition of water to adjust moisture content. ...............................................................16

Figure 13. Loading processed $\mathrm{CH}$ into haul truck. ......................................................................16

Figure 14. Leveling $\mathrm{CH}$ material in test pit prior to compaction......................................................17

Figure 15. Compacting $\mathrm{CH}$ subgrade with pneumatic roller............................................................17

Figure 16. Nuclear moisture-density gauge test...........................................................................19

Figure 17. Field CBR test. ..................................................................................................19

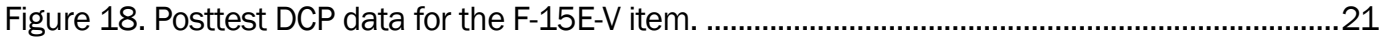

Figure 19. F-15E and C-17 items instrumentation layout...................................................................23

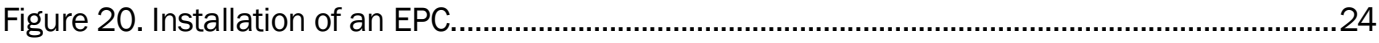

Figure 21. Strain gauge locations on upper underlap and lower overlap regions. .............................25

Figure 22. Typical strain gauge installation on lower overlap region. ..................................................25

Figure 23. F-15E-V item instrumentation layout. ............................................................................26

Figure 24. Void installation on subgrade surface...........................................................................2

Figure 25. Insertion of aluminum locking bar between adjacent panels..........................................28

Figure 26. Installation of AM2 panels on the test section subgrade...............................................28

Figure 27. Typical installation of towing to the edges of the test section. ……...................................29

Figure 28. Typical Installation of male keylock...............................................................................29

Figure 29. Brickwork pattern on voided subgrade final assembled test section...............................30

Figure 30. F-15E (left) and C-17 (right) items...........................................................................30

Figure 31. F-15E test load cart................................................................................................31

Figure 32. Plan view showing F-15E normally distributed traffic lanes............................................32

Figure 33. C-17 test load cart. ..................................................................................................33

Figure 34. Plan view showing C-17 normally distributed traffic lanes................................................33 


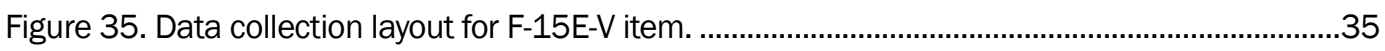

Figure 36. Data collection layout for F-15E and C-17 items..........................................................36

Figure 37. Surveying unloaded cross-section. ................................................................................

Figure 38. Surveying loaded cross-section...............................................................................38

Figure 39. Prism mounted on F-15E load cart.............................................................................38

Figure 40. Borescope (left) and depth measurement (right)...........................................................39

Figure 41. Corner curl in Panel 26 after 240 passes.......................................................................42

Figure 42. Broken upper under lap rail in Panel B40-1.................................................................43

Figure 43. Damage noted in Panel 25 after picking up mats..........................................................44

Figure 44. Layout of damaged and failed panels in the F-15E-V item..............................................46

Figure 45. Subgrade centerline profile of the F-15E-V item after 322 passes...................................4 47

Figure 46. Centerline profile on mat surface of F-15E-V item at different pass levels.......................48

Figure 47. Average deformation on subgrade of F-15E-V item after 322 passes. .............................48

Figure 48. Average deformation on the loaded mat surface of the F-15E-V item at different pass levels.

Figure 49. Average deformation on unloaded mat surface of the F-15E-V item at different

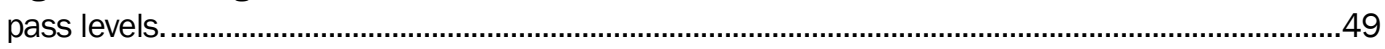

Figure 50. Void depth beneath the mat throughout traffic in the F-15E-V item................................51

Figure 51. V2W, V2E (a) pretest and (b) posttest and V1-C (c) pretest and (d) posttest....................51

Figure 52. Elastic deflection elevation distribution on F-15E-V item, pass 33-48. ...........................52

Figure 53. Elastic deflection on F-15E-V item. ........................................................................52

Figure 54. Strain gauge data for F-15E-V item, SG B37-1F2, passes 1-4........................................53

Figure 55. Strain gauge data for F-15E-V item, SG B38-1F2, passes 1-4 ......................................54

Figure 56. Max tensile strain at F-15E-V item panels B37-1 and B38-1 .........................................55

Figure 57. Max compressive strain at F-15E-V item panels B37-1 and B38-1.................................55

Figure 58. Max tensile strain at F-15E-V item panels B37-2 and B38-2 .......................................56

Figure 59. Max compressive strain at F-15E-V item panels B37-2 and B38-2 ...............................56

Figure 60. Max tensile strain at F-15E-V item panels B40-1 and B41-1 ......................................57

Figure 61. Max compressive strain at F-15E-V item panels B40-1 and B41-1...............................57

Figure 62. Max tensile strain at F-15E-V item panels B40-2 and B41-2 ......................................58

Figure 63. Max compressive strain at F-15E-V item panels B40-2 and B41-2 ………...................58

Figure 64. Layout of failed and damaged panels in F-15E and C-17 items.....................................59

Figure 65. Panel 89 after 430 passes...........................................................................................61

Figure 66. Damage noted in Panel 101 after removing from test section.......................................61

Figure 67. Damage noted in Panel 68 after removing from test section. .........................................62

Figure 68. Panel 69 after removing from test section. ......................................................................64

Figure 69. Panel 67 after 1,308 passes. ......................................................................................65

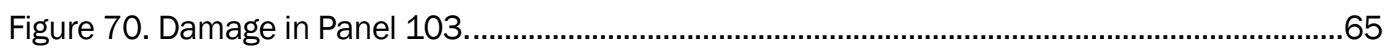

Figure 71. Panel B52 after removing from C-17 test item..............................................................66

Figure 72. Subgrade centerline profile of the F-15E item after 430 passes.....................................68

Figure 73. Subgrade centerline profile of the $\mathrm{C}-17$ item after 1,308 passes....................................69 
Figure 74. Centerline profile on the mat surface of the F-15E item at different pass levels.............69

Figure 75. Centerline profile on the mat surface of the $\mathrm{C}-17$ item at different pass levels................70

Figure 76. Average deformation on the subgrade of the F-15E item...............................................70

Figure 77. Average deformation on the subgrade of the $\mathrm{C}-17$ item after 1,308 passes. ...................71

Figure 78. Average deformation on the loaded mat surface of the F-15E item at different

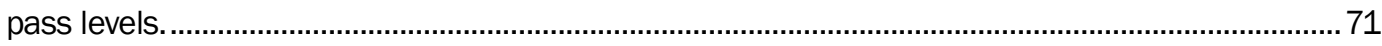

Figure 79. Average deformation on the loaded mat surface of the C-17 item at different pass levels.

Figure 80. Average deformation on the unloaded mat surface of the F-15E item at different pass levels.

Figure 81. Average deformation on the unloaded mat surface of the $\mathrm{C}-17$ item at different pass levels. .73

Figure 82. Elastic deflection measurements' wander distribution on F-15E item, passes 1-10.............. 74

Figure 83. Elastic deflection elevation distribution on F-15E item.................................................. 74

Figure 84. Elastic deflection on F-15E item mat surface at various pass levels.................................75

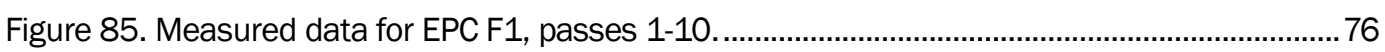

Figure 86. Measured data for EPC F2, passes 1-10.....................................................................

Figure 87. Measured data for EPC F3, passes 1-10.....................................................................

Figure 88. Measured data for EPC F4, passes 1-10 . .....................................................................77

Figure 89. Measured data for EPC C1, passes 1-12.................................................................78

Figure 90. Measured data for EPC C2, passes 1-12 ……………………………………….......78

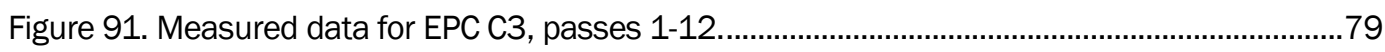

Figure 92. Measured data for EPC C4, passes 1-12. ……......................................................79

Figure 93. Summary of normalized maximum pressure for the F-15E item. ...................................80

Figure 94. Summary of normalized maximum pressure for the C-17 item. .....................................81

Figure 95. Strain gauge data for F-15E item, SG B73-F2, passes 1-10........................................83

Figure 96. Strain gauge data for C-17 item, SG B49-F1, passes 1-12 …........................................83

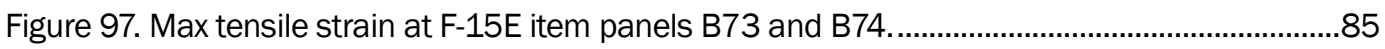

Figure 98. Max compressive strain at F-15E item panels B73 and B74..........................................8

Figure 99. Max tensile strain at F-15E item panels B51 and B60................................................86

Figure 100. Max compressive strain at F-15E item panels B51 and B60......................................86

Figure 101. Max tensile strain at F-15E item panels B62 and B63................................................8

Figure 102. Max compressive strain at F-15E item panels B62 and B63........................................8

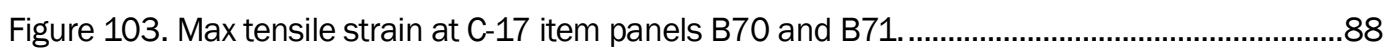

Figure 104. Max compressive strain at C-17 item panels B70 and B71. ........................................8

Figure 105. Max tensile strain at C-17 item panels B48 and B49.................................................89

Figure 106. Max compressive strain at C-17 item panels B48 and B49........................................89

Figure 107. Max tensile strain at C-17item panels B52 and B59. ……........................................90

Figure 108. Max compressive strain at C-17item panels B52 and B59........................................90

Figure 109. Summary of maximum tensile strain measured in F-15E-V item. ................................94

Figure 110. Summary of maximum compressive strain measured in F-15E-V item........................94 
Figure 111. Summary of maximum tensile strain measured in F-15E item................................. 102

Figure 112.Summary of maximum compressive strain measured in F-15E item.......................... 102

Figure 113. Summary of maximum tensile strain measured in C-17 item................................... 103

Figure 114. Summary of maximum compressive strain measured in C-17 item. ......................... 103

\section{Tables}

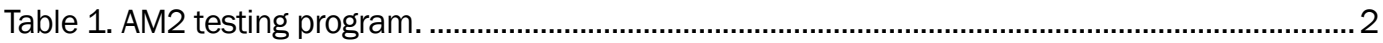

Table 2. Summary of AM2 brickwork pattern subgrade sensitivity testing results.............................. 4

Table 3. Summary of test program. ...........................................................................................

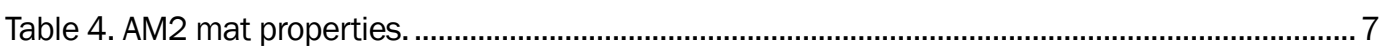

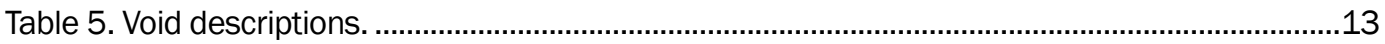

Table 6. Average in situ properties of the subgrade in each test item............................................20

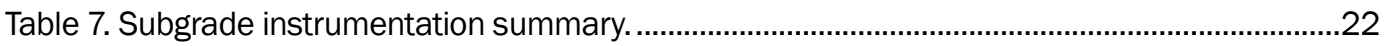

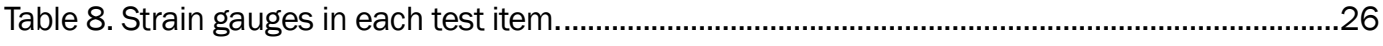

Table 9. Data collection intervals for F-15E traffic............................................................................

Table 10. Data collection intervals for C-17 traffic. ………...............................................................35

Table 11. Damage noted after picking up mats in the F-15E-V item (322 passes)............................44

Table 12. F-15E-V item mat damage summary. ………..............................................................45

Table 13. Maximum permanent deformation values for the F-15E-V item.......................................4

Table 14. Damage noted after picking up mats in the F-15E item (430 passes).............................62

Table 15. F-15E item mat damage summary..............................................................................63

Table 16. Damage noted after removing panels from C-17 item (1,308 passes). .............................66

Table 17. C-17 item mat damage summary.....................................................................................67

Table 18. Maximum permanent deformation values for the F-15E and C-17 items. .........................68

Table 19. Maximum normalized pressure ranges during each test. .................................................. 81 


\section{Preface}

This study was conducted for the U.S. Naval Air Systems Command (NAVAIR) Expeditionary Airfield (EAF) team and the U.S. Air Force Civil Engineer Center (AFCEC). The work was performed by the Airfields and Pavements Branch (APB) of the Engineering Systems and Materials Division (ESMD), U.S. Army Engineer Research and Development Center, Geotechnical and Structures Laboratory (ERDC-GSL). At the time of publication, Dr. John F. Rushing was Acting Chief, APB; Dr. Larry N. Lynch was Chief, ESMD; and Nicholas Boone was the Technical Director for Force Projection and Maneuver Support; Technical oversight was provided by Jeb S. Tingle. The Acting Deputy Director of ERDC-GSL was Dr. Will McMahon and Dr. William P. Grogan was the Acting Director.

LTC John T. Tucker III was the Acting Commander of ERDC, and Dr. Jeffery P. Holland was the Director. 


\section{Unit Conversion Factors}

\begin{tabular}{|l|c|l|}
\hline Multiply & \multicolumn{1}{|l|}{ By } & To Obtain \\
\hline cubic feet & 0.02831685 & cubic meters \\
\hline feet & 0.3048 & meters \\
\hline inches & 0.0254 & meters \\
\hline kip-inches & 112.948 & newton-meters \\
\hline pounds (force) & 4.448222 & newtons \\
\hline pounds (force) per square foot & 47.88026 & pascals \\
\hline pounds (force) per square inch & 6.894757 & kilopascals \\
\hline pounds (mass) & 0.45359237 & kilograms \\
\hline square feet & 0.09290304 & square meters \\
\hline square inches & 6.4516 E-04 & square meters \\
\hline
\end{tabular}




\section{Introduction}

\subsection{Background}

\subsubsection{Naval Air Systems Command Dynamic Interface Model}

AM2 aluminum matting has been the primary temporary airfield matting system used by the U.S. military since the late 1960s. AM2 was developed by the U.S. Navy, but has been adopted for use by the U.S. Air Force (USAF) and U.S. Army for fixed-wing and rotary-wing operational surfaces. Over the years, AM2 has been modified to address limiting structural concerns. The current production version of AM2 is modification (Mod) 5 .

An AM2 surface is composed of interlocking 2-ft by 12-ft full panels and 2-ft by 6 - $\mathrm{ft}$ half panels that are 1.5 in. thick. An AM2 mat expanse can be assembled to form runways, vertical takeoff and landing pads, taxiways, and aircraft parking areas. The Naval Air Systems Command (NAVAIR) developed a Dynamic Interface Model (DIM) to analyze aircraft landings and takeoffs on AM2. The model was validated through laboratory subscale tests, but additional development and validation was required to accurately model the matting subsurface and soil interaction for various installation patterns. Therefore, a program was initiated to validate the model through full-scale testing using simulated fighter and cargo aircraft loads. The NAVAIR Expeditionary Airfield Team (EAF) partnered with the Air Force Civil Engineer Center (AFCEC) to sponsor the evaluations listed in Table 1.

\subsubsection{AM2 certified configuration lay patterns}

Descriptions of the placement, or lay, patterns in Table 1 (brickwork, 2-1, and 3-4) are provided in Expeditionary airfield AM2 mat certification requirements (Naval Air Warfare Center 2006). The individual patterns were established as part of an initiative to optimize the use of 6-ft half panels. The original AM2 shipping package, F44, contained sixteen 12-ft panels and four 6-ft panels. Each package was designed to allow assembly of two 108-ft wide rows or four 54-ft wide rows in a brickwork configuration with no continuous longitudinal joints. The brickwork pattern assures excellent load carrying capability of the system. Since 6-ft panels are only used for the row ends, more 12-ft panels are required for assembly. However, ship transportation of the mats across the globe led to a need for 
the mats to be shipped on an International Organization of Standardization (ISO) flat rack for compatibility with other containerized goods. A decision was made by the U.S. Navy to repackage AM2 into new shipping packages, which resulted in the development of the F71 and F72 shipping configurations. Therefore, they were included in the test program.

Table 1. AM2 testing program.

\begin{tabular}{|c|c|c|c|c|c|}
\hline $\begin{array}{l}\text { Test } \\
\text { sequence }\end{array}$ & Test Name & $\begin{array}{l}\text { AM2 lay } \\
\text { pattern }\end{array}$ & $\begin{array}{l}\text { Condition of AM2 } \\
\text { mats }\end{array}$ & $\begin{array}{l}F-15 E \\
\text { traffic }\end{array}$ & $\begin{array}{l}\text { C-17 } \\
\text { traffic }\end{array}$ \\
\hline 1 & $\begin{array}{l}\text { In-plane bow on asphalt } \\
\text { surface }\end{array}$ & Brickwork & New & N/A & N/A \\
\hline 2 & $\begin{array}{l}\text { Vehicle braking test on } \\
\text { asphalt surface }\end{array}$ & Brickwork & New & $\mathrm{N} / \mathrm{A}$ & $\mathrm{N} / \mathrm{A}$ \\
\hline 3 & $\begin{array}{l}\text { Brickwork on voided } \\
\text { subgrade (CBR of } 6 \text { ) }\end{array}$ & Brickwork & $\begin{array}{l}\text { New and } \\
\text { Refurbished }\end{array}$ & Yes & No \\
\hline 4 & Brickwork on CBR of 6 & Brickwork & $\begin{array}{l}\text { New and } \\
\text { Refurbished }\end{array}$ & Yes & Yes \\
\hline 5 & In-plane bow on CBR of 6 & Brickwork & New & N/A & N/A \\
\hline 6 & $\begin{array}{l}\text { Opposite Lay on CBR of } \\
6 *\end{array}$ & Brickwork & New & Yes & Yes \\
\hline 7 & 3-4 Lay on CBR of 6 & 3-4 & New & Yes & Yes \\
\hline 8 & 2-1 Lay on CBR of 6 & $2-1$ & New & Yes & Yes \\
\hline 9 & $\begin{array}{l}\text { Brickwork on voided } \\
\text { subgrade (CBR of } 6 \text { ) }\end{array}$ & Brickwork & New & Yes & No \\
\hline 10 & Brickwork on CBR of 6 & Brickwork & New & Yes & Yes \\
\hline
\end{tabular}

*traffic applied parallel to long dimension of AM2 panels

The F71 contains eighteen 12-ft mats, and the F72 contains eighteen 6-ft mats. The new configurations allow one F71 and one F72 to be placed endto-end on a 20-ft ISO flat rack and optimize use of the available space. The new package configuration also reduced confusion when designing a mat surface. In some instances, F44 packages were rebundled with different numbers of 6-ft panels inside the $12-\mathrm{ft}$ mat packages. Separating the panels into the F71 and F72 packages eliminated the need to include mixed sizes in packages and improved the accuracy of panel inventories.

The optimization of packaging and shipping of AM2 required equal numbers of 12-ft and 6-ft mat panels to be delivered with each AM2 order. Since only a fraction of the available 6-ft panels are needed to assemble a brickwork pattern, many extra 6-ft panels were unused. To optimize mat use, NAVAIR EAF created an allowance for two alternate assembly lay 
patterns, the 2-1 and the 3-4 lay patterns. Although the two patterns were approved by NAVAIR EAF, they had not been evaluated under simulated aircraft loading conditions to determine if any reduction in the number of allowable passes was caused by the allowance of continuous longitudinal joints. Therefore, they were included in the test program. Results for the 3-4 lay pattern are reported in ERDC/GSL TR-14-38 (Rushing et al. 2014).

\subsubsection{AM2 brickwork lay pattern and NAVAIR void criteria}

Although the brickwork pattern has been evaluated over different subgrade materials and strengths (Table 2), information obtained from these tests was not sufficient to validate the model. Therefore, NAVAIR and AFCEC included testing of the brickwork pattern in the program with appropriate strain gauge instrumentation at the end connector joint to calibrate the DIM. The brickwork pattern test on a voided subgrade was also included in the program to test NAVAIR criteria for the serviceability of AM2 on a subgrade with voids. NAWCADLKE-MISC-48J200-0011 (Naval Air Warfare Center 2006) describes a void as a space in a soil or rock mass that is not occupied by solid mineral matter. Operational realities required that some leeway be provided to accommodate small voids in the subgrade that would not affect the integrity of the AM2 mat. Therefore, the following criteria were established, according to NAWCADLKE-MISC-48J200-0011:

1. One (1) 6-ft sheet of AM2 mat shall have no more than 1 void underneath its surface.

2. One (1) 12-ft sheet of AM2 mat shall have no more than 2 voids underneath its surface.

3. Separation distance is not required between voids, other than the maximum allowable per individual AM2 mat sheet; however, a void cannot exist within $1 \mathrm{ft}$ of any end connector of any sheet of AM2 mat.

4. A void has no depth limit; however, the void shall not exceed 6 in. in any horizontal dimension.

\subsubsection{AM2 refurbished matting}

In an effort to limit the need for frequent large procurements of new AM2 Mod 5, NAVAIR implemented a refurbishment program that restores AM2 panels that have been damaged during aircraft operations. Therefore, previous design versions of AM2 that have not been produced since the 1960s, such as two-piece (i.e., two 1-ft-wide welded extrusions) and Mod 4, 
are still encountered in the field and can be reused to fulfill mission requirements. Initial efforts of the full-scale testing program were focused on obtaining data from new AM2 Mod 5 mats to validate the DIM. Since refurbished AM2 matting is frequently encountered in the theater, NAVAIR and AFCEC then decided to sponsor evaluations where new and refurbished matting were combined in an AM2 surface. To accurately make an assessment, the new and refurbished matting test sections were assembled in the brickwork pattern, both on a voided and non-voided subgrade surface. Although the model would only be accurate for pristine mat, both new and refurbished panels were instrumented. The data would not necessarily be used for model validation, but would still provide some insight into life expectancy of refurbished mat.

Table 2. Summary of AM2 brickwork pattern subgrade sensitivity testing results.

\begin{tabular}{|l|c|l|l|}
\hline \multicolumn{4}{|c|}{ Sustained Traffic Passes } \\
\hline Subgrade Strength (CBR) & F-15E & C-17 & \multicolumn{1}{c|}{ Reference } \\
\hline 6 & 1,500 & 1,500 & Rushing and Tingle (2007) \\
\hline 10 & 3,000 & 6,000 & Rushing et al. (2008) \\
\hline 15 & 4,100 & 7,000 & Rushing and Mason (2008) \\
\hline 25 & 6,300 & $10,000^{*}$ & Garcia et al. (2014a) \\
\hline 100 & 23,000 & - & Garcia et al. (2014b) \\
\hline
\end{tabular}

* Failure was not achieved. Trafficking was stopped because of time constraints.

\subsection{Objective and scope}

The objectives of the effort described herein were to:

1. Evaluate the brickwork pattern using both new and refurbished AM2 matting on a subgrade with a California Bearing Ratio (CBR) of 6 under simulated $\mathrm{F}-15 \mathrm{E}$ and $\mathrm{C}-17$ aircraft traffic.

2. Evaluate the brickwork pattern using both new and refurbished AM2 matting on a subgrade with a CBR of 6 with voids on the subgrade surface under F-15E traffic.

Each test was conducted to:

1. Document refurbished matting behavior under simulated aircraft loads.

2. Provide insight on damage rates of refurbished matting as compared to new matting (i.e., new AM2 Mod 5).

3. Record strain measurements at the end connectors.

4. Record subgrade deformation. 
To accomplish these objectives, a full-scale test section was constructed with a 36-in.-deep high-plasticity clay $(\mathrm{CH})$ subgrade, which had been processed to obtain a CBR of 6 . Voids were excavated at specific locations on the subgrade surface. The AM2 mat system was installed in the brickwork pattern to conduct simulated F-15E traffic above the voided surface. After completion of this test, mat panels were removed and a new set of panels were installed to conduct the $\mathrm{F}-15 \mathrm{E}$ and $\mathrm{C}-17$ traffic tests on a uniform subgrade surface, next to the previously trafficked area. A brief summary of the test program described in this report is provided in Table 3. The results were compared to those shown in Table 2.

Table 3. Summary of test program.

\begin{tabular}{|l|c|c|c|l|l|}
\hline Test section name & $\begin{array}{l}\text { Test section } \\
\text { number }\end{array}$ & $\begin{array}{l}\text { Test item } \\
\text { name }\end{array}$ & $\begin{array}{l}\text { Traffic } \\
\text { type }\end{array}$ & $\begin{array}{l}\text { Test } \\
\text { sequence }\end{array}$ & Traffic application \\
\hline $\begin{array}{l}\text { Brickwork on } \\
\text { voided subgrade }\end{array}$ & 1 & F-15E-V & F-15E & 1 & $\begin{array}{l}\text { Two tracks, 4.5 in. } \\
\text { from centerline }\end{array}$ \\
\hline Brickwork & 2 & F-15E & F-15E & 2 & $\begin{array}{l}\text { Normally } \\
\text { distributed }\end{array}$ \\
\hline Brickwork & 2 & C-17 & C-17 & 3 & $\begin{array}{l}\text { Normally } \\
\text { distributed }\end{array}$ \\
\hline
\end{tabular}




\section{Experimental Program}

The following sections describe the AM2 airfield mat, construction of the full-scale test section, traffic application, data collection, and the failure criteria.

\subsection{Materials}

\subsubsection{AM2 airfield mat}

AM2 airfield mat was developed in the 1960 s under a program sponsored by the Naval Air Engineering Center, in Philadelphia, PA. Various versions of AM2 were tested under simulated aircraft loads at the U.S. Army Engineer Waterways Experiment Station in Vicksburg, MS from 1961 through 1971, with major procurements beginning in 1965. The original AM2 mat has been modified through the years to address limiting structural concerns. The current production version of AM2 is Mod 5.

AM2 full panels are $2 \mathrm{ft}$ by $12 \mathrm{ft}$ by $1.5 \mathrm{in}$. and fabricated from a single 6061-T6 aluminum alloy extrusion with end connectors welded to the 2-ft ends to form a complete panel. The core of the extruded panels is comprised of vertical stiffeners spaced $1.75 \mathrm{in}$. apart in the $12 \mathrm{ft}$ direction. The mat is also made in half-panels to allow a staggered brickwork configuration. The panels were joined along the two 12-ft edges by a hingetype male/female connection. The adjacent 2 -ft ends were joined by an overlap/underlap connection secured by an aluminum locking bar. The panels were coated with a nonskid material to increase the surface friction. Pertinent properties of AM2 mat are shown in Table 4.

All AM2 mat used for testing, including new Mod 5 and refurbished matting, was obtained from NAVAIR. The AM2 panels were delivered in F71 and F72 packages. Photos of the AM2 F71 and F72 packages similar to those used in this test are shown in Figure 1. Minor damage, such as that shown in Figure 2, was noted on some of the refurbished panel designs received. A few panels were noted to be two-piece AM2 and other versions prior to Mod 5 . 
Table 4. AM2 mat properties.

\begin{tabular}{|l|l|l|}
\hline & Full-panel & Half-panel \\
\hline Length (ft) & 12.0 & 6.0 \\
\hline Width (ft) & 2.0 & 2.0 \\
\hline Thickness (in.) & 1.5 & 1.5 \\
\hline *Panel Weight (lbf) & 145.5 & 74.4 \\
\hline *Unit Weight (lbf/ft2) & 6.1 & 6.3 \\
\hline
\end{tabular}

*Typical weight of Mod 5. May be different for previous versions.

Figure 1. F71 (left) and F72 (right) mat packages.
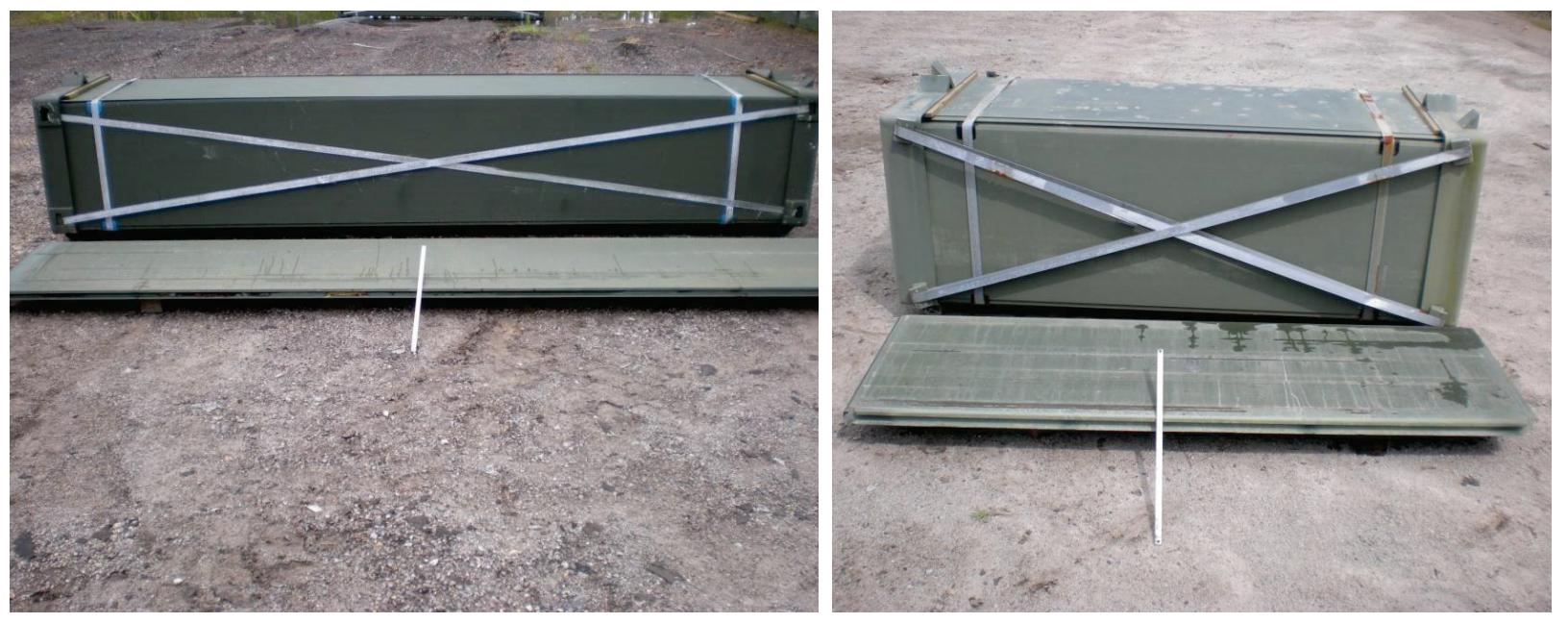

Figure 2. Damage noted on refurbished AM2 panel before applying traffic.

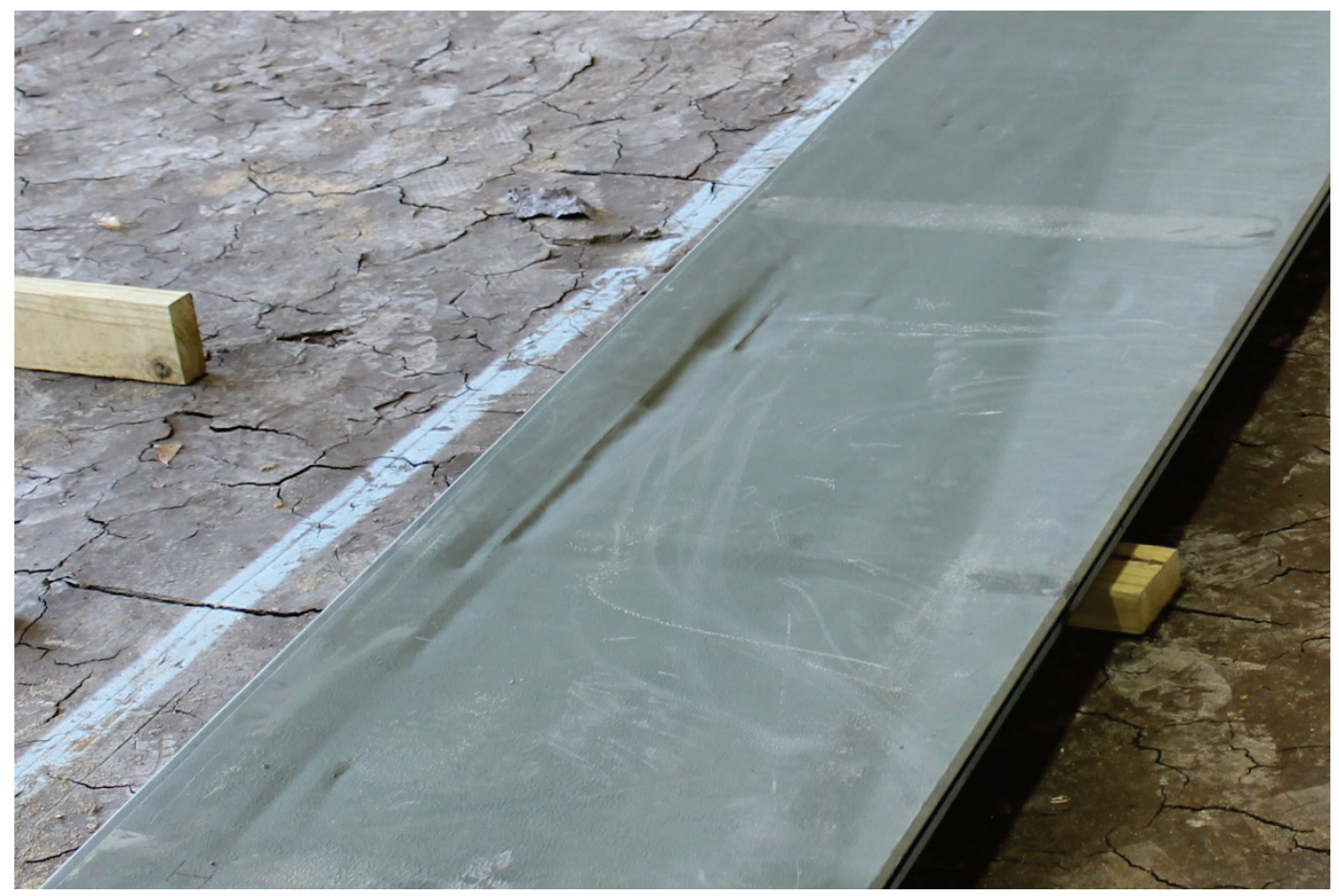




\subsubsection{High-plasticity clay (CH) subgrade}

The $\mathrm{CH}$ material used for subgrade construction was procured from a local source in Vicksburg, MS, and was subjected to laboratory tests including grain-size analysis (hydrometer), Atterberg Limits, modified-Proctor compaction, and unsoaked CBR testing. Classification data for the subgrade soil are shown in Figure 3. Moisture-density and CBR-moisture content relationships are shown in Figures 4 and 5, respectively. These data were used to determine the target moisture content and dry density required to obtain the target CBR of 6.

Figure 3. Gradation curve for Vicksburg Buckshot high-plasticity clay (CH).

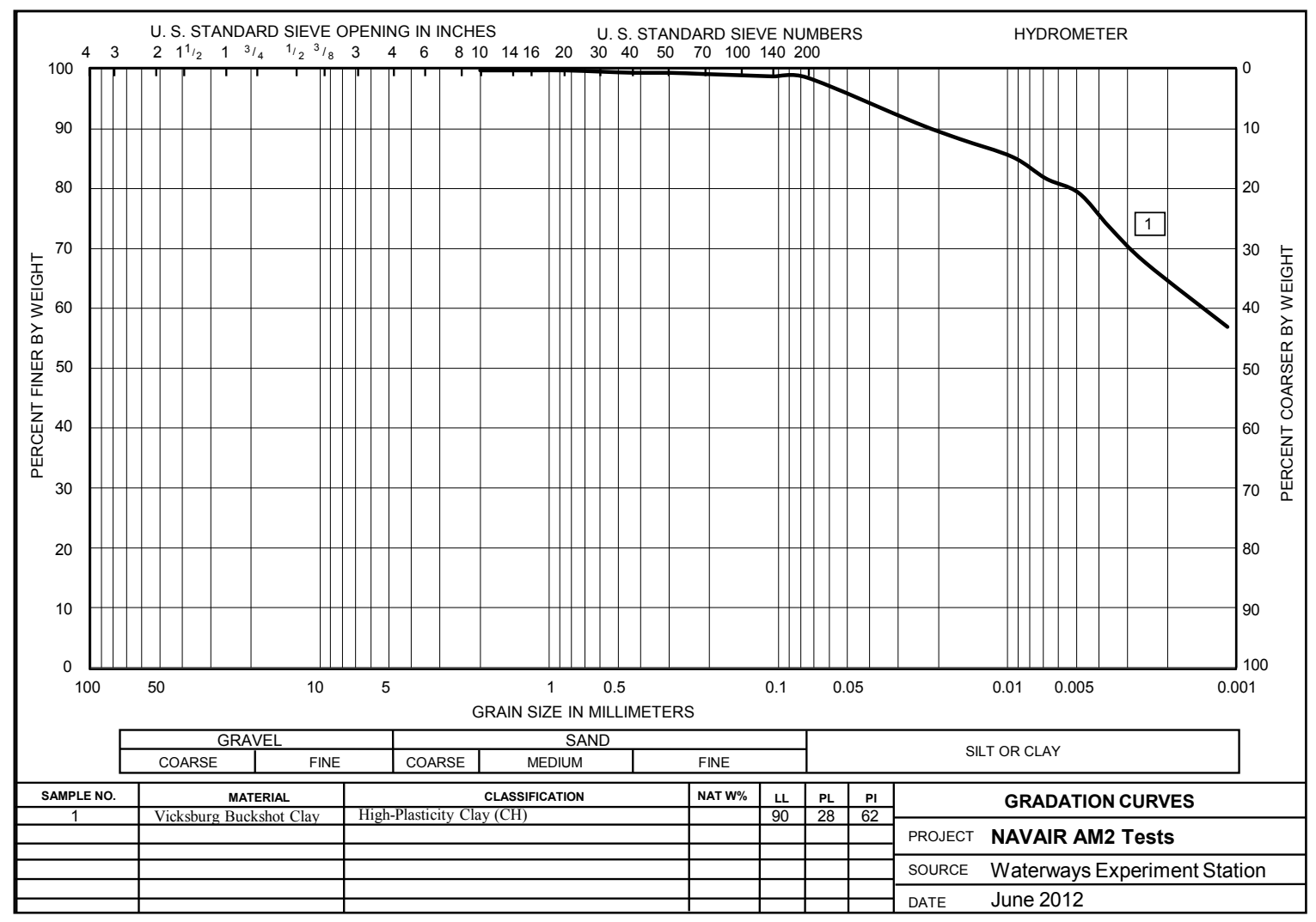


Figure 4. Dry density vs. moisture content for $\mathrm{CH}$ subgrade material.

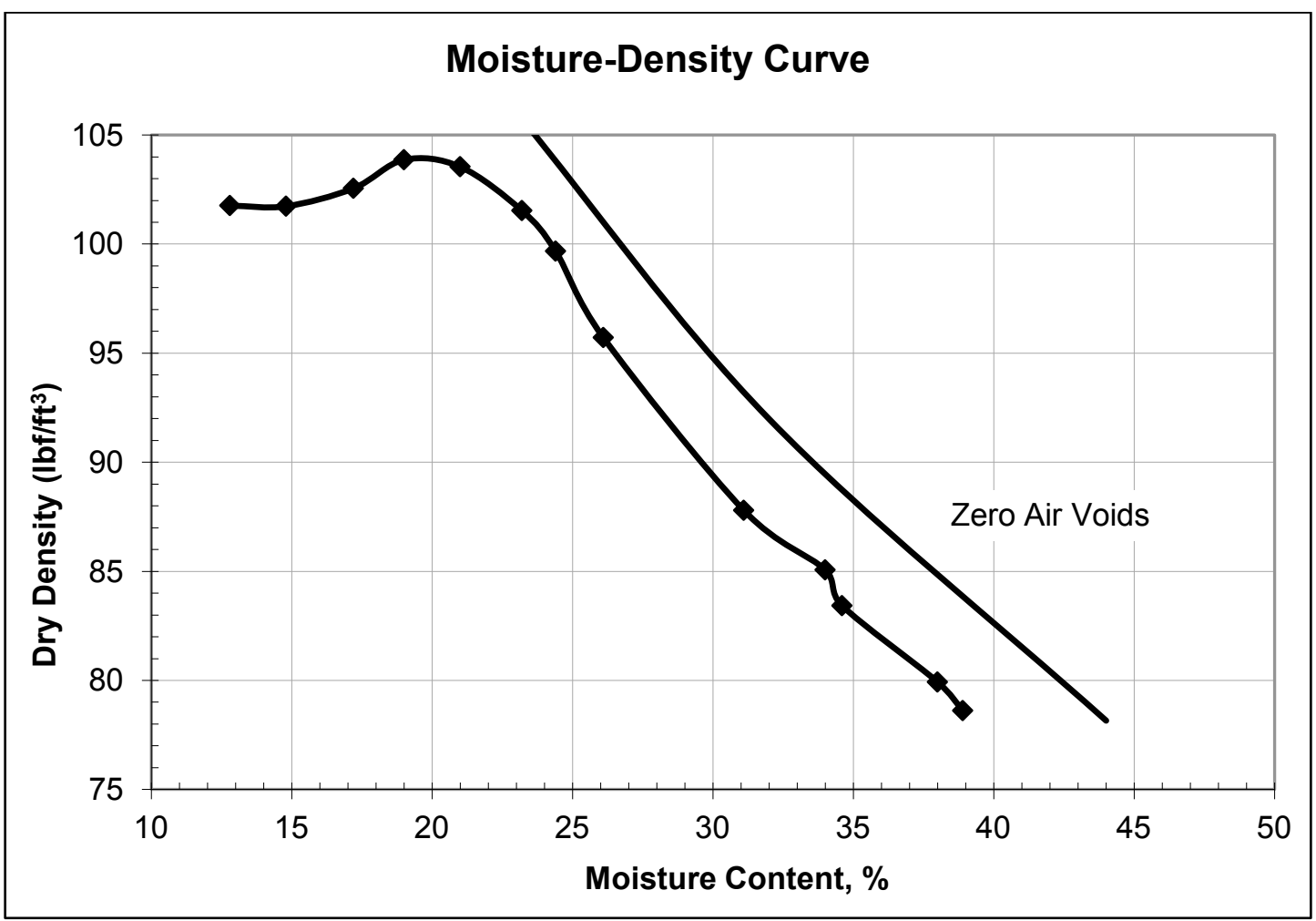

Figure 5. CBR vs. moisture content for $\mathrm{CH}$ subgrade material.

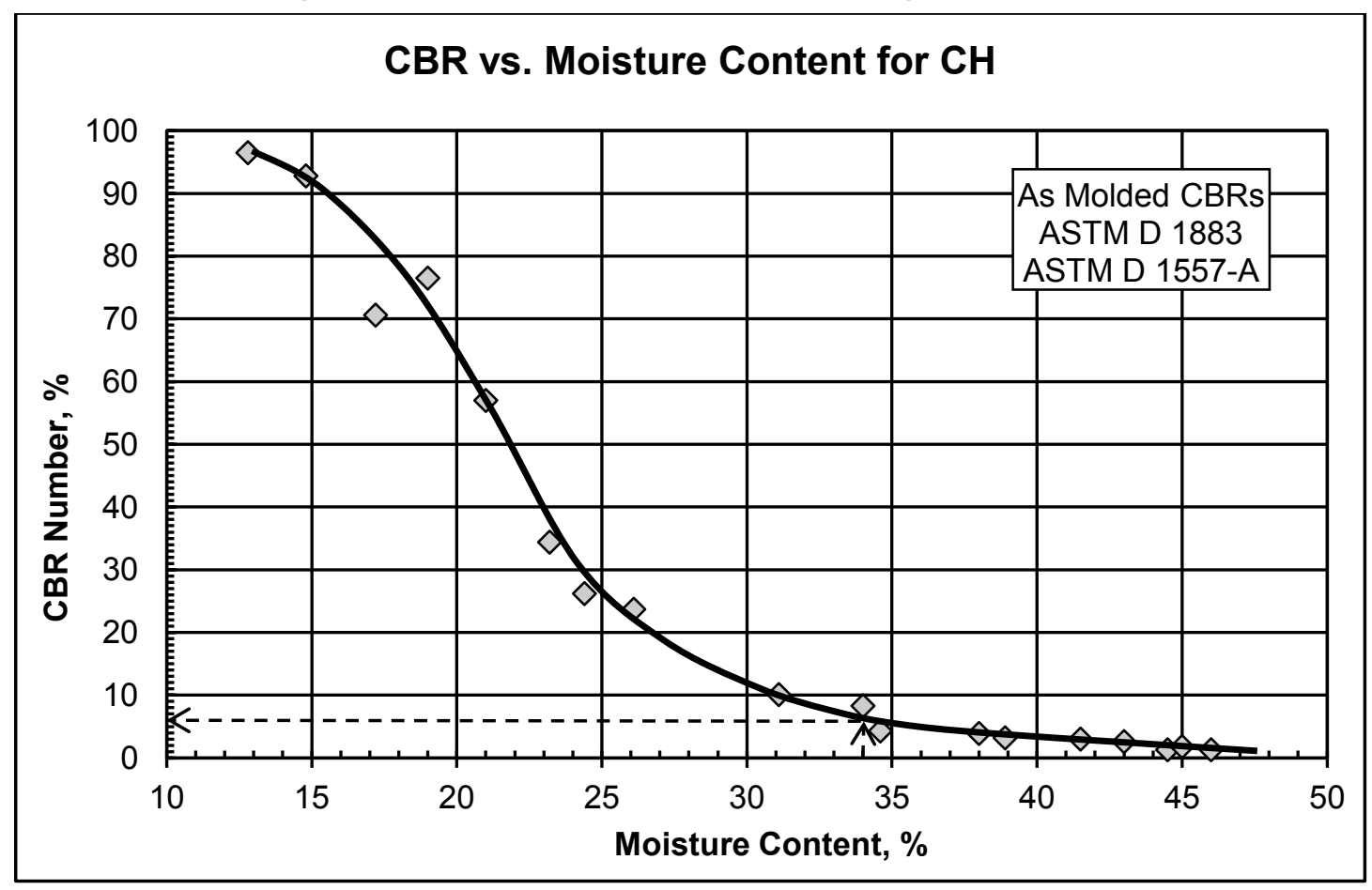




\subsection{Test section general description}

The traffic tests were conducted on full-scale test sections constructed and trafficked under shelter in the Hangar 4 pavement test facility at the ERDC. AM2 mat panels were placed directly over a 36-in.-deep CH subgrade prepared to a target CBR of 6 over an existing silt foundation, as shown in Figure 6. General layouts of each test section, along with panel designations, are shown in Figures 7 and 8. Each panel was identified with a number to track damage during trafficking.

Each test consisted of a 60 -ft-wide by 40 -ft-long section of matting. For the brickwork pattern test on a voided subgrade, voids were excavated on the subgrade surface (approximately $24 \mathrm{ft}$ from the west edge of the test section) before placing AM2 mat. Void locations and descriptions are provided in Figure 7 and Table 5. The area chosen for testing was 24-ftwide and centered $24 \mathrm{ft}$ from the west edge of the test section. The test item width was chosen to maintain consistency with previous airfield matting tests, which typically have 24 -ft-wide items for normally distributed F-15E traffic. Two tracks centered 4.5 in. either side of the centerline were designated for $\mathrm{F}-15 \mathrm{E}$ traffic to maintain most of the load above the voids. Once this test was completed, the mat surface was picked up and replaced with matting for the second brickwork pattern test.

Figure 6. Test section profile.

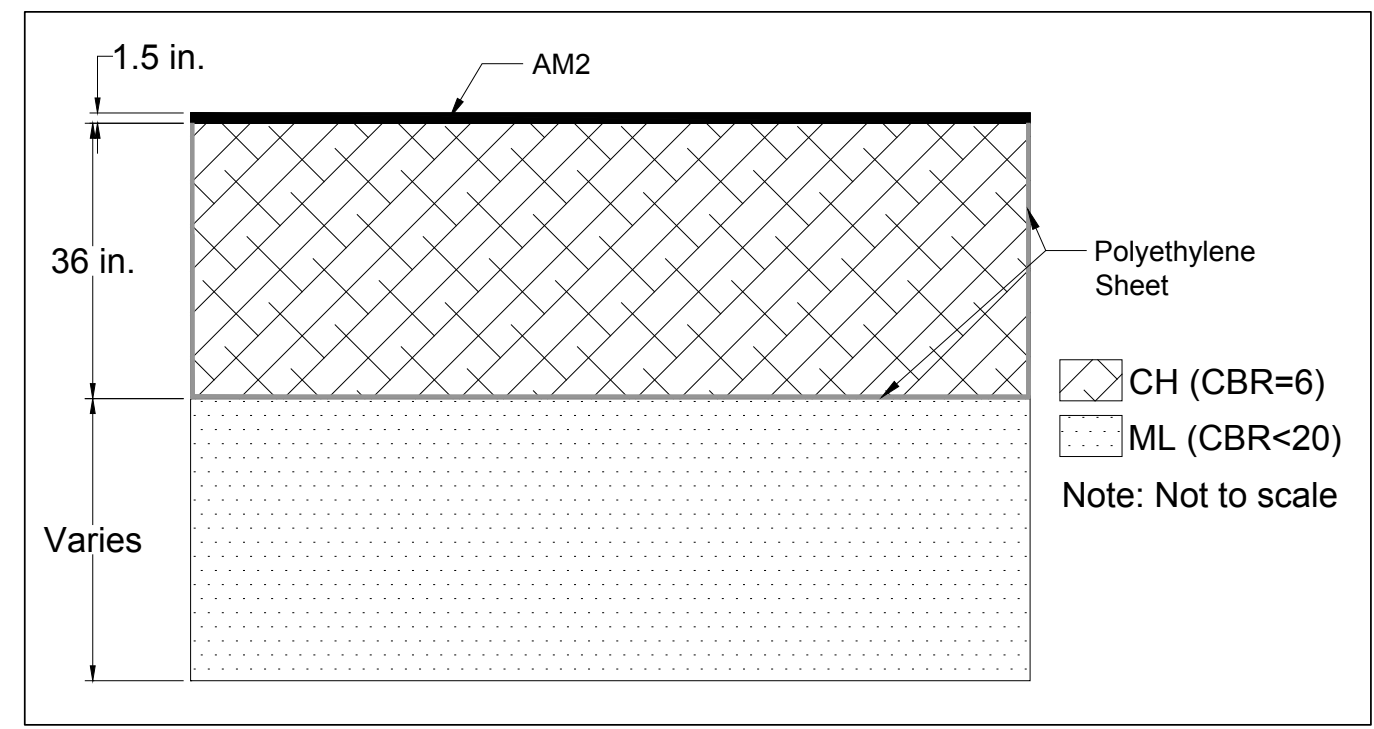




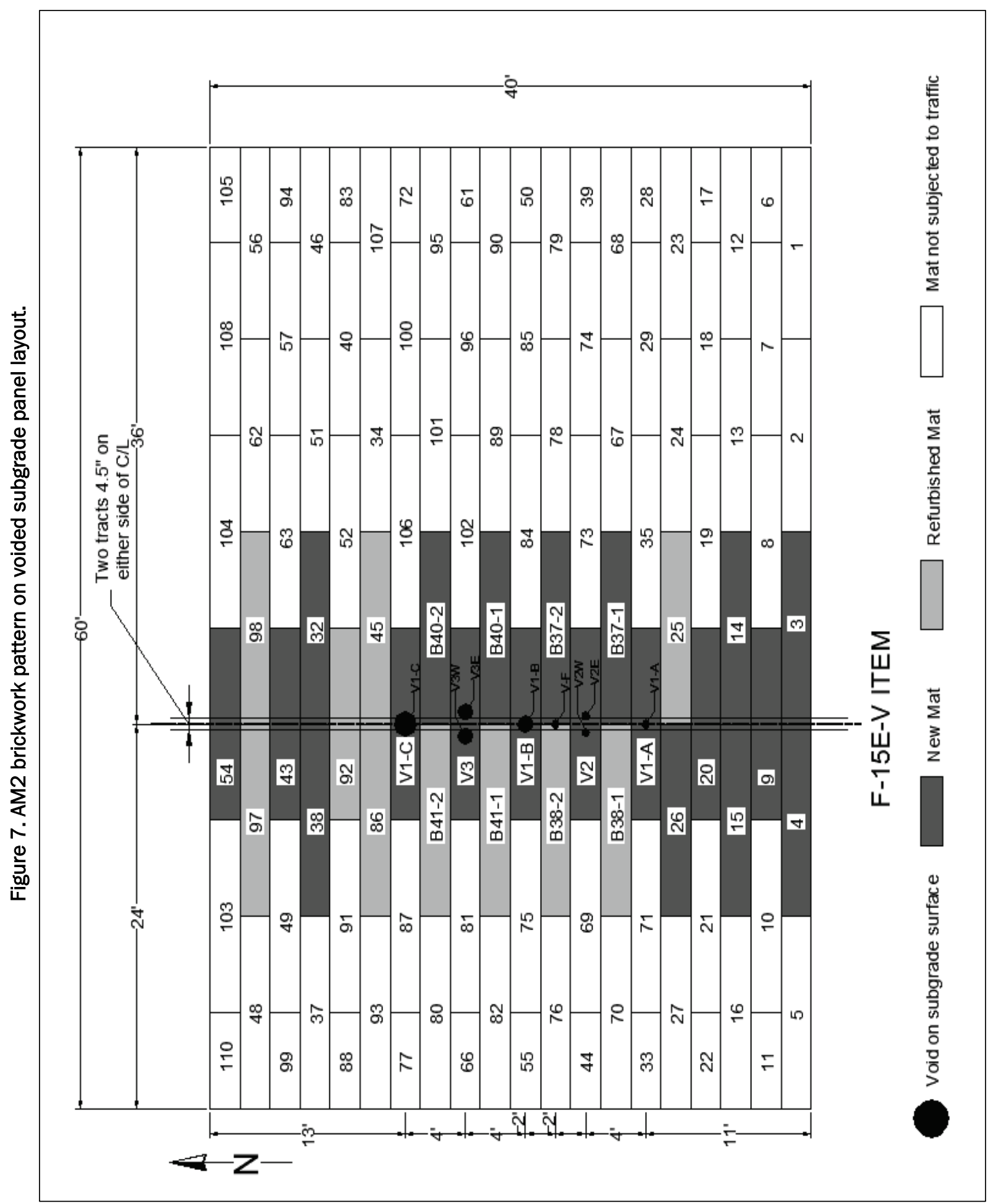




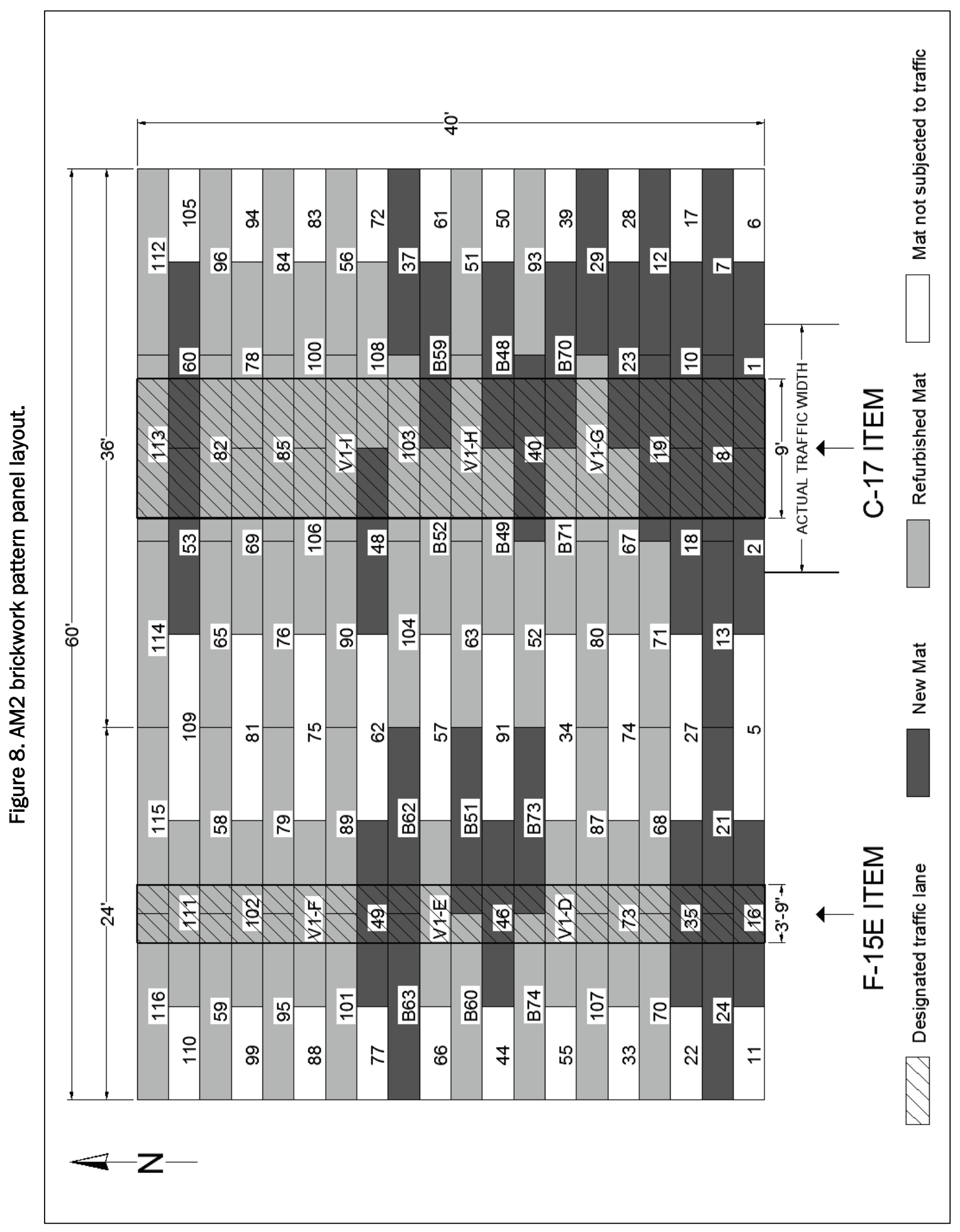


Table 5. Void descriptions.

\begin{tabular}{|l|l|l|}
\hline Void Designation & Diameter (in.) & Location \\
\hline V1-A & 6 & Center of Panel V1-A \\
\hline V2E & 6 & 6 in. offset east from center of Panel V2 \\
\hline V2W & 6 & 6 in. offset west from center of Panel V2 \\
\hline V-F* & 6 & Center of joint between Panels B38-2 and B37-2 \\
\hline V1-B & 12 & Center of Panel V1-B \\
\hline V3E & 12 & 9 in. offset east from center of Panel V3 \\
\hline V3W & 12 & 9 in. offset west from center of Panel V3 \\
\hline V1-C & 18 & Center of Panel V1-C \\
\hline
\end{tabular}

* Not monitored during traffic

Note: all voids 2 in. deep

The second brickwork pattern test section consisted of two test items (Figure 8). An area centered $12 \mathrm{ft}$ from the west edge of the test section had a 3.75-ft-wide lane designated for simulated F-15E traffic, and an area centered $18 \mathrm{ft}$ from the east edge had a 9-ft-wide lane designated for simulated $\mathrm{C}-17$ traffic. Lanes for the $\mathrm{F}-15 \mathrm{E}$ and $\mathrm{C}-17$ items were trafficked according to normally distributed wander patterns associated with the F-15E and C-17 aircrafts, which are described later in this chapter.

As shown in Table 3 and throughout this report, the brickwork test item on the voided subgrade will be called "F-15E-V". The two test items on the second brickwork test section will be called "F-15E" and "C-17". Although there was some overlap of the F-15E-V item with the $\mathrm{F}-15 \mathrm{E}$ and $\mathrm{C}-17$ items, researchers concluded that any influence would be minimal since traffic on the F-15E-V item was limited to a width of 18 in. The actual trafficked area in the F-15E-V item was about $10 \mathrm{ft}$ offset from the traffic area in both the $\mathrm{F}-15 \mathrm{E}$ item and $\mathrm{C}-17$ items, therefore giving no cause to believe that a reduction in the fatigue life of the panels in the $\mathrm{F}-15 \mathrm{E}$ and $\mathrm{C}-17$ items would be caused by any subgrade deformation on the F-15E-V item.

\subsection{Test section construction}

The following sections describe the construction of the foundation subgrade and the AM2 mat installation. Field and laboratory soil testing data used to determine the moisture, density, and bearing capacity in terms of CBR are also included. 


\subsubsection{Subgrade construction and posttest forensics}

The subgrade was constructed by excavating a 60 -ft-wide by $40-\mathrm{ft}-$ long test pit to a minimum 36-in. depth below the existing finished grade in Hangar 4, as shown in Figure 9. The soil at the bottom of the excavation was a silt material (ML) having a CBR less than 20. The existing ML material was leveled with a bulldozer and compacted with a pneumatic roller and a vibratory steel-wheel compactor to ensure that the remainder of the test section was constructed over a stable foundation. The bottom and sides of the test pit were lined with impervious 6-mil polyethylene sheeting to minimize moisture migration from the $36 \mathrm{in}$. of new $\mathrm{CH}$ soil serving as the test section subgrade, as shown in Figure 10.

The $\mathrm{CH}$ was processed at a nearby preparatory site by spreading the material to a uniform 12-in. depth, pulverizing the material with a rotary mixer, adjusting the moisture content, pulverizing the material again, and stockpiling it as shown in Figures 11 through 13. This was an iterative process necessary to achieve a uniform distribution of moisture throughout the material. Once the $\mathrm{CH}$ had been processed to the target moisture content, it was placed in the test section, spread by a bulldozer in 8 -in. lifts, and compacted with a pneumatic roller to a depth of 6 in., as shown in Figures 14 and 15.

Figure 9. Test section excavation.

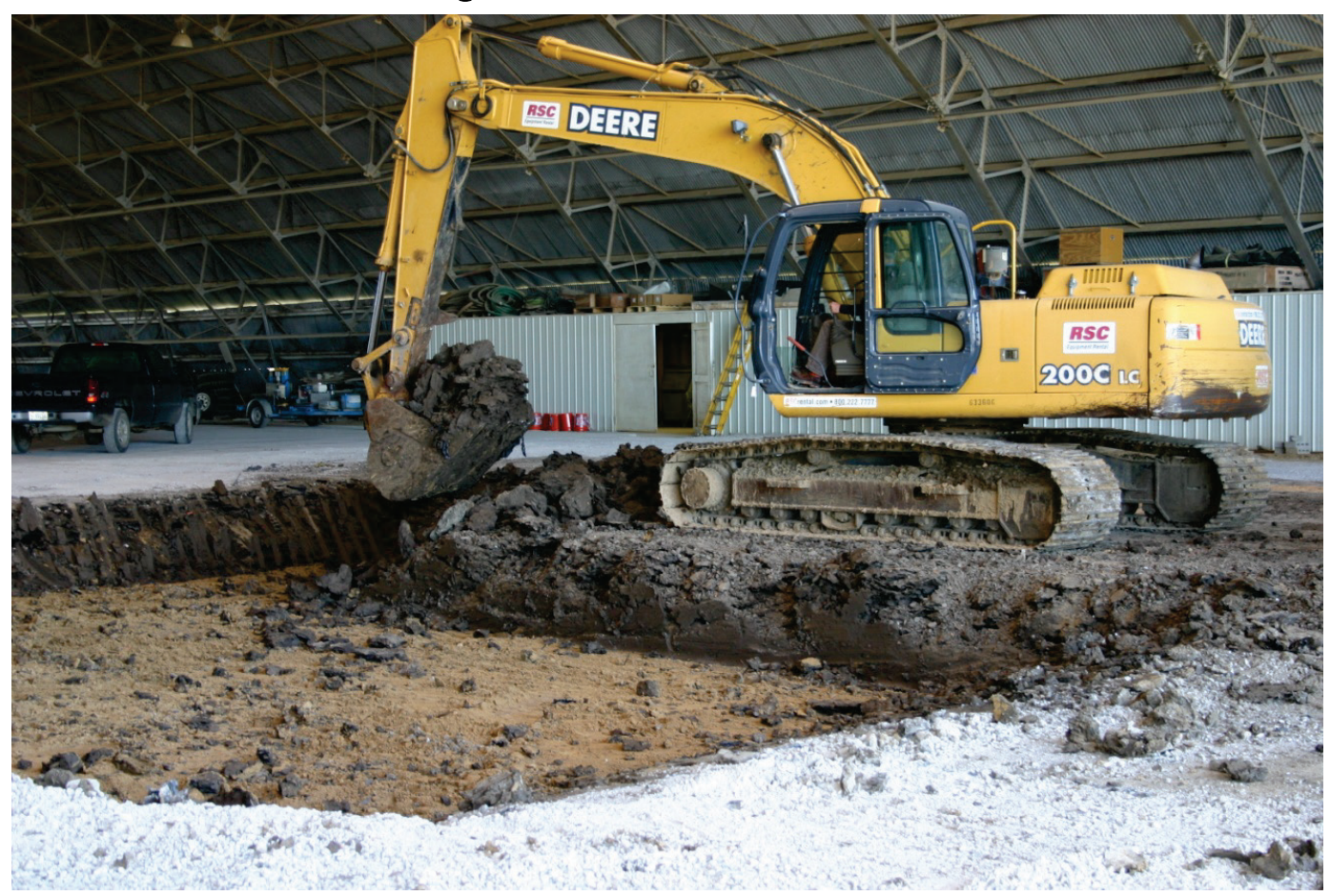


Figure 10. Test pit lined with impervious sheeting.

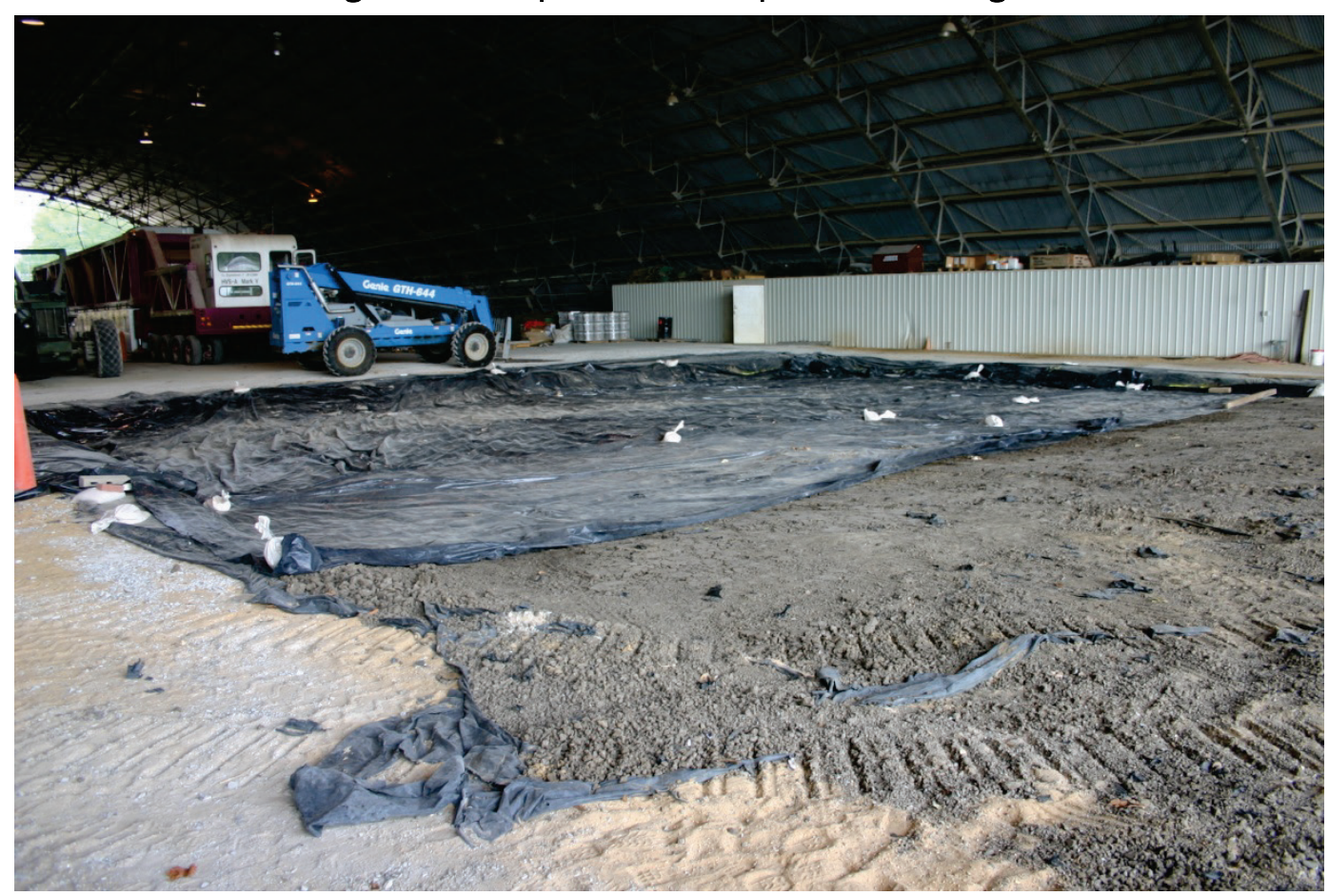

Figure 11. Pulverizing $\mathrm{CH}$.

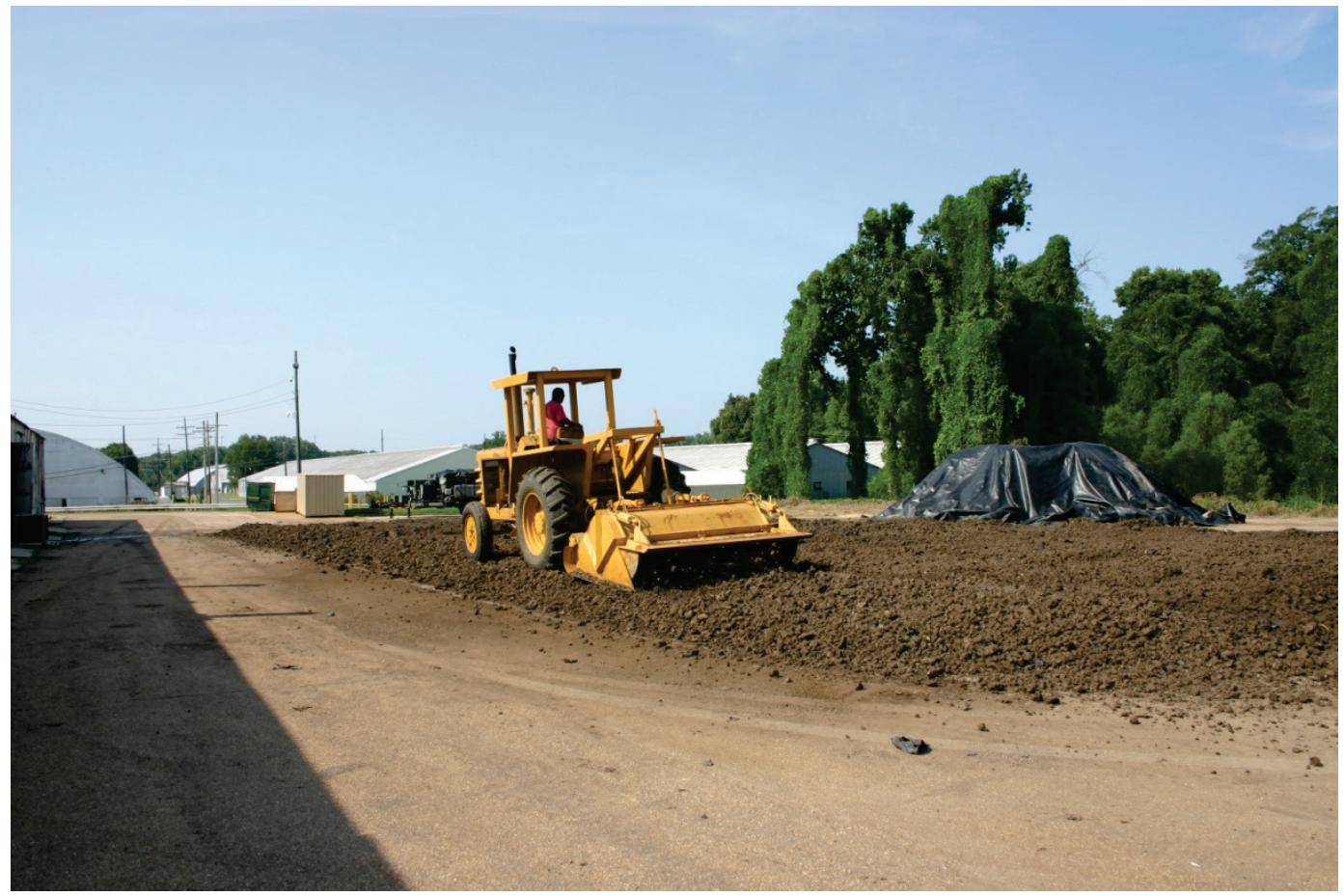


Figure 12. Addition of water to adjust moisture content.

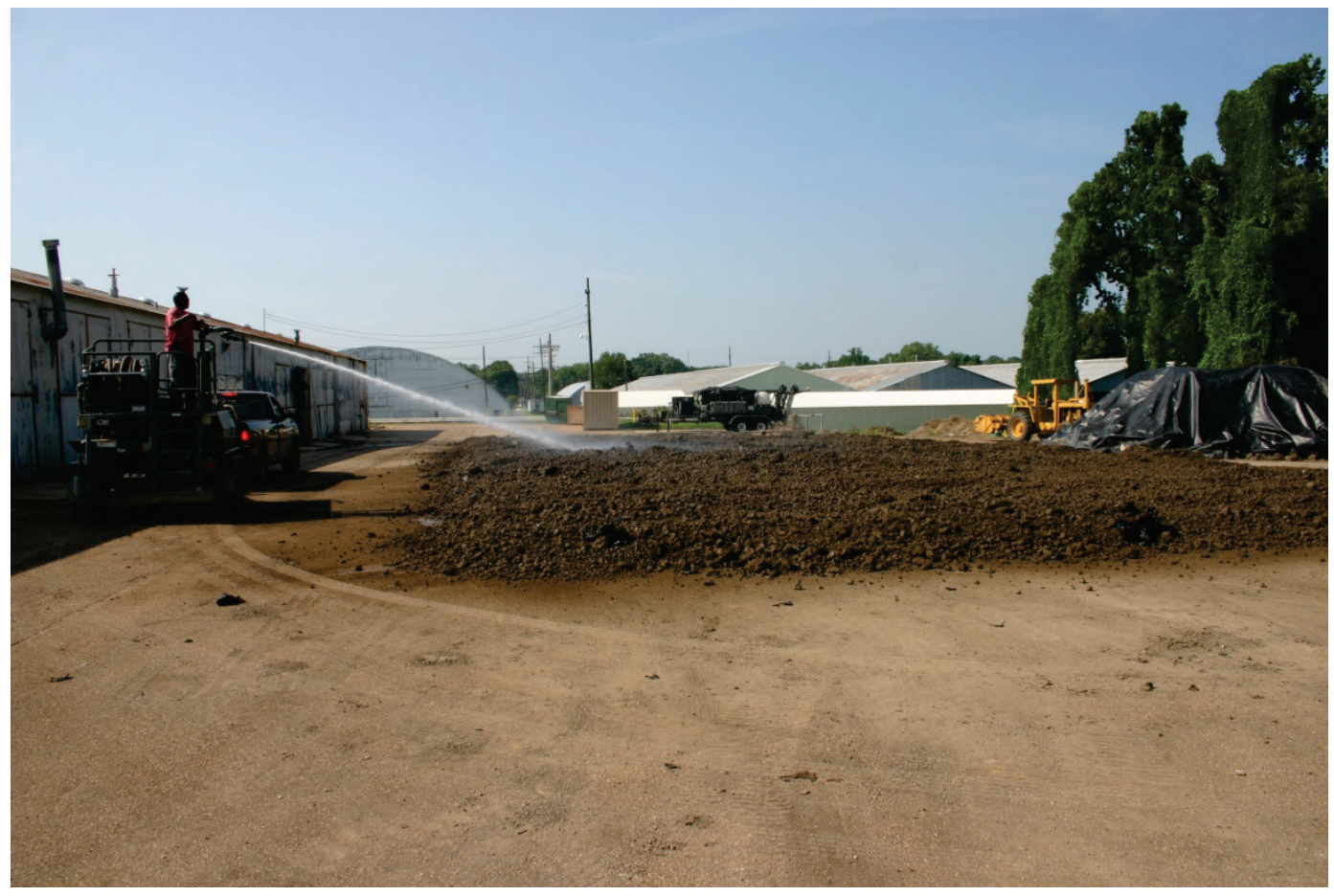

Figure 13. Loading processed $\mathrm{CH}$ into haul truck.

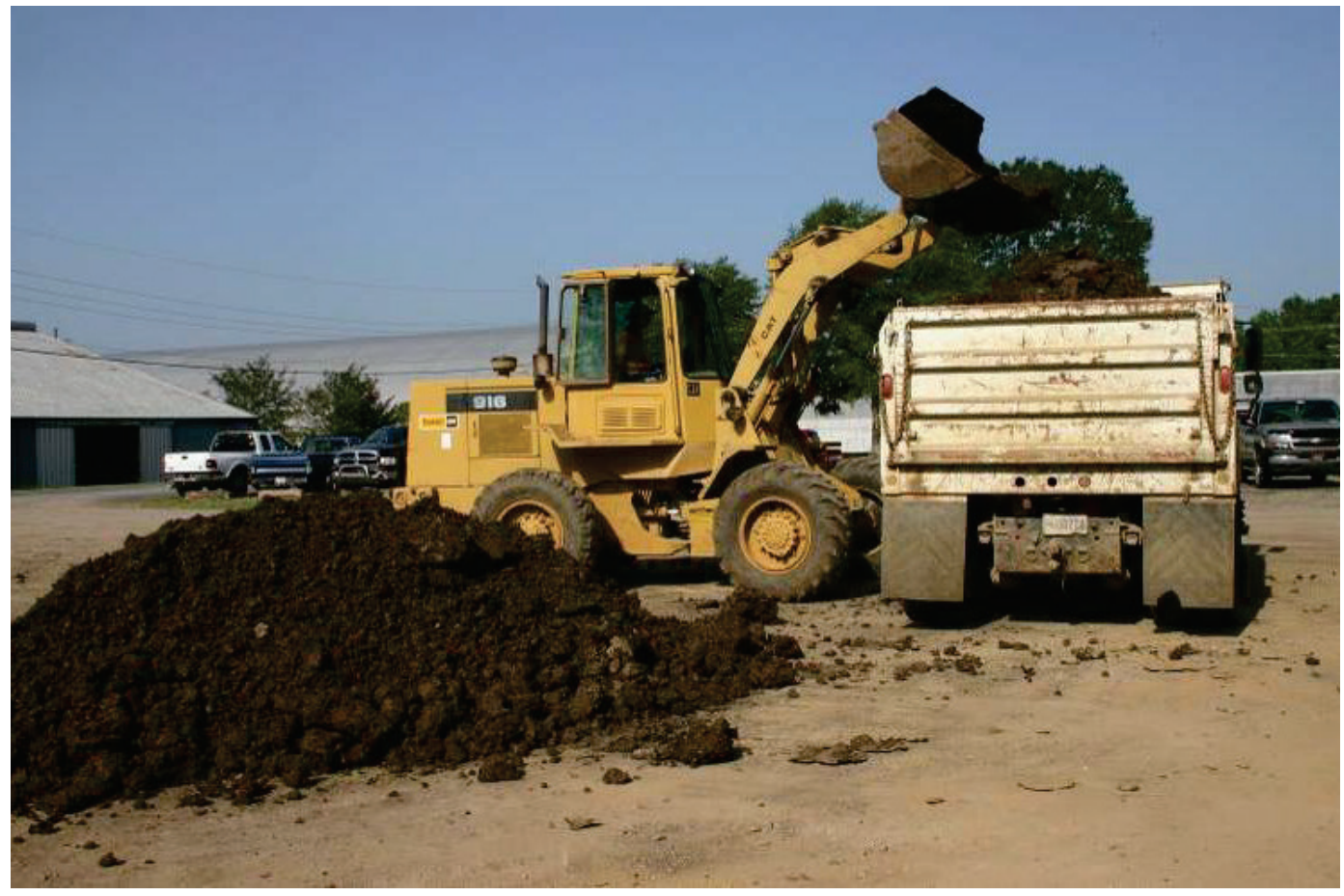


Figure 14. Leveling $\mathrm{CH}$ material in test pit prior to compaction.

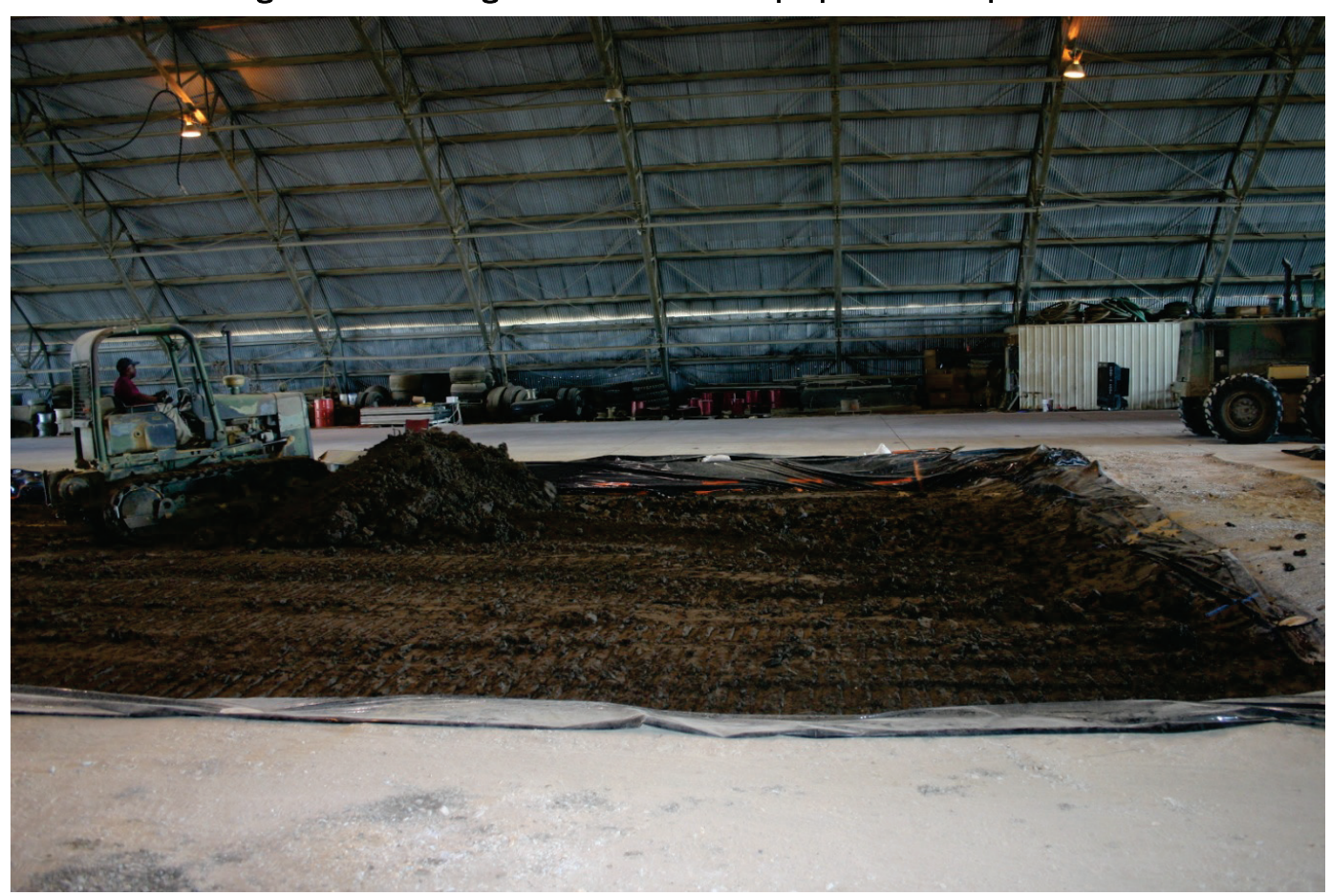

Figure 15. Compacting $\mathrm{CH}$ subgrade with pneumatic roller.

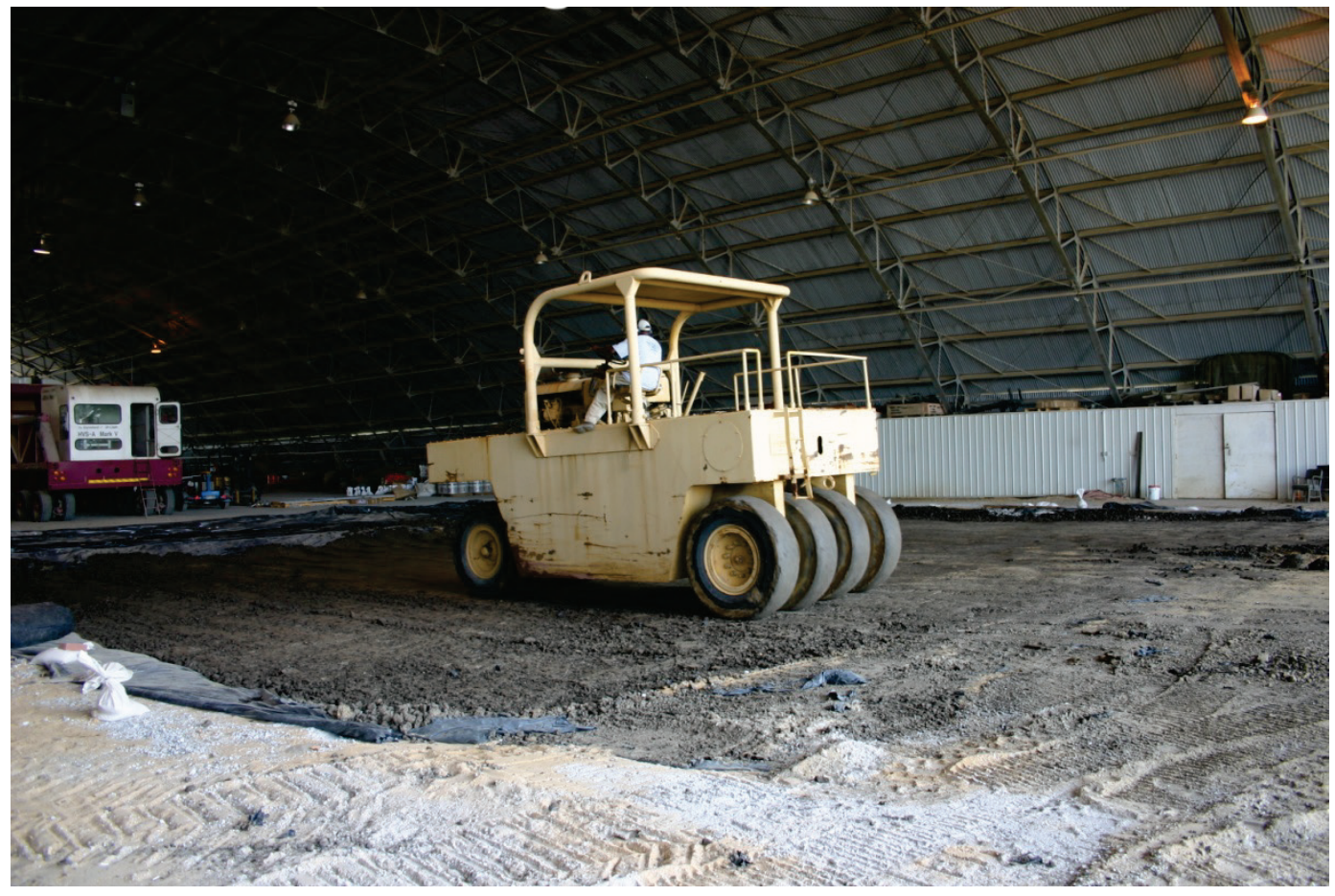

Each compacted lift was subjected to nuclear moisture/density tests (ASTM D 6938), as shown in Figure 16, in addition to convection oven moisture determination tests (ASTM D4643) to verify that target values 
had been met. In situ CBR tests (CRD-C 654-95), as shown in Figure 17, were conducted at stations 10 and 30 along the centerline of both the F${ }_{15} \mathrm{E}$ and $\mathrm{C}-17$ test items on every 6 -in. compacted lift to verify that the target CBR of 6 had been reasonably achieved. Pretest values for the F${ }_{15} \mathrm{E}-\mathrm{V}$ item were assumed to be relatively equal to those for the $\mathrm{F}-15 \mathrm{E}$ and $\mathrm{C}-17$ items. Therefore, the average of the in situ CBR, moisture, and density measurements of the $\mathrm{F}-15 \mathrm{E}$ and $\mathrm{C}-17$ items are reported for the $\mathrm{F}$ $15 \mathrm{E}-\mathrm{V}$ item.

If the average pretest CBR of a lift differed from the target value by more than +1.0 or -0.5 CBR, the lift was reconstituted. Each lift was surveyed to obtain an average thickness. After data collection, the surface was scarified an average depth of 1 in. with a rotary mixer prior to placement of the following lift to facilitate bonding at the interface.

The results of the CBR, moisture, and density tests during construction (pretest) and after trafficking (posttest) for each test item are shown in Table 6. To avoid drying of the subgrade surface while removing panels from the first brickwork test section and replacing them for the second test, in situ CBR tests were not conducted on the subgrade surface where the F-15-V item was located. Instead, dynamic cone penetrometer (DCP) (ASTM D 6951) and nuclear moisture density tests were conducted at stations 10, 20, and 30 along the centerline where the rut had formed. An example of the DCP data is shown in Figure 18. Large increases in strength after the 10-in. depth are usually noted in CBR values calculated using DCP data in buckshot clay. These are assumed to be associated with the added frictional resistance as material adheres to the rod while it is penetrating deeper into the subgrade, and not necessarily with increased confinement provided by the material.

The posttest DCPs, in situ CBR, moisture, and density measurements were used to determine the depth of subgrade that might have undergone gradual drying and possible densification under traffic. Some increase in CBR was expected because of thixotropic properties of clay structures and gradual drying and densification during trafficking. Based on historic testing data (Rushing and Tingle, 2007; Rushing and Torres, 2007; Rushing et al., 2011; Garcia et al., 2012; Rushing et al., 2012), surface increases of less than 5 CBR and increases of less than 3 CBR at a depth of 6 in. are common and therefore acceptable. 
Figure 16. Nuclear moisture-density gauge test.

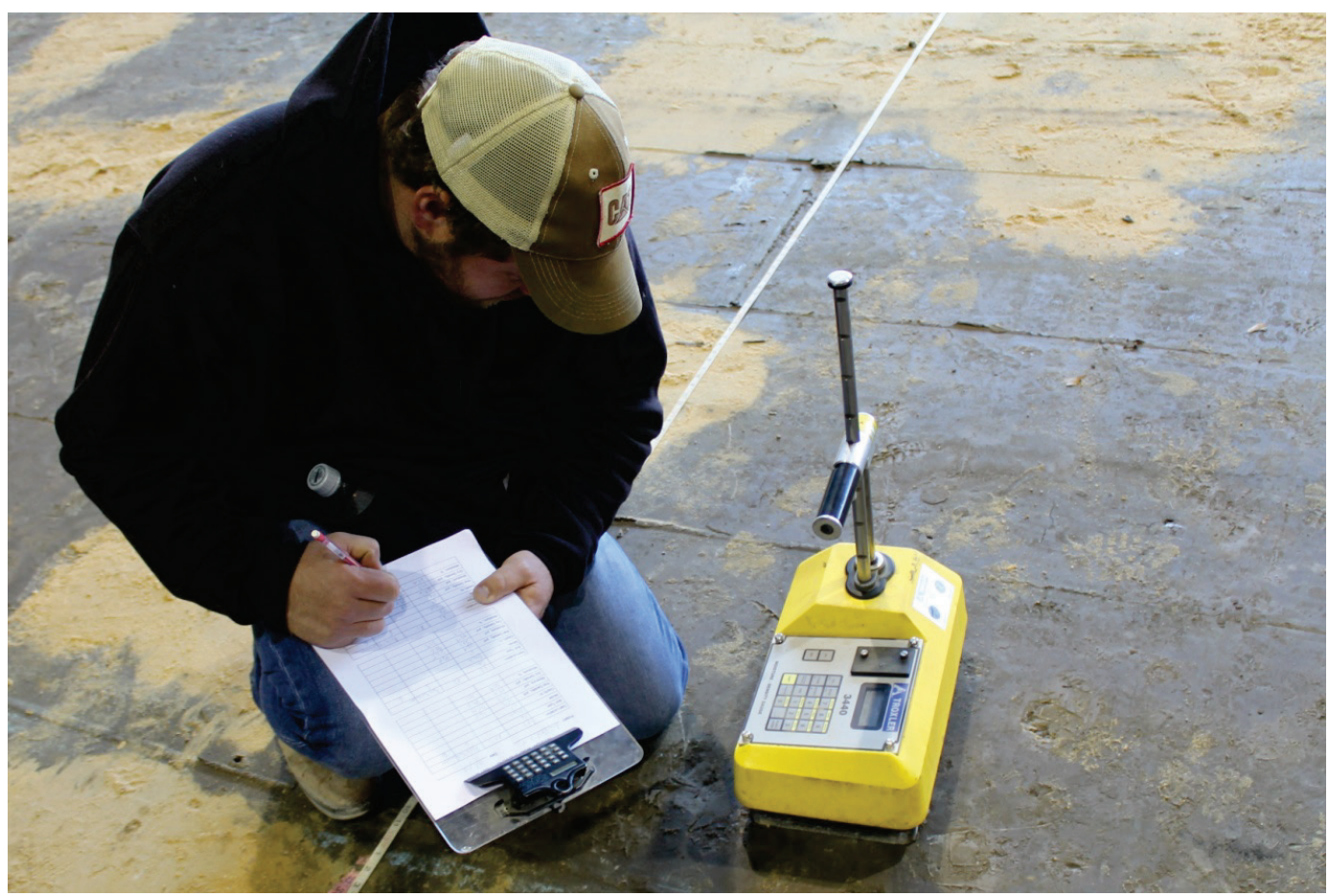

Figure 17. Field CBR test.

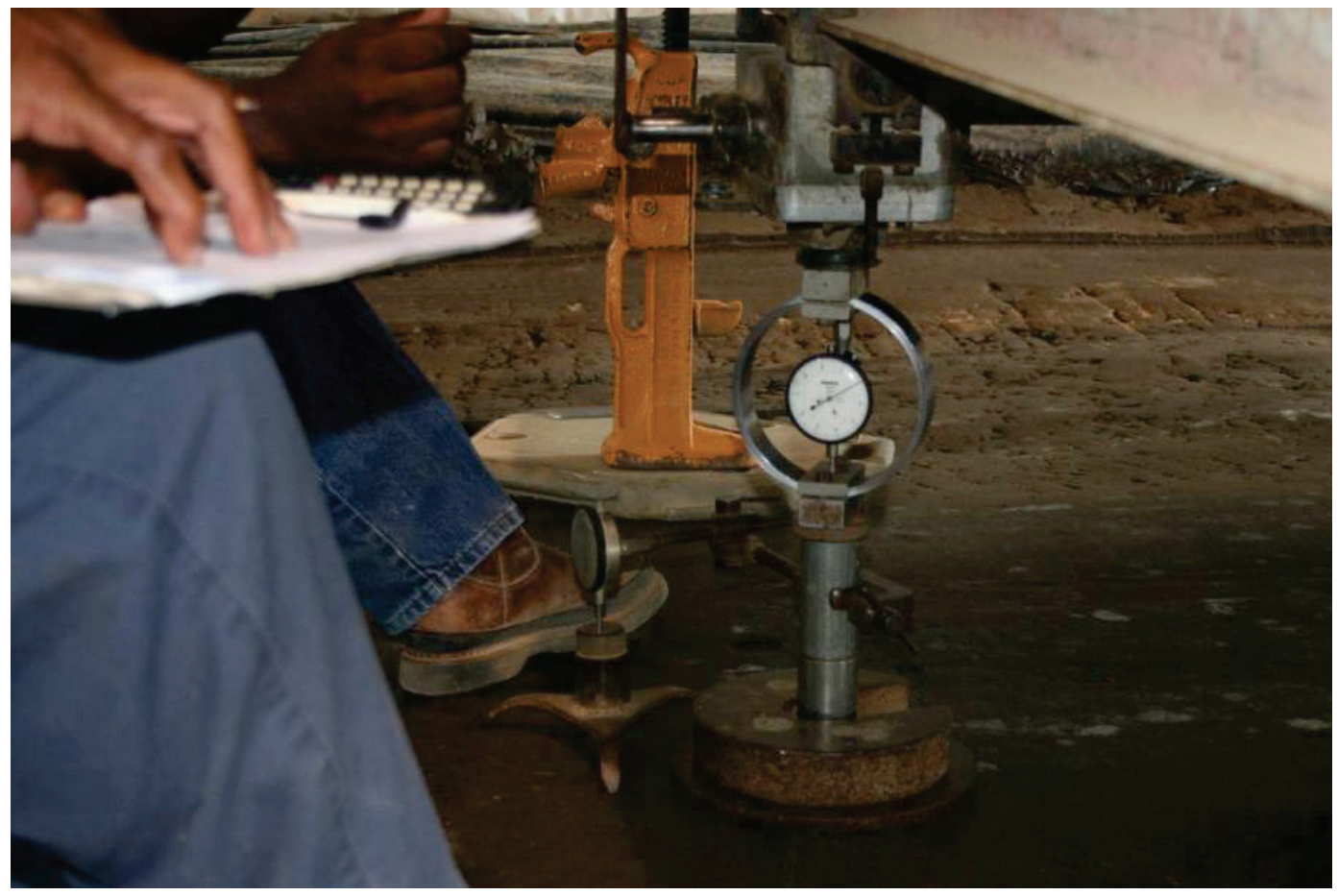


Table 6. Average in situ properties of the subgrade in each test item.

\begin{tabular}{|c|c|c|c|c|c|c|}
\hline \multirow[b]{2}{*}{$\begin{array}{l}\text { Test } \\
\text { Depth }\end{array}$} & \multicolumn{3}{|c|}{ Nuclear gauge test } & \multicolumn{2}{|c|}{ CBR test } & \multirow[b]{2}{*}{$\begin{array}{l}\text { Change in } \\
\text { CBR (\%) }\end{array}$} \\
\hline & $\begin{array}{l}\text { Wet } \\
\text { Density } \\
\left(\mathrm{lbf} / \mathrm{ft}^{3}\right)\end{array}$ & $\begin{array}{l}\text { Dry Density } \\
\left(\mathrm{lbf} / \mathrm{ft}^{3}\right)\end{array}$ & Moisture (\%) & $\begin{array}{l}\text { Oven } \\
\text { Moisture } \\
\text { (\%) }\end{array}$ & $\begin{array}{l}\text { In Situ } \\
\text { CBR } \\
(\%)\end{array}$ & \\
\hline \multicolumn{7}{|c|}{ F-15E ITEM } \\
\hline \multicolumn{7}{|c|}{ PRETEST } \\
\hline Surface & 117.2 & 89.2 & 31.4 & 32.7 & 6.5 & - \\
\hline 6 in. & 118.8 & 92.2 & 28.8 & 30.7 & 5.9 & - \\
\hline 12 in. & 118.8 & 92.3 & 28.7 & 29.1 & 6.2 & - \\
\hline $18 \mathrm{in.}$ & 118.1 & 91.4 & 29.3 & 31.3 & 6.1 & - \\
\hline $24 \mathrm{in.}$ & 116.3 & 87.6 & 32.7 & 27.2 & 5.7 & - \\
\hline $30 \mathrm{in.}$ & 117.4 & 88.9 & 32.0 & 32.5 & 6.2 & - \\
\hline \multicolumn{7}{|c|}{ POSTTEST } \\
\hline Surface & 117.9 & 90.8 & 29.9 & 32.5 & 9.4 & 2.9 \\
\hline \multicolumn{7}{|c|}{ C-17 ITEM } \\
\hline \multicolumn{7}{|c|}{ PRETEST } \\
\hline Surface & 116.6 & 89.6 & 37.7 & 31.8 & 6.0 & - \\
\hline 6 in. & 118.9 & 92.1 & 29.1 & 30.2 & 6.3 & - \\
\hline $12 \mathrm{in.}$ & 116.1 & 88.7 & 30.8 & 32.2 & 5.8 & - \\
\hline $18 \mathrm{in.}$ & 117.1 & 90.1 & 29.9 & 30.8 & 6.0 & - \\
\hline $24 \mathrm{in.}$ & 115.1 & 88.5 & 30.2 & 27.5 & 5.9 & - \\
\hline $30 \mathrm{in.}$ & 115.2 & 86.8 & 32.7 & 33.2 & 6.1 & - \\
\hline \multicolumn{7}{|c|}{ POSTTEST } \\
\hline Surface & 119.6 & 91.6 & 30.6 & 32.0 & 8.5 & 2.5 \\
\hline \multicolumn{7}{|c|}{ F-15E-V ITEM } \\
\hline \multicolumn{7}{|c|}{ PRETESTa } \\
\hline Surface & 116.9 & 89.4 & 34.6 & 32.2 & 6.2 & - \\
\hline 6 in. & 118.8 & 92.1 & 28.9 & 30.5 & 6.1 & - \\
\hline $12 \mathrm{in.}$ & 117.4 & 90.5 & 29.8 & 30.7 & 6.0 & - \\
\hline $18 \mathrm{in.}$ & 117.6 & 90.7 & 29.6 & 31.1 & 6.0 & - \\
\hline $24 \mathrm{in.}$ & 115.7 & 88.0 & 31.4 & 27.4 & 5.8 & - \\
\hline $30 \mathrm{in.}$ & 116.3 & 87.8 & 32.3 & 32.9 & 6.1 & - \\
\hline \multicolumn{7}{|c|}{ POSTTEST } \\
\hline Surface & 118.0 & 89.5 & 31.8 & - & $7.5^{b}$ & 1.3 \\
\hline
\end{tabular}

a Average of pretest values in $\mathrm{F}-15 \mathrm{E}$ and $\mathrm{C}-17$ items

b Estimated from the top $6 \mathrm{in}$. of DCP data measured at stations 10, 20 and 30 along the centerline 
Figure 18. Posttest DCP data for the F-15E-V item.

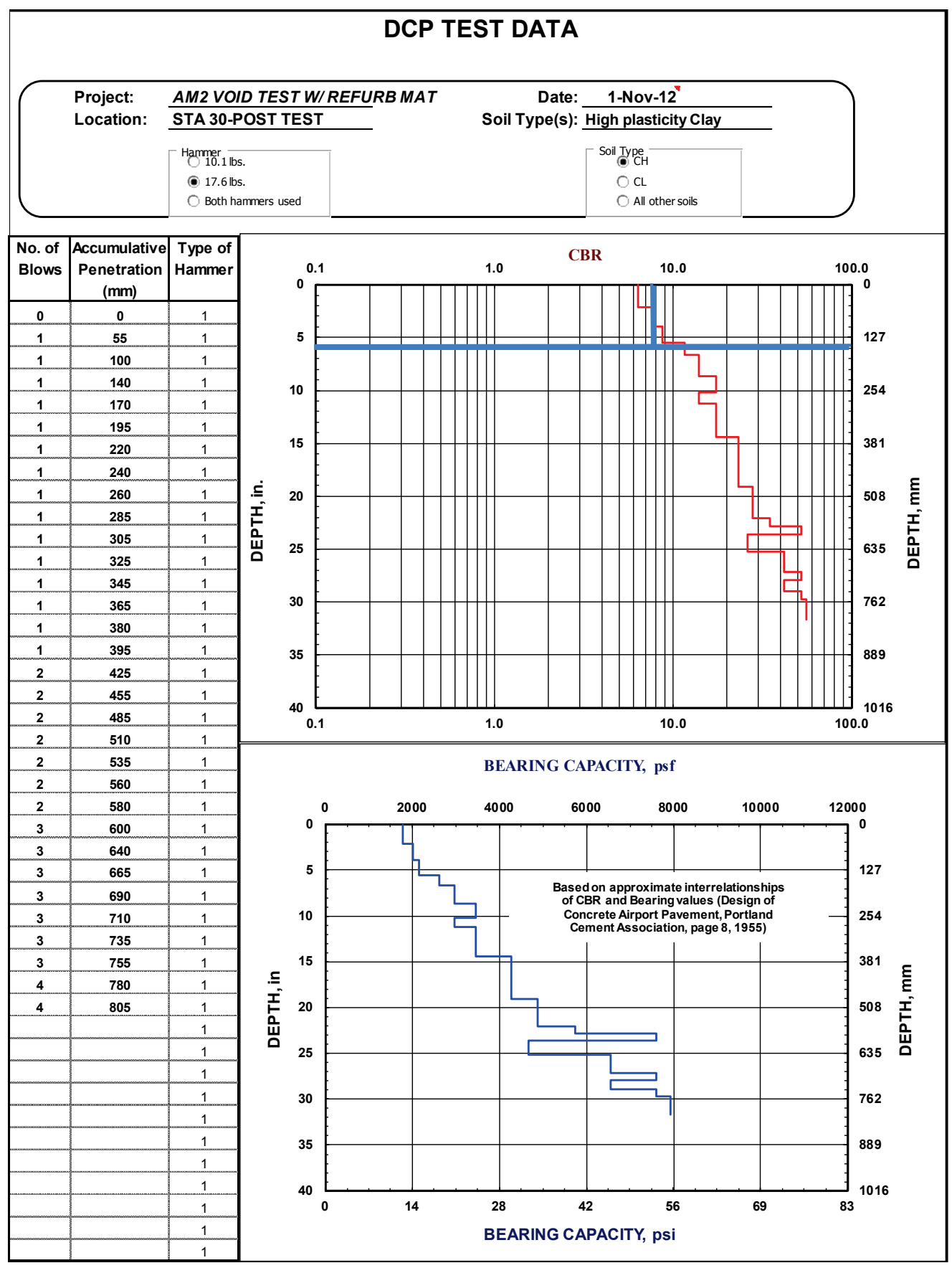


The moisture content and density measurements presented in Table 6 generally follow the trends found in laboratory measurements presented in Figures 4 and 5. However, previous experience has shown that the field moisture content required to construct a CBR of 6 typically ranges from $30 \%$ to $32 \%$ instead of $34 \%$, as suggested in Figure 5, due to the higher compaction energy used in the field compared to laboratory procedures.

For the F-15E-V item, the post-test CBR measured with the DCP was an average of 7.5 for the top $6 \mathrm{in}$. at the three stations. The post-test CBR increased by 1.3 from the pretest value of 6.2. For the F-15E test item, the post-test CBR measurements at the surface increased from 6.5 to 9.4 during trafficking. For the $\mathrm{C}-17$ test item, the post-test CBR measurements at the surface increased from 6.0 to 8.5. Since the surface measurements were within historic ranges, the strength of the subgrade remained within acceptable limits throughout testing.

\subsubsection{Subgrade instrumentation}

The subgrade was instrumented with 9-in.-diam RocTest ${ }^{\circledR}$ earth pressure cells (EPCs) installed at specific locations under the F-15E and C-17 items to monitor the stress distribution below the mat system. EPCs were not installed beneath the F-15E-V item. National Instruments NI SCXI data acquisition hardware was used to collect data points at a rate of $100 \mathrm{~Hz}$. Eight EPCs were installed 3 in. below the surface of the subgrade. EPC details are provided in Table 7. Figure 19 shows the instrumentation locations relative to mat placement. During subgrade construction, the EPCs were placed, as shown in Figure 20, and surveyed for elevation to ensure placement at the proper depths.

Table 7. Subgrade instrumentation summary.

\begin{tabular}{|l|l|l|}
\hline Test Item & EPC Designation & EPC Range (lbf/in. ${ }^{2}$ ) \\
\hline \multirow{4}{*}{ F-15E } & F1 & 290 \\
\cline { 2 - 3 } & F2 & 290 \\
\cline { 2 - 3 } & F3 & 300 \\
\cline { 2 - 3 } & F4 & 290 \\
\hline \multirow{5}{*}{ C-17 } & C1 & 300 \\
\cline { 2 - 3 } & C2 & 300 \\
\cline { 2 - 3 } & C3 & 300 \\
\hline & C4 & 200 \\
\hline
\end{tabular}




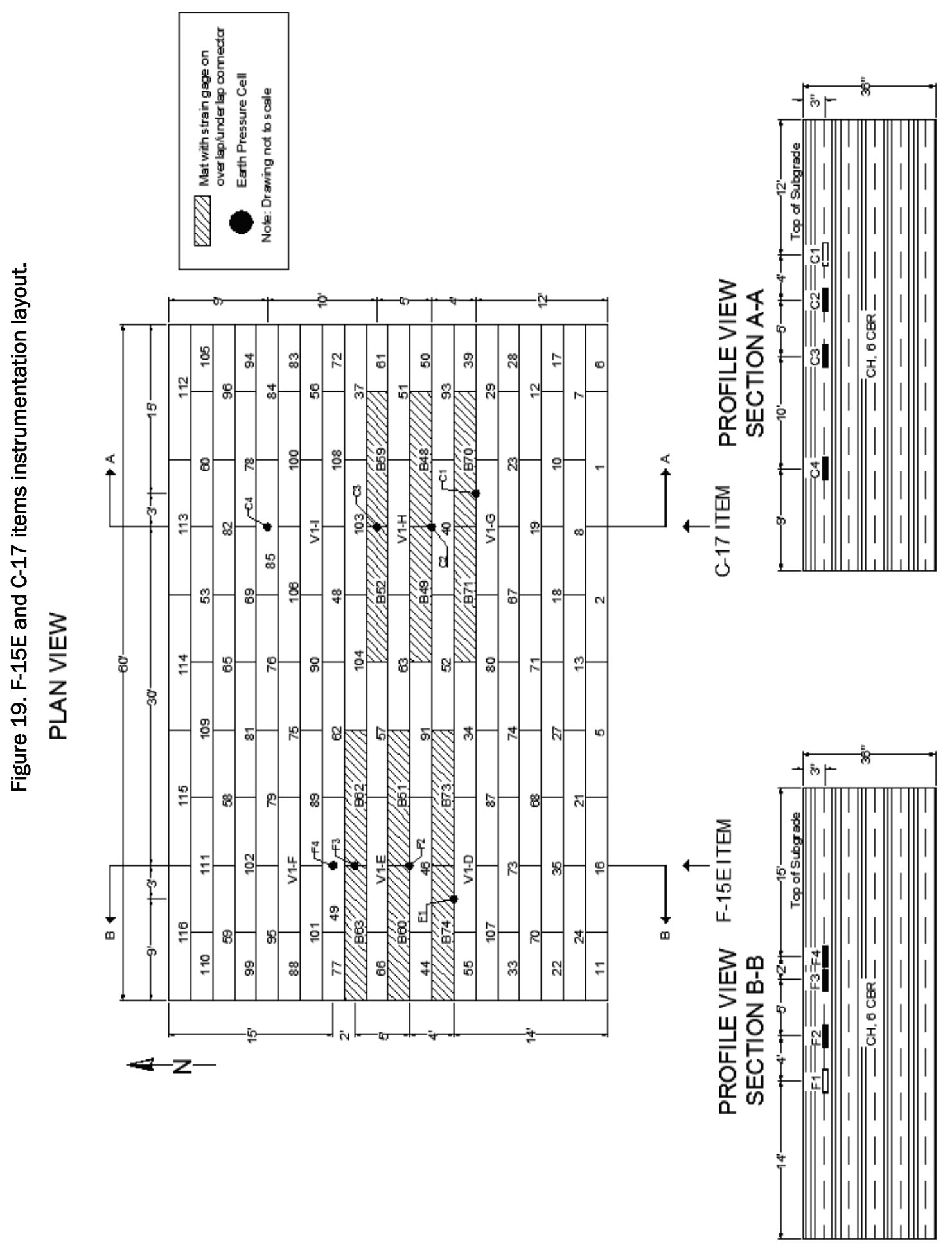


Figure 20. Installation of an EPC.

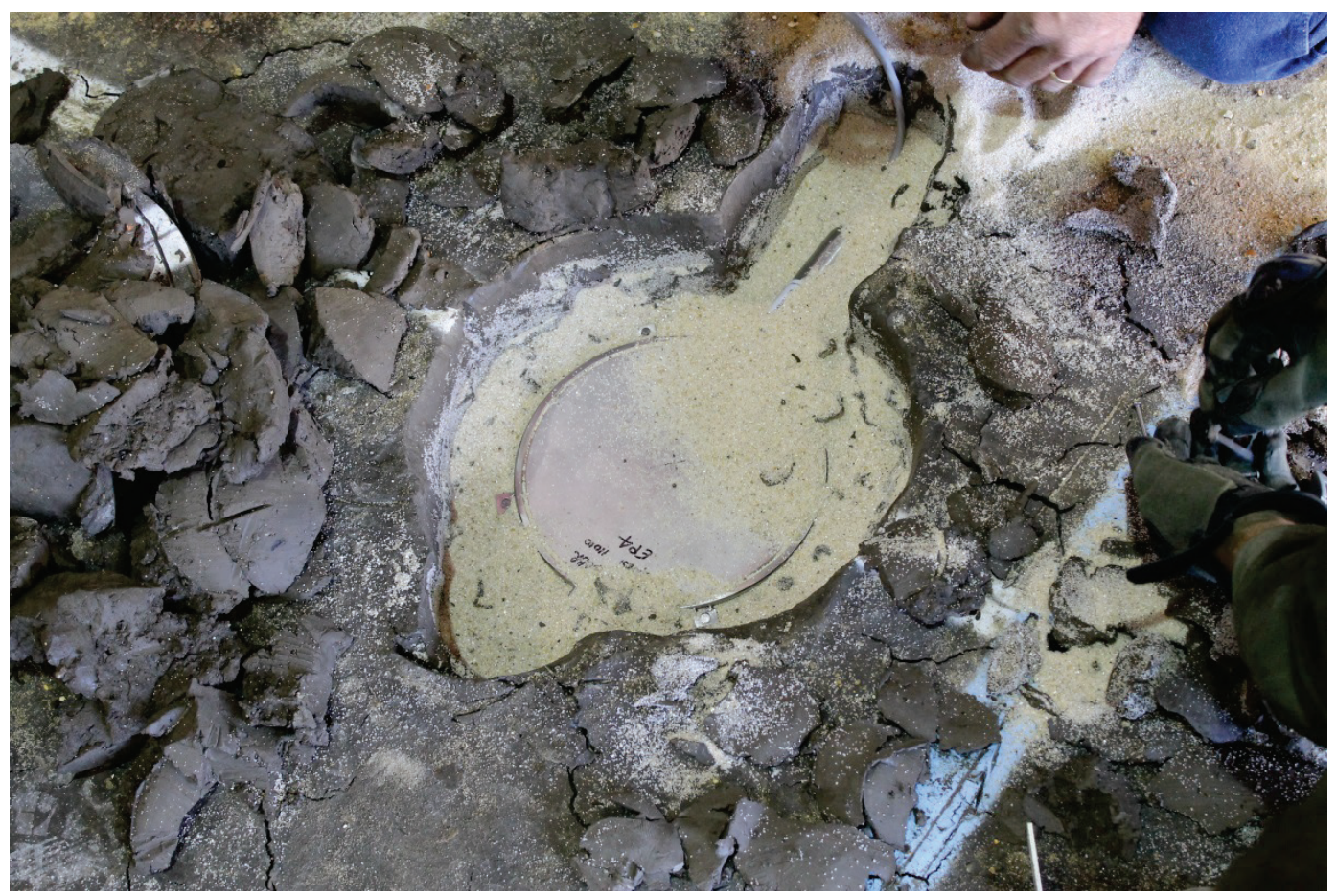

\subsubsection{AM2 strain gauge instrumentation}

Prior to installation, several mat panels were instrumented with foil strain gauges on the upper underlap or lower overlap regions of the 2 - $\mathrm{ft}$ end connectors as shown in Figure 21 and Figure 22. The gauges were installed by the Applied Research Laboratory (ARL) at Pennsylvania State University (PSU) under a contract with NAVAIR. The gauged mats were delivered to the ERDC for this evaluation. The locations of gauged panels in the test array are shown in Figure 19 for theF- $15 \mathrm{E}$ and $\mathrm{C}-17$ items and Figure 23 for the $\mathrm{F}-15 \mathrm{E}-\mathrm{V}$ item. The number and location of gauges installed on each panel are detailed in Table 8.

The strain gauges were used to gather critical strain information. The DIM showed the installation regions on the prongs to be the component most susceptible to breaking. These regions have also been shown to be the predominant failure regions in full-scale tests of AM2 reported by Rushing and Tingle (2007), Rushing and Torres (2007), Rushing et al. (2008), Rushing and Mason (2008), and Garcia and Rushing (2013). The gauged end connectors were placed along the centerline of each item to measure the maximum strains induced under simulated aircraft traffic loads. 
Figure 21. Strain gauge locations on upper underlap and lower overlap regions.

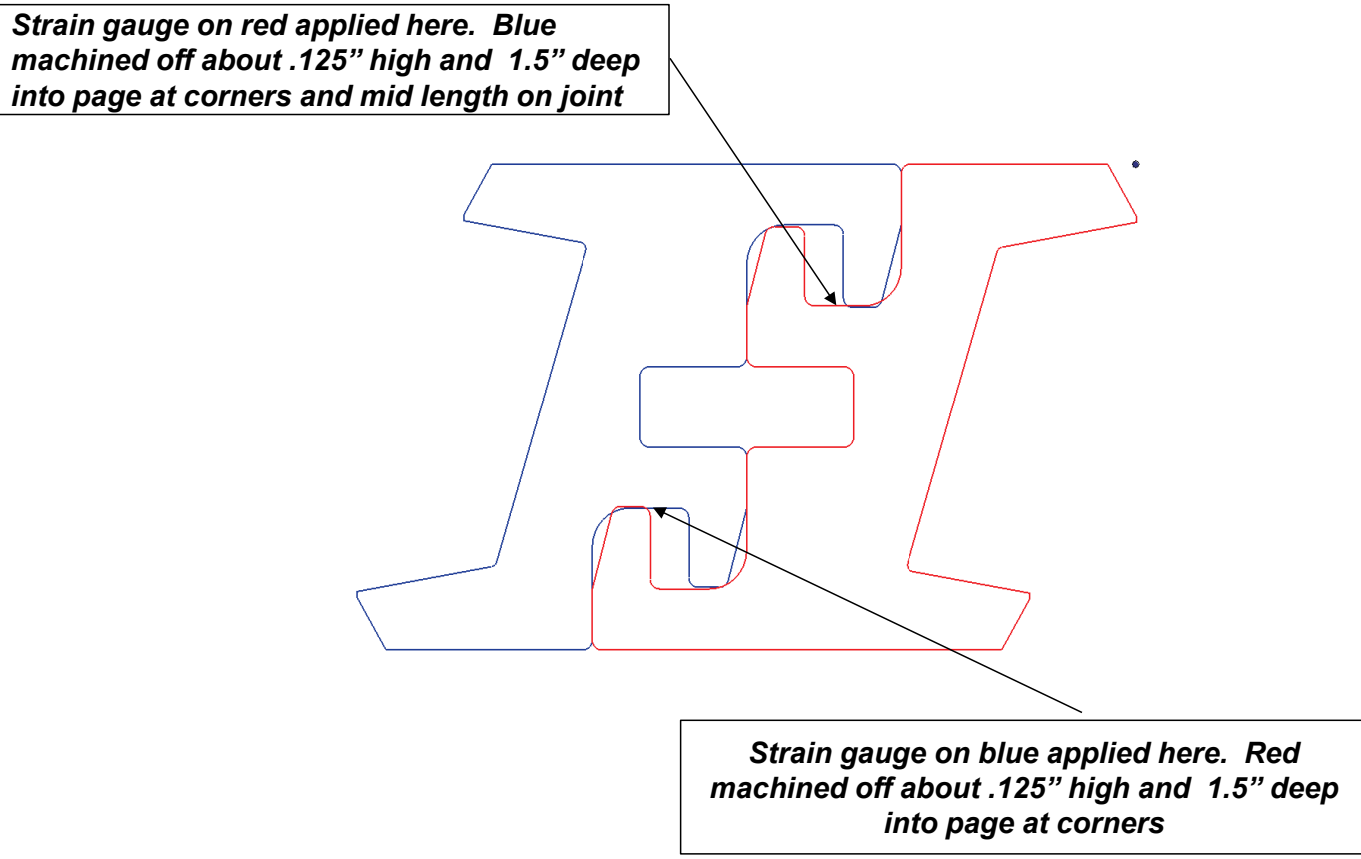

Figure 22. Typical strain gauge installation on lower overlap region.

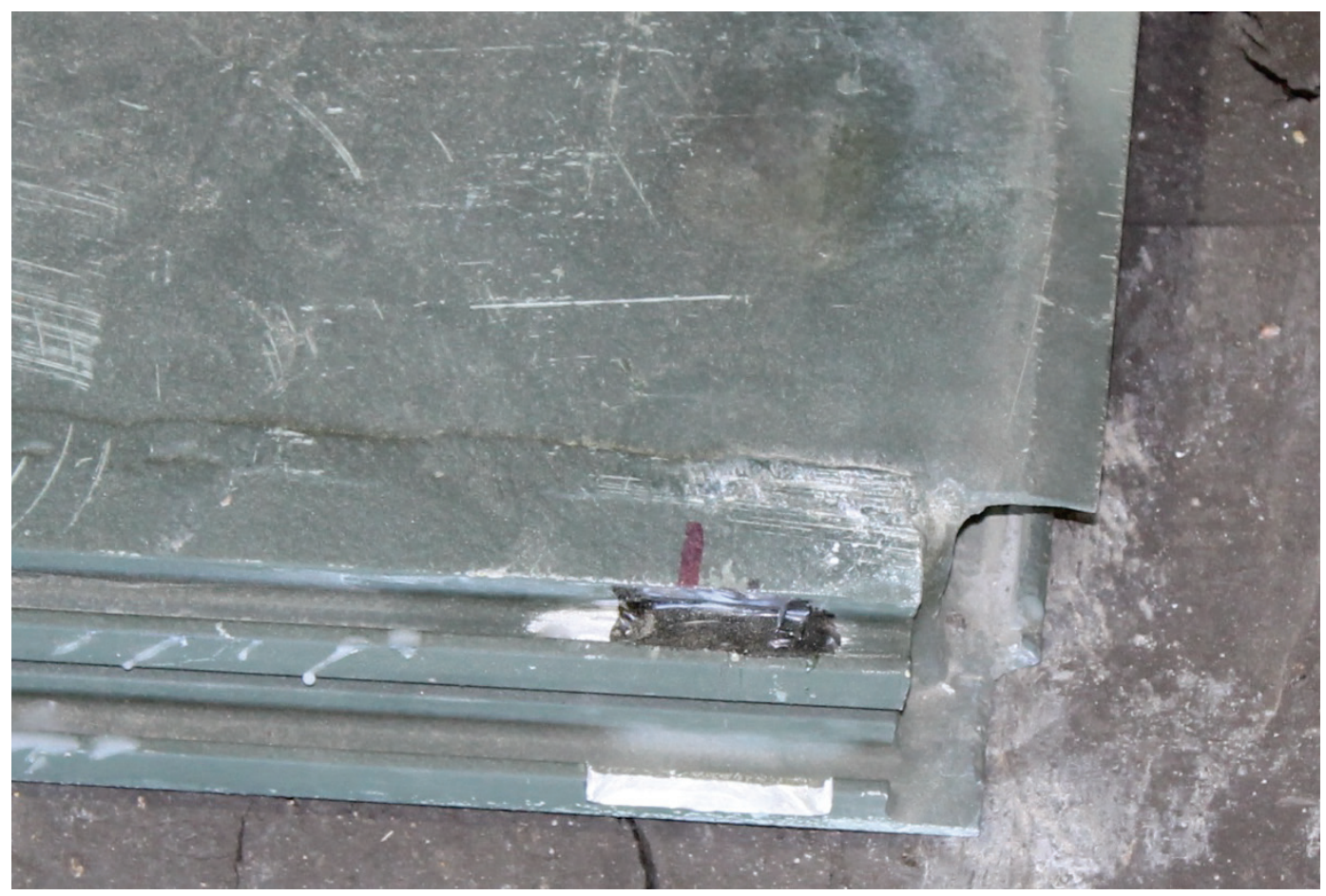


Figure 23. F-15E-V item instrumentation layout.

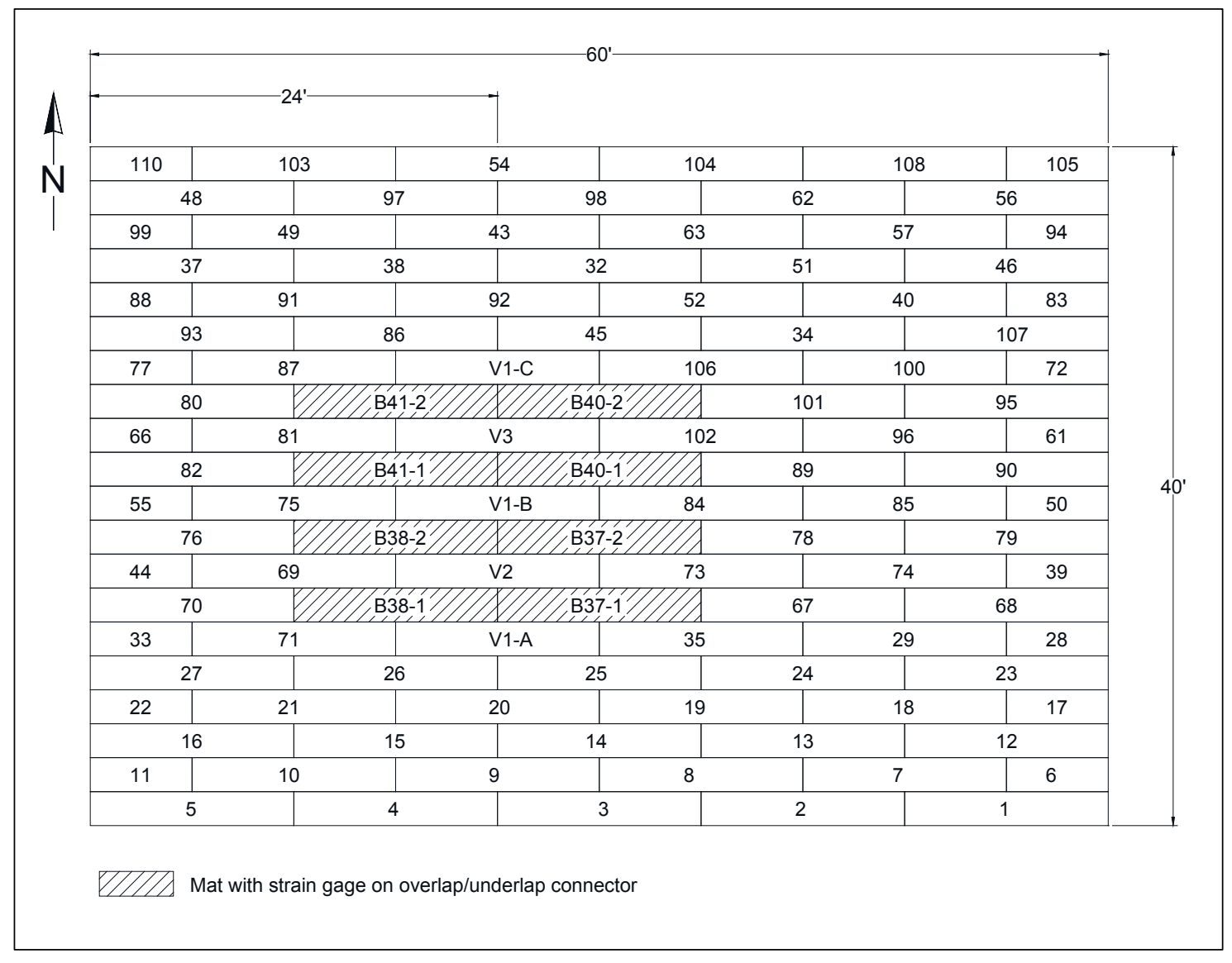

Table 8. Strain gauges in each test item.

\begin{tabular}{|l|l|l|}
\hline \multirow{4}{*}{ Test item } & \multicolumn{2}{|c|}{ Panel Number (gauge count) } \\
\cline { 2 - 3 } & $\begin{array}{c}\text { 12-ft panel lower } \\
\text { overlap }\end{array}$ & $\begin{array}{c}\text { 12-ft panel upper } \\
\text { underlap }\end{array}$ \\
\hline \multirow{4}{*}{ F-15E-V } & B41-2 (2) & B40-2 (2) \\
\cline { 2 - 3 } & B41-1 (2) & B40-1 (2) \\
\cline { 2 - 3 } & B38-2 (2) & B37-2 (2) \\
\cline { 2 - 3 } & B38-1 (2) & B37-1 (2) \\
\hline \multirow{4}{*}{ F-15E } & B63 (3) & B62 (3) \\
\cline { 2 - 3 } & B60 (3) & B51 (3) \\
\cline { 2 - 3 } & B74 (2) & B73 (2) \\
\hline \multirow{2}{*}{ C-17 } & B52 (3) & B59 (3) \\
\cline { 2 - 3 } & B49 (3) & B48 (3) \\
\cline { 2 - 3 } & B71 (2) & B70 (2) \\
\hline
\end{tabular}




\subsubsection{AM2 mat installation}

Prior to installation of AM2 on the subgrade surface, 2-in.-deep voids were excavated on the surface at the locations shown in Figure 7 and to the diameters listed in Table 5. Photos of the process are shown in Figure 24. The AM2 airfield mat system was placed on the surface of the prepared test section subgrade by an experienced crew. The mat bundles were placed on the test section with a forklift, and the individual panels were carried by two men and placed into position.

Figure 24. Void installation on subgrade surface.
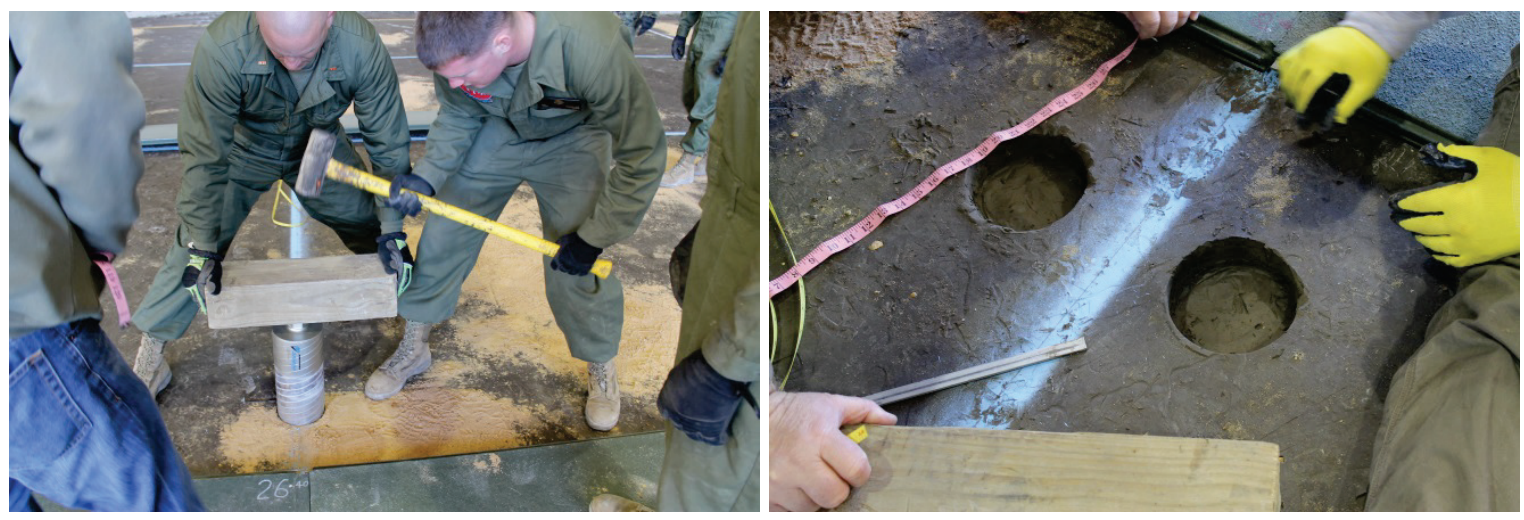

The first mat panel was placed flat on the ground with the long dimensions perpendicular to the direction of traffic and with the male hinge connector facing north. The second panel was positioned adjacent to the 2 - $\mathrm{ft}$ end of the first, allowing the overlapping end connector of the second panel to drop into position over the underlapping end connector of the first panel. A rectangular slot was formed between the two end connector rails, and an aluminum locking bar was inserted into the slot, as shown in Figure 25. This locking bar prevented the ends of the mat panels from separating. This process was continued until the first row was installed.

For the second row, the 12-ft female hinge connector was attached to the male hinge connector of panels from the first row, and the panel was pivoted into place, as shown in Figure 26. The next panel was installed by attaching the female hinge connector to the male hinge connector of panels in the first row and allowing the overlapping end connector rail to pivot over and connect to the underlapping end connector rail of the adjacent panel. An aluminum locking bar was inserted into the space provided to keep the panels from separating. This process was repeated until the entire mat test section was assembled in a brickwork configuration with half-panels on alternating ends of every other row. Towing tubes, mandrels, and end caps 
available at ERDC from older U.S. Air Force Airfield Damage Repair kits were installed on the east and west edges of the test section to minimize shifting of the rows during traffic. Photos of these accessories are shown in Figure 27.

Figure 25. Insertion of aluminum locking bar between adjacent panels.

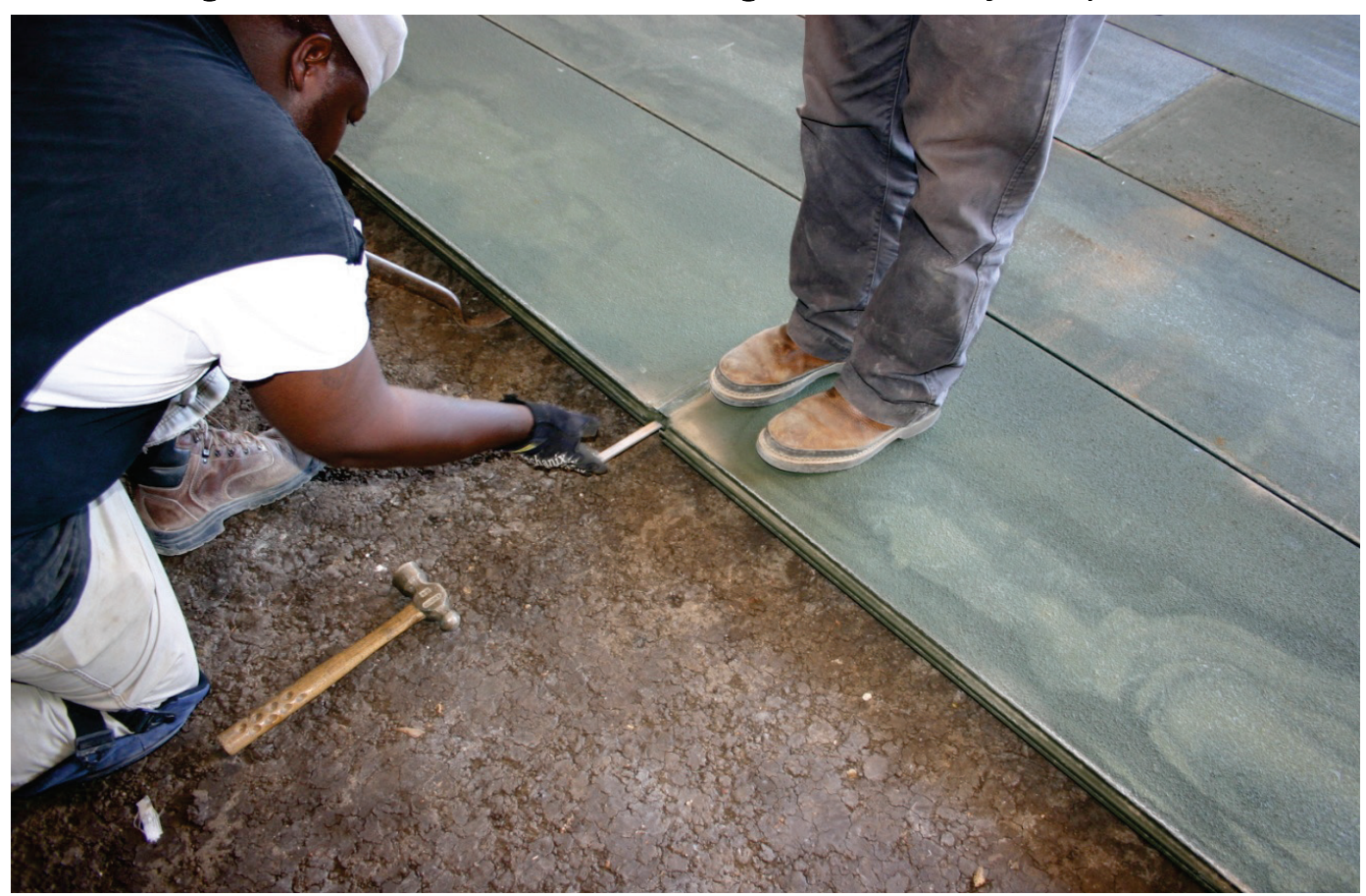

Figure 26. Installation of AM2 panels on the test section subgrade.

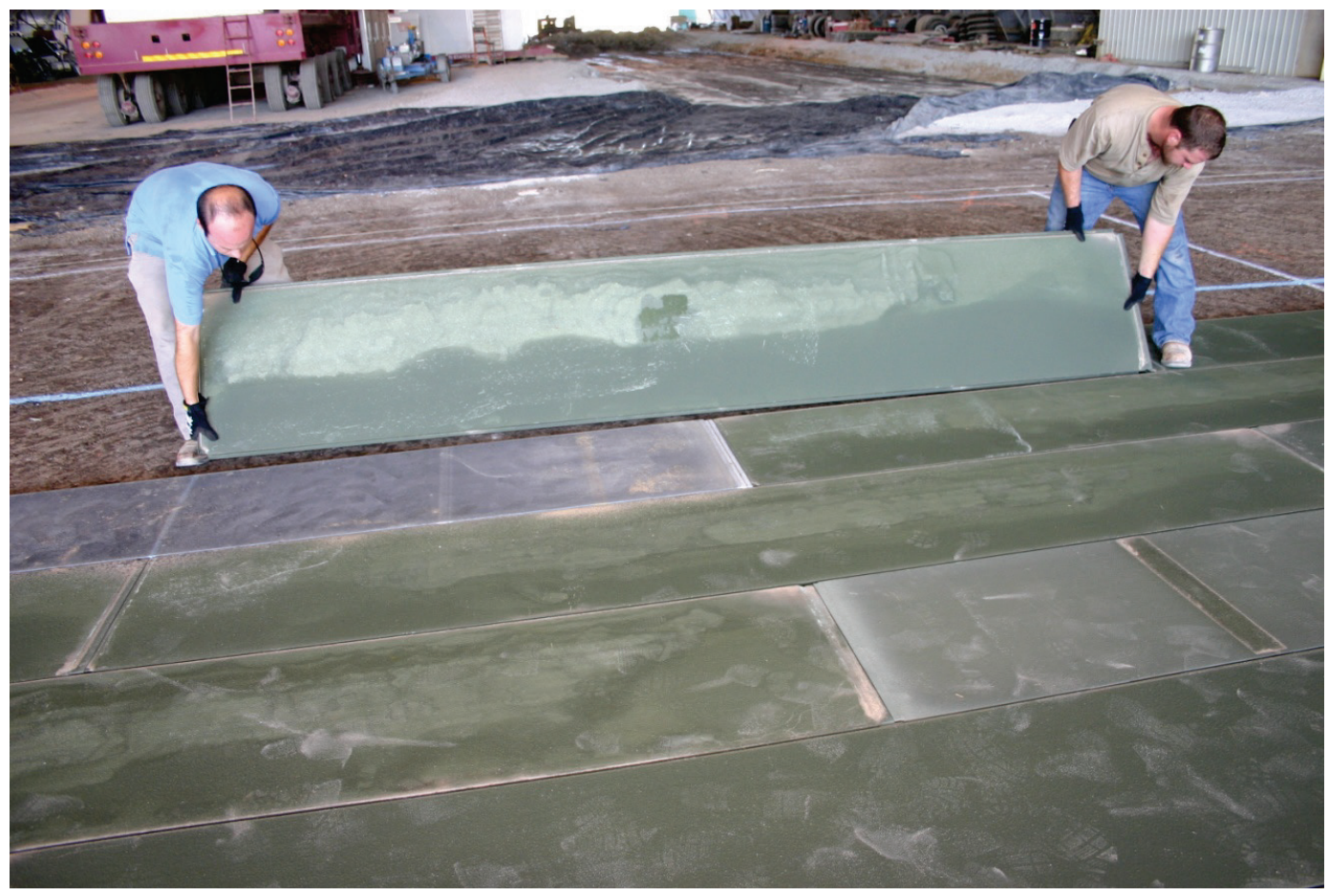


Figure 27. Typical installation of towing to the edges of the test section.
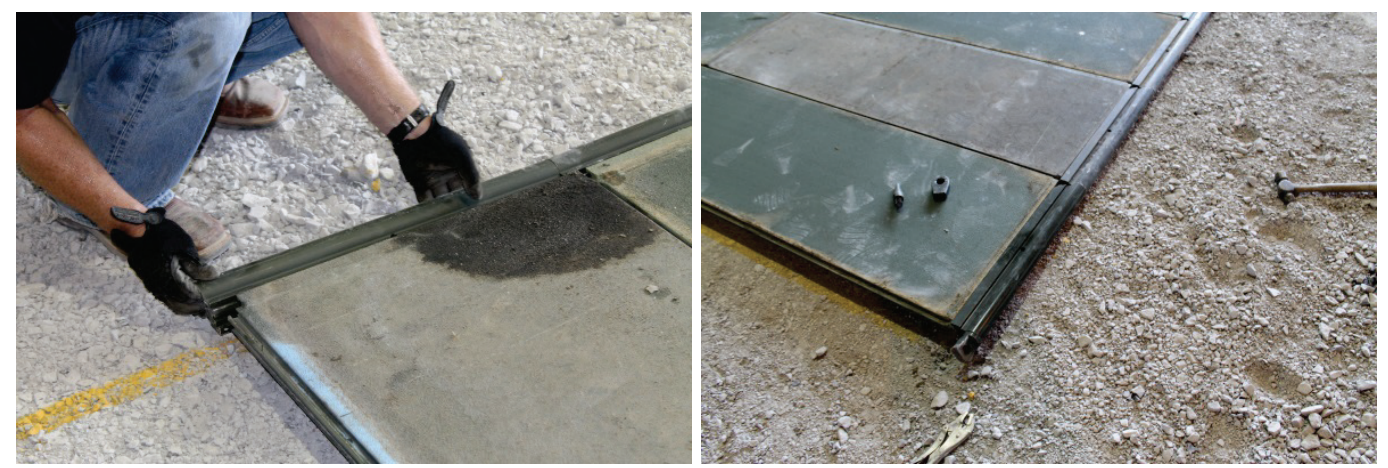

Once assembly was complete, full-panels of AM2 were installed along the ends of the traffic lanes to facilitate the entrance and exit of the test vehicles. Male keylocks were attached to the female hinge connector of the panels in the first row to facilitate ramp installation, as shown in Figure 28. A photo of the assembled F-15E-V test item is shown in Figure 29. Once the mats had been installed, 1,00o-lb steel weights were placed along the edges of the test section to anchor the mats and simulate the resistance to movement provided by a large expanse of matting.

Figure 28. Typical Installation of male keylock.

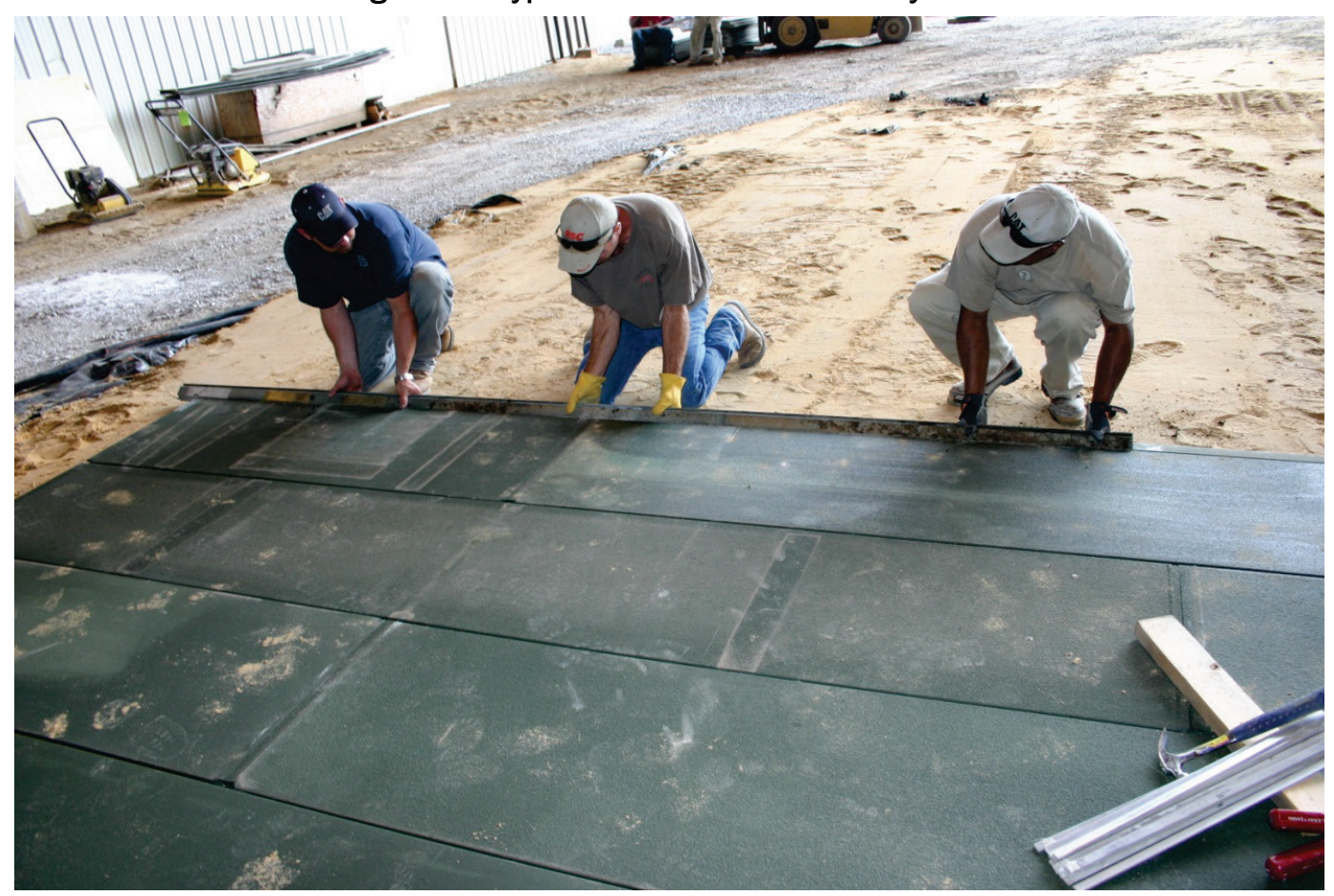


Figure 29. Brickwork pattern on voided subgrade final assembled test section.

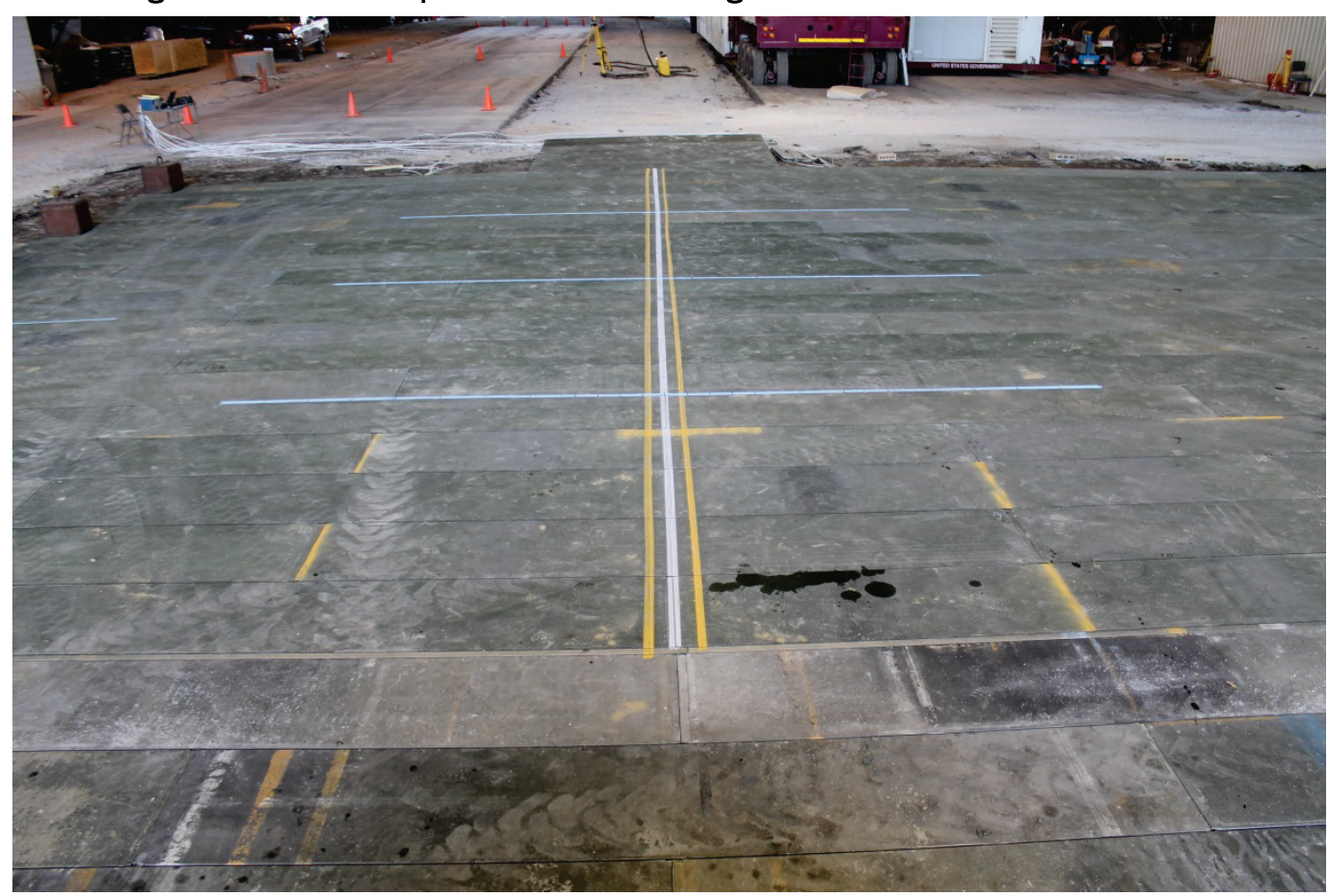

After completing the F-15E-V item test, the panels were removed and replaced with panels for the $\mathrm{F}-15 \mathrm{E}$ and $\mathrm{C}-17$ items. Towing accessories, entrance/exit ramps, and steel weights were placed in the same manner. General views of each item in the second brickwork test section are shown in Figure 30.

Figure 30. F-15E (left) and C-17 (right) items.
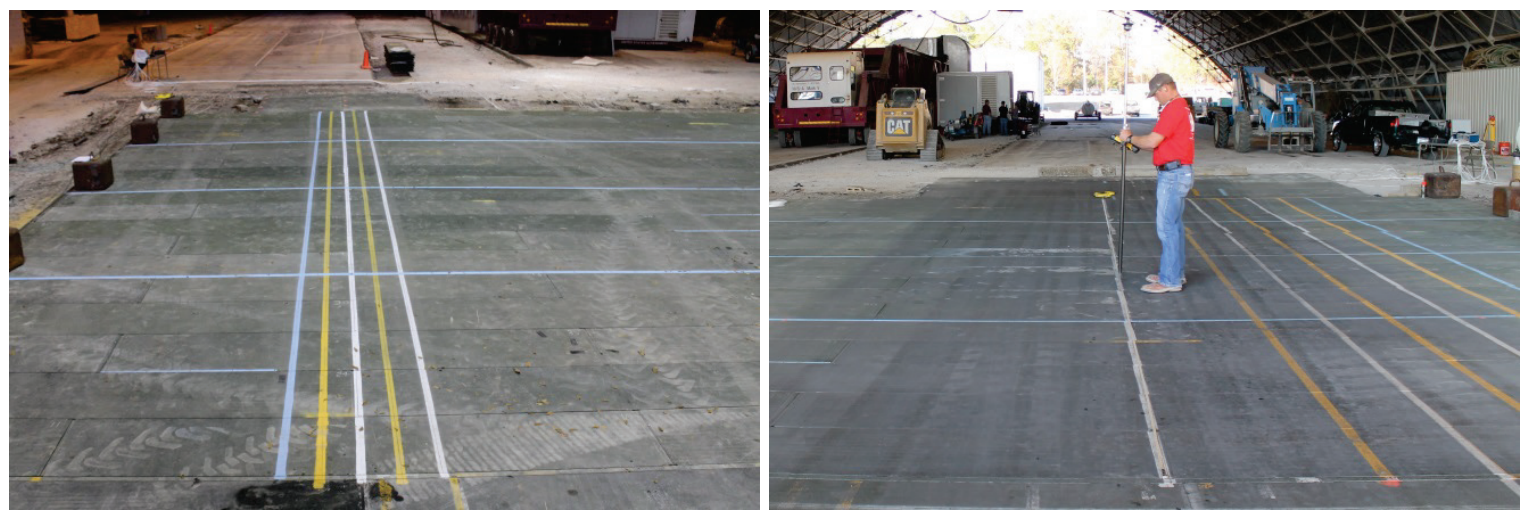

\subsection{Traffic application}

This section describes the application of simulated aircraft traffic on the AM2 airfield mat system. Pertinent data concerning the test load carts are provided. 


\subsubsection{F-15E load cart}

A specially designed single-wheel load cart was used to simulate F-15E aircraft traffic. The load cart was equipped with a 36-in. by 11-in., 30-ply tire inflated to $325 \mathrm{lbf} / \mathrm{in} .^{2}$ and loaded such that the test wheel was supporting $35,235 \mathrm{lb}$. The F-15E load cart was equipped with two outrigger wheels to prevent overturning and was powered by the prime mover of a Case vibratory steel-wheel roller as shown in Figure 31.

Figure 31. F-15E test load cart.

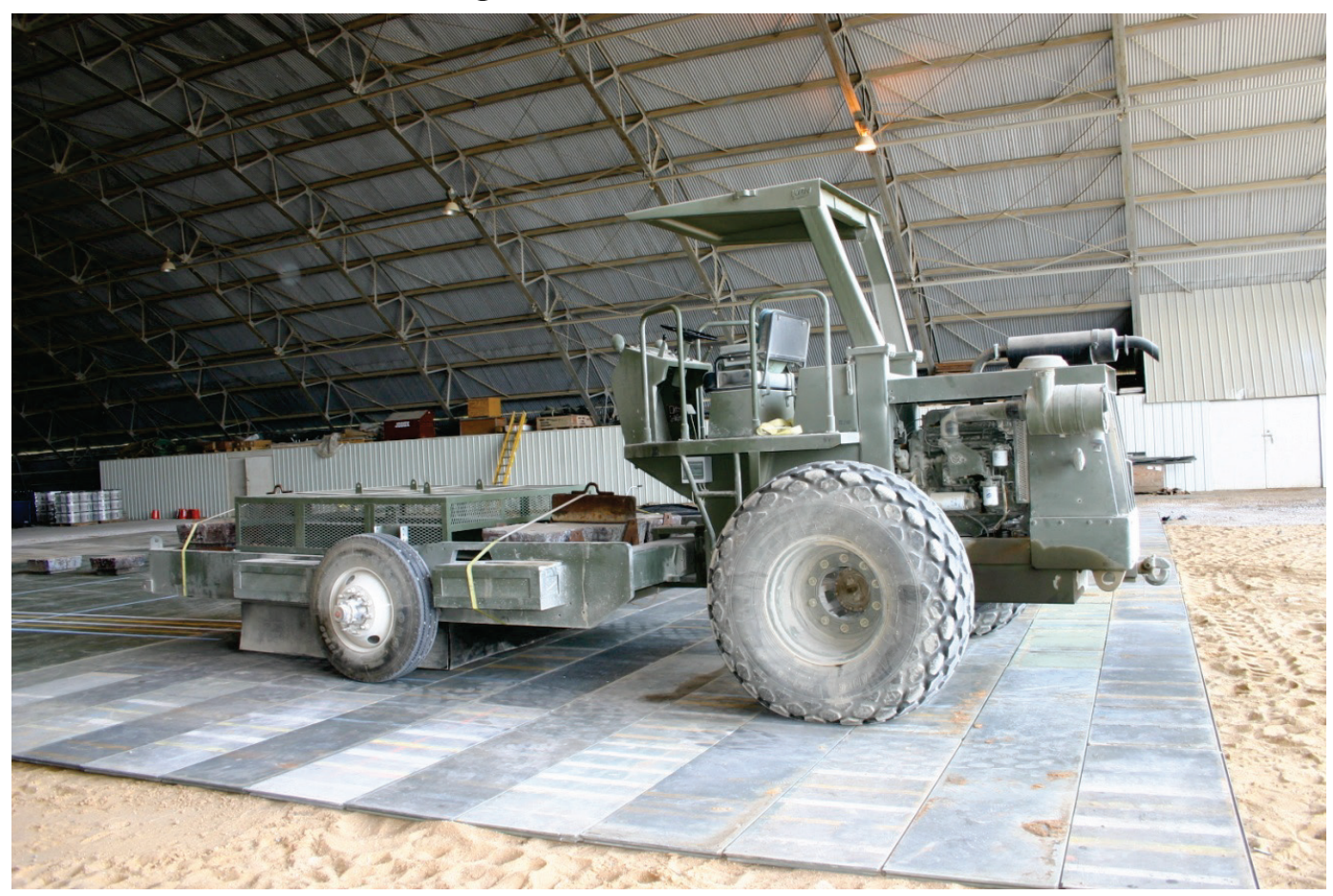

\subsubsection{Traffic on F-15E-V item}

Traffic on the F-15E-V was applied in an 18-in.-wide area. The traffic area was divided into two lanes that were centered 4.5 in. east and west of the centerline, as shown in Figure 7. This was done to focus most of the traffic above the excavated voids. The width of each lane corresponded to the measured contact width, 9-in., of the F-15E tire when fully loaded, and not the overall published tire width of $11 \mathrm{in}$. Traffic was applied by driving the load cart forward and then backward over the length of the test item and then shifting the path of the load cart laterally to the next lane (approximately one tire width) on each forward path. 


\subsubsection{Traffic on F-15E item}

A normally distributed pattern of simulated traffic was applied in a 3.75-ftwide traffic area for the F-15E test item, as shown in Figure 32. The traffic area was divided into five lanes that were designed to simulate the traffic distribution pattern, or wander width, of the main landing gear wheel on a mat surface when taxiing to and from an active runway. The width of each lane corresponded to the measured contact width of the F-15E tire when fully loaded. The normally distributed traffic patterns were simplified for ease-of-use by the load cart operator. Traffic was applied by driving the load cart forward and then backward over the length of the test item and then shifting the path of the load cart laterally approximately one tire width on each forward path. This procedure was continued until one pattern of traffic was completed. One pattern resulted in 16 passes, or 4 coverages.

Figure 32. Plan view showing F-15E normally distributed traffic lanes.

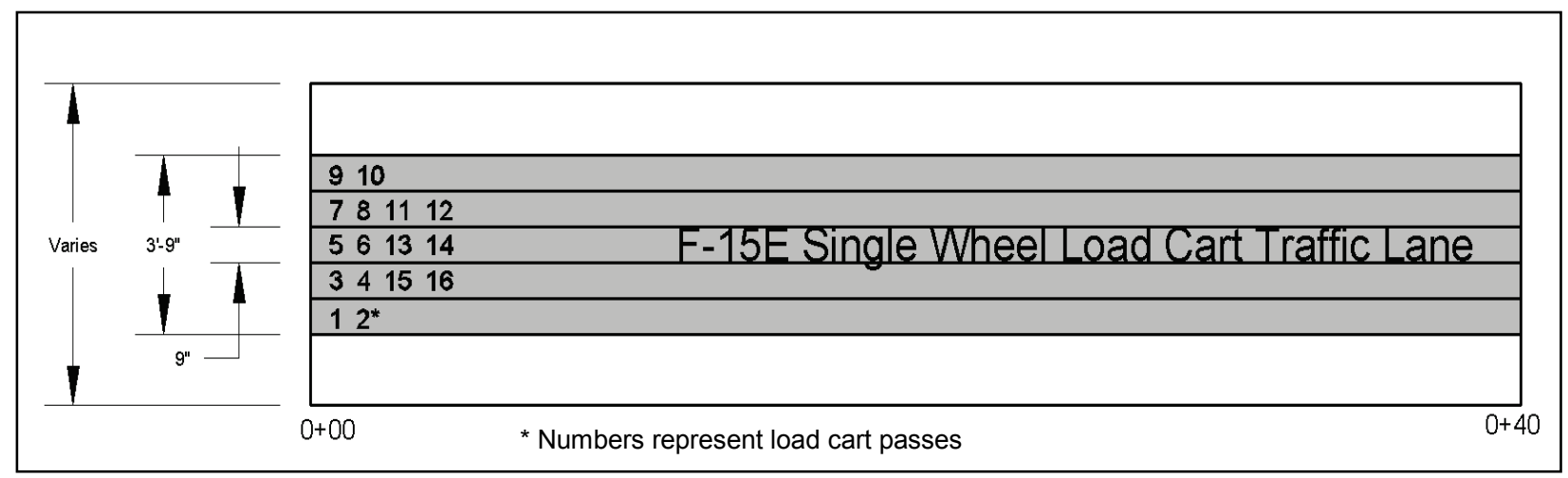

\subsubsection{C-17 load cart}

The multiple-wheel $\mathrm{C}-17$ load cart was designed to exactly match half of the main gear of a C-17 aircraft. The multiple-wheel $\mathrm{C}-17$ load cart was equipped with six 50-in. by 21-in., 20-ply tires inflated to $142 \mathrm{lbf} / \mathrm{in}^{2}{ }^{2}$ and loaded such that the test gear was supporting $269,560 \mathrm{lb}$, with estimated individual wheel loads of $44,930 \mathrm{lb}$. The test cart was powered by the front half of a Fiat scraper as shown in Figure 33.

A simulated normally distributed traffic pattern was applied in a 9-ft-wide traffic area for the $\mathrm{C}-17$ test item, as shown in Figure 34. The traffic areas were divided into individual lanes designed to simulate the traffic distribution pattern, or wander width, of the main landing gear wheels on a mat surface when taxiing to and from an active runway. The width of each lane corresponded to the measured contact width, 18 in., of the $\mathrm{C}-17$ 
tires when fully loaded and not the overall published tire width of 21 in. The normally distributed traffic patterns were simplified for ease-of-use by the load cart operator. Traffic was applied by driving the load cart forward and then backward over the length of the $\mathrm{C}-17$ test item and then shifting the path of the load cart laterally approximately one tire width on each forward pass. Tracking guides were attached to assist the driver in shifting the load cart the proper amount for each forward pass. This procedure was continued until one pattern of traffic was completed. For the $\mathrm{C}-17$ test item, one pattern resulted in 28 passes, or 25 coverages.

Figure 33. C-17 test load cart.

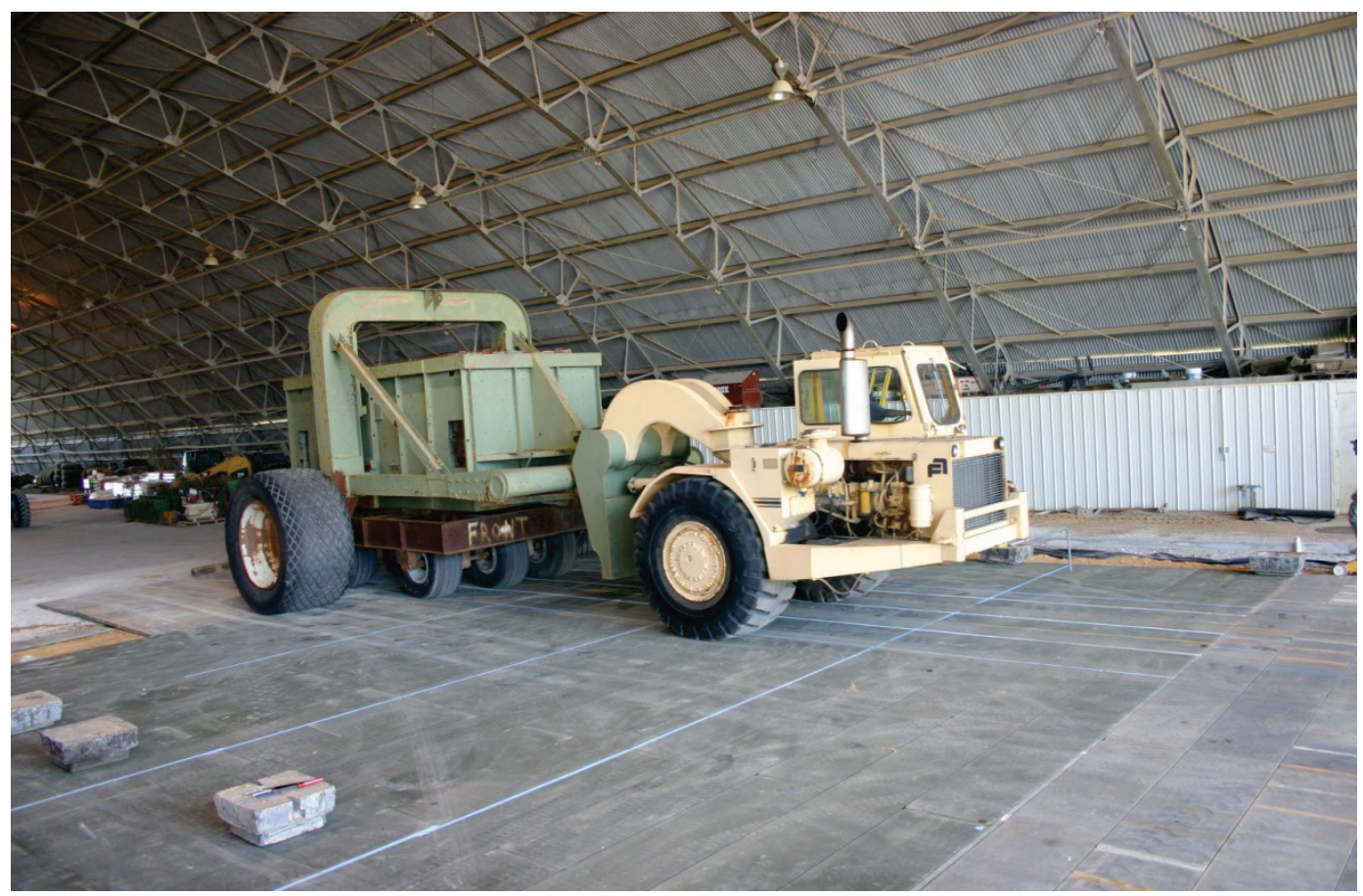

Figure 34. Plan view showing C-17 normally distributed traffic lanes.

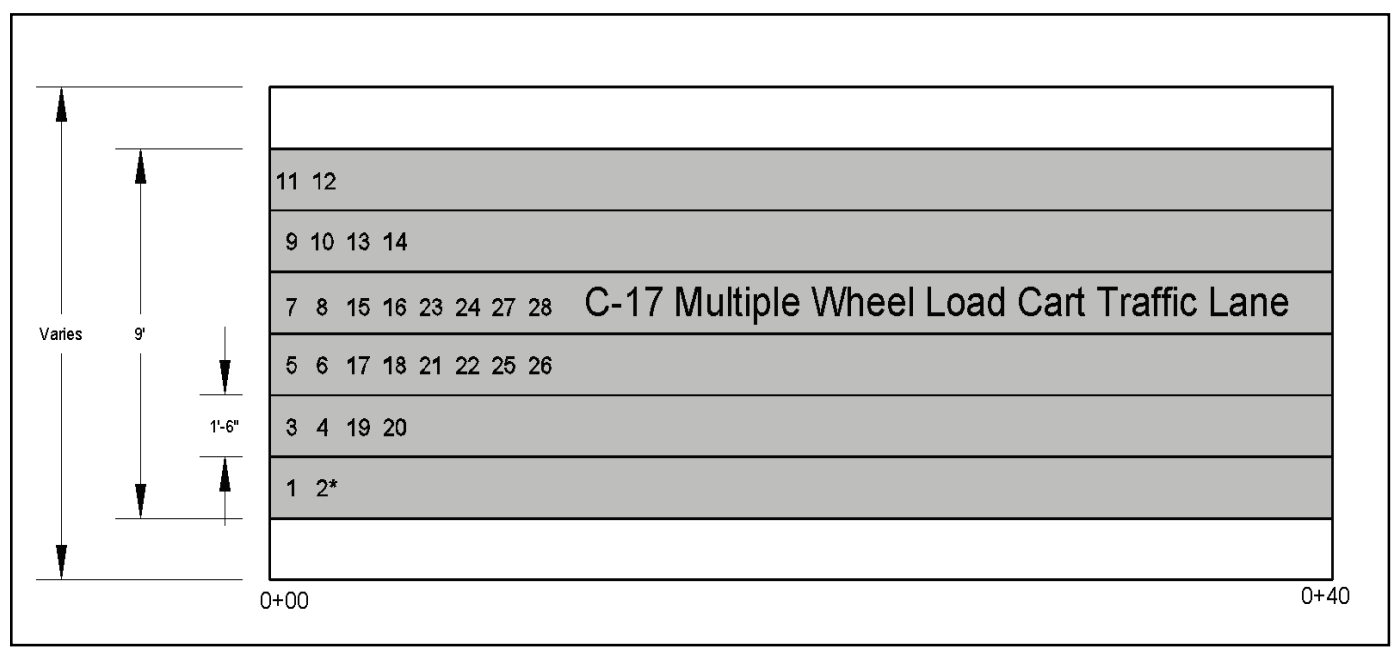




\subsection{Data collection}

Data collection included robotic total station measurements of centerline profiles, cross-sections, dynamic elastic deflections, dynamic strain measurements, borescope observation videos, and mat hole depth measurements. Dynamic Earth pressures were measured for the $\mathrm{F}-15 \mathrm{E}$ and $\mathrm{C}-17$ items. Data collection intervals for $\mathrm{F}-15 \mathrm{E}$ and $\mathrm{C}-17$ traffic are shown in Tables 9 and 10, respectively. Data collection layouts are shown in Figures 35 and 36 . For the F-15E-V item, voids on the subgrade surface were measured before mat installation to verify they were excavated to the correct dimensions and depth and inspected after traffic was concluded to determine the extent of movement of the material. The mat surface was inspected for damage periodically during traffic.

Table 9. Data collection intervals for F-15E traffic.

\begin{tabular}{|c|c|c|c|c|c|c|c|c|c|}
\hline $\begin{array}{l}\text { F-15E-V Item } \\
\text { Total Passes }\end{array}$ & $\begin{array}{c}\text { F-15E Item } \\
\text { Total } \\
\text { Passes }\end{array}$ & Profile & $\begin{array}{l}\text { Unloaded } \\
\text { Cross } \\
\text { sections }\end{array}$ & $\begin{array}{l}\text { Loaded } \\
\text { Cross } \\
\text { sections }\end{array}$ & $\begin{array}{l}\text { Dynamic } \\
\text { Deflection }\end{array}$ & $\begin{array}{c}\text { Strain } \\
\text { Gauges } 1\end{array}$ & $\begin{array}{c}\text { EPCs } \\
1,2\end{array}$ & $\begin{array}{l}\text { Borescope } \\
\text { video }\end{array}$ & $\begin{array}{c}\text { Hole depth } \\
\text { measurements }\end{array}$ \\
\hline Pretest Subgrade & $\begin{array}{l}\text { Pretest } \\
\text { Subgrade }\end{array}$ & $x$ & $x$ & & & & & & \\
\hline 0 & 0 & $x$ & $x$ & $x$ & $x$ & $x$ & $x$ & $x$ & $x$ \\
\hline 4 & 10 & $x$ & $x$ & $x$ & $x$ & $x$ & $x$ & $x$ & $x$ \\
\hline 8 & 16 & $x$ & $x$ & $x$ & $x$ & $x$ & $x$ & $x$ & $x$ \\
\hline 16 & 32 & $x$ & $x$ & $x$ & $x$ & $x$ & $x$ & $x$ & $x$ \\
\hline 32 & 48 & $x$ & $x$ & $x$ & $x$ & $x$ & $x$ & $x$ & $x$ \\
\hline 48 & 112 & $x$ & $x$ & $x$ & $x$ & $x$ & $x$ & $x$ & $x$ \\
\hline 112 & 240 & $x$ & $x$ & $x$ & $x$ & $x$ & $x$ & $x$ & $x$ \\
\hline 240 & 430 & $x$ & $x$ & $x$ & $x$ & $x$ & $x$ & $x$ & $x$ \\
\hline 322 & - & $x$ & $x$ & $x$ & $x$ & $x$ & & $x$ & $x$ \\
\hline Post-Test Subgrade & $\begin{array}{l}\text { Post-Test } \\
\text { Subgrade }\end{array}$ & $x$ & $x$ & & & & & & \\
\hline
\end{tabular}

1Data was collected continuously.

${ }^{2}$ Not collected for brickwork pattern on voided subgrade 
Table 10. Data collection intervals for C-17 traffic.

\begin{tabular}{|l|l|l|l|l|l|l|l|}
\hline Total Passes & Profile & $\begin{array}{l}\text { Unloaded Cross } \\
\text { Sections }\end{array}$ & $\begin{array}{l}\text { Loaded } \\
\text { Cross Sections }\end{array}$ & $\begin{array}{l}\text { Strain } \\
\text { Gauges 1 }\end{array}$ & EPCs 1 & $\begin{array}{l}\text { Borescope } \\
\text { video }\end{array}$ & $\begin{array}{l}\text { Hole depth } \\
\text { measurements }\end{array}$ \\
\hline Pretest Subgrade & $\mathrm{X}$ & $\mathrm{X}$ & & & & & \\
\hline 0 & $\mathrm{X}$ & $\mathrm{X}$ & $\mathrm{X}$ & $\mathrm{X}$ & $\mathrm{X}$ & $\mathrm{X}$ & $\mathrm{X}$ \\
\hline 12 & $\mathrm{X}$ & $\mathrm{X}$ & $\mathrm{X}$ & $\mathrm{X}$ & $\mathrm{X}$ & $\mathrm{X}$ & $\mathrm{X}$ \\
\hline 28 & $\mathrm{X}$ & $\mathrm{X}$ & $\mathrm{X}$ & $\mathrm{X}$ & $\mathrm{X}$ & $\mathrm{X}$ & $\mathrm{X}$ \\
\hline 56 & $\mathrm{X}$ & $\mathrm{X}$ & $\mathrm{X}$ & $\mathrm{X}$ & $\mathrm{X}$ & $\mathrm{X}$ & $\mathrm{X}$ \\
\hline 84 & $\mathrm{X}$ & $\mathrm{X}$ & $\mathrm{X}$ & $\mathrm{X}$ & $\mathrm{X}$ & $\mathrm{X}$ & $\mathrm{X}$ \\
\hline 168 & $\mathrm{X}$ & $\mathrm{X}$ & $\mathrm{X}$ & $\mathrm{X}$ & $\mathrm{X}$ & $\mathrm{X}$ & $\mathrm{X}$ \\
\hline 308 & $\mathrm{X}$ & $\mathrm{X}$ & $\mathrm{X}$ & $\mathrm{X}$ & $\mathrm{X}$ & $\mathrm{X}$ & $\mathrm{X}$ \\
\hline 504 & $\mathrm{X}$ & $\mathrm{X}$ & $\mathrm{X}$ & $\mathrm{X}$ & $\mathrm{X}$ & $\mathrm{X}$ & $\mathrm{X}$ \\
\hline 784 & $\mathrm{X}$ & $\mathrm{X}$ & $\mathrm{X}$ & $\mathrm{X}$ & $\mathrm{X}$ & $\mathrm{X}$ & $\mathrm{X}$ \\
\hline 1008 & $\mathrm{X}$ & $\mathrm{X}$ & $\mathrm{X}$ & $\mathrm{X}$ & $\mathrm{X}$ & $\mathrm{X}$ & $\mathrm{X}$ \\
\hline 1308 & $\mathrm{X}$ & $\mathrm{X}$ & $\mathrm{X}$ & $\mathrm{X}$ & $\mathrm{X}$ & $\mathrm{X}$ & $\mathrm{X}$ \\
\hline $\begin{array}{l}\text { Post-Test } \\
\text { Subgrade }\end{array}$ & $\mathrm{X}$ & $\mathrm{X}$ & & & & & \\
\hline
\end{tabular}

${ }^{1}$ Data was collected continuously.

Figure 35. Data collection layout for F-15E-V item.

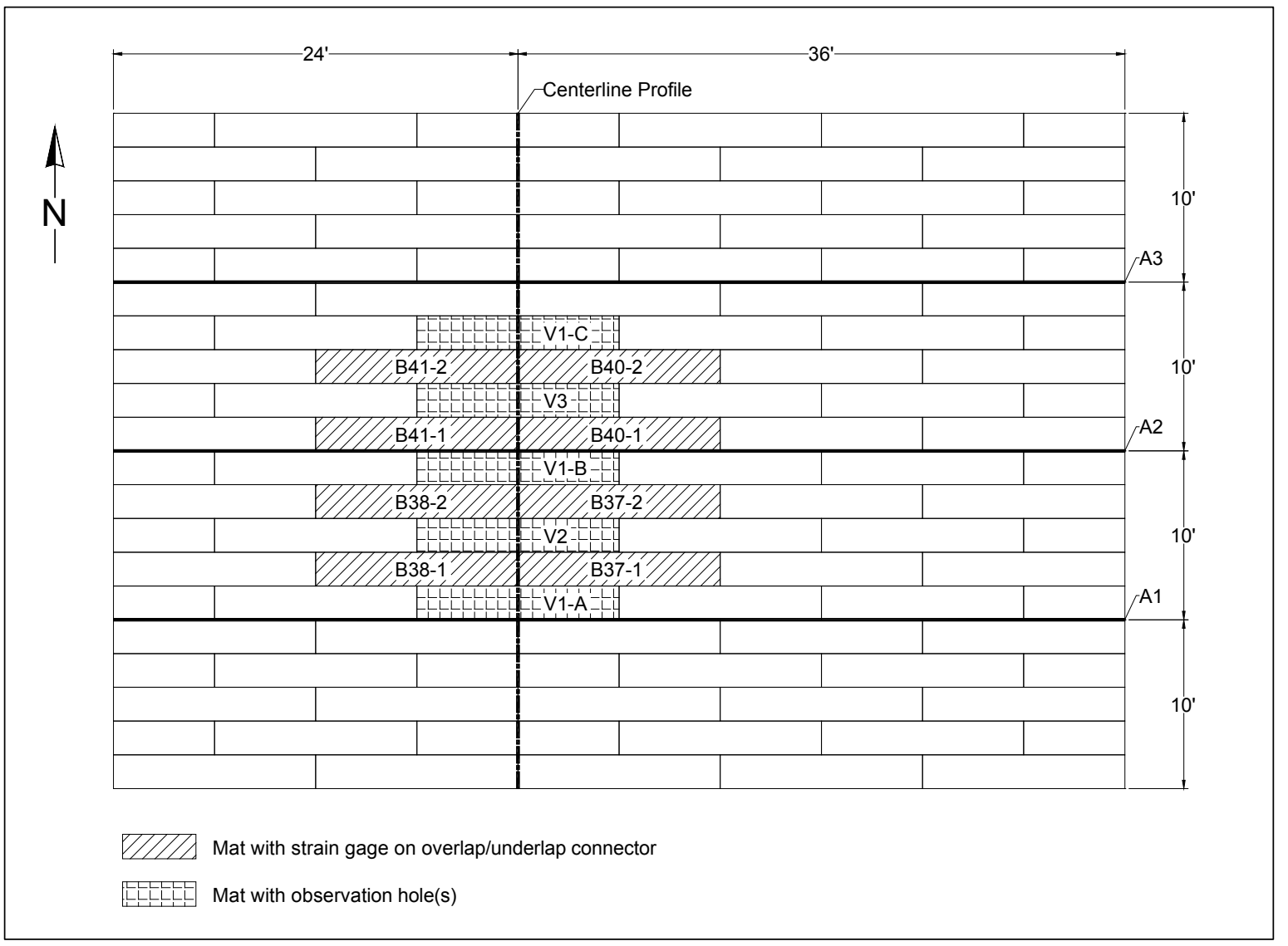


Figure 36. Data collection layout for F-15E and C-17 items.

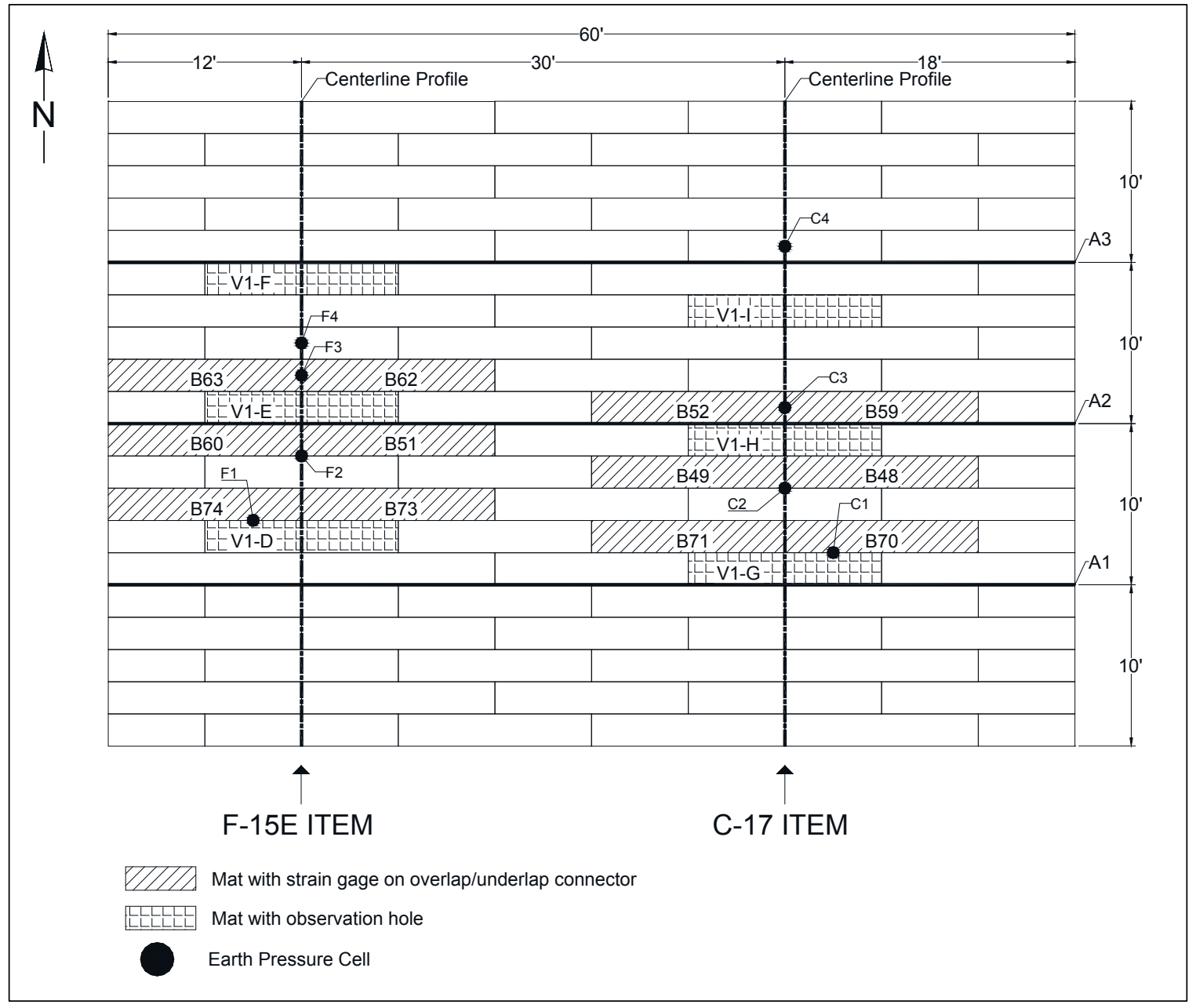

\subsubsection{Centerline profile}

Data collected on the subgrade prior to, at scheduled pass levels during, and after trafficking along the traffic centerline are labeled "centerline profiles" in this report (Figures 35 and 36). For the F-15E and F-15E-V items, robotic total station elevation data were collected at 6-in. intervals on both the subgrade and mat surface. Data was collected at 1-ft intervals for the $\mathrm{C}-17$ item.

\subsubsection{Unloaded cross-sections}

Data collected on the subgrade prior to, at scheduled pass levels during, and after trafficking at the locations labeled A1, A2, and A3 (Figures 35 and 36) are called "cross sections" in this report. The locations of perpendicular lines A1, A2, and A3 were selected near the quarter-points of the test items to characterize the average performance while avoiding potential end effects 
associated with boundary conditions at the ends of the test sections. Robotic total station elevation data were collected at 1 - $\mathrm{ft}$ intervals from $2 \mathrm{ft}$ to $10 \mathrm{ft}$ offset from the centerline and at 6-in. intervals up to $2 \mathrm{ft}$ offset from the centerline for the $\mathrm{F}-15 \mathrm{E}$ and $\mathrm{F}-15 \mathrm{E}-\mathrm{V}$ items. For the $\mathrm{C}-17$ item, data were recorded at 1 - $\mathrm{ft}$ intervals from $8 \mathrm{ft}$ to $18 \mathrm{ft}$ offset from the centerline and at $6 \mathrm{in}$. intervals up to $8 \mathrm{ft}$ offset from the centerline (Figure 37).

Figure 37. Surveying unloaded cross-section.

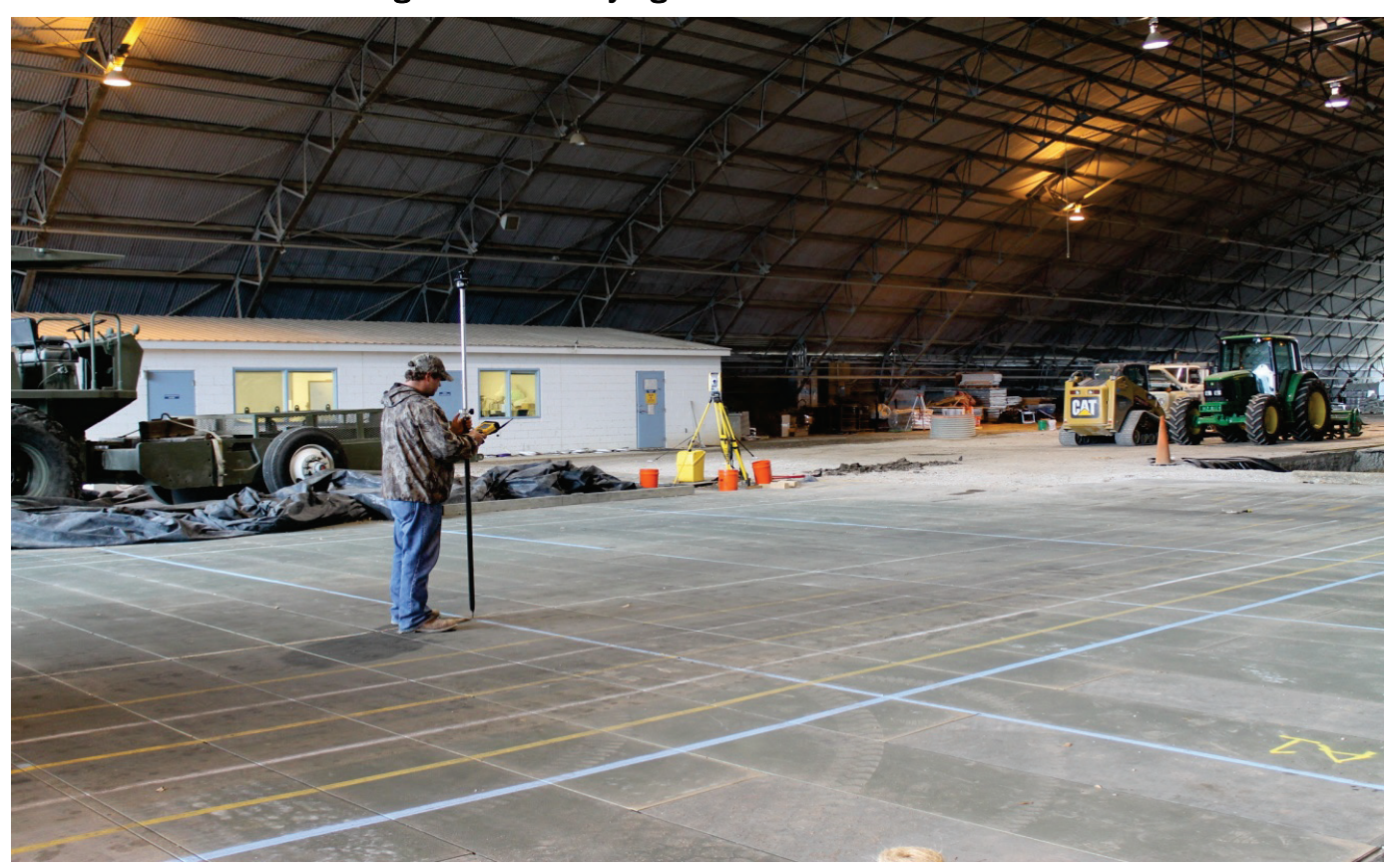

\subsubsection{Loaded cross-sections}

In an attempt to measure the permanent deformation of the subgrade underneath the mat surface, a forklift carrying two 2,00o lb. lead weights was parked on the mat surface adjacent to each cross-section, and elevation data were once again recorded at the same intervals (Figure 38 ). The wheel load applied was approximately $6,000 \mathrm{lb}$. These data are noted as "loaded cross-sections" in this report. The goal of the load application was to deflect the mat enough to contact the subgrade but not so much as to induce elastic deflections in the subgrade.

\subsubsection{Dynamic deflection}

Dynamic elastic deflection data were collected on the F-15E and F-15E-V items by mounting a survey prism just above the load wheel on the F-15E load cart, as shown in Figure 39, during the first 16 passes of each data collection interval (or all passes during an interval that was less than 16 
passes). The robotic total station recorded elevation measurements for every $6 \mathrm{in}$. of forward or backward movement of the load cart to determine the total deflection occurring in the subgrade and matting system caused by the applied load. Elastic deflection was not measured on the $\mathrm{C}-17$ item because of the inability to mount a survey prism in an acceptable location on the load cart and other safety concerns.

Figure 38. Surveying loaded cross-section.

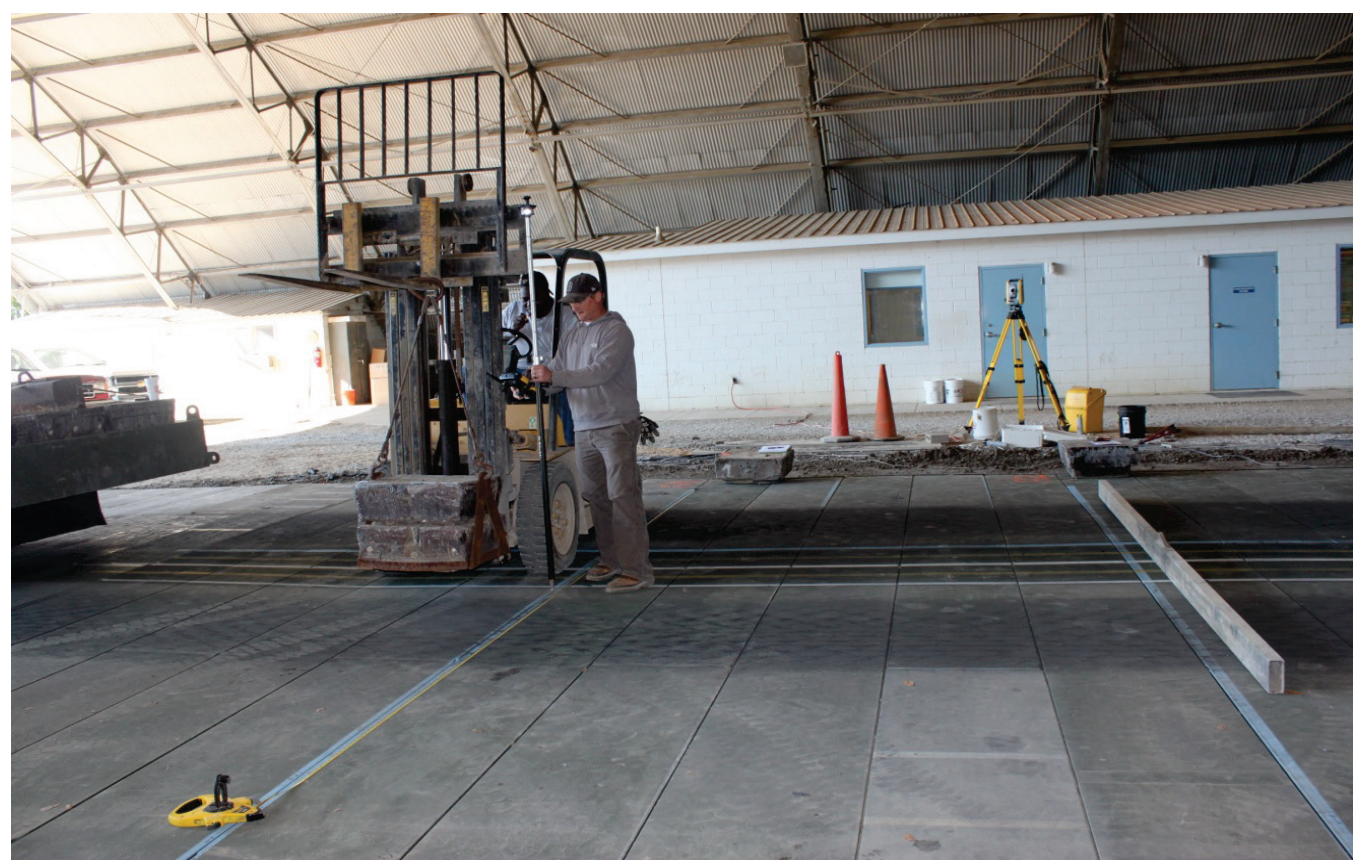

Figure 39. Prism mounted on F-15E load cart.

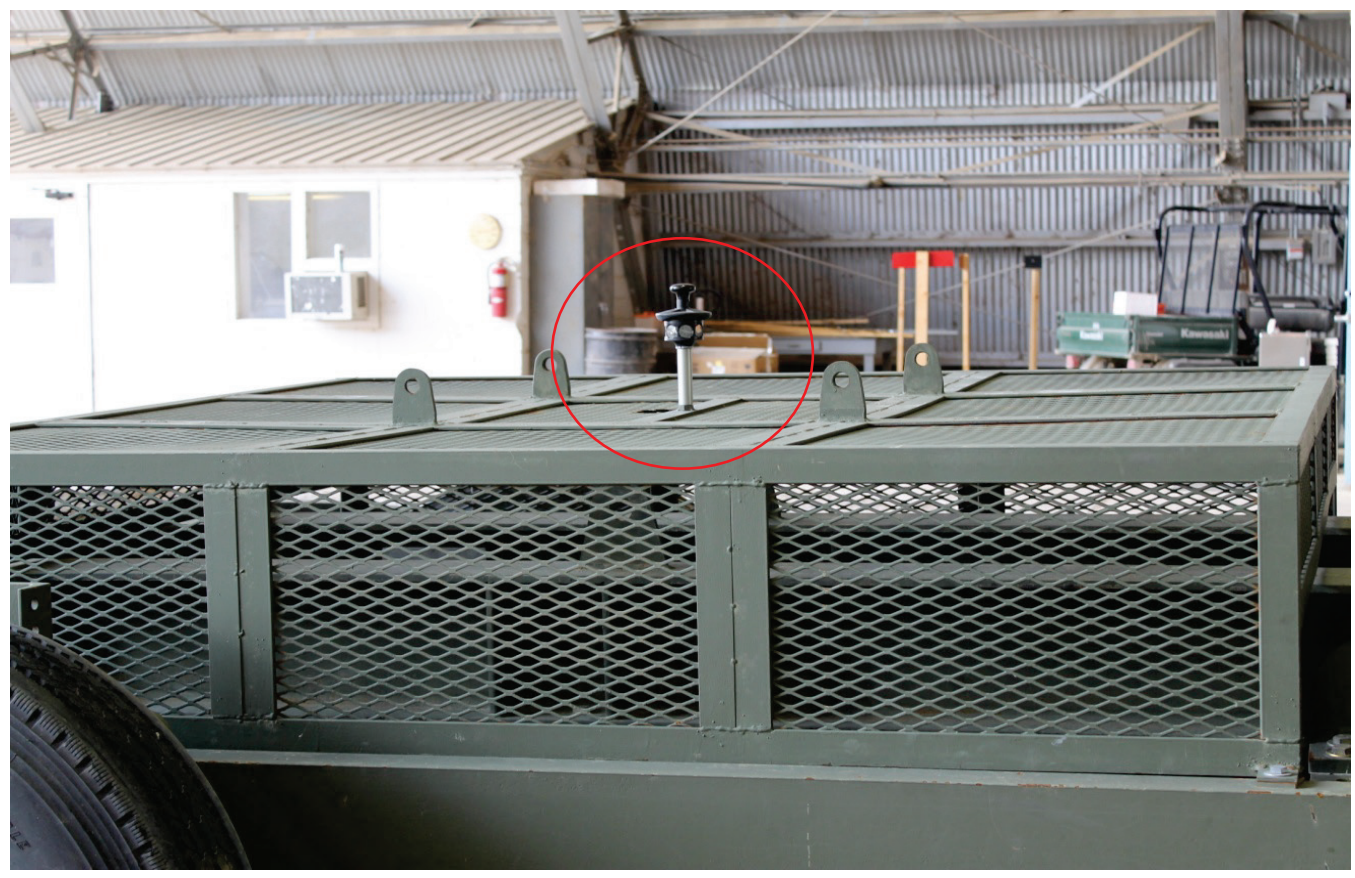




\subsubsection{Earth pressure and strain measurements}

National Instruments NI SCXI data acquisition hardware was used to collect data points at a rate of $100 \mathrm{~Hz}$. Strain data were collected continuously and data recording was only paused at the pass levels shown in Tables 9 and 10, and when traffic needed to be stopped temporarily for inspection of the mat surface. Earth pressure data was collected in the same manner for the $\mathrm{F}-15 \mathrm{E}$ and $\mathrm{C}-17$ items.

\subsubsection{Borescope observation and depth measurement}

Observation holes were installed in several panels in each test item in an attempt to monitor the deformation progression of the subgrade underneath the mats (Figure 40). Panel locations are shown in Figures 35 and 36. Concentric circles were drawn on the underside of these panels with radii of 3, 6, and 9 in., and two flexible tapes were laid orthogonally across the subgrade to assist in scaling during video review. In addition, a depth gauge was inserted through each hole to measure the distance from the surface of the mat to the surface of the subgrade. By subtracting the thickness of the mat, the distance between the bottom surface of the mat and the surface of the subgrade could be determined (Figure 40).

For the F-15E-V item, holes were drilled to take these measurements and collect borescope video directly above each of the voids (except void V-F). Therefore, Panels V2 and V3 each had two holes drilled, so that each hole was centered above specific voids on the subgrade surface. Videos of the borescope observations have been retained for archiving. Depth measurements for the $\mathrm{F}-15 \mathrm{E}$ and $\mathrm{C}-17$ items are not reported in this document. Depth measurements are reported for the F-15E-V item in terms of void designation.

Figure 40. Borescope (left) and depth measurement (right).
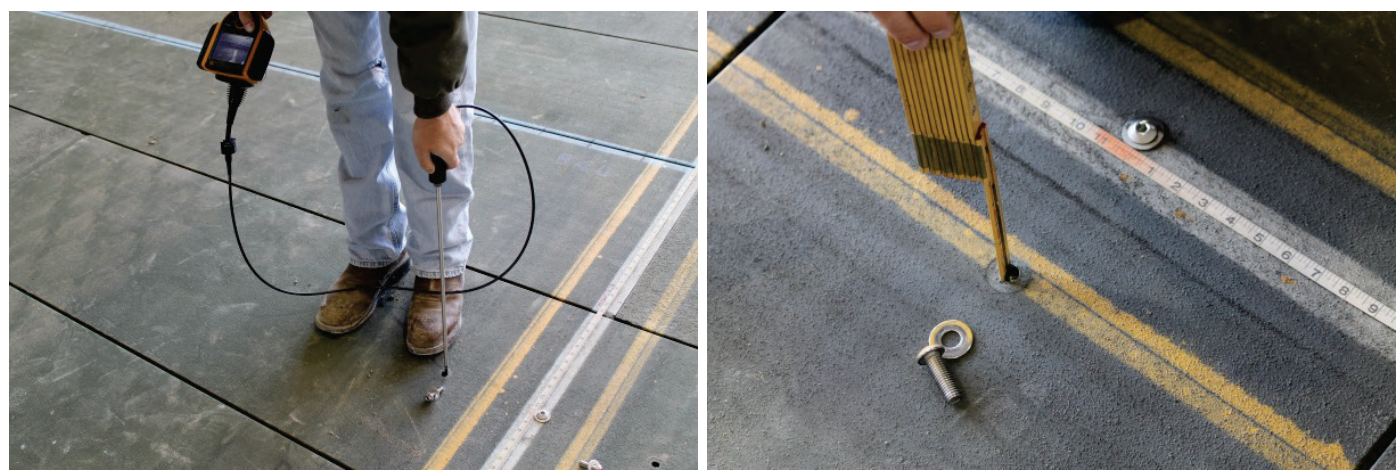


\subsection{Failure criteria}

The failure criteria established were either (1) 10\% mat breakage or (2) the development of $1.25 \mathrm{in}$. of permanent surface deformation for the F-15E or 3.0 in. of permanent surface deformation for the $\mathrm{C}-17$. These failure criteria were developed based upon previous testing of airfield matting and USAF requirements. Failure criteria values were recorded and monitored for compliance.

\subsubsection{Mat breakage}

Mat breakage percentages were calculated by dividing the area of the failed panel (or half-panel) by the total area influenced by the simulated traffic application in the assembled test item. For example, the total area influenced by the $\mathrm{F}-15 \mathrm{E}$ item was $960 \mathrm{ft}^{2}(24 \mathrm{ft}$ by $40 \mathrm{ft})$. Ten percent of this area is $96 \mathrm{ft}^{2}$, which is equal to the area of four (4) 2-ft by $12-\mathrm{ft}$ panels. Individual panels were considered failed if observed damage posed a significant tire hazard or caused instability of the load cart. Tire hazards were defined as damage that could not be reasonably maintained by simple field maintenance procedures. A typical example was a top skin tear in excess of 10 in., representing significant structural damage to the surface skin with sharp edges that may endanger an aircraft tire.

\subsubsection{Permanent deformation}

The permanent surface deformation limits of 1.25 in. and 3.0 in. are based on roughness limitations for the $\mathrm{F}-15 \mathrm{E}$ and $\mathrm{C}-17$ aircraft, respectively. An abrupt change in elevation or the development of a rut in the wheel path greater than the allowable values may exceed roughness limits. The rut depth limit is required, since many connecting taxiways and aprons intersect at $90 \mathrm{deg}$, and crossing perpendicular to a pre-formed rut may cause an abrupt change in elevation, exceeding aircraft limits. Permanent surface deformation was determined from robotic total station elevation measurements of cross-sections and centerline profiles. Each of the following data collection categories were analyzed for compliance with the failure criterion:

1. centerline profile deformation,

2. loaded surface deformation, and

3. unloaded surface deformation. 


\subsubsection{Centerline profile deformation}

The difference in elevation one or two stations apart ( $1 \mathrm{ft}$ or $2 \mathrm{ft}$ apart) was analyzed from plots of the centerline profile data to determine if an abrupt change in elevation reached failure limits during trafficking.

\subsubsection{Loaded surface deformation}

Loaded surface deformation was determined from data collected according to the procedures described in section 2.5.3. The maximum deformation at each location was determined as the difference in elevation from the average height of the elevated material on each side of the trough to the deepest point in the bottom of the trough. Measurements were averaged to obtain a single value for comparison to the failure criterion.

\subsubsection{Unloaded surface deformation}

Unloaded surface deformation was determined from data collected according to the procedures described in section 2.5.2. The maximum deformation at each location was determined as the difference in elevation from the average height of the elevated material on each side of the trough to the deepest point in the bottom of the trough. Measurements were averaged to obtain a single value for comparison to the failure criterion. 


\section{Test Results-Brickwork Pattern on Voided Subgrade}

\subsection{Mat behavior under traffic (visual observations)}

Trafficking of the F-15E-V test item began on October 30, 2012. No panel damage was observed until 112 passes were reached, when 0.125-in. corner curls developed in Panels 25, 26, B37-1, B38-1, B37-2, B38-2, B40-1, B41-2, and 86 on the south corner located on the centerline of traffic. After 240 passes, the corner curls in the same panels were noted to increase slightly (Figure 41), and Panels 45, 97, and 98 were noted to have developed 0.125-in. corner curls. Panel B40-1 developed a 1.25-in. hairline crack at the southwest corner as a result of the corner curl. Panels B38-2 and B41-1 each had developed a 0.25 -in. hairline crack that began at the southeast corner of the weld of the end connector of each panel along the centerline.

Figure 41. Corner curl in Panel 26 after 240 passes.

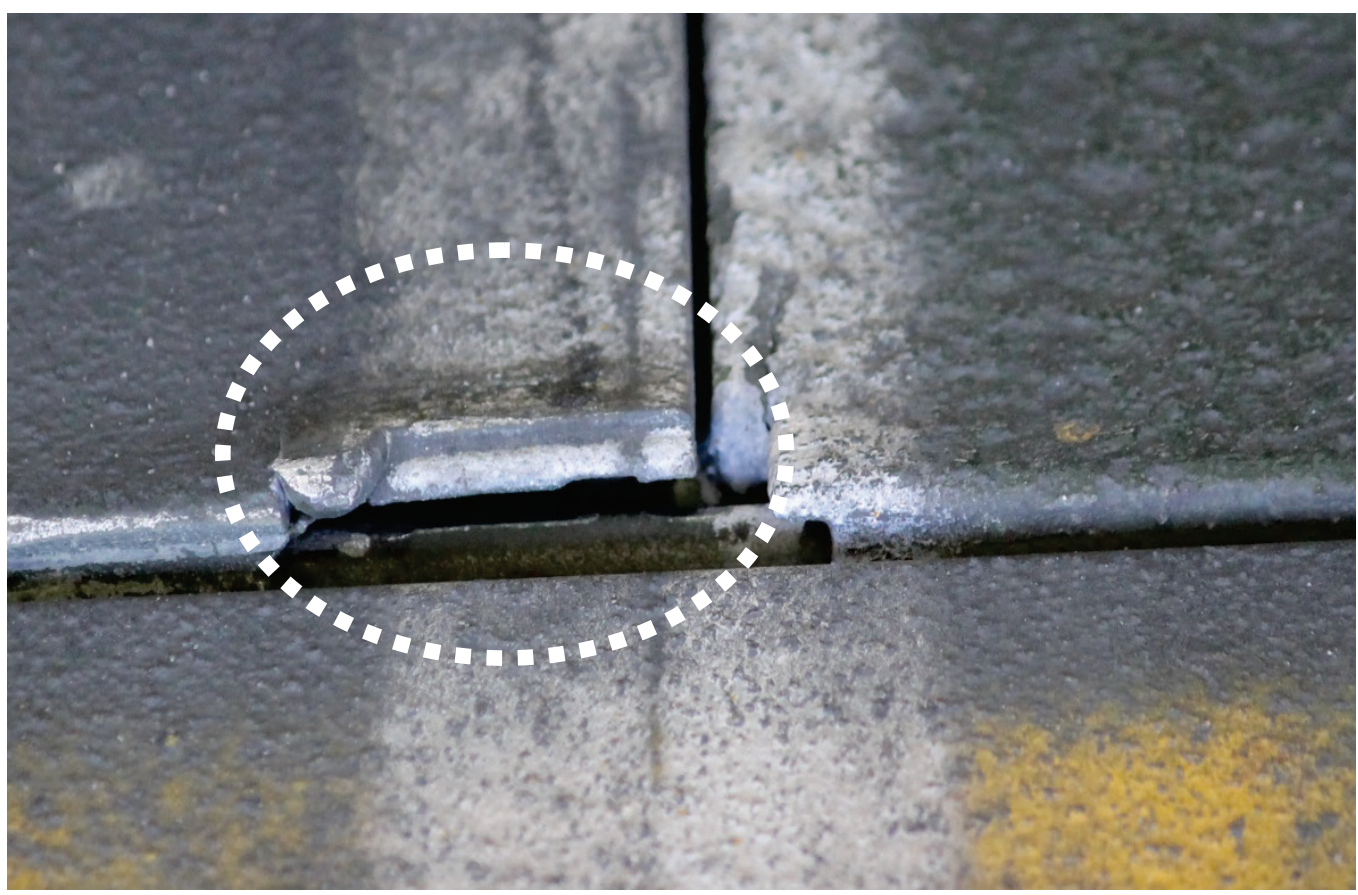

After 256 passes, the last six rows were picked up to inspect the 18-in. void (V1-C) beneath Panel V1-C. It was noted to have decreased in diameter and depth, with the center of the void nearly uniform with the subgrade surface. While reinstalling the panels to continue trafficking, Panel 92 was noted to have bowed considerably, making it difficult to connect with 
adjoining panels. It also had a 16-in.-long crack along the center of the female hinge. The panel was replaced and trafficking continued.

After 322 passes, Panel B40-1 failed when the upper underlap rail broke free from the panel, allowing separation from the adjacent panel and causing a tire hazard (Figure 42). Panel 25 had developed a 1-in.-long hairline crack that seemed to progress along the weld. The crack in Panel 98 had increased to 0.5 in. and propagated along the weld. The corner curls in Panels B37-2, 26, B38-1, B37-1, 97, 98, and B38-2 had increased to 0.19 in. and were posing tire hazards. Although the corner curls could have been maintained by grinding, the failure at Panel $\mathrm{B} 4 \mathrm{O}-1$ was posing a risk to the tire, and trafficking could not be continued without replacing the panel. Therefore, trafficking was concluded, since the required mat behavior and instrumentation response data required for the test were collected.

Figure 42. Broken upper under lap rail in Panel B40-1.
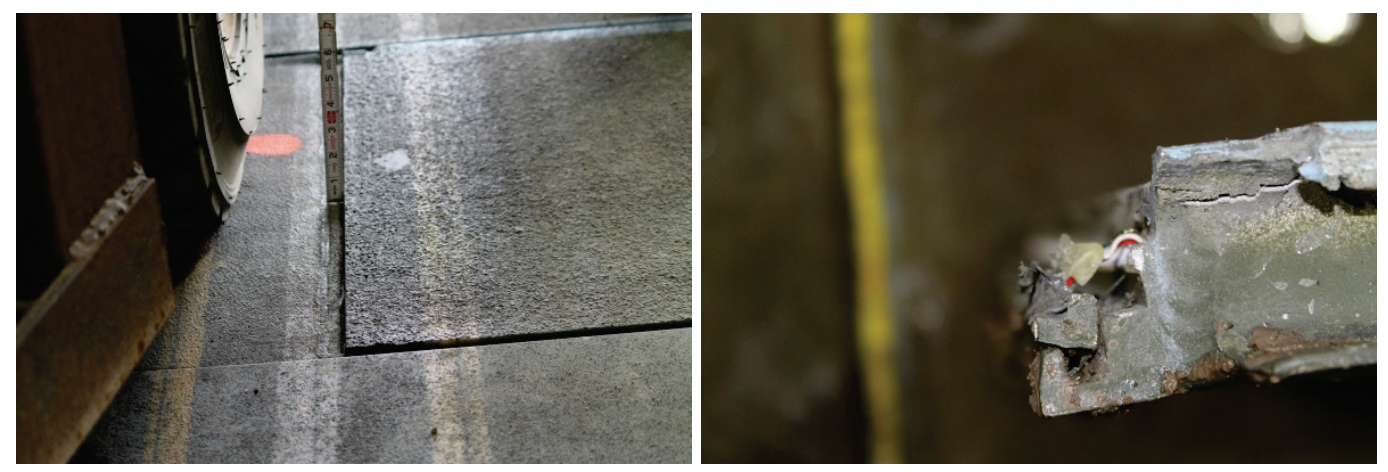

When panels were removed after trafficking completed, additional damage was noted, but none that rendered any other panel failed. Panel $V_{3}$ had a tear along the bottom flange of the female hinge connector that was 14 in. long, starting at the center and propagating toward the east edge. Panel 20 had a 12-in.-long crack along the center of the female hinge.

Table 11 summarizes additional damage found in other panels, specifically damage noted at the end connectors of panels with joints along the centerline of traffic (Figure 43). Table 12 lists mat distresses and failures on the mat surface at various pass levels for the $\mathrm{F}-15 \mathrm{E}-\mathrm{V}$ item. Figure 44 shows the layout of failed and damaged panels relative to void locations after trafficking concluded. New and refurbished panels were identified to provide insight on the level of damage in new versus refurbished panels. In summary, ten refurbished were damaged, five new panels were damaged, and one new panel failed. Damage was noted throughout the test item and not necessarily near void locations. 
Table 11. Damage noted after picking up mats in the F-15E-V item (322 passes).

\begin{tabular}{|l|l|l|l|l|}
\hline $\begin{array}{l}\text { Panel } \\
\text { Designation }\end{array}$ & Mat condition & $\begin{array}{l}\text { End connector } \\
\text { along centerline }\end{array}$ & $\begin{array}{l}\text { Length of crack below } \\
\text { corner of top flange of } \\
\text { female conn.* } \\
\text { (in.) }\end{array}$ & $\begin{array}{l}\text { Length of crack along weld } \\
\text { of end connector (at face } \\
\text { of female conn.)** } \\
\text { (in.) }\end{array}$ \\
\hline B41-2 & Refurbished & Overlap & 1 & - \\
\hline B38-2 & Refurbished & Overlap & 0.5 & - \\
\hline B37-2 & New & Underlap & 0.5 & - \\
\hline B41-1 & Refurbished & Overlap & 0.5 & - \\
\hline B40-1 & New & Underlap & 1 & - \\
\hline B38-1 & Refurbished & Overlap & 0.5 & $\begin{array}{l}0.5, \text { starting at the top } \\
\text { skin }\end{array}$ \\
\hline B37-1 & New & Underlap & 1 & - \\
\hline 25 & Refurbished & Underlap & 4.5 & $\begin{array}{l}1.5, \text { top skin to bottom } \\
\text { skin }\end{array}$ \\
\hline 26 & New & Overlap & 0.5 & $\begin{array}{l}1.5, \text { top skin to bottom } \\
\text { skin }\end{array}$ \\
\hline 86 & Refurbished & Overlap & 0.25 & - \\
\hline 97 & Refurbished & Overlap & 1 & - \\
\hline 98 & Refurbished & Underlap & 5 & - \\
\hline
\end{tabular}

*See Figure 43a

**See Figure $43 b$

Figure 43. Damage noted in Panel 25 after picking up mats.

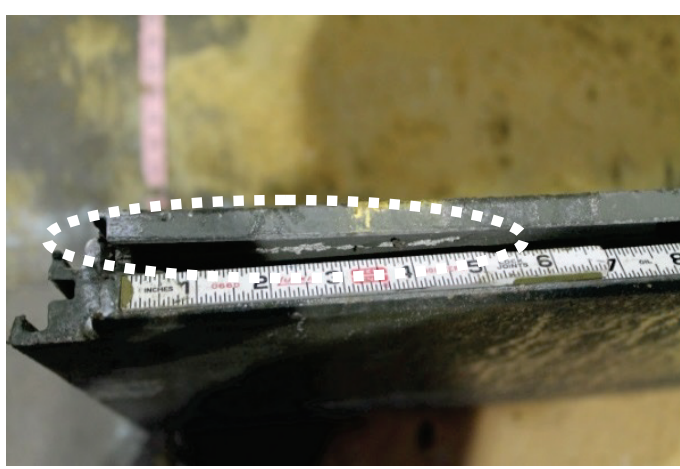

(a)

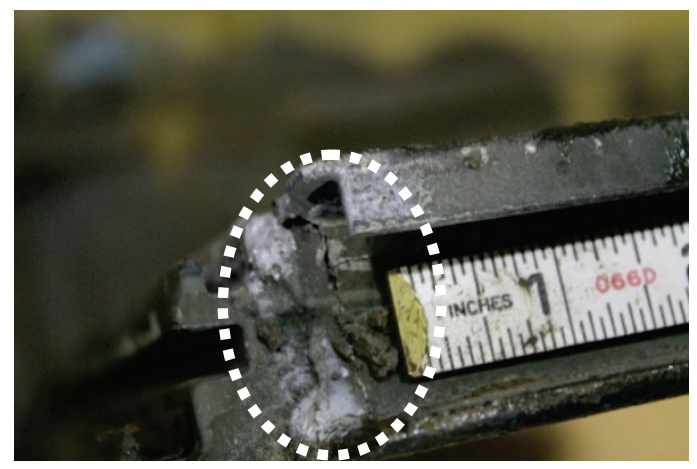

(b) 
Table 12. F-15E-V item mat damage summary.

\begin{tabular}{|c|c|c|c|c|c|}
\hline $\begin{array}{l}\text { F-15E } \\
\text { Passes }\end{array}$ & Failure Type & Damage Description & $\begin{array}{l}\text { Cumulative } \\
\text { Failed } \\
\text { Panels }\end{array}$ & $\begin{array}{l}\text { Cumulative } \\
\text { Percent Mat } \\
\text { Failure }\end{array}$ & Panel Number \\
\hline 112 & - & Corner curls & - & - & $\begin{array}{l}\text { 25, 26, B37-1, B38-1, } \\
\text { B37-2, B38-2, B40-1, } \\
\text { B41-2, } 86\end{array}$ \\
\hline \multirow[t]{2}{*}{240} & \multirow[t]{2}{*}{-} & Corner curls & - & - & $45,97,98$ \\
\hline & & Top skin crack & - & - & B40-1, B38-2, B41-1 \\
\hline 256 & - & $\begin{array}{l}\text { Bow at center, } \\
\text { Crack along female } \\
\text { connector }\end{array}$ & - & - & 92 \\
\hline \multirow[t]{2}{*}{322} & $\begin{array}{l}\text { Mat breakage } \\
\text { and tire hazard }\end{array}$ & $\begin{array}{l}\text { Broken upper } \\
\text { underlap }\end{array}$ & 1 & $2.5 \%$ & B40-1 \\
\hline & Tire hazard & Corner curls & - & - & $\begin{array}{l}\text { B37-2, 26, B38-1, B37-1, } \\
\text { 98, B38-2, } 97\end{array}$ \\
\hline \multirow[t]{3}{*}{ Posttest } & \multirow[t]{3}{*}{-} & $\begin{array}{l}\text { Crack along female } \\
\text { connector }\end{array}$ & - & - & 20 \\
\hline & & $\begin{array}{l}\text { Tear along bottom } \\
\text { flange of female } \\
\text { connector }\end{array}$ & - & - & V3 \\
\hline & & \multicolumn{4}{|l|}{ Refer to Table 11} \\
\hline
\end{tabular}

\subsection{Permanent deformation}

To show only the changes that occurred because of trafficking, the pretraffic elevation data were subtracted from all subsequent data collected after trafficking began to normalize the data. The discussions that follow are based on normalized data. Table 13 summarizes maximum deformation values measured from data collected along the centerline profile and cross sections. Each of these values was compared to the failure criteria.

Plots of the centerline profile data on the subgrade and mat surface, as determined from robotic total station recordings, are shown in Figures 45 and 46, respectively. In Figure 45, peaks observed at stations 11, 17, 19, and 27 were the locations of voids V1-A, V-F, V1-B, and V1-C, respectively, along the centerline. The positive values are a result of rearrangement of material into the excavated void area during traffic. The initial depth of the voids was 2 in., but the depth decreased throughout traffic with the rearrangement of particles. These were ignored when determining the maximum roughness value. Plots of the average cross-section elevation data, collected along lines A1, A2, and A3, are shown in Figures 47 through 49. 


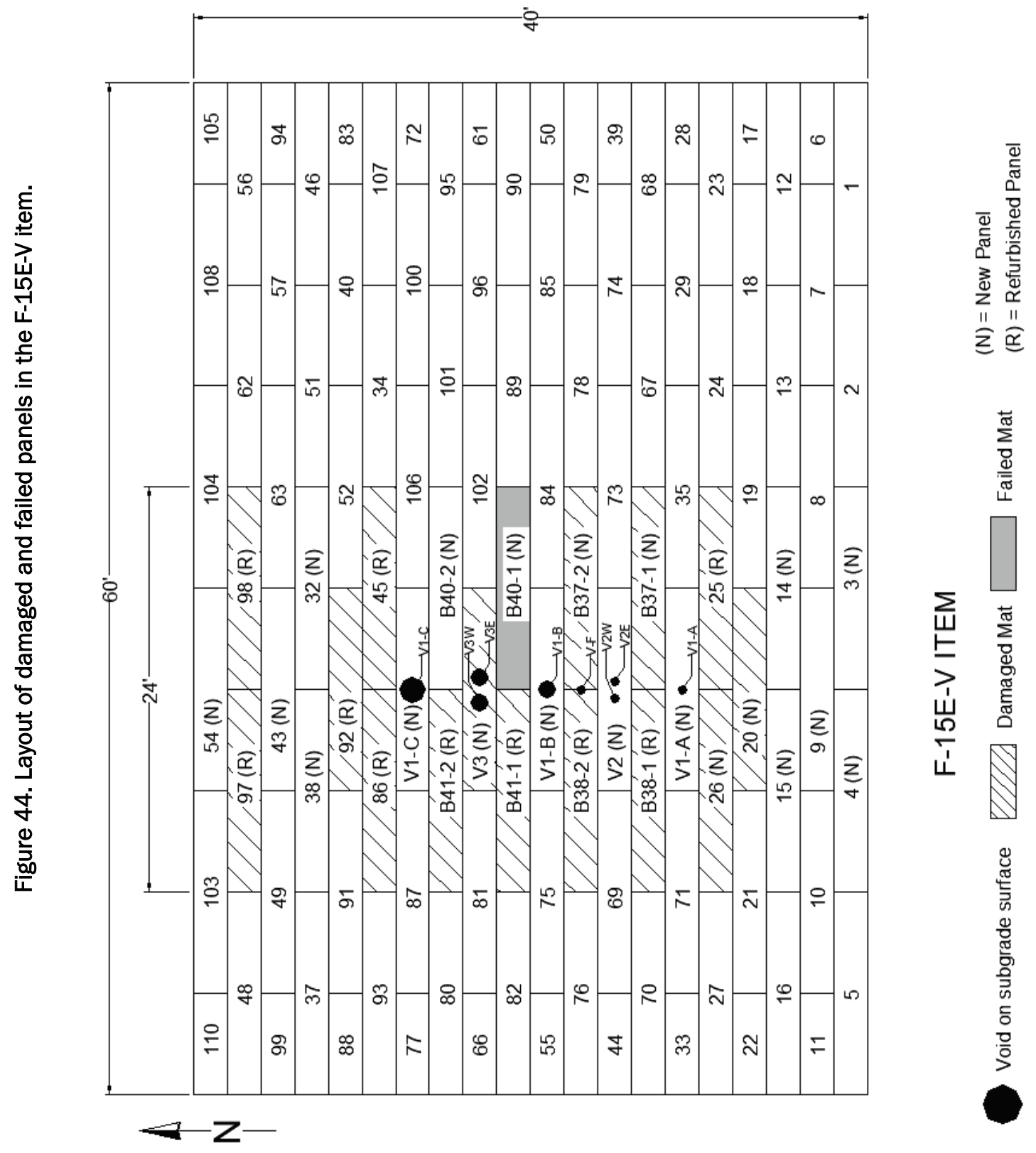


Table 13. Maximum permanent deformation values for the F-15E-V item.

\begin{tabular}{|l|l|}
\hline Pass Number & 322 \\
\hline Subgrade Profile Max Abrupt Change in Elevation, (in.) & 0.54 \\
\hline Mat Surface Profile Max Abrupt Change in Elevation, (in.) & 0.16 \\
\hline Subgrade Permanent Deformation, (in.) & 0.64 \\
\hline Loaded Deformation on Mat Surface, (in.) & 0.50 \\
\hline Unloaded Deformation on Mat Surface, (in.) & 0.31 \\
\hline
\end{tabular}

Figure 45. Subgrade centerline profile of the F-15E-V item after 322 passes.

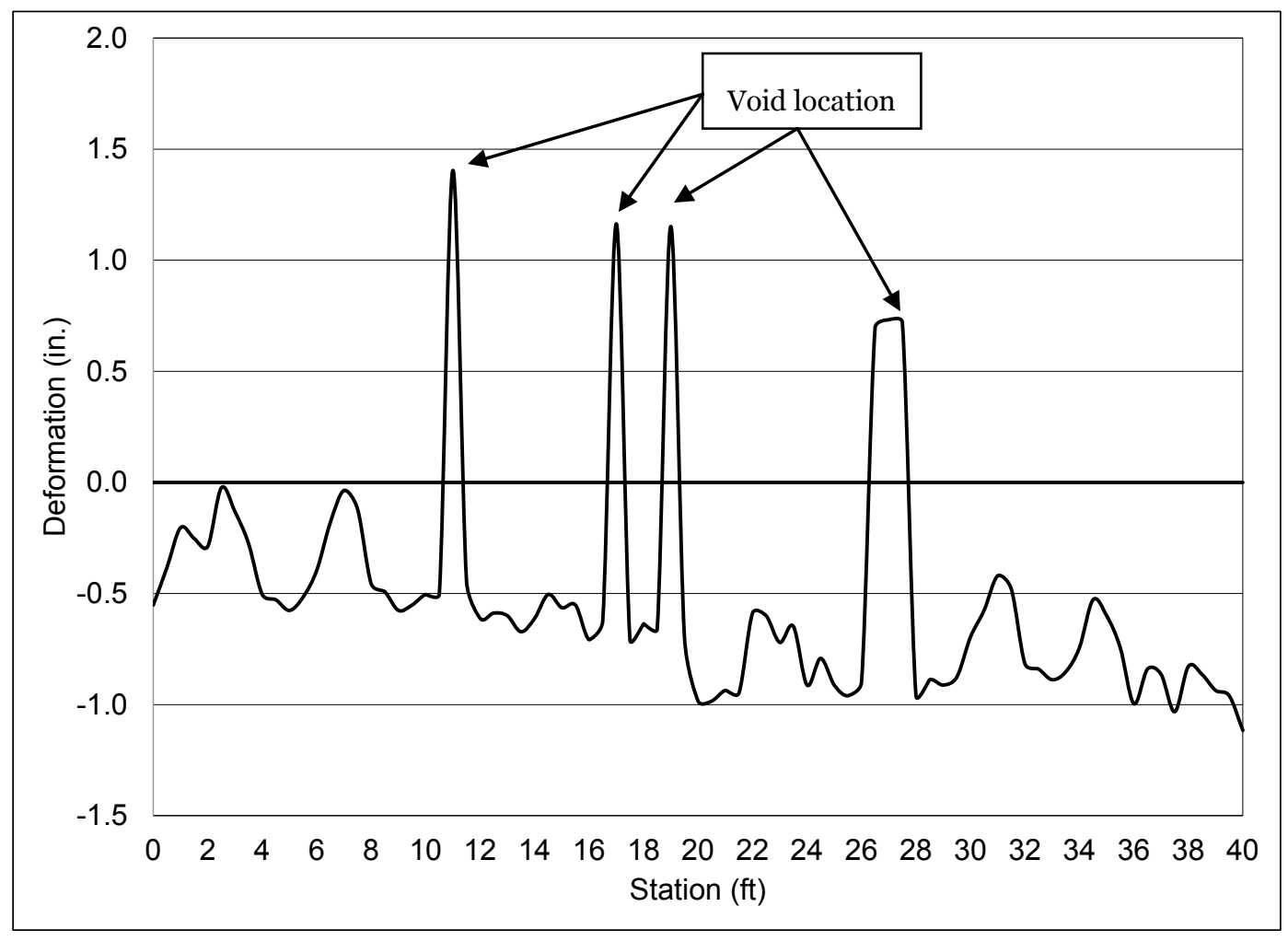


Figure 46. Centerline profile on mat surface of F-15E-V item at different pass levels.

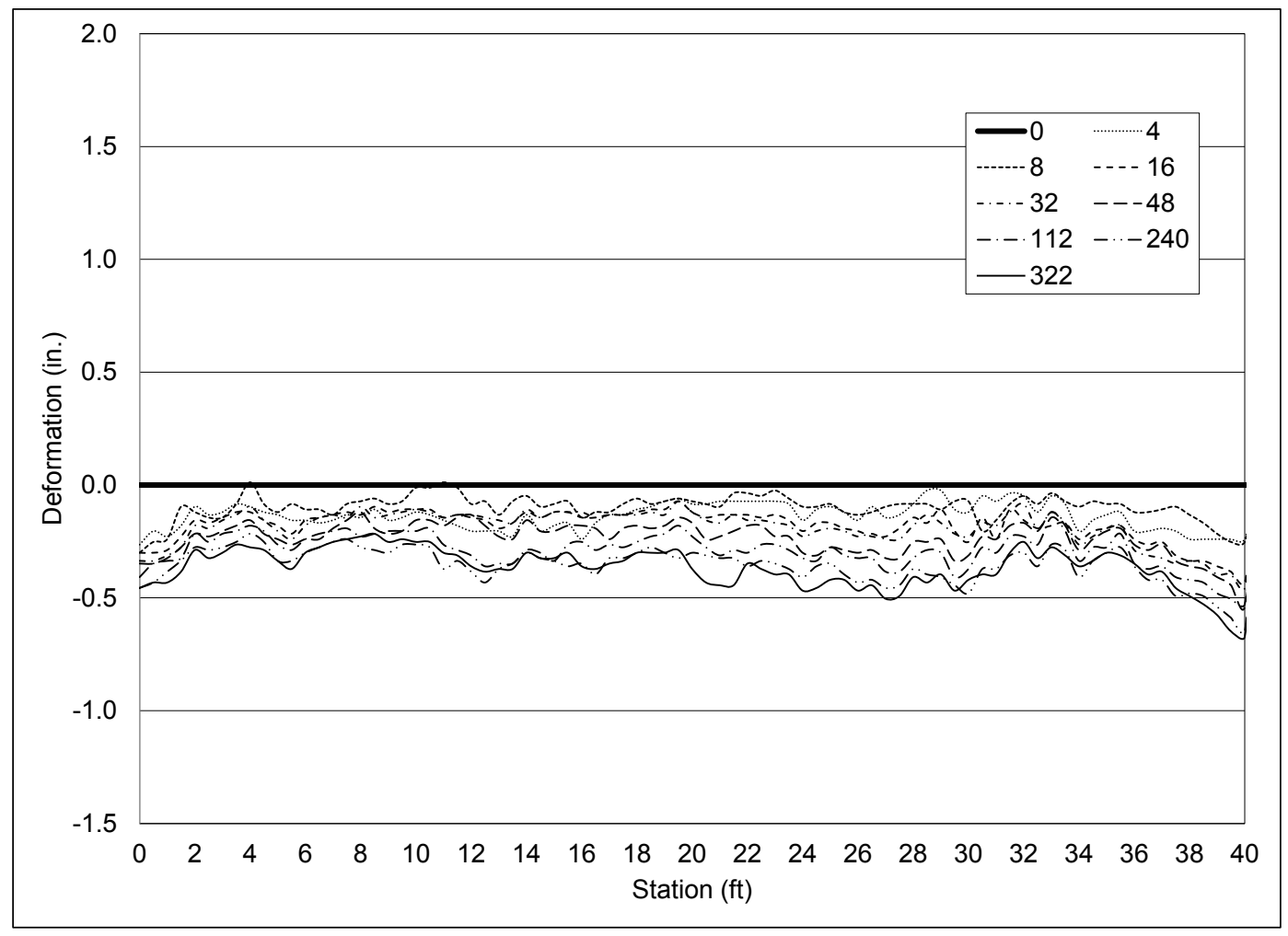

Figure 47. Average deformation on subgrade of F-15E-V item after 322 passes.

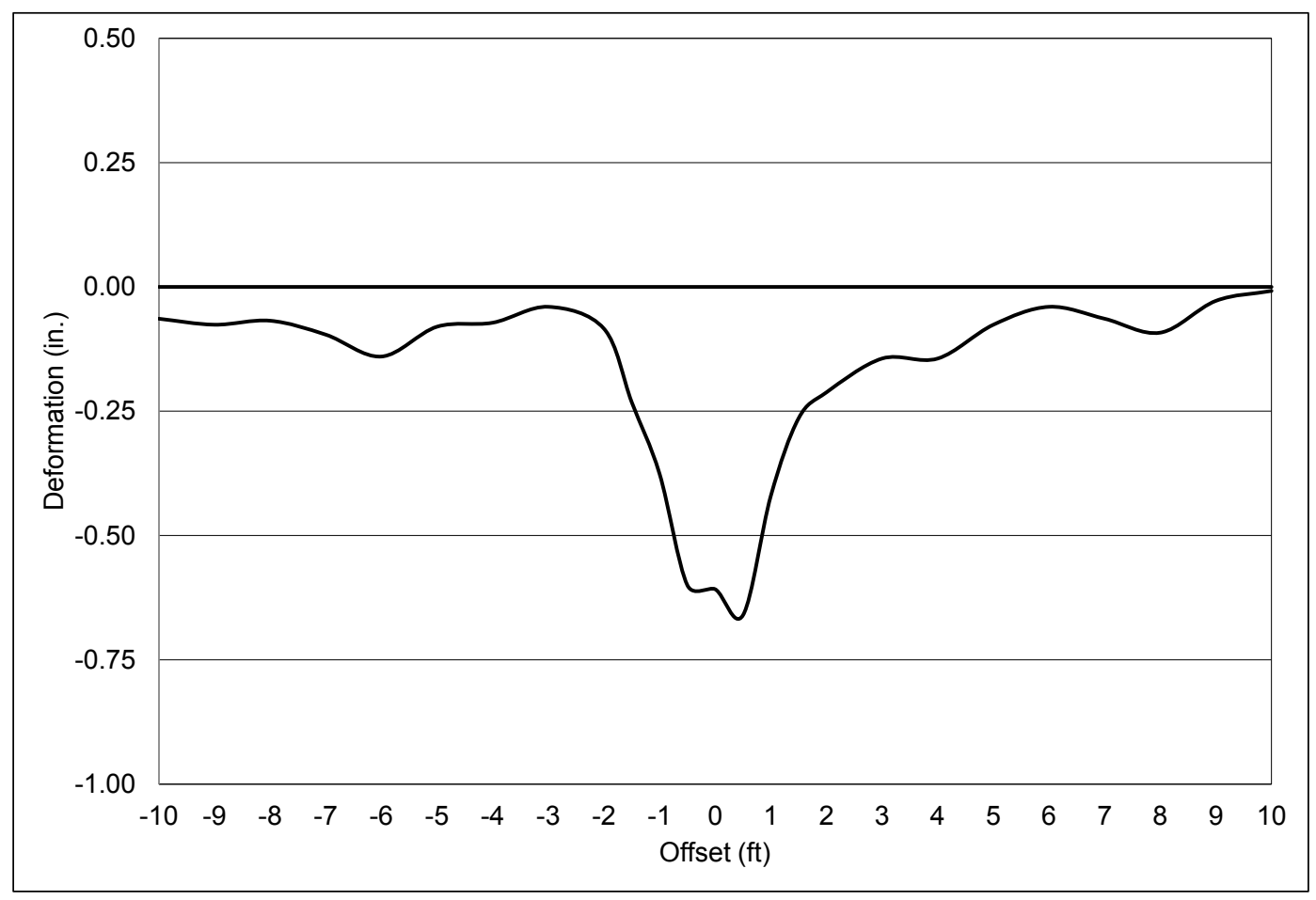


Figure 48. Average deformation on the loaded mat surface of the F-15E-V item at different pass levels.

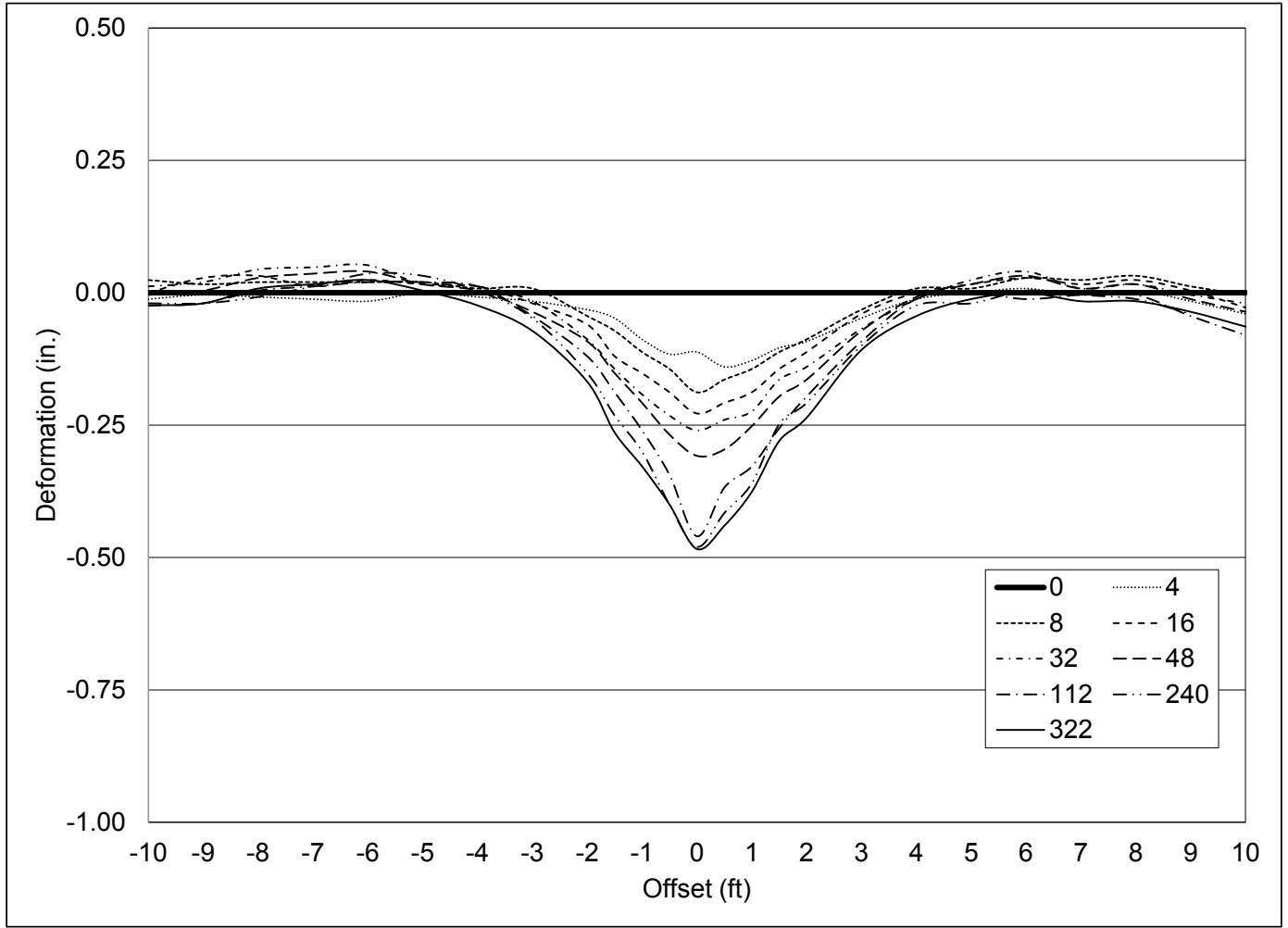

Figure 49. Average deformation on unloaded mat surface of the F-15E-V item at different pass levels.

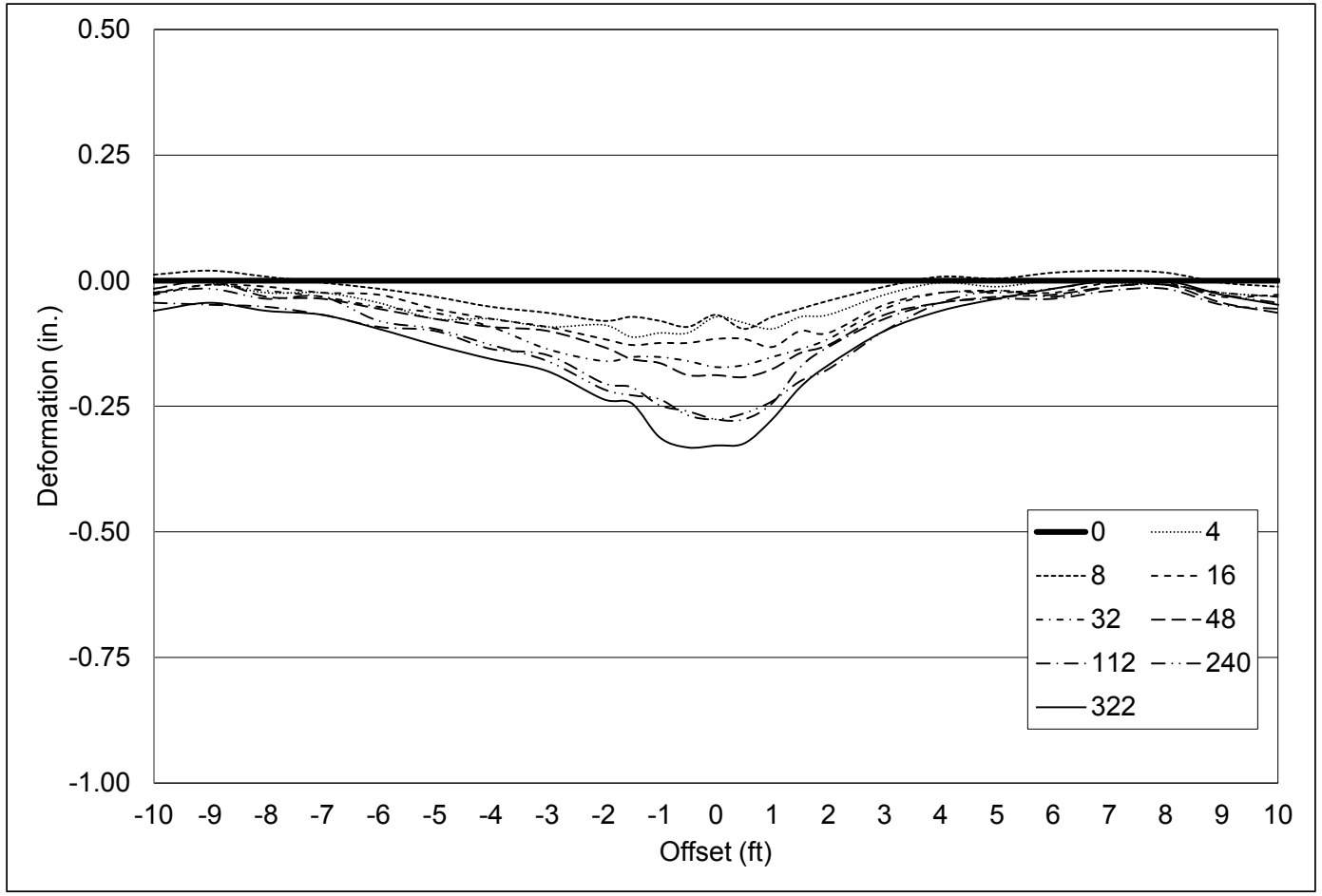




\subsection{Void measurements}

In an attempt to monitor the progression of deformation where voids were excavated, observation holes were drilled in several panels at the positions where voids were located (with the exception of void V-F). Void V-F was excavated to determine the effect on the performance and strain measurements at an F-joint. Figure 50 shows the variation of the depth of the voids underneath the mat during traffic. After removing the mats, the voids were visually inspected to determine the extent of movement of material in those specific areas. It was observed that the diameter of the voids reduced and that material filled in the excavated areas, making the center of the voids nearly level and uniform with the subgrade surface. Figure 51 shows pretest and posttest photos of voids V2W, V2E and V1-C.

\subsection{Elastic deflection}

The elevation measurements of the data collected along the two tracks $4.5 \mathrm{in}$. from the centerline were used for the analysis. Calculations determined the average elevation of points within \pm 3 in. of each centerline profile elevation location in terms of northing. The calculated average elevation corresponding to each station was then subtracted from measurements taken on the unloaded mat surface at the same location. For example, the average of dynamic deflections at each station for Passes 32 through 48 was subtracted from the unloaded centerline profile recordings at each station collected at pass 32. The difference in the loaded and unloaded measurements is the elastic deflection, or rebound, of the mat and subgrade as the test wheel moved over the surface. An example of the raw data as collected is shown in Figures 52. The average elastic deflection at each station for each data collection interval is shown in Figure 53. For the $\mathrm{F}-15 \mathrm{E}-\mathrm{V}$ item, the elastic deflection remained at approximately 1.o in. throughout testing. Elastic deflection was not measured at the end of the test (322 passes) to prevent damage to the $\mathrm{F}-15 \mathrm{E}$ tire by tire hazards present in the traffic lane. 
Figure 50. Void depth beneath the mat throughout traffic in the F-15E-V item.

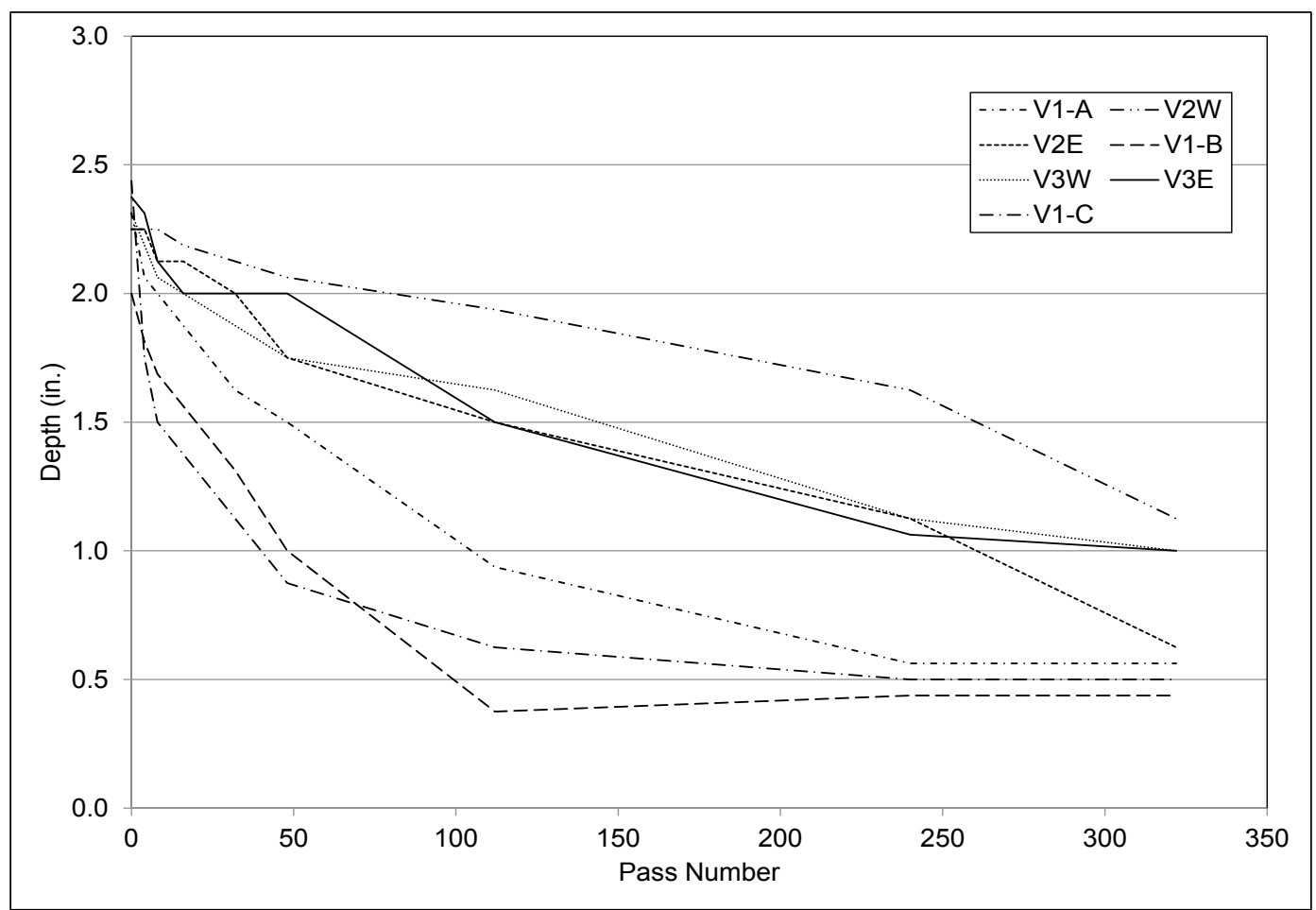

Figure 51. V2W, V2E (a) pretest and (b) posttest and V1-C (c) pretest and (d) posttest.

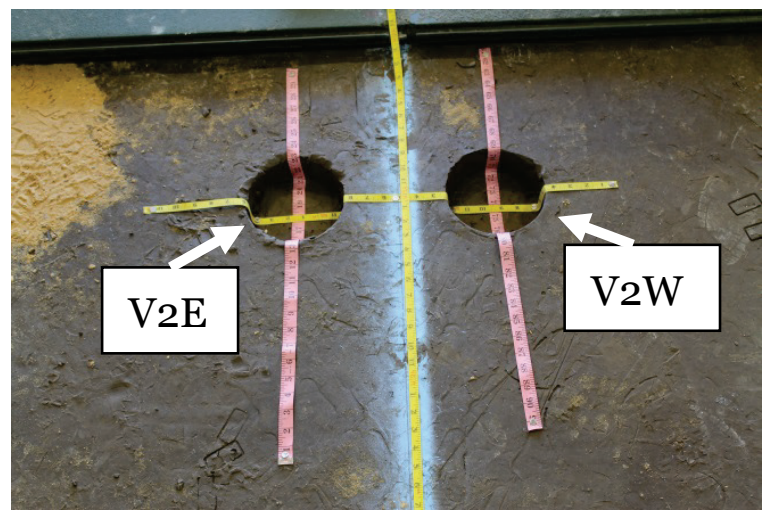

(a)

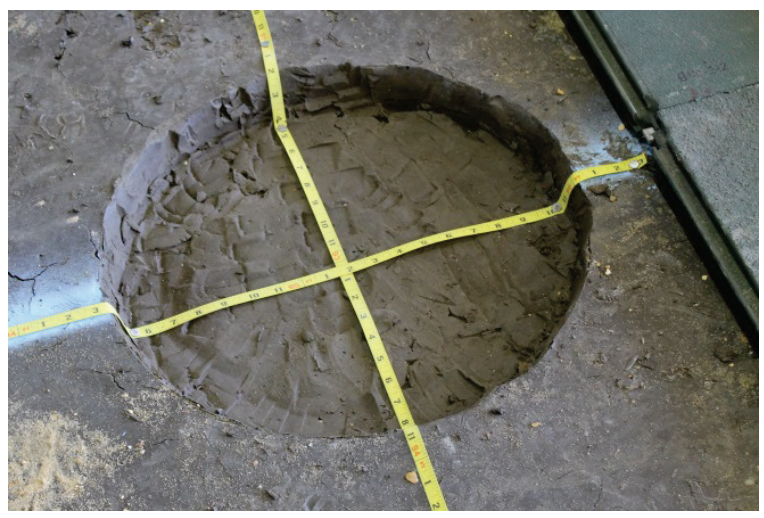

(c)

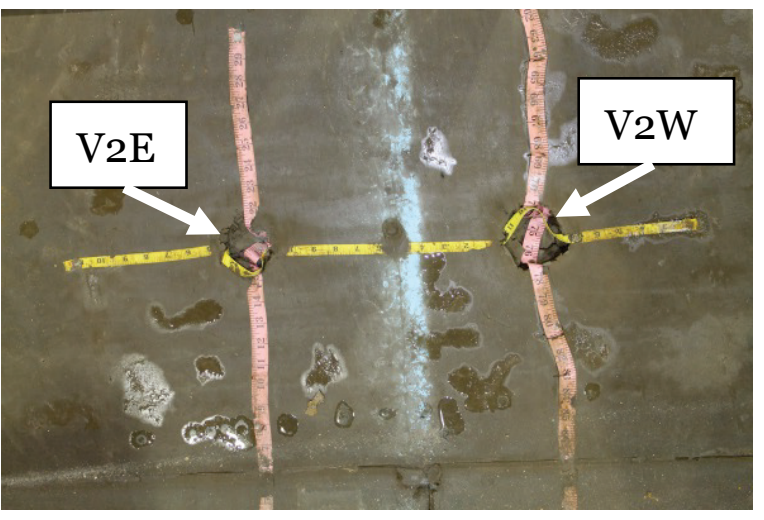

(b)

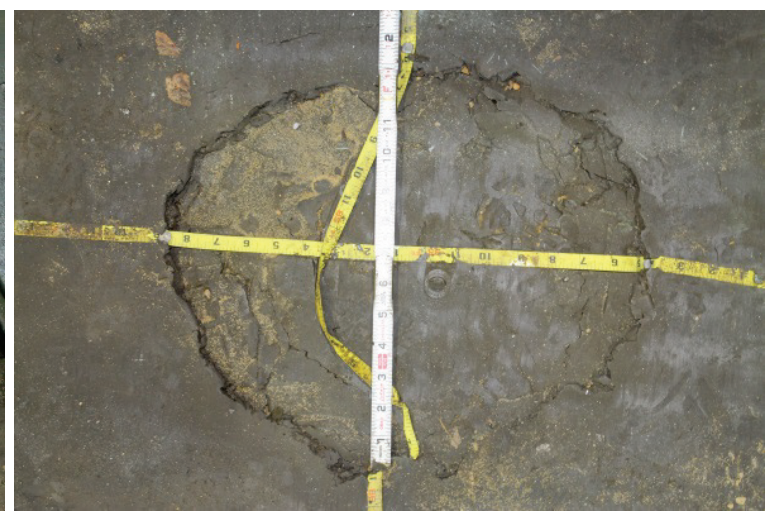

(d) 
Figure 52. Elastic deflection elevation distribution on F-15E-V item, pass 33-48.

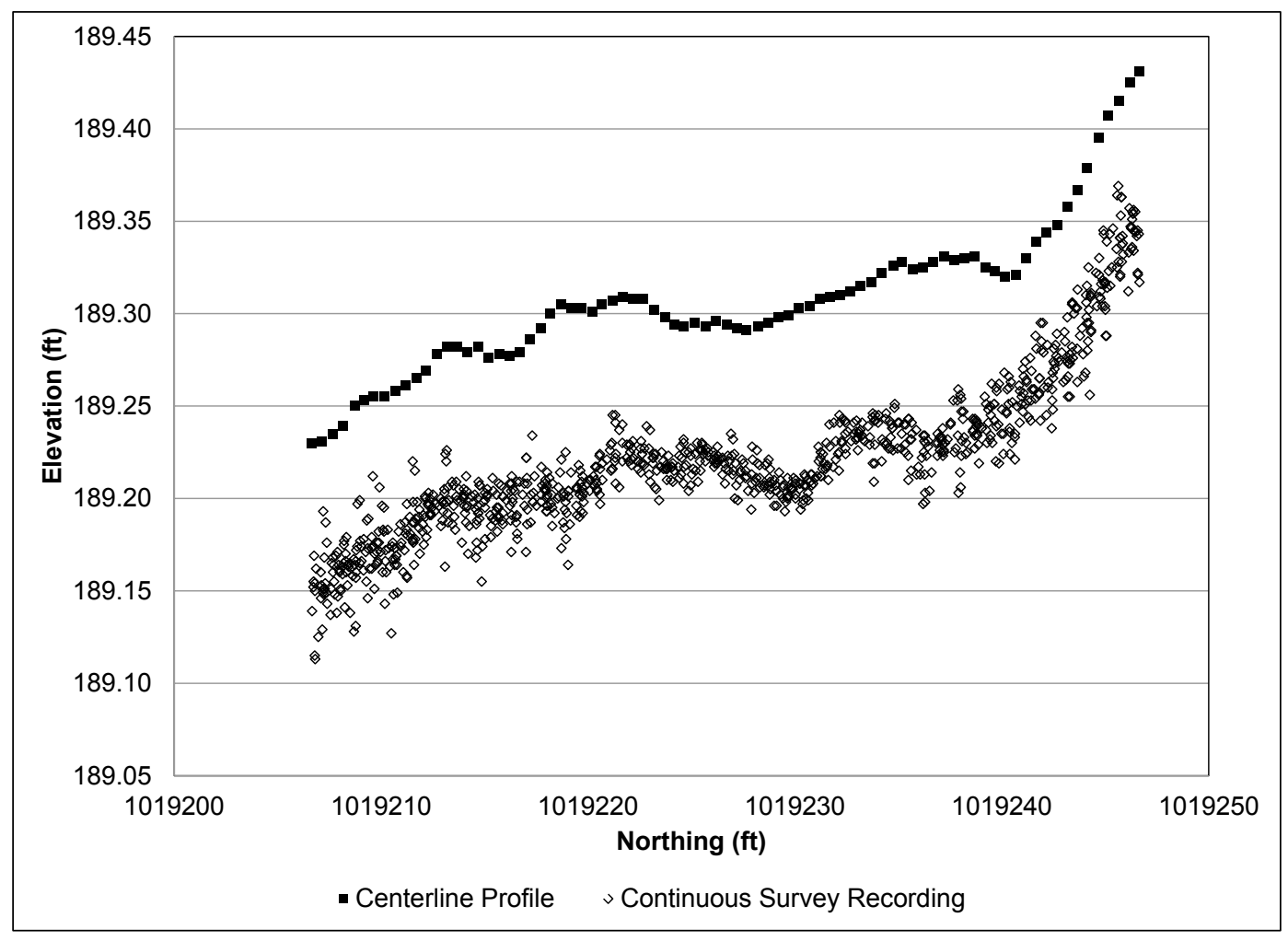

Figure 53. Elastic deflection on F-15E-V item.

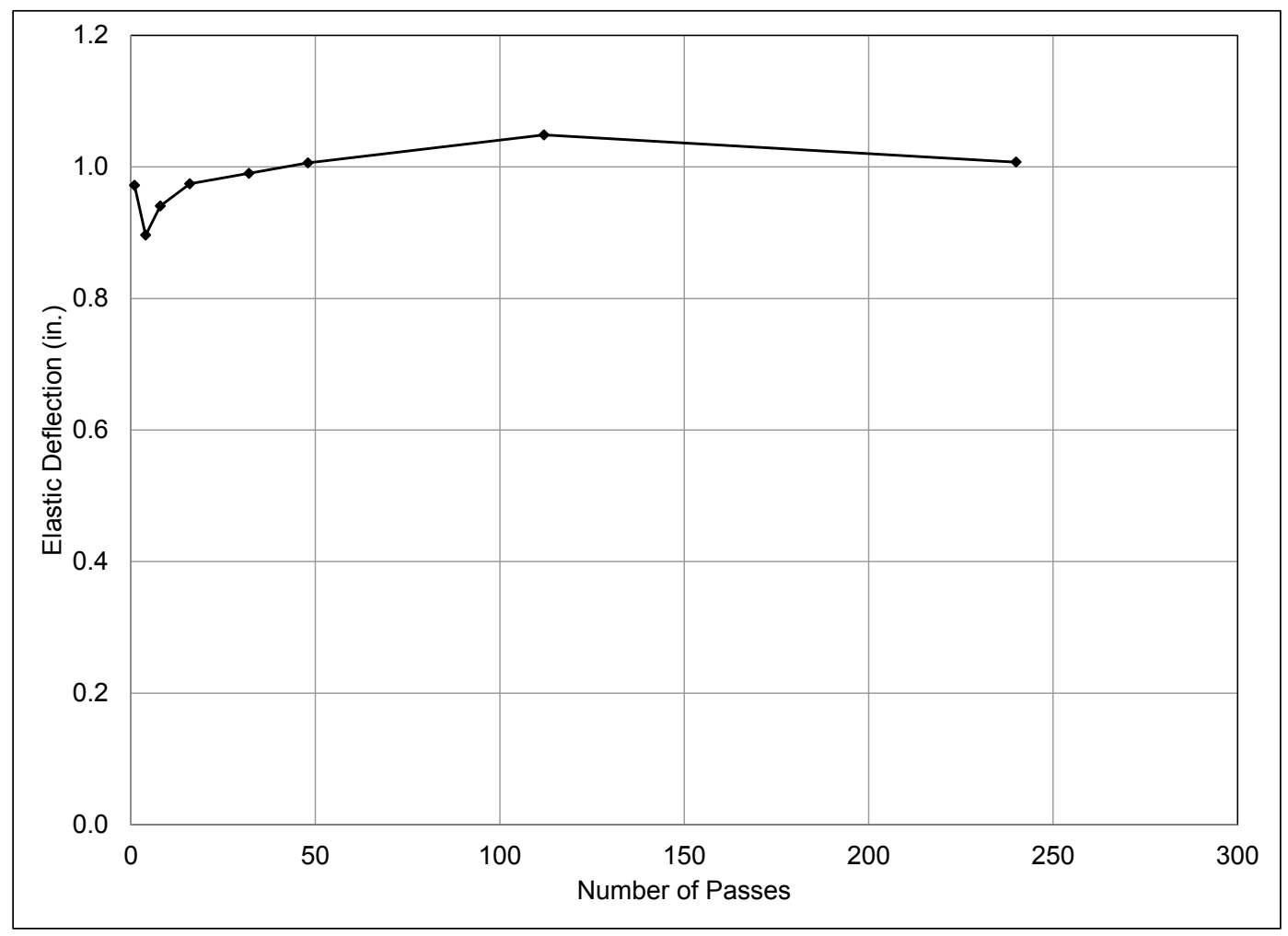




\subsection{Strain gauge data}

Example plots of the strain gauge raw data are shown in Figures 54 and 55, for joining panels B37-1 and B38-1, respectively. The plots represent the response from the first four passes of $\mathrm{F}-15 \mathrm{E}$ traffic from a gauge installed on the upper underlap of Panel B37-1 and a gauge installed on the lower overlap rail of Panel B38-1. Each pass can be associated with a measured peak, where positive peaks represent tensile strain, and the negative peaks represent compressive strain. The data set validates that traffic started with two passes on the east side of the centerline (i.e., east side of the locations of gauges) that were followed by two passes on the west side of the centerline. This is observed in the higher magnitude of the response of gauge $\mathrm{B} 37-1 \mathrm{~F} 2$ during the first two passes when compared to the response of gauge B38$1 \mathrm{~F} 2$, where the former was located on the panel east of the centerline. The same is true for the response of $\mathrm{B} 38-1 \mathrm{~F} 2$ when the load was applied on panel B38-1 on the west side of the centerline, except that measured strain when the load was applied at this location was compressive.

Figure 54. Strain gauge data for F-15E-V item, SG B37-1F2, passes 1-4.

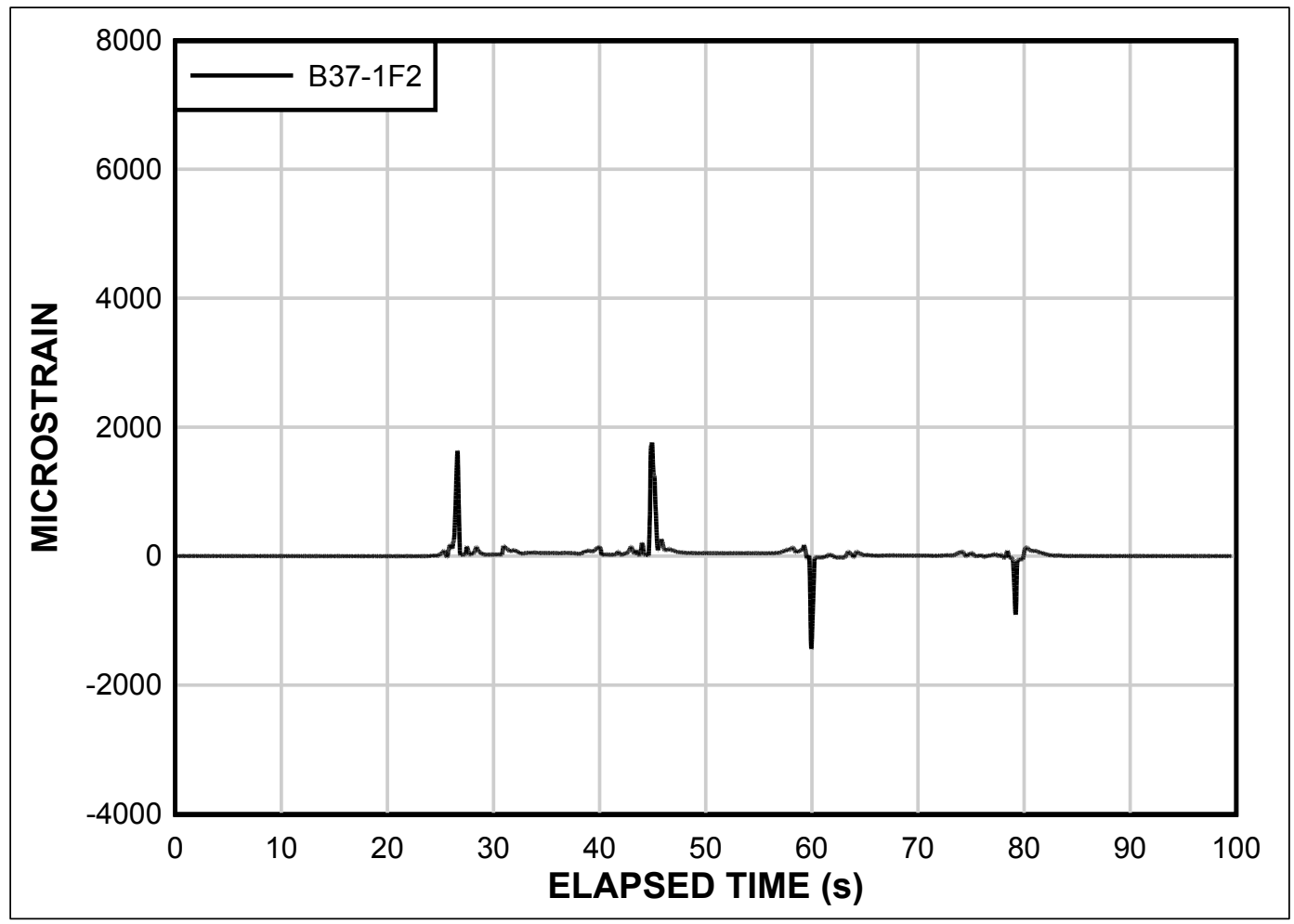


Figure 55. Strain gauge data for F-15E-V item, SG B38-1F2, passes 1-4.

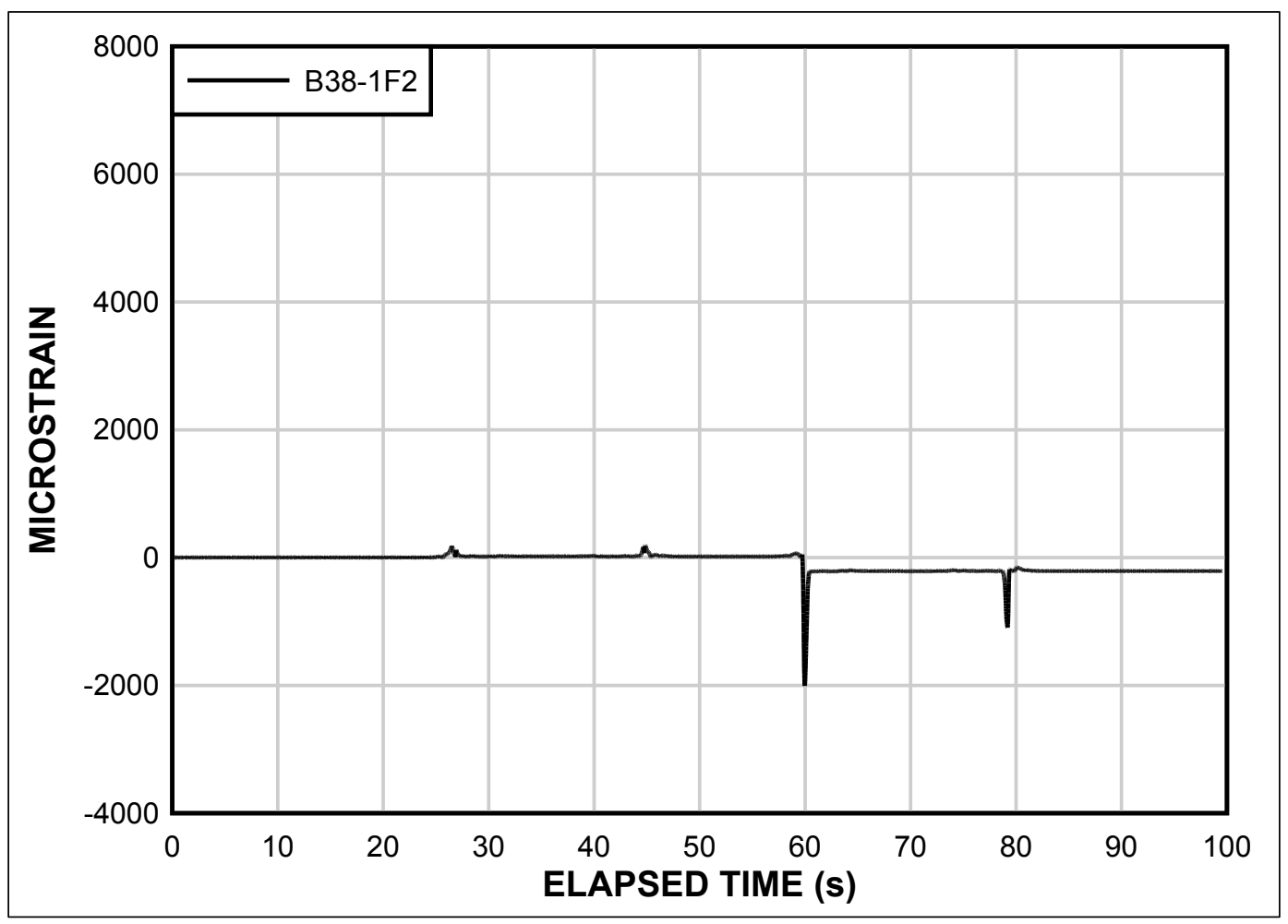

From the raw data, the maximum tensile strains and the absolute value of the maximum compressive strains were captured for each gauge throughout traffic and are reported in Figures 56 through 63. Each figure shows the response of gauges installed on joining panels along the traffic lane. The full data set is archived at ERDC and may be made available upon request.

Failure of the upper underlap rail of panel B40-1 at 322 passes is apparent from the disappearance of data in Figures 60 and 61 during pass interval 257-322. Gauges B4O-1F1 and B40-1F2 both malfunctioned and recorded unusable data after the rail broke. Gauge B37-2F2 was damaged during mat installation; therefore, any data recorded by this gauge was disregarded and not reported. High compressive strains were recorded throughout at the test at $\mathrm{B} 37-2 \mathrm{~F} 1$, which was located above void V-F. Tensile and compressive strains at refurbished Panel B41-2 (located between the largest voids) on average appeared to be higher than at other locations. Its connecting panel (B4O-2), which was new, recorded relatively high tensile strains, but very low compressive strains (on average) at the lower overlap rail. The remaining data show that a clear trend is not observed that links void size the panel strain measurements. 
Figure 56. Max tensile strain at F-15E-V item panels B37-1 and B38-1.

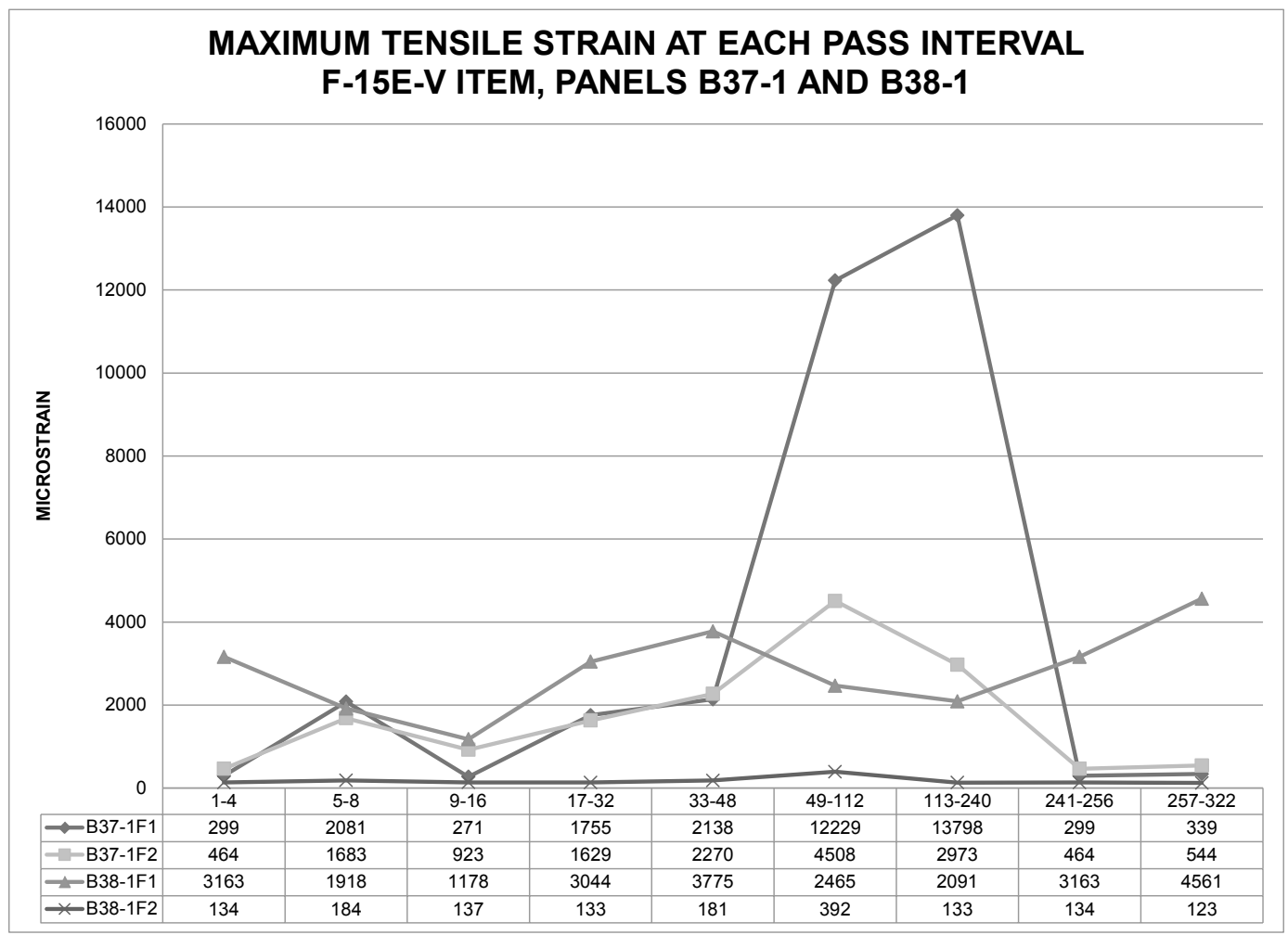

Figure 57. Max compressive strain at F-15E-V item panels B37-1 and B38-1.

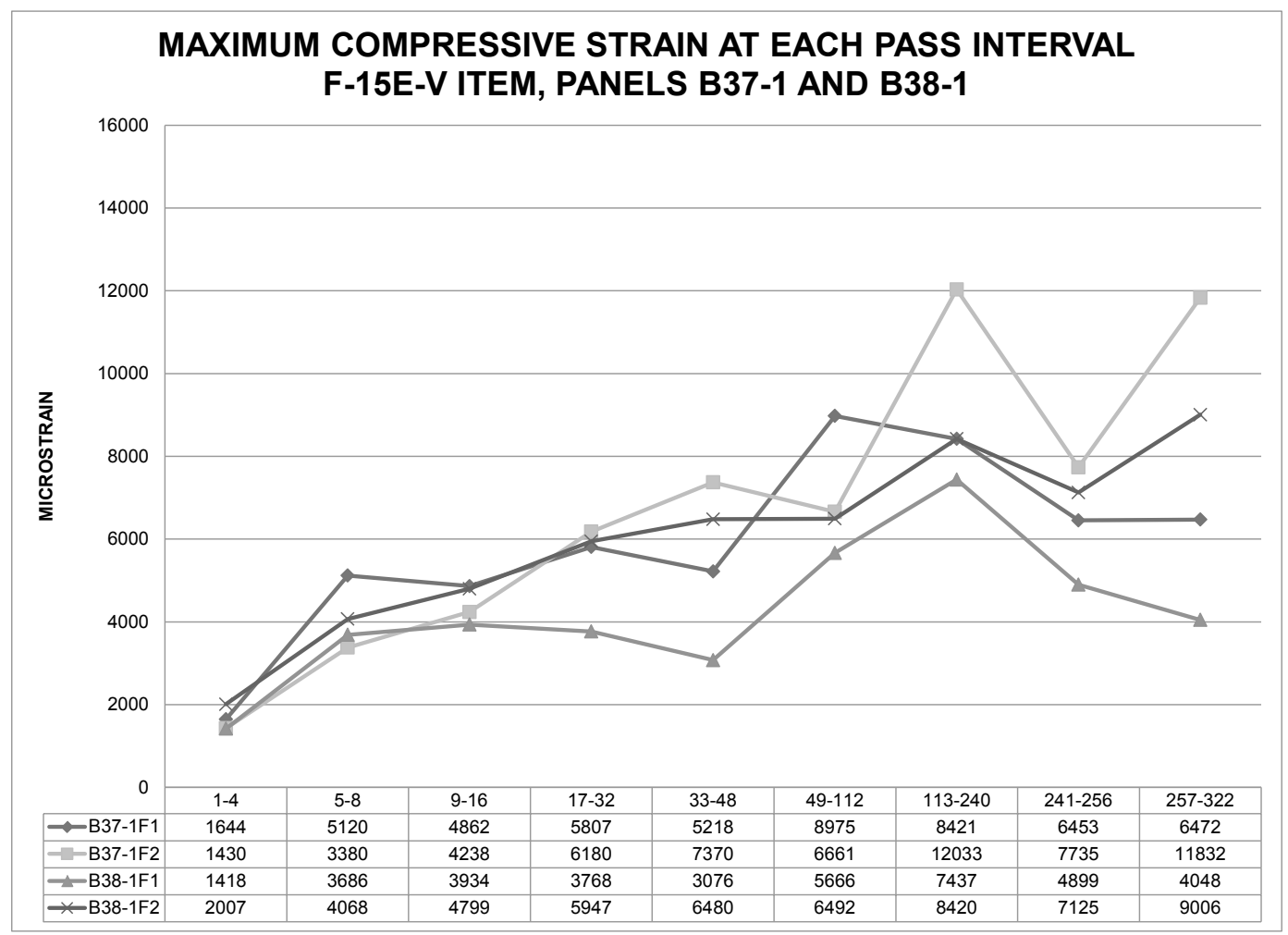


Figure 58. Max tensile strain at F-15E-V item panels B37-2 and B38-2.

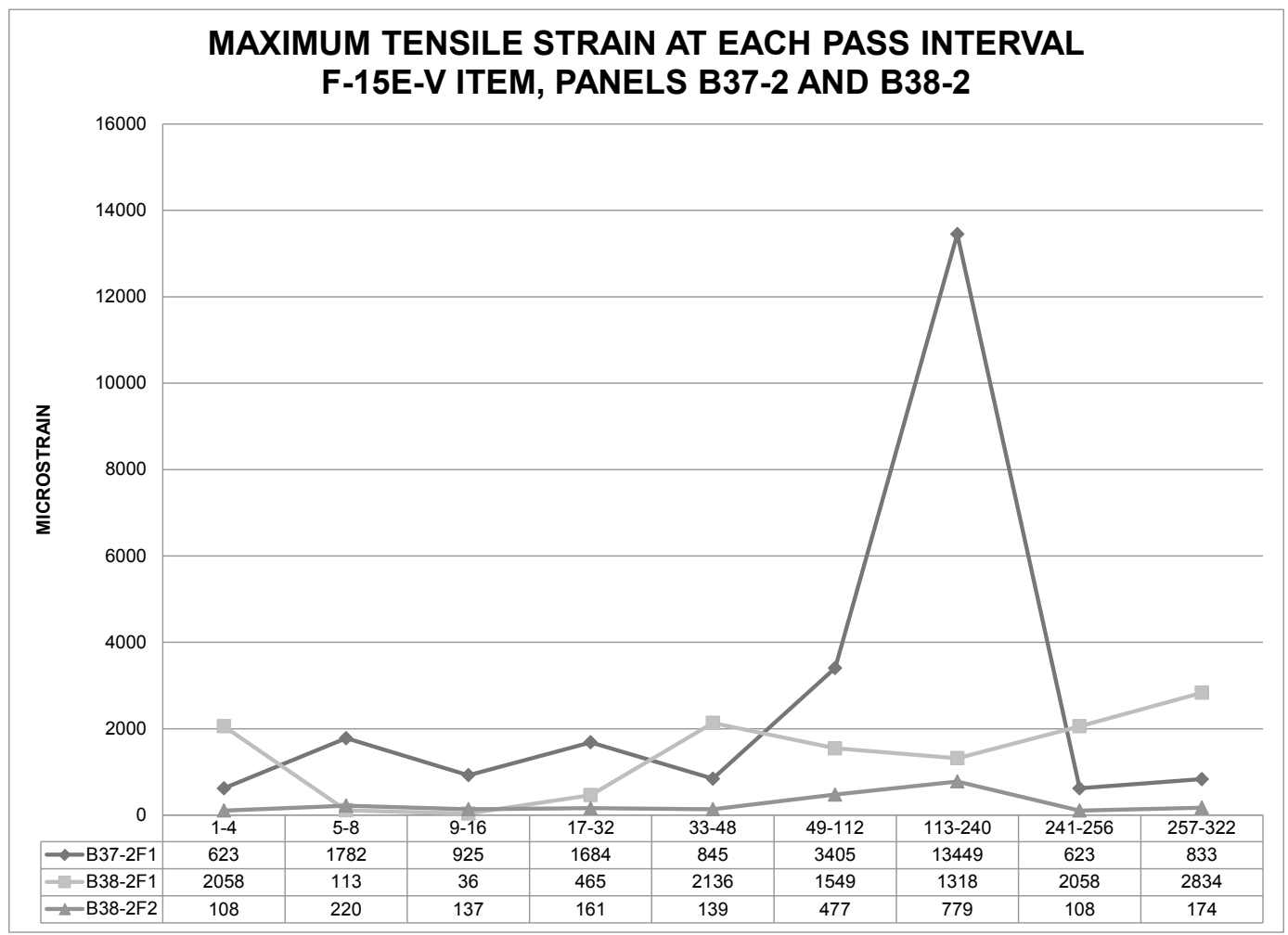

Figure 59. Max compressive strain at F-15E-V item panels B37-2 and B38-2.

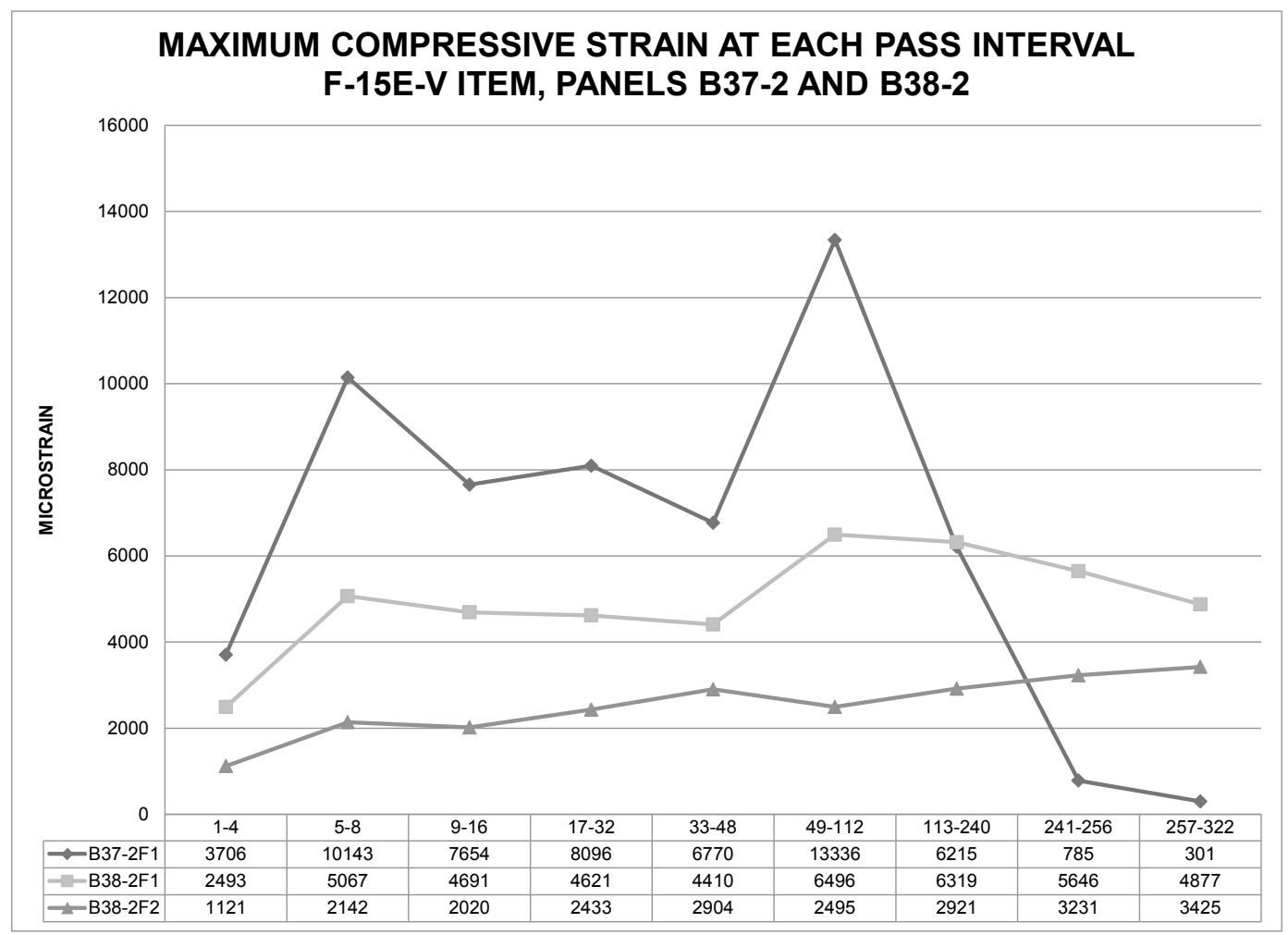


Figure 60. Max tensile strain at F-15E-V item panels B40-1 and B41-1.

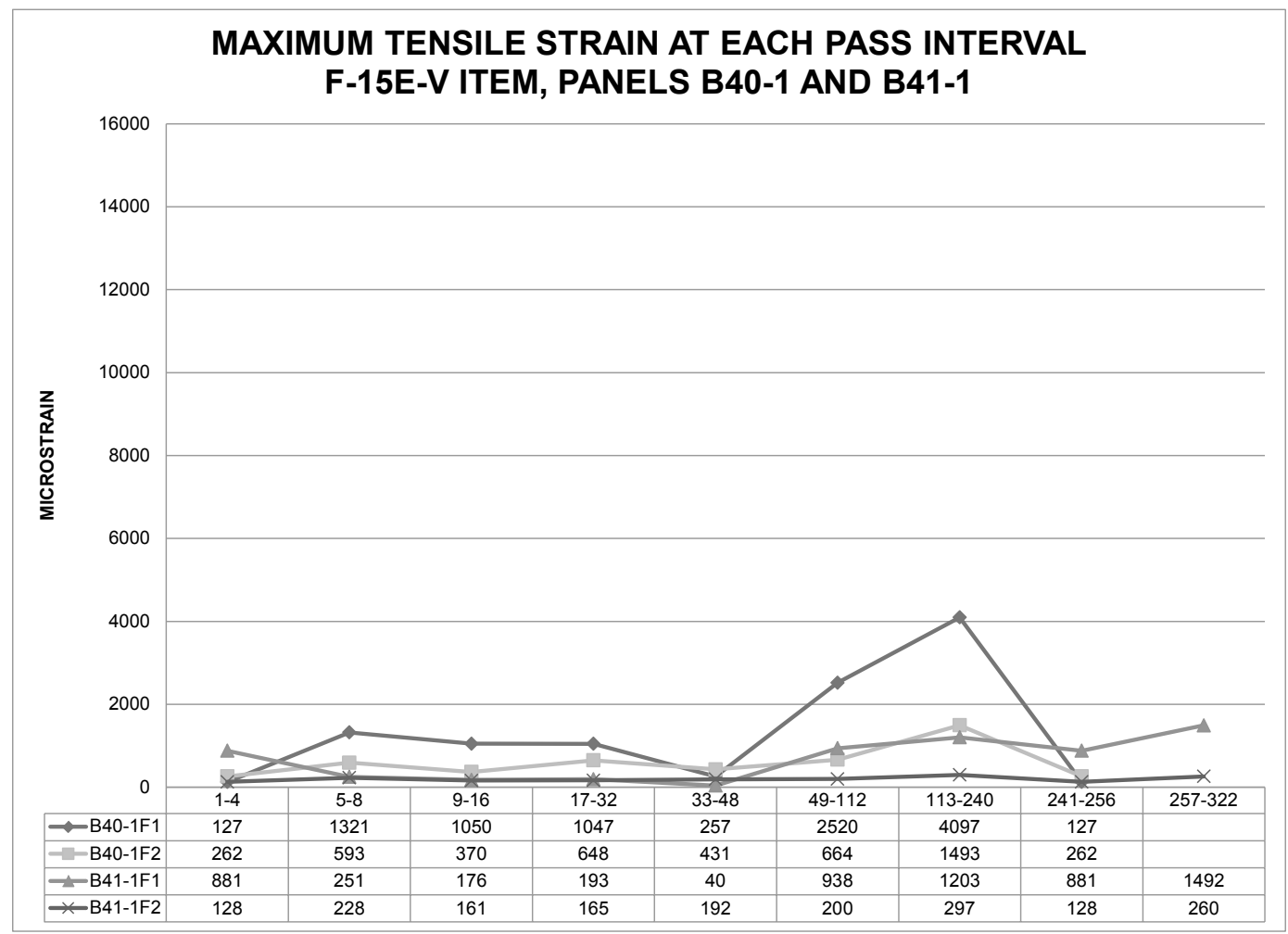

Figure 61. Max compressive strain at F-15E-V item panels B40-1 and B41-1.

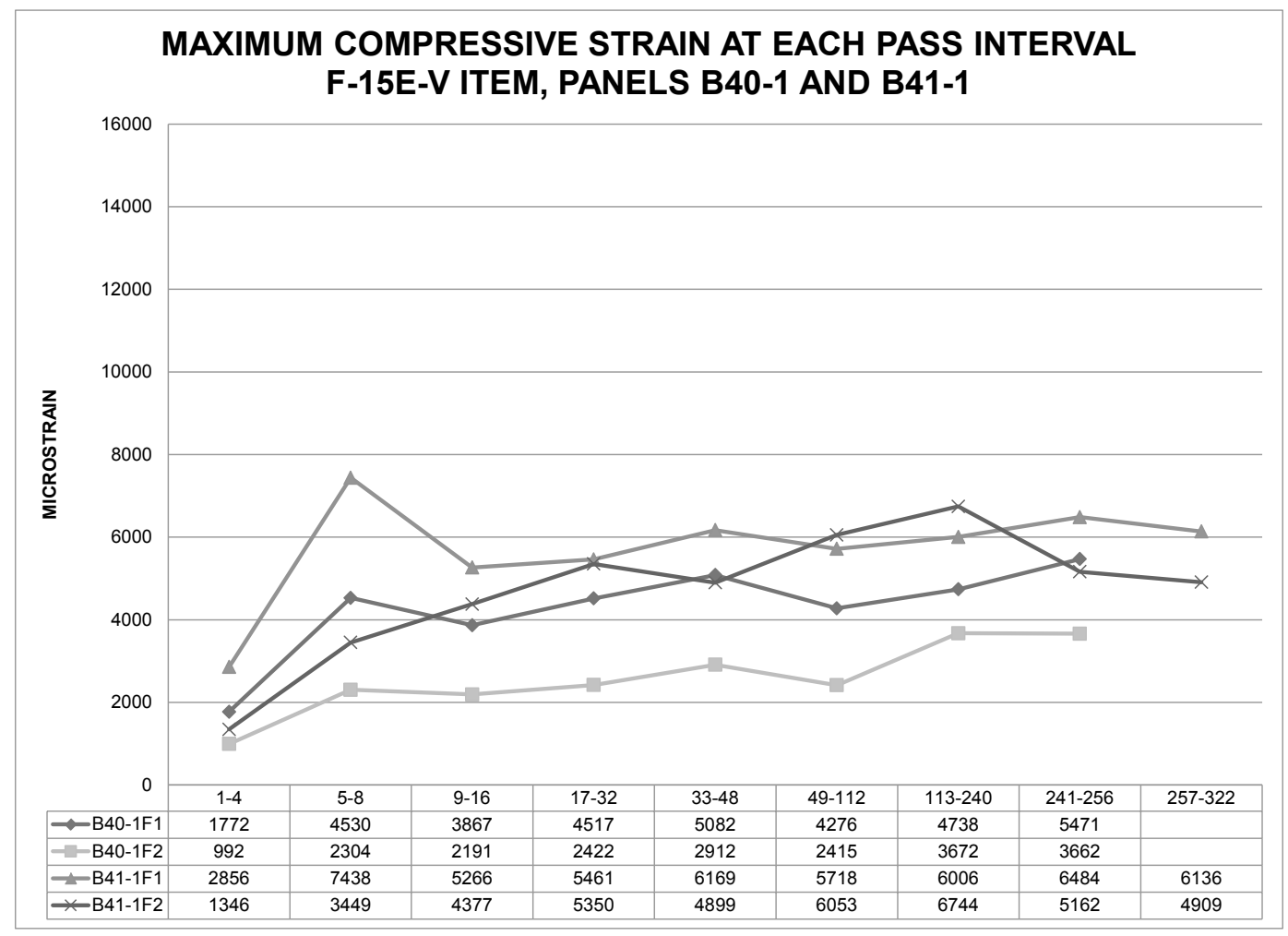


Figure 62. Max tensile strain at F-15E-V item panels B40-2 and B41-2.

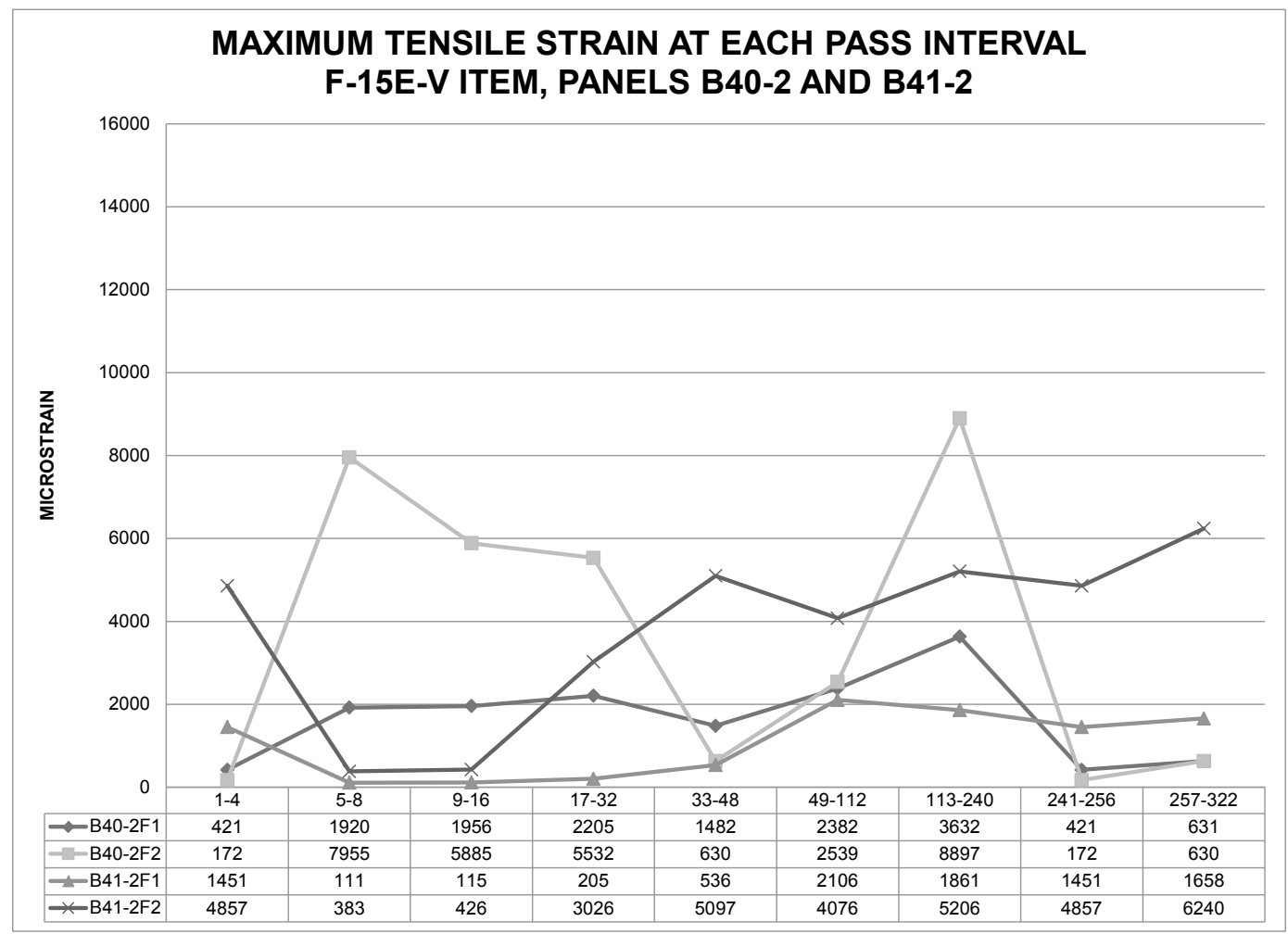

Figure 63. Max compressive strain at F-15E-V item panels B40-2 and B41-2.

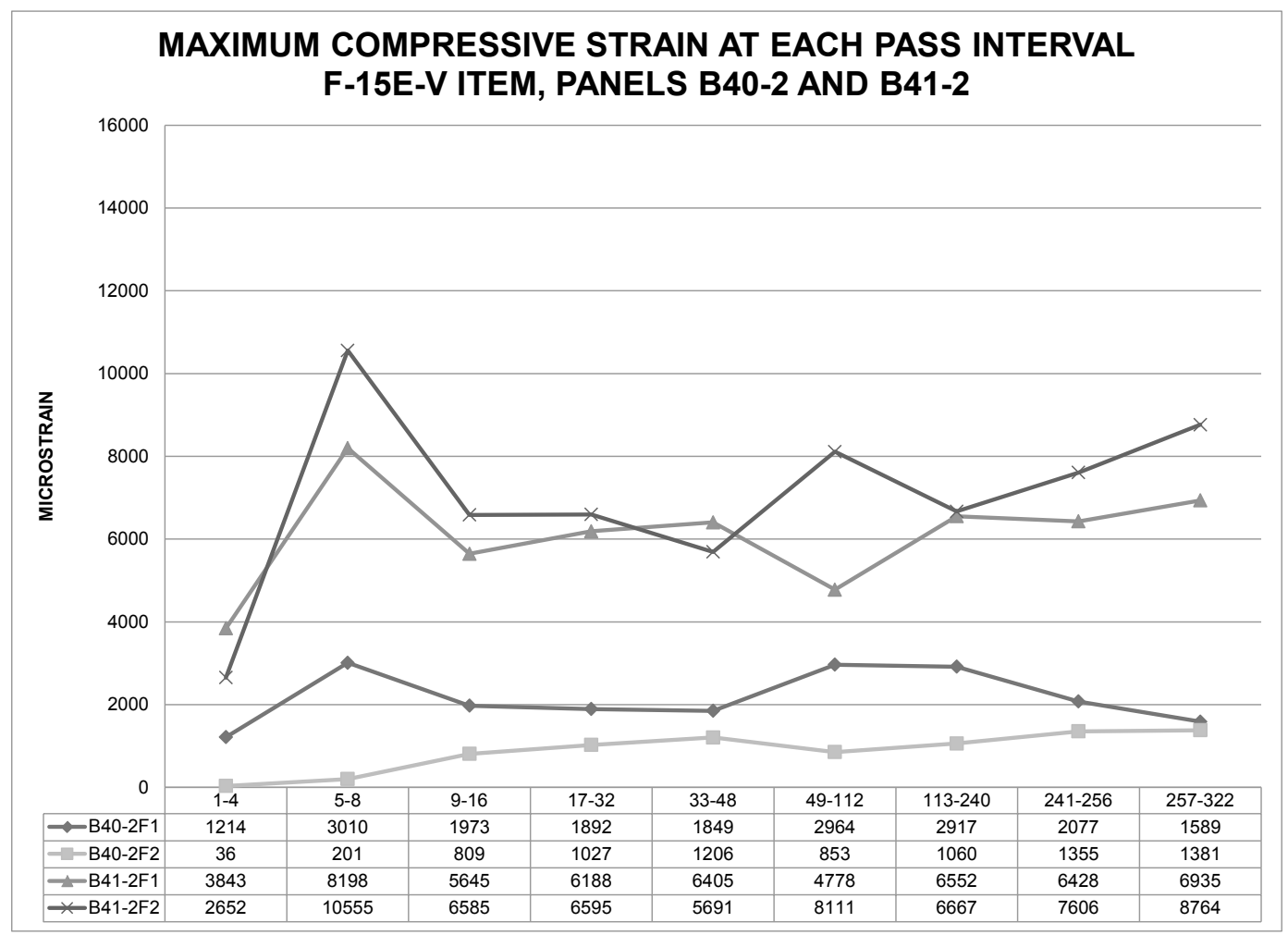




\section{Test Results-Brickwork Pattern}

\subsection{Mat behavior under traffic (visual observations)}

The following sections describe all mat breakage and the behavior of the AM2 airfield mat under simulated F-15E and C-17 traffic when installed in the brickwork pattern using both new and refurbished panels on a subgrade without voids. Figure 64 shows the layout of failed and damaged panels for the $\mathrm{F}-15 \mathrm{E}$ and $\mathrm{C}-17$ items after trafficking concluded.

Figure 64. Layout of failed and damaged panels in F-15E and C-17 items.

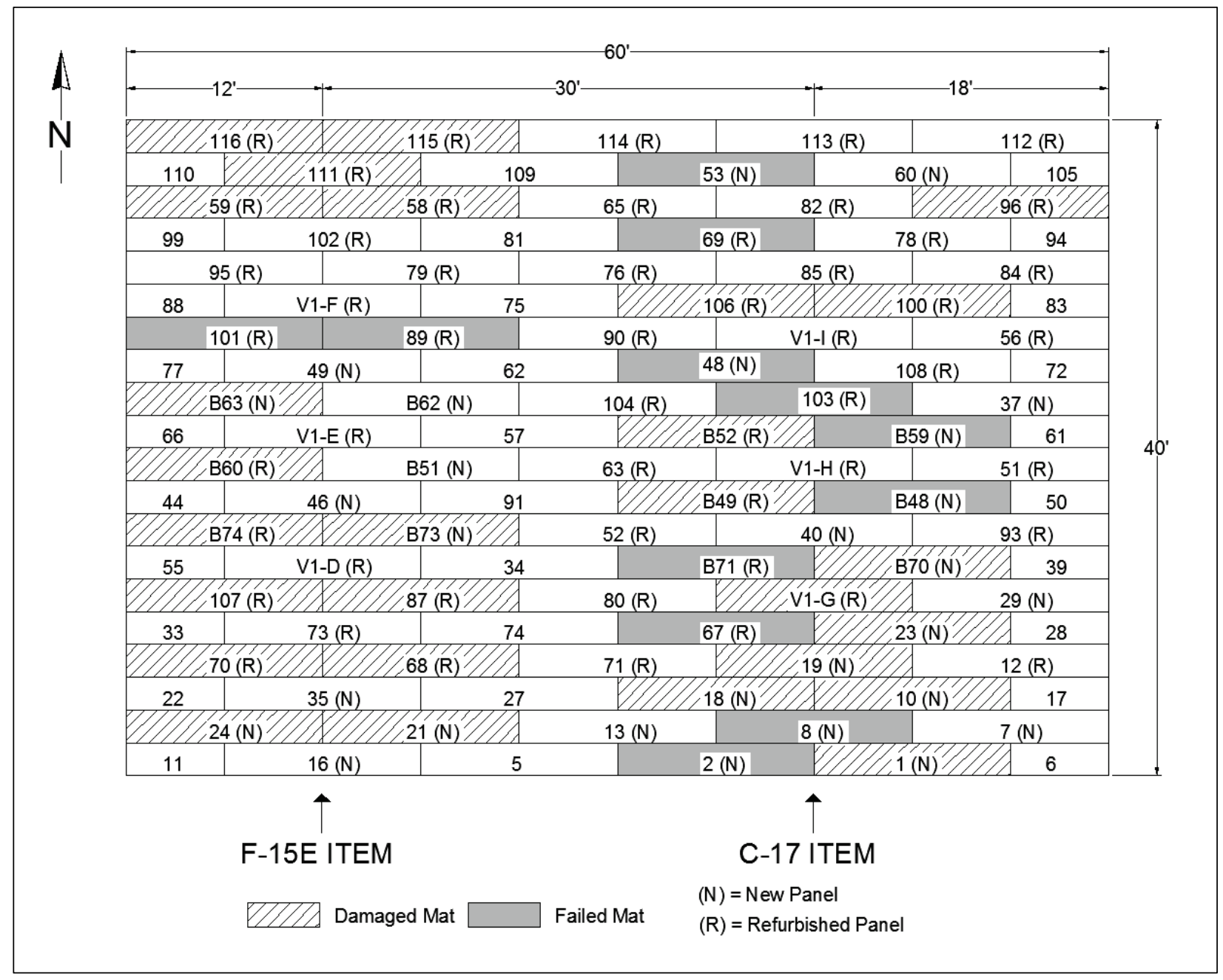

\subsubsection{F-15E test item}

Trafficking of the F-15E test item began on November 5, 2012. No panel damage was noted until 112 passes were reached. Panel 101 had a small 
piece of the southeast corner of the top skin break, and a 1-in.-long crack had developed along the weld of the overlap end connector, starting at the south edge of the top skin. Panel 89 had a 1.5-in.-long crack propagating along the weld of the underlap end connector located at the centerline of traffic. Panels 115, 58, B60, B73, B74, 107, 87, 70, 68, and 24 each had 0.125-in. corner curls at the south corner of the top skin located at the centerline of traffic. Panel B73 also had minor cracks develop where the corner curl was located. After 240 passes, a small piece of the southeast corner of Panel 115 broke. The crack on the surface of Panel 101 increased to a length of 3 in., and the crack on Panel 89 increased to a length of 14 in. The corner curls on Panels 24, 87, B73, and B74 increased to 0.19 in., and o.13-in. corner curls developed in Panel 21.

After 430 passes, Panel 89 failed when the end connector detached from the panel and the top skin detached from the core of the panel within $1.5 \mathrm{in}$. from the broken weld, creating a severe tire hazard (Figure 65). The location of weld and the lack of an insert gave indication that Panel 89 was an earlier version of AM2 (prior to Mod 5). The crack on the surface of Panel 101 increased to $4.25 \mathrm{in}$. The corner curls on Panels 24, B74, and B73 increased to 0.25 in., and the corner curls in Panels 70, 107, and B6o had increased to 0.19 in. Although the corner curls could have been maintained by grinding, the failure at Panel 89 was posing a risk to the tire, and trafficking could not be continued without replacing the panel. Therefore, trafficking was concluded, since sufficient data was collected for analyzing instrumentation response and refurbished matting damage rates.

When panels were removed after trafficking completed, additional damage was noted. The overlap end connector of Panel 101 had detached a length of 5 in., starting at the female hinge connector edge (Figure 66). With the failure of this panel, mat breakage at the end of the test increased to 5 percent. Panel 11 had a crack 3 in. long at the center of the female hinge connector. Table 14 summarizes additional damage found in other panels, specifically damage noted at the end connectors of panels with joints along the centerline of traffic (Figure 67). Table 15 gives a summary of mat distresses and failures on the mat surface at various pass levels for the F-15E item. Figure 64 shows a layout of damaged and failed panels at the end of the test with refurbished and new panels identified for comparison. In summary, eleven refurbished were damaged, four new panels were damaged, and two refurbished panels failed. 
Figure 65. Panel 89 after 430 passes.

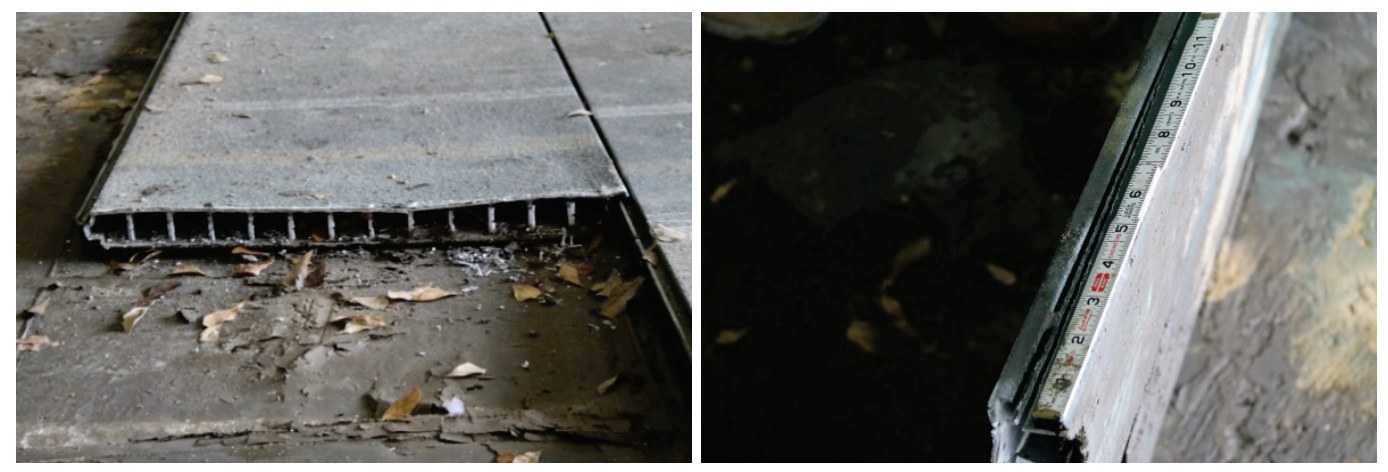

Figure 66. Damage noted in Panel 101 after removing from test section.

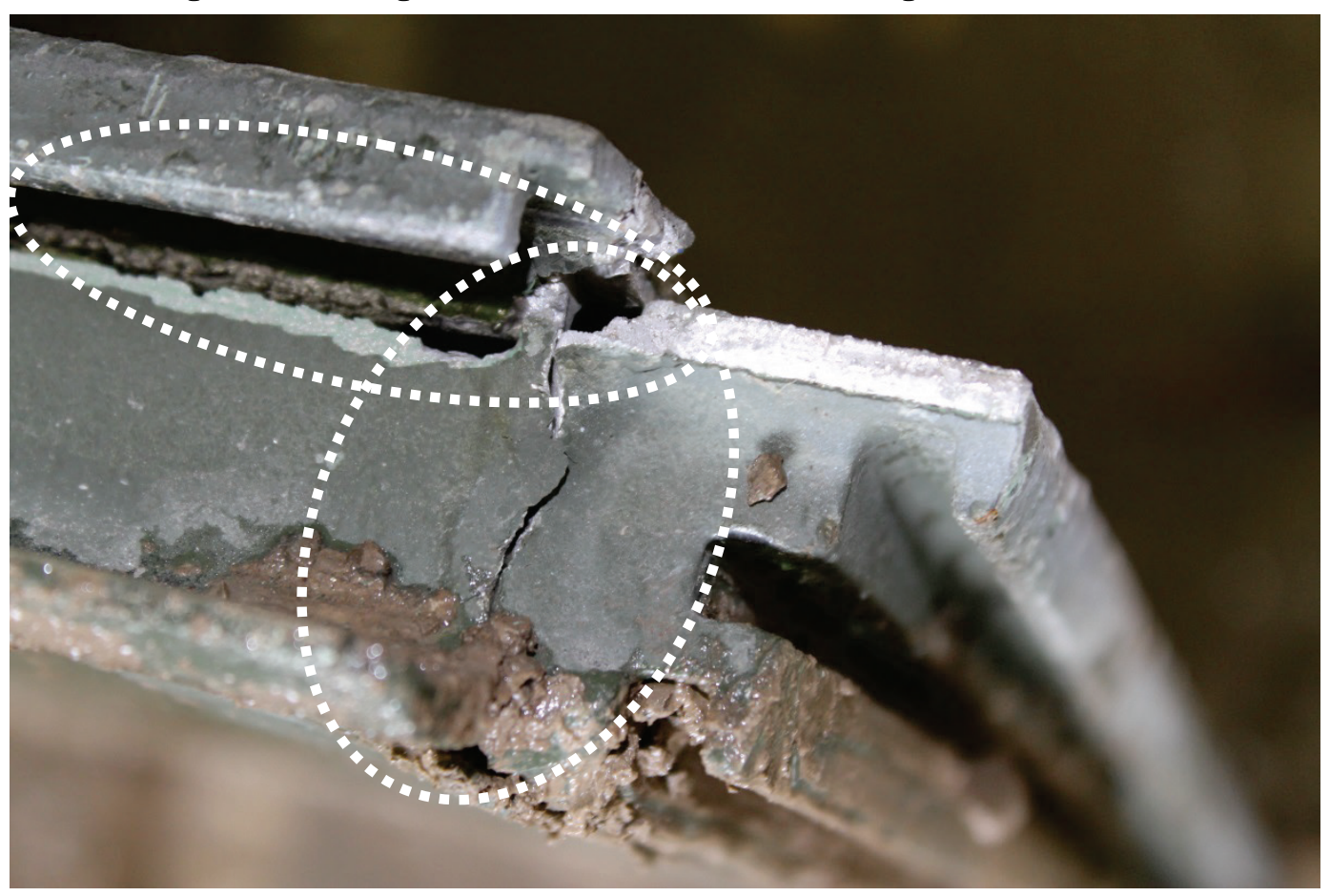


Table 14. Damage noted after picking up mats in the F-15E item (430 passes).

\begin{tabular}{|l|l|l|l|l|}
\hline $\begin{array}{l}\text { Panel } \\
\text { Designation }\end{array}$ & Mat condition & $\begin{array}{l}\text { End connector } \\
\text { along centerline }\end{array}$ & $\begin{array}{l}\text { Length of crack below } \\
\text { corner of top flange of } \\
\text { female conn., (in.) }\end{array}$ & $\begin{array}{l}\text { Length of crack along weld of } \\
\text { end connector (at face of } \\
\text { female conn.), (in.)* }\end{array}$ \\
\hline 116 & Refurbished & Overlap & 1 & - \\
\hline 59 & Refurbished & Underlap & 0.5 & - \\
\hline 101 & Refurbished & Overlap & 6.5 & End connector detached 5 in. \\
\hline 89 & Refurbished & Underlap & 14 & End connector detached \\
\hline B63 & New & Overlap & 0.5 & - \\
\hline B60 & Refurbished & Overlap & 1 & $\begin{array}{l}1.5, \text { top surface to bottom } \\
\text { surface }\end{array}$ \\
\hline 107 & Refurbished & Overlap & 1 & $\begin{array}{l}1.5, \text { top surface to bottom } \\
\text { surface }\end{array}$ \\
\hline 70 & Refurbished & Overlap & 1 & - \\
\hline 68 & Refurbished & Underlap & - & $\begin{array}{l}1.5, \text { top surface to bottom } \\
\text { surface }\end{array}$ \\
\hline 24 & New & Overlap & 0.5 & - \\
\hline
\end{tabular}

*See Figure 67

Figure 67. Damage noted in Panel 68 after removing from test section.

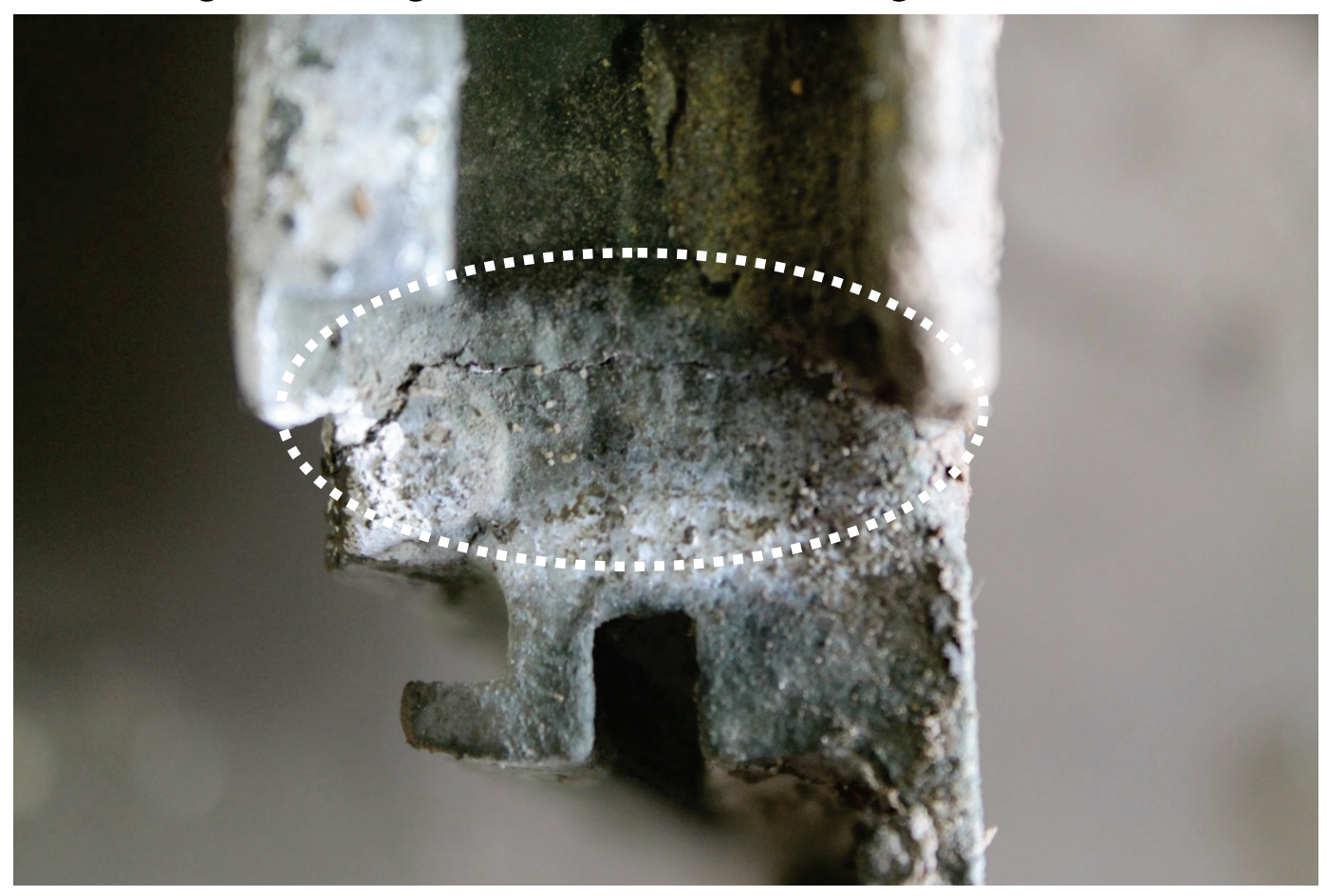


Table 15. F-15E item mat damage summary.

\begin{tabular}{|c|c|c|c|c|c|}
\hline $\begin{array}{l}\text { F-15E } \\
\text { Passes }\end{array}$ & Failure Type & Damage Description & $\begin{array}{l}\text { Cumulative } \\
\text { Failed Panels }\end{array}$ & $\begin{array}{l}\text { Cumulative } \\
\text { Percent Mat } \\
\text { Failure }\end{array}$ & Panel Number \\
\hline \multirow[t]{3}{*}{112} & \multirow[t]{3}{*}{-} & Corner curls & - & - & $\begin{array}{l}115,58, \mathrm{~B} 60, \mathrm{~B} 73, \mathrm{~B} 74, \\
107,87,70,68,24\end{array}$ \\
\hline & & Top skin cracking & - & - & 101, 89, B73 \\
\hline & & $\begin{array}{l}\text { Small piece from } \\
\text { corner of top skin } \\
\text { broke }\end{array}$ & - & - & 101 \\
\hline \multirow[t]{2}{*}{240} & \multirow[t]{2}{*}{-} & Corner curls & - & - & 21 \\
\hline & & $\begin{array}{l}\text { Small piece from } \\
\text { corner of top skin } \\
\text { broke }\end{array}$ & - & - & 115 \\
\hline \multirow[t]{2}{*}{430} & $\begin{array}{l}\text { Mat breakage } \\
\text { and tire hazard }\end{array}$ & $\begin{array}{l}\text { Detached end } \\
\text { connector }\end{array}$ & 1 & $2.5 \%$ & $89(\mathrm{R})$ \\
\hline & Tire hazard & Corner curls & - & - & $\begin{array}{l}\text { B74, 70, 107, 24, B60, } \\
\text { B73 }\end{array}$ \\
\hline \multirow[t]{3}{*}{ Posttest } & Mat breakage & $\begin{array}{l}\text { Partially detached } \\
\text { end connector }\end{array}$ & 2 & $5.0 \%$ & 101(R) \\
\hline & \multirow[t]{2}{*}{-} & $\begin{array}{l}\text { Crack along female } \\
\text { connector }\end{array}$ & - & - & 111 \\
\hline & & \multicolumn{4}{|l|}{ Refer to Table 14} \\
\hline
\end{tabular}

\subsubsection{C-17 test item}

Trafficking of the C-17 item began on November 14, 2012. No damage was noted until 784 passes were reached, when a vertical separation was noted at the joint of Panels B59 and B52. The upper underlap rail of Panel B59 had broken; therefore, the panel was considered failed. After 938 passes, a crack was noted throughout the length of the weld of the overlap end connector of Panel 69. The end connector detached, rendering Panel 69 failed (Figure 68). A piece of the southeast corner of the top skin of Panel B52 broke, and 0.13-in. corner curls were noted on the top skin of Panels 67, $23, \mathrm{~B} 71,18$, and 10 at the south corner located along the centerline of traffic.

After 1,008 passes, Panel 103 failed when a 15-in.-long crack was noted on the top skin, about 2 in. from and parallel to the female hinge connector. Mat breakage at this point increased to 5 percent. Panel 18 had developed a 1.5-in.-long top skin tear at the southeast corner that propagated along the top flange of the female hinge. 
Figure 68. Panel 69 after removing from test section.
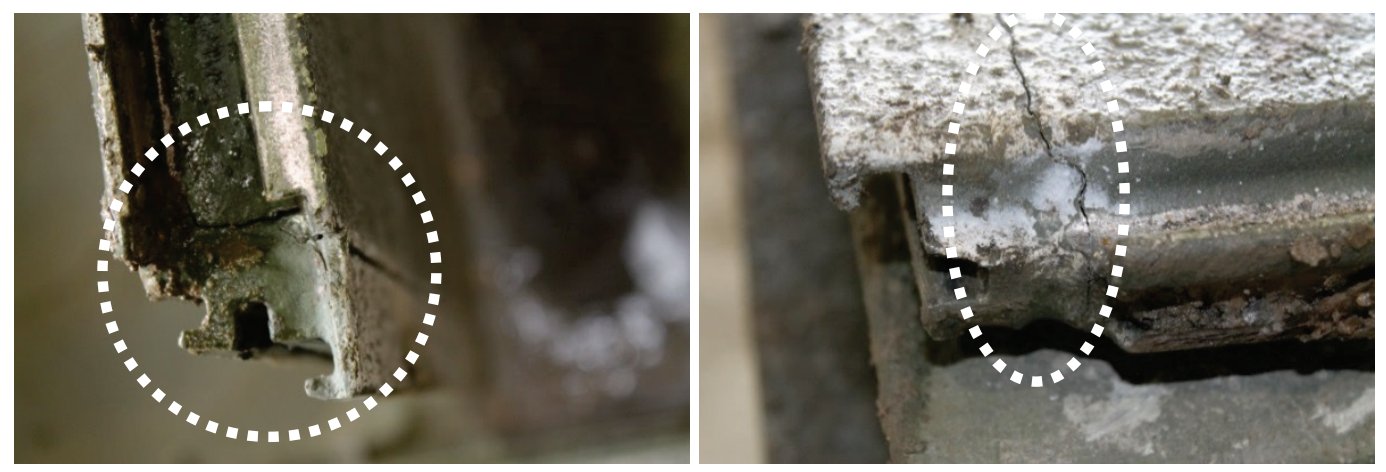

After 1,162 passes, the length of the crack on Panel 103 increased to 40 in. Panels B59 and B70 were noted to have 0.13-in. corner curls on the southeast corner of each panel. Panel B49 had a 1.5-in.-long crack along the weld of the overlap end connector. Panel 67 developed a top skin tear along the top flange of the female hinge that was $1.5 \mathrm{in}$. long. The corner curls in Panels 67 and 23 increased to 0.19 in.

After 1,308 passes, the joint between Panels 1 and 2 was seen separating during traffic. It was likely that the lower overlap rail of Panel 2 had broken, but the exact damage could not be identified until the mat was picked up. The same was noted at the joint of Panels 67 and 23, but the panel with a damaged end connector could not be identified from the surface. The upper underlap rail of Panel B48 was noted to have broken, rendering the panel failed. At this point in the test, at least four panels had failed, equaling 6.6 percent of the test item. Panels 1, B70 and 23 each had top skin tears that were 6 in., 4 in., and 4 in. long, respectively, along the top flange of the female hinge connector. The crack on the surface of Panel 103 had increased to $70 \mathrm{in}$. Trafficking was concluded due to the extent of damage in the traffic lane and the assertion that additional panel failures could be verified upon mat removal.

After removing the panels from the test section, it was confirmed that the lower overlap rails of Panels 67 and 2 broke (Figure 69) and the upper underlap rail of Panel 23 broke a length of 2 in. (starting at the female hinge edge). Panels 48 and B71 each had a broken lower overlap rail. Panel 53 had the lower overlap rail broken a length of 16 in., Panel 100 had the upper underlap rail broken a length of 4 in., and Panel 8 had the upper underlap rail broken a length of 17 in., all starting at the female hinge edge. The male hinge connector of Panel 8 also had a crack that propagated 1.25 in. from the overlap end connector edge. Panel 103 
(Figure 70) was noted to have a 36-in.-long crack on the bottom skin, about 2 in. from and parallel to the female hinge connector. The panel also had an 82-in.-long crack along the center of the female hinge. Failure of Panels $67,53,8,2,48$, and B71 increased mat breakage to 16.6 percent. Therefore, the $\mathrm{C}-17$ item failed at 1,308 passes. Panels V1-G and 19 each had a crack 7 in. and 24 in. long, respectively, along at the center of the female hinge connector. Table 16 summarizes additional damage found, noted specifically at the end connectors (Figure 71). Table 17 gives a summary of mat distresses and failures on the mat surface at various pass levels for the $\mathrm{C}-17$ item. Figure 64 shows a layout of failed and damaged panels, with new and refurbished panels identified for comparison.

Figure 69. Panel 67 after 1,308 passes.

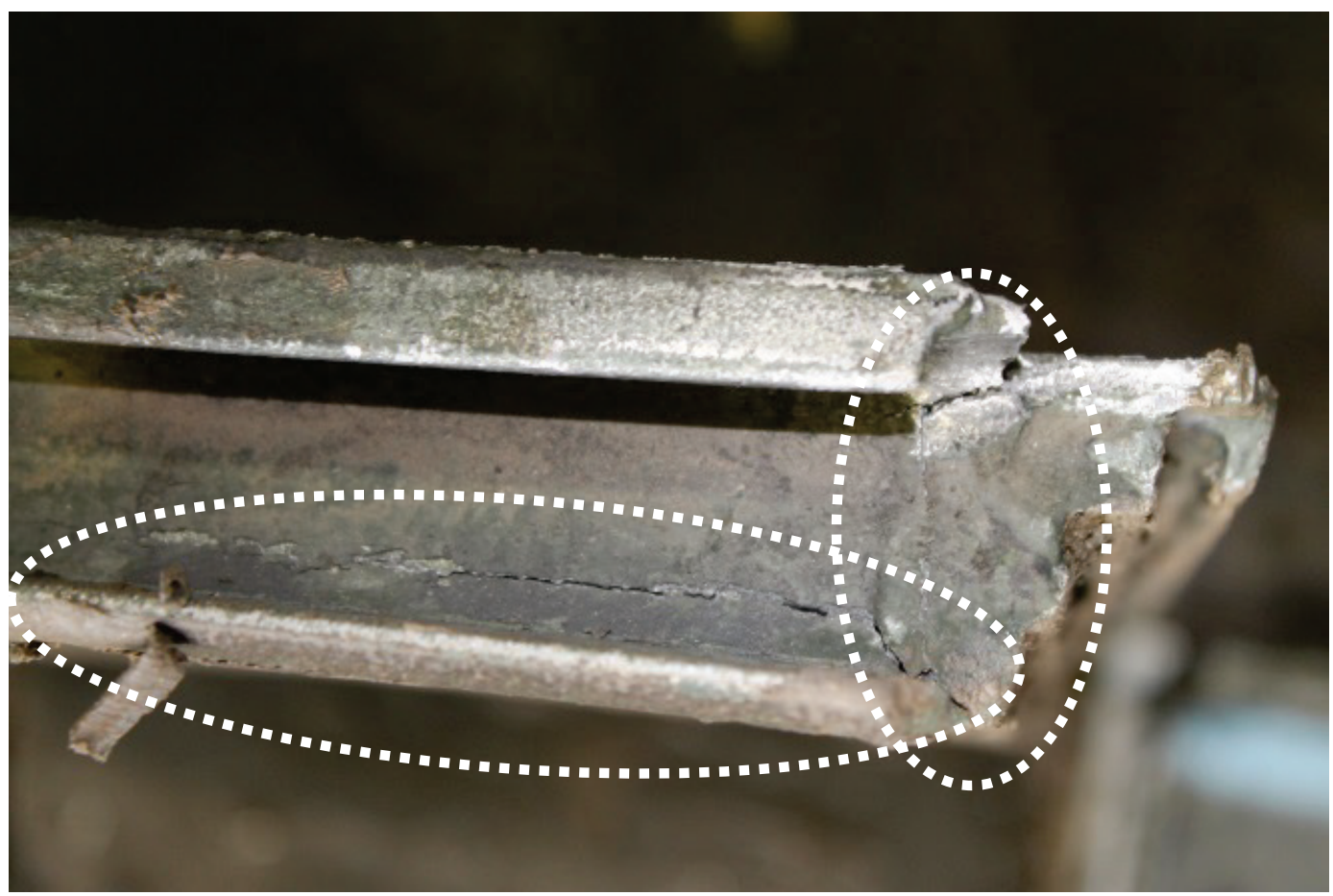

Figure 70. Damage in Panel 103.

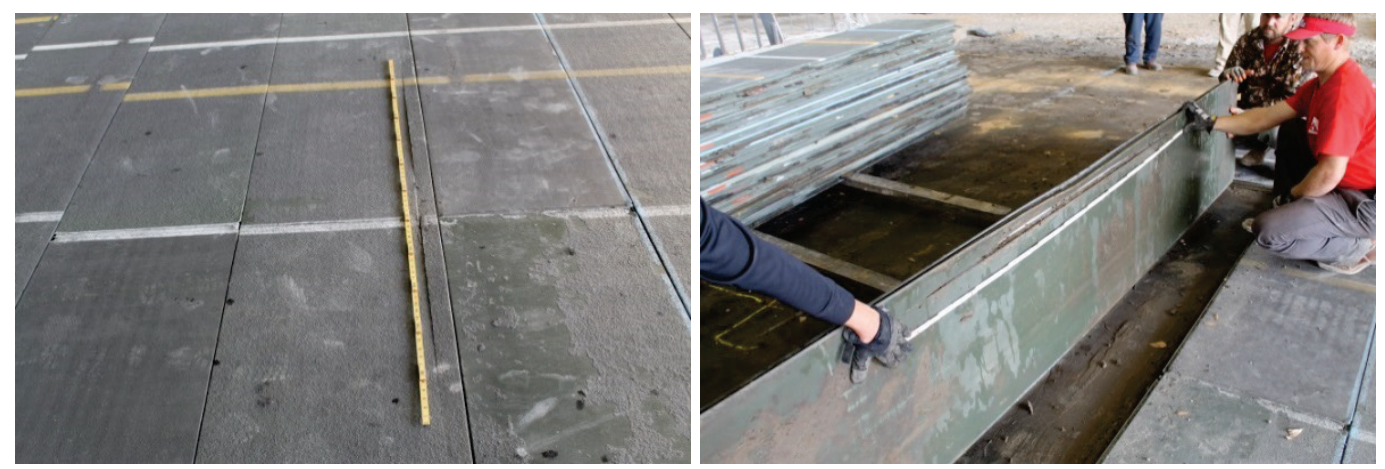


Table 16. Damage noted after removing panels from C-17 item (1,308 passes).

\begin{tabular}{|l|l|l|l|l|}
\hline Panel Number & Mat condition & End connector & $\begin{array}{l}\text { Length of crack along } \\
\text { face of female hinge } \\
\text { (near end connector), } \\
\text { (in.)* }\end{array}$ & $\begin{array}{l}\text { Length of crack along } \\
\text { weld of end connector } \\
\text { (at face of female } \\
\text { conn.), (in.)* }\end{array}$ \\
\hline 96 & Refurbished & Underlap & - & $\begin{array}{l}\text { 0.5, starting at top } \\
\text { surface }\end{array}$ \\
\hline 106 & Refurbished & Overlap & 1 & - \\
\hline 100 & Refurbished & Underlap & & $\begin{array}{l}\text { 1.5, top surface to } \\
\text { bottom surface }\end{array}$ \\
\hline B52 & Refurbished & Overlap & 8 & $\begin{array}{l}1.5, \text { top surface to } \\
\text { bottom surface }\end{array}$ \\
\hline B49 & Refurbished & Overlap & 5 & $\begin{array}{l}1.5, \text { top surface to } \\
\text { bottom surface }\end{array}$ \\
\hline B71 & Refurbished & Overlap & 1.5 & $\begin{array}{l}0.5, \text { starting at top } \\
\text { surface }\end{array}$ \\
\hline B70 & New & Underlap & 1 & $\begin{array}{l}1.5, \text { top surface to } \\
\text { bottom surface }\end{array}$ \\
\hline 67 & Refurbished & Overlap & 3 & - \\
\hline
\end{tabular}

*See Figure 71

Figure 71. Panel B52 after removing from C-17 test item.
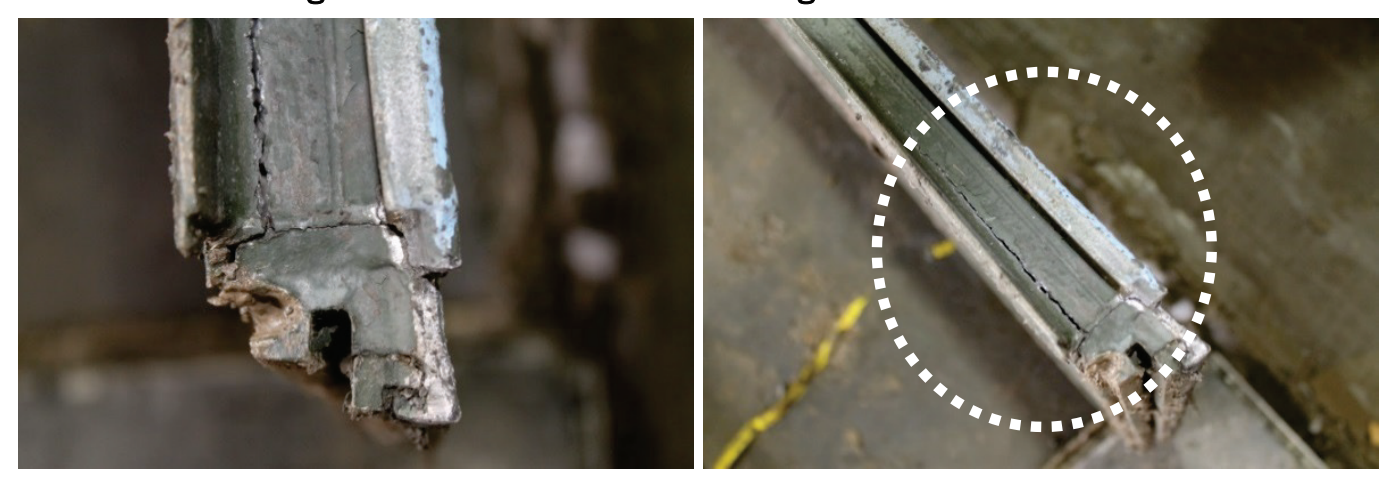
Table 17. C-17 item mat damage summary.

\begin{tabular}{|c|c|c|c|c|c|}
\hline $\begin{array}{l}\text { C-17 } \\
\text { Passes }\end{array}$ & Failure Type & Damage Description & $\begin{array}{l}\text { Cumulative } \\
\text { Failed } \\
\text { Panels }\end{array}$ & $\begin{array}{l}\text { Cumulative } \\
\text { Percent Mat } \\
\text { Failure }\end{array}$ & Panel Number \\
\hline 784 & Mat breakage & $\begin{array}{l}\text { Upper underlap rail } \\
\text { broke }\end{array}$ & 1 & 1.6 & B59(N) \\
\hline \multirow[t]{3}{*}{938} & Mat breakage & $\begin{array}{l}\text { End connector } \\
\text { detached }\end{array}$ & 2 & 3.3 & $69(\mathrm{R})$ \\
\hline & \multirow[t]{2}{*}{-} & $\begin{array}{l}\text { Small piece from corner } \\
\text { of top skin broke }\end{array}$ & - & - & B52 \\
\hline & & Corner curls & - & - & $67,23, \mathrm{~B} 71,18,10$ \\
\hline \multirow[t]{2}{*}{1,008} & Mat breakage & $\begin{array}{l}\text { Top skin crack along } \\
\text { vertical stiffeners }\end{array}$ & 3 & 5.0 & $103(R)$ \\
\hline & - & Top skin tear & - & - & 18 \\
\hline \multirow[t]{3}{*}{1,162} & \multirow[t]{3}{*}{-} & Corner curls & - & - & B59, B70 \\
\hline & & Crack along weld & - & - & B49 \\
\hline & & Top skin tear & - & - & 67 \\
\hline \multirow[t]{2}{*}{1,308} & Mat breakage & $\begin{array}{l}\text { Upper underlap rail } \\
\text { broke }\end{array}$ & 4 & 6.6 & $\mathrm{~B} 48(\mathrm{~N})$ \\
\hline & - & Top skin tear & - & & 1, B70, 23 \\
\hline \multirow[t]{6}{*}{ Posttest } & \multirow[t]{2}{*}{ Mat breakage } & $\begin{array}{l}\text { Lower overlap rail broke } \\
\text { completely or }>12 \text { in. }\end{array}$ & 9 & 15 & $\begin{array}{l}\text { 67(R), 2(N), B71(R), } \\
48(N), 53(N)\end{array}$ \\
\hline & & $\begin{array}{l}\text { Upper underlap rail } \\
\text { broke }>12 \text { in. }\end{array}$ & 10 & 16.6 & $8(N)$ \\
\hline & \multirow[t]{4}{*}{-} & $\begin{array}{l}\text { Upper under rail broke } \\
<12 \text { in. }\end{array}$ & - & - & 23,100 \\
\hline & & Bottom skin crack & - & - & 103 \\
\hline & & $\begin{array}{l}\text { Crack along center of } \\
\text { female hinge }\end{array}$ & - & - & 103, V1-G, 19 \\
\hline & & \multicolumn{4}{|l|}{ Refer to Table 16} \\
\hline
\end{tabular}

\subsection{Permanent deformation}

To show only the changes that occurred because of trafficking, the pretraffic data were subtracted from all subsequent data collected after trafficking began to normalize the data. The discussions that follow are based on normalized data. Table 18 summarizes maximum deformation values measured on each item from data collected along the centerline profile and cross-sections.

Plots of the centerline profile data, as determined from robotic total station recordings, for the F-15E and C-17 test items are shown in Figures 72 through 75 . When determining the maximum roughness value in each item, 
boundary conditions were ignored (i.e., first eight and last six stations along the centerline in Figure 73). This was done because of the different properties at the interface of the test section subgrade and the surrounding material (the latter being much stronger). In Figure 74, a peak shown at station 26 was a result of material buildup where Panels 101 and 89 failed. This was ignored when analyzing the profile for roughness values. Plots of the average cross-section elevation data, collected along lines A1, A2, and A3 from Figure 36 for each test item, are shown in Figures 76 through 81.

Table 18. Maximum permanent deformation values for the F-15E and C-17 items.

\begin{tabular}{|l|l|l|}
\hline Test Item & F-15E & C-17 \\
\hline Pass Number & 430 & 1,308 \\
\hline Subgrade Profile Max Abrupt Change in Elevation (in.) & 0.84 & 0.90 \\
\hline Mat Surface Profile Max Abrupt Change in Elevation (in.) & 0.17 & 0.52 \\
\hline Subgrade Permanent Deformation (in.) & 0.75 & 3.06 \\
\hline Loaded Deformation on Mat Surface (in.) & 0.65 & 2.72 \\
\hline Unloaded Deformation on Mat Surface (in.) & 0.44 & 1.67 \\
\hline
\end{tabular}

Figure 72. Subgrade centerline profile of the F-15E item after 430 passes.

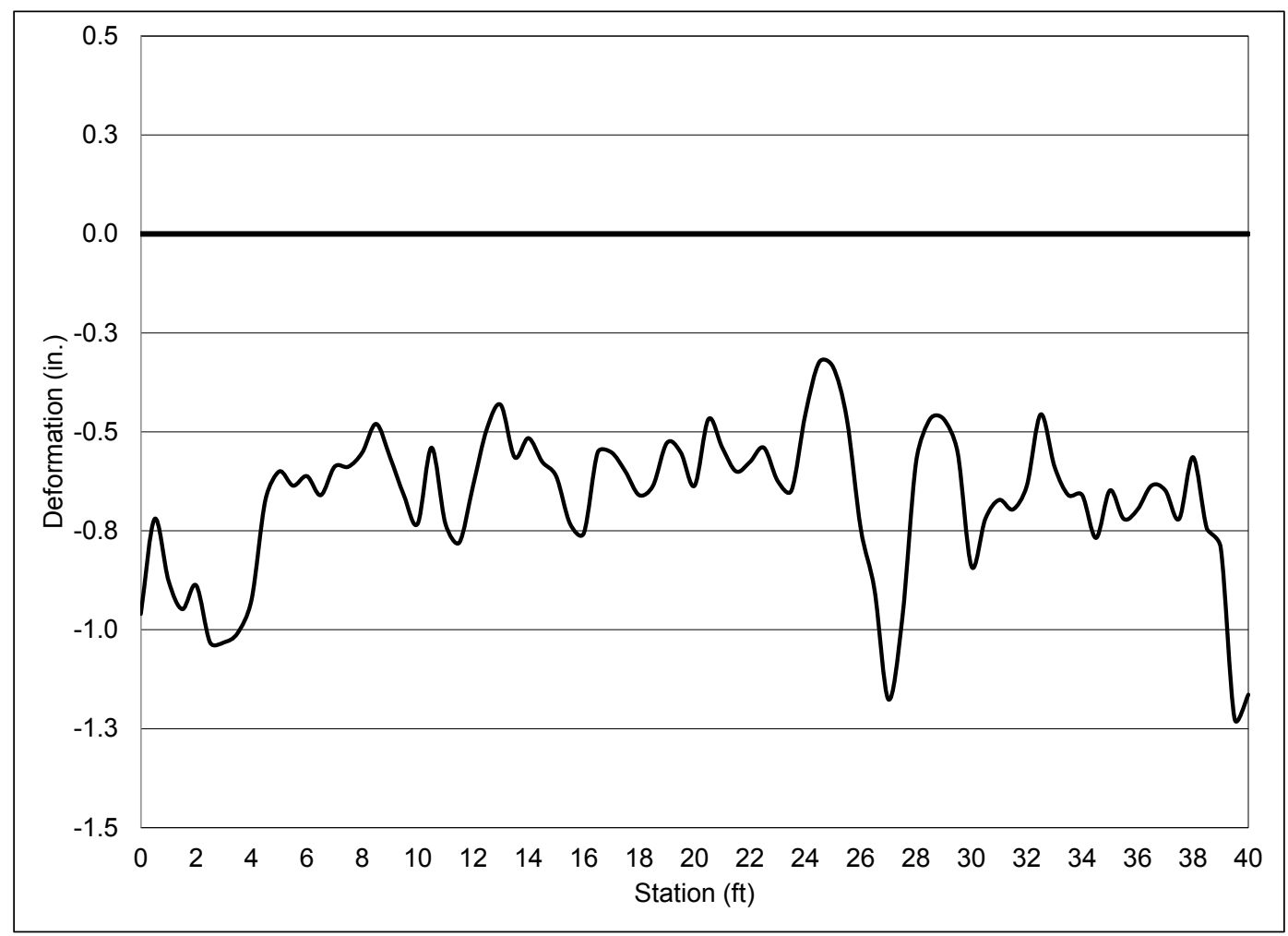


Figure 73. Subgrade centerline profile of the C-17 item after 1,308 passes.

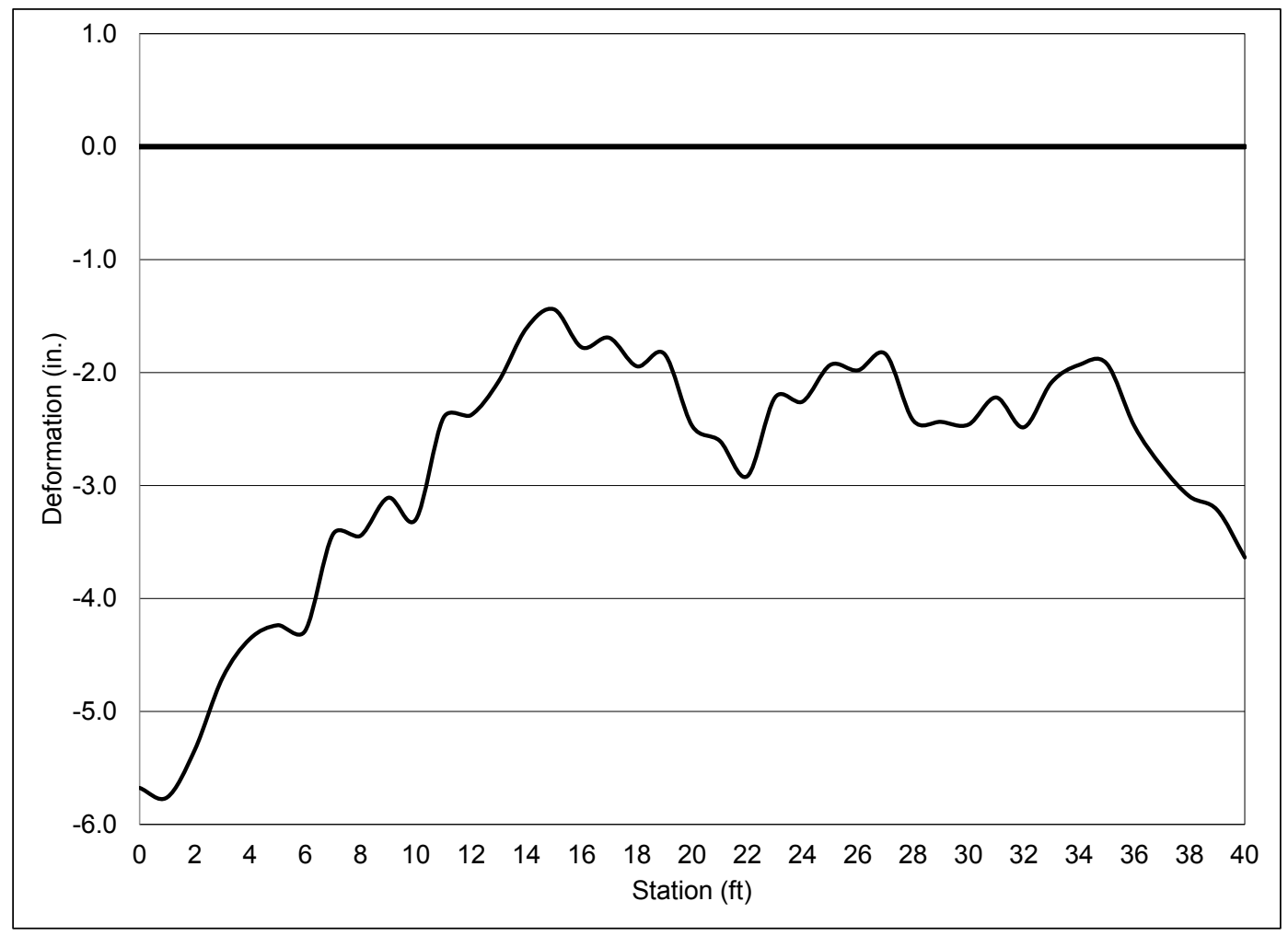

Figure 74. Centerline profile on the mat surface of the F-15E item at different pass levels.

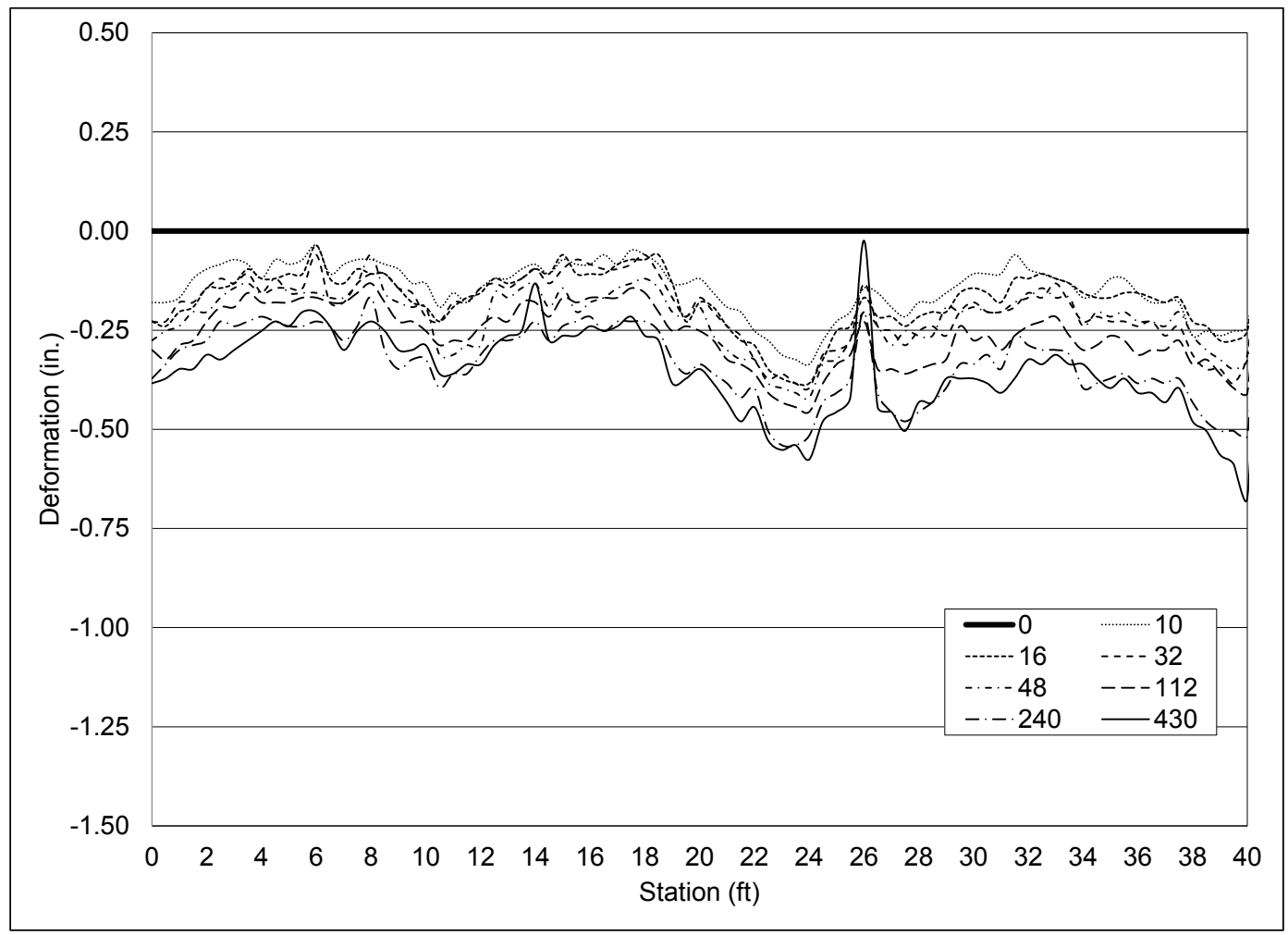


Figure 75. Centerline profile on the mat surface of the $\mathrm{C}-17$ item at different pass levels.

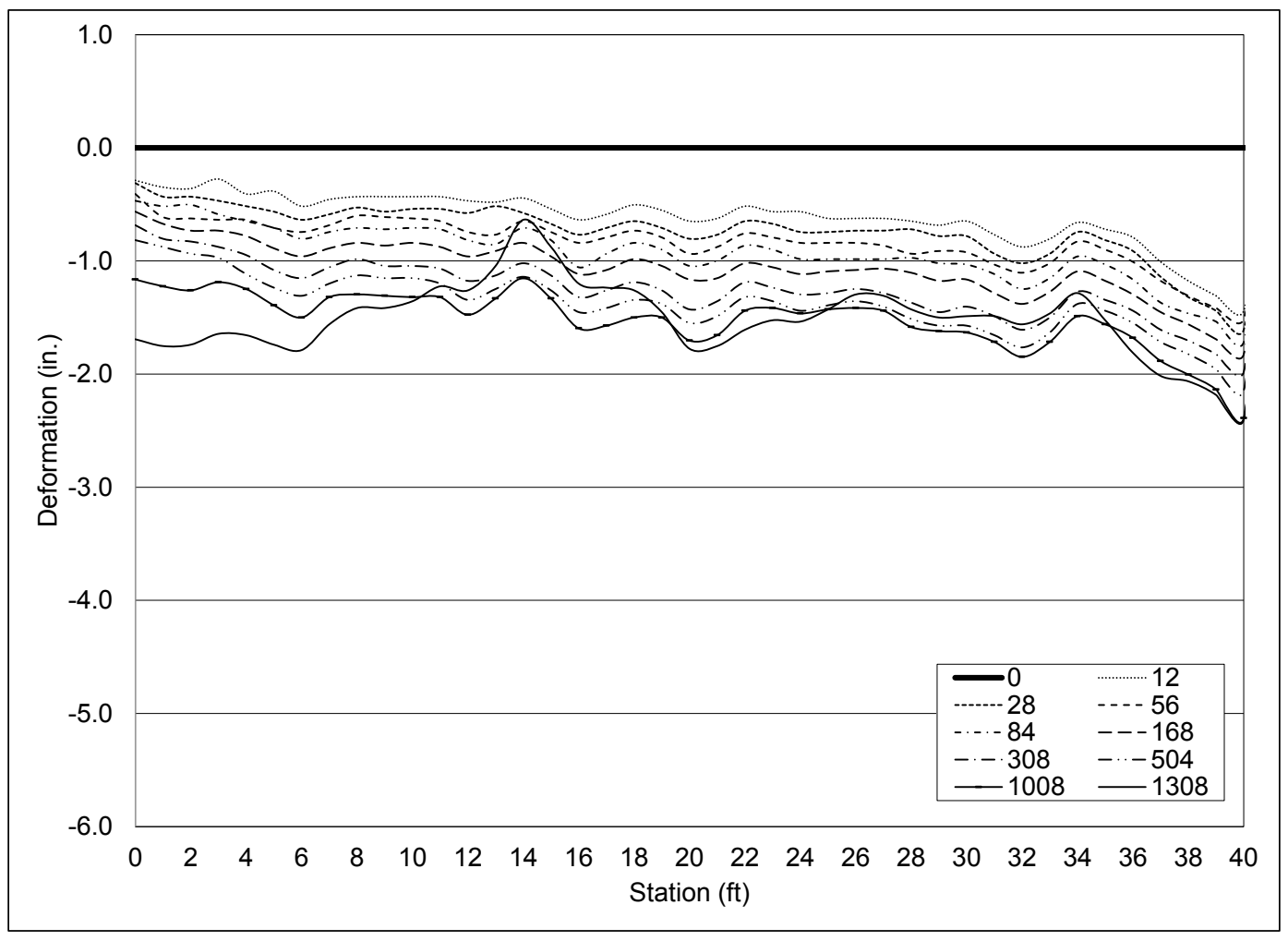

Figure 76. Average deformation on the subgrade of the F-15E item.

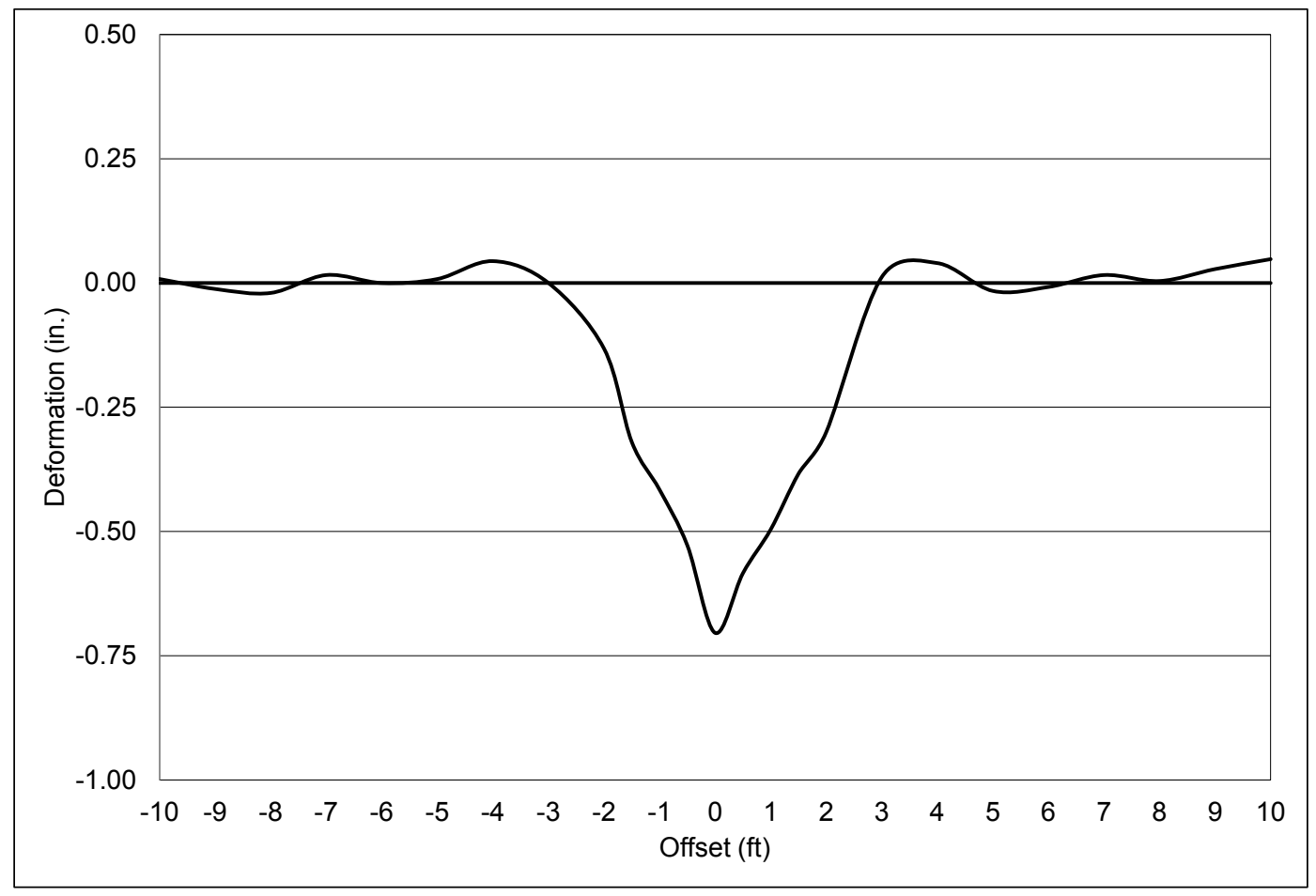


Figure 77. Average deformation on the subgrade of the C-17 item after 1,308 passes.

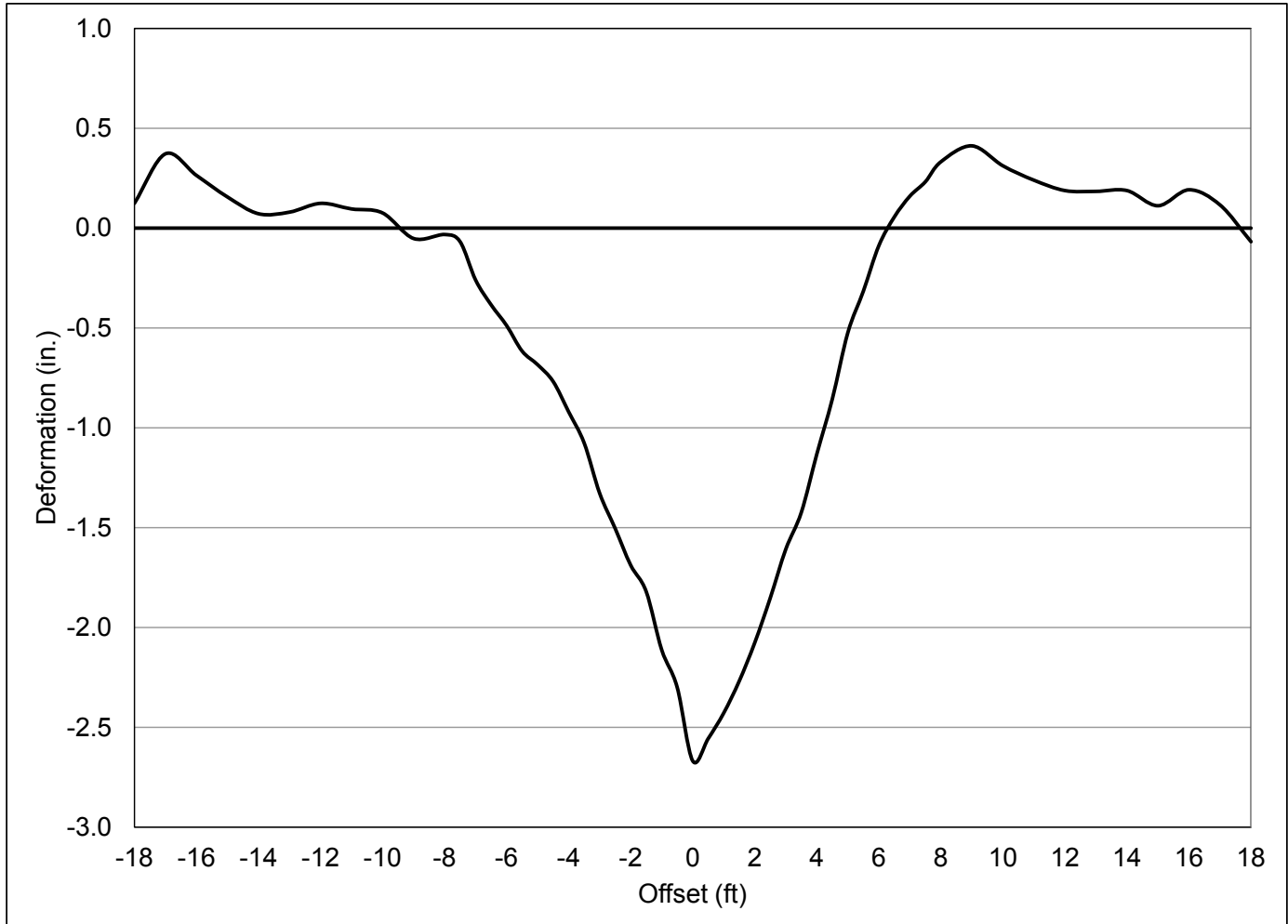

Figure 78. Average deformation on the loaded mat surface of the F-15E item at different pass levels.

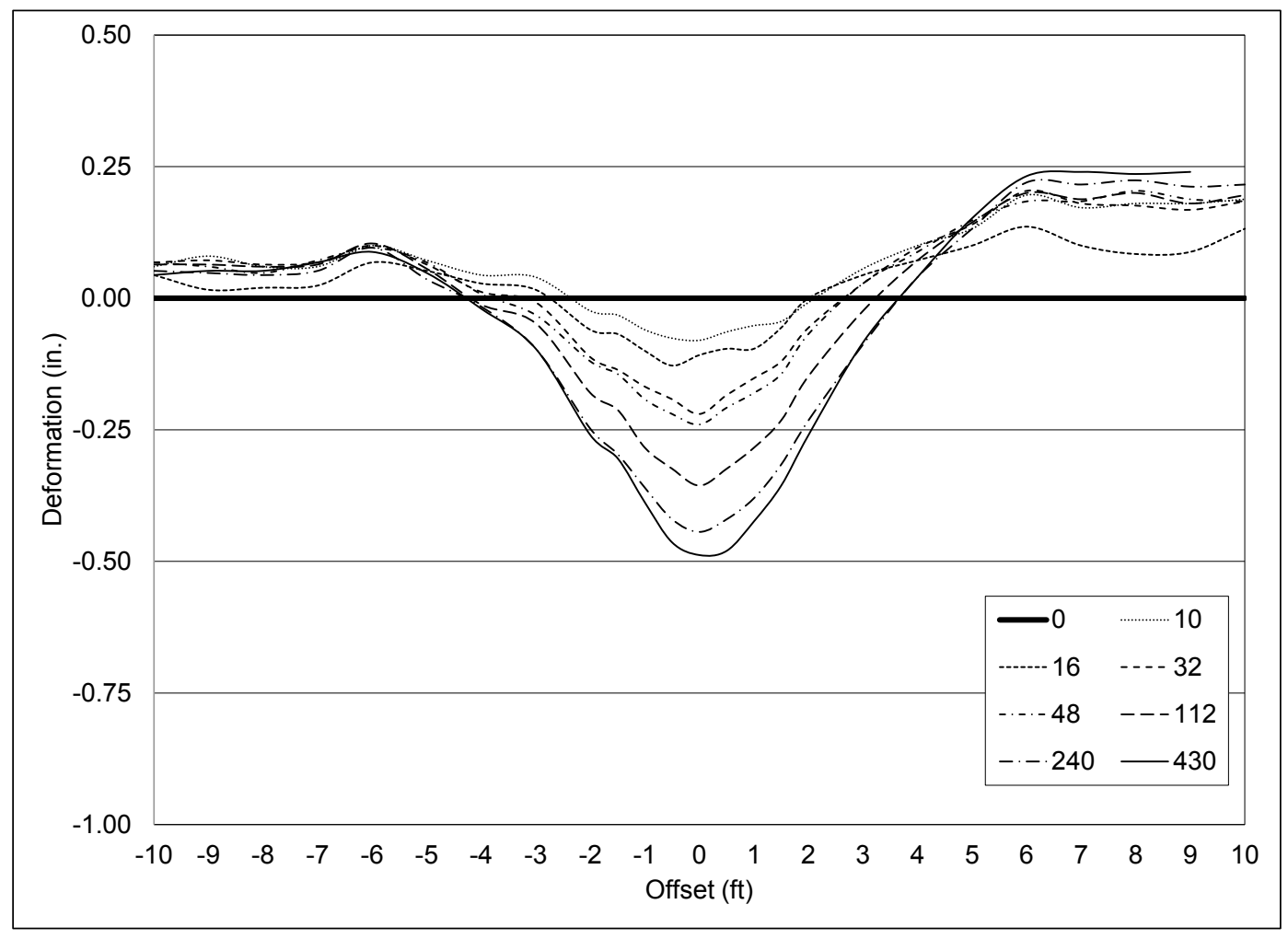


Figure 79. Average deformation on the loaded mat surface of the $\mathrm{C}-17$ item at different pass levels.

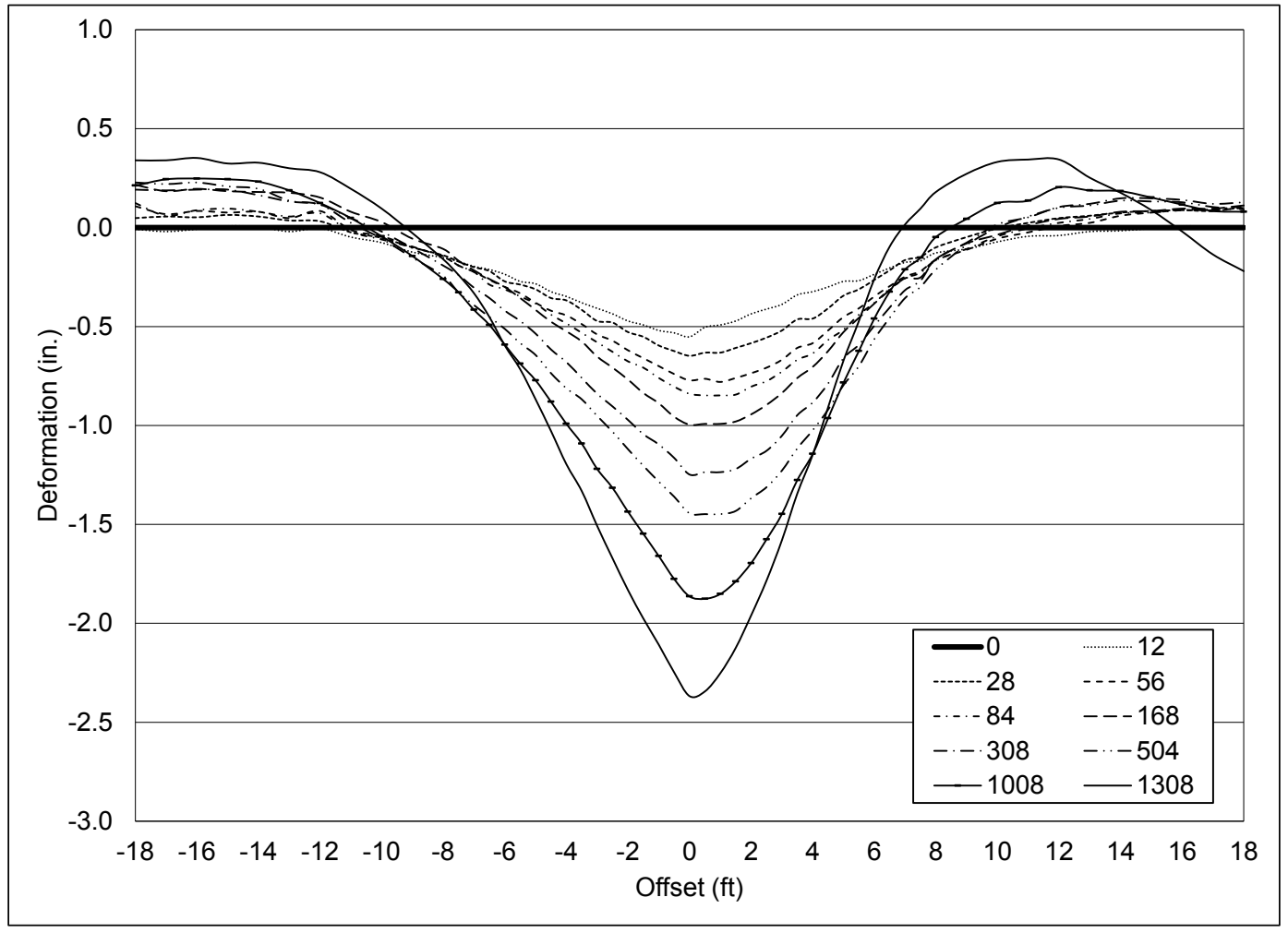

Figure 80. Average deformation on the unloaded mat surface of the F-15E item at different pass levels.

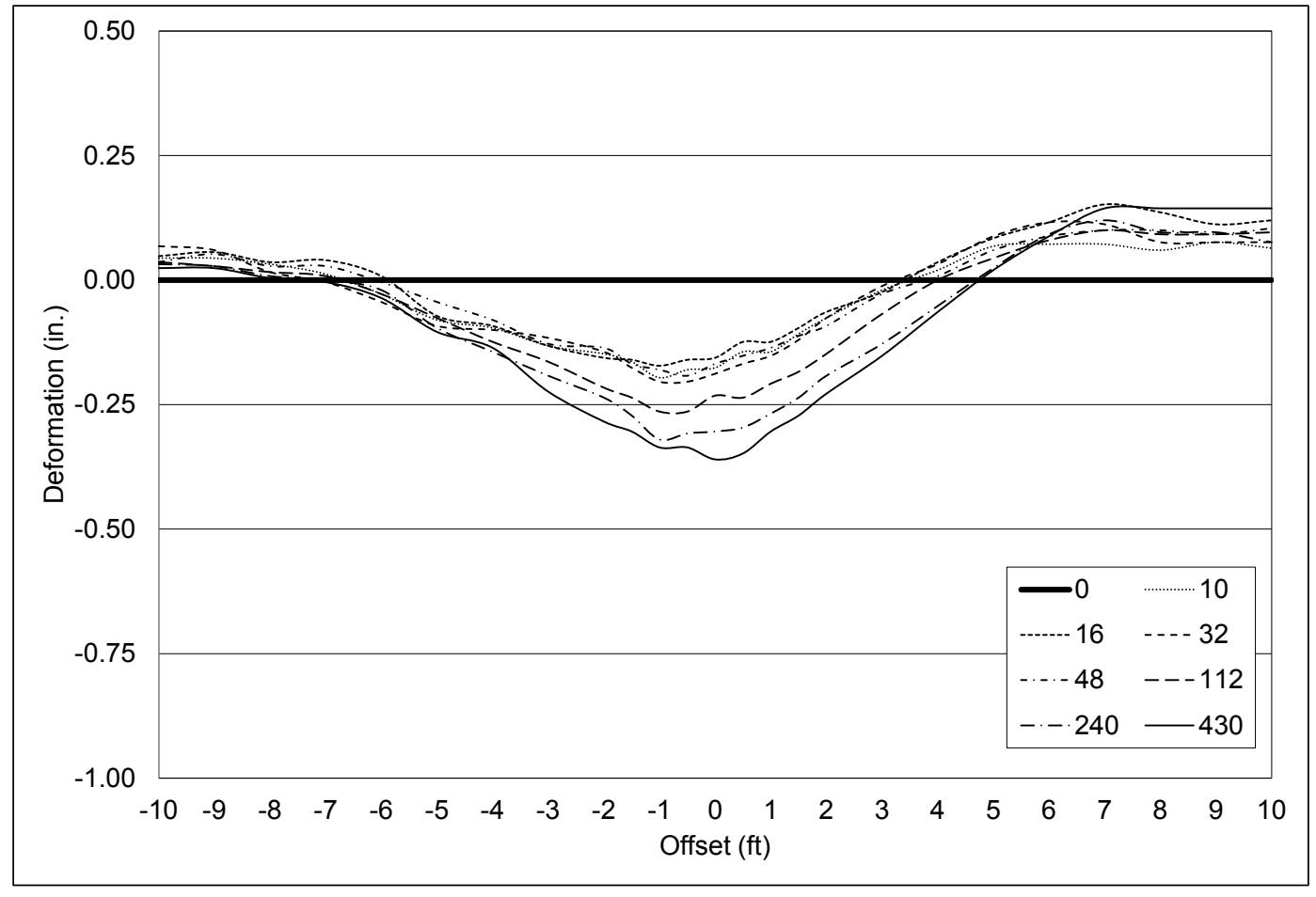


Figure 81. Average deformation on the unloaded mat surface of the $\mathrm{C}-17$ item at different pass levels.

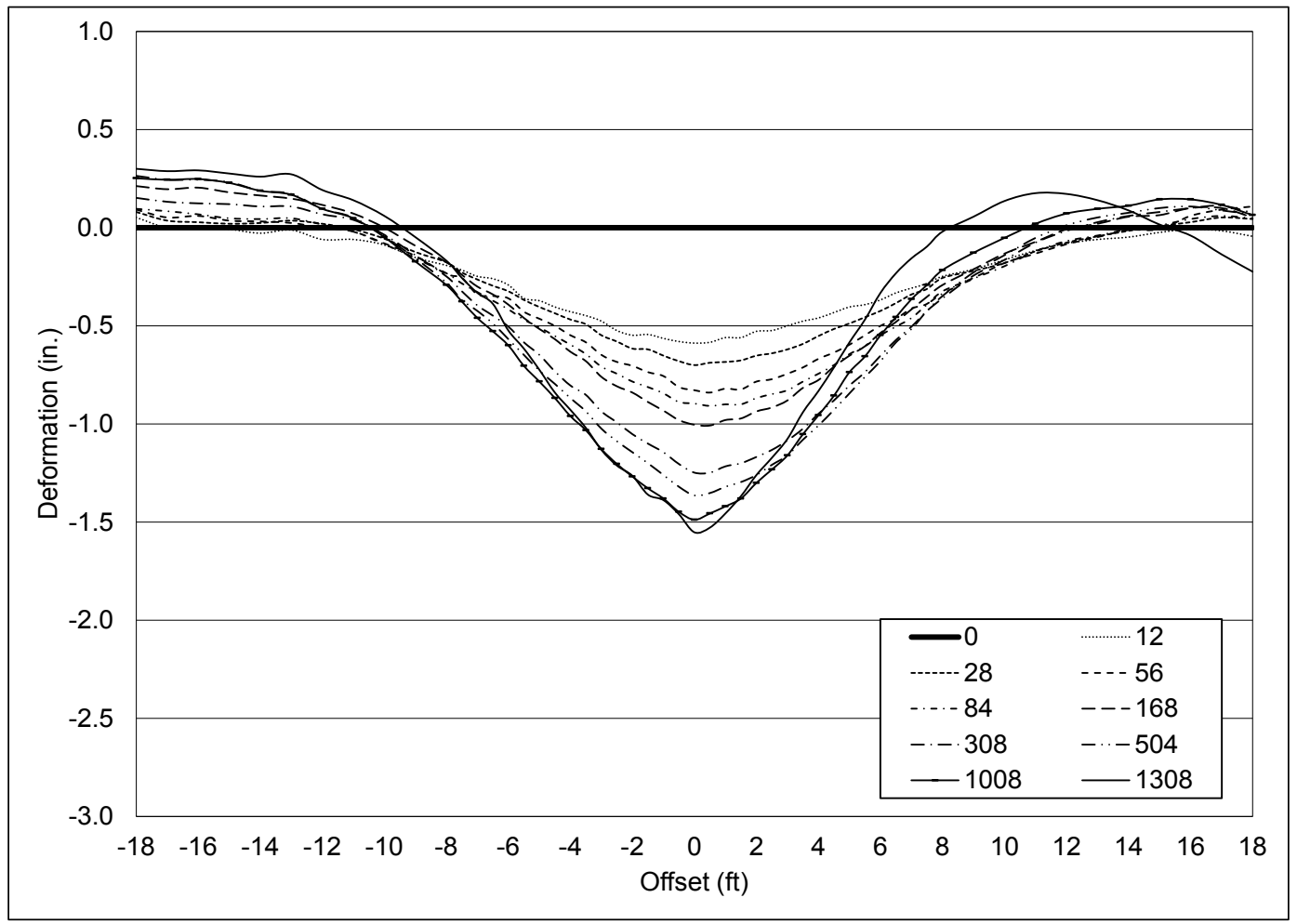

\subsection{Elastic deflection}

Examples of the raw data as collected are shown in Figures 82 and 83. These data were collected dynamically at scheduled pass intervals throughout trafficking. The data were reduced by evaluating the elevation measurements within 3 in. from the centerline, as shown as boundaries in Figure 82 and depicted as elevations in Figure 52. Calculations determined the average elevation of points within \pm 3 in. of each centerline profile elevation location in terms of northing. The calculated average elevation corresponding to each station was then subtracted from measurements taken on the unloaded mat surface at the same location. For example, the average of dynamic deflections at each station for Passes 1 through 10 was subtracted from the unloaded centerline profile recordings at each station collected at pass 10 . The difference in the loaded and unloaded measurements is the elastic deflection, or rebound, of the mat and subgrade as the test wheel moved over the surface. The average elastic deflection at each station for each data collection interval is shown in Figure 84. For the F-15E item, the elastic deflection increased from 1 in. to 1.25 in. throughout testing. Elastic deflection was not measured at the end of the test (430 passes) to prevent damage to the $\mathrm{F}-15 \mathrm{E}$ tire by tire hazards present in the traffic lane. 
Figure 82. Elastic deflection measurements' wander distribution on F-15E item, passes 1-10.

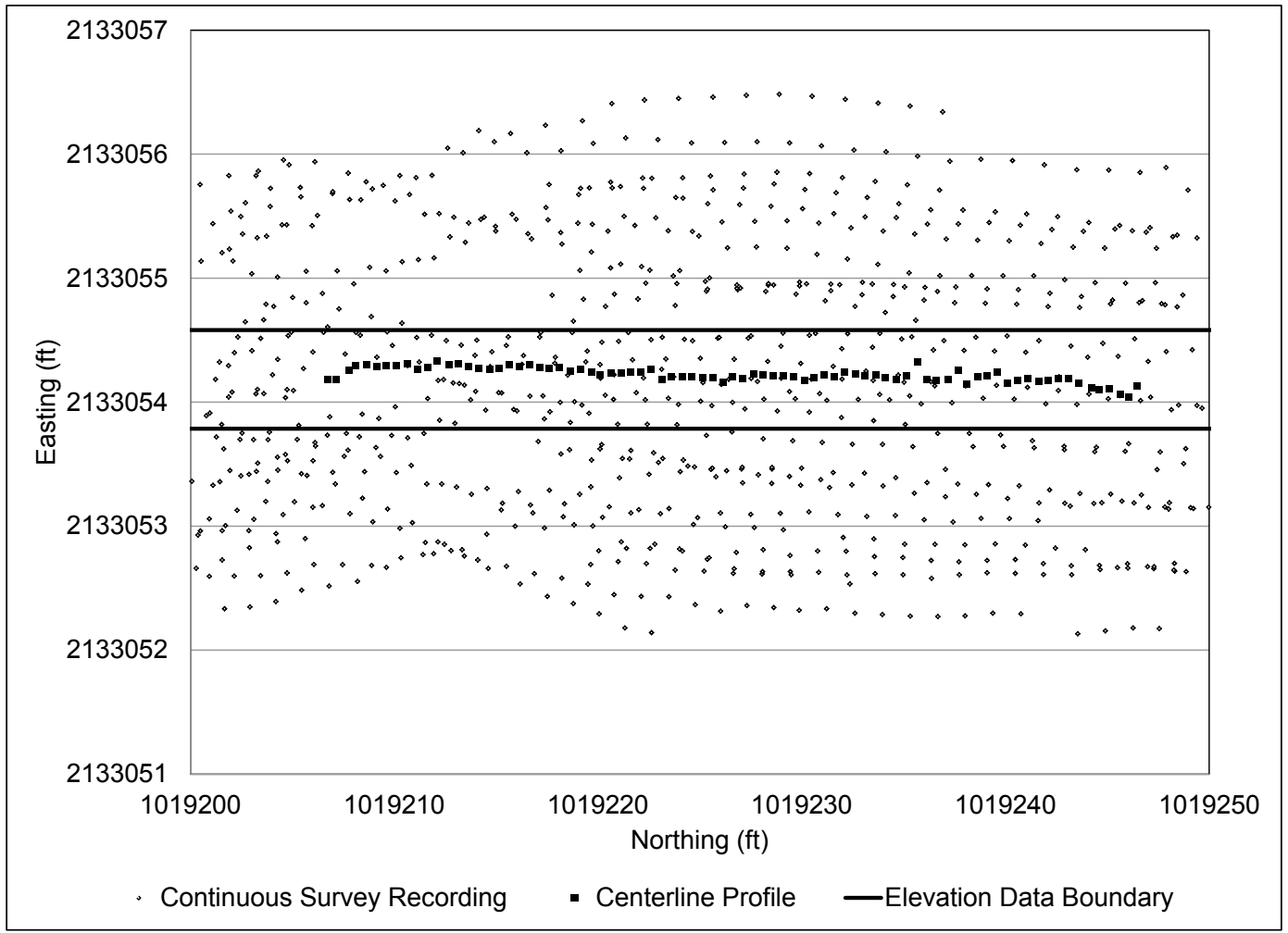

Figure 83. Elastic deflection elevation distribution on F-15E item.

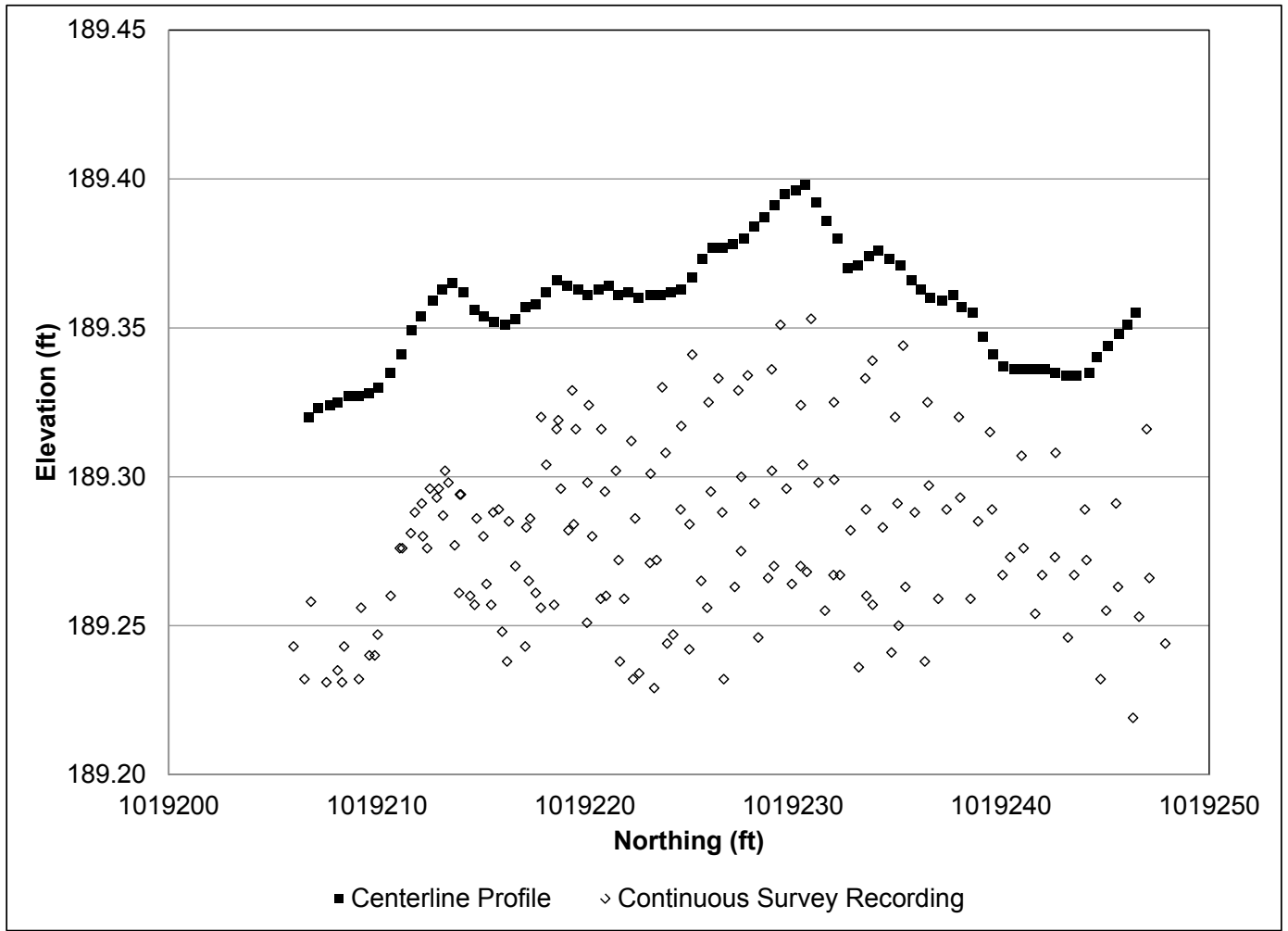


Figure 84. Elastic deflection on F-15E item mat surface at various pass levels.

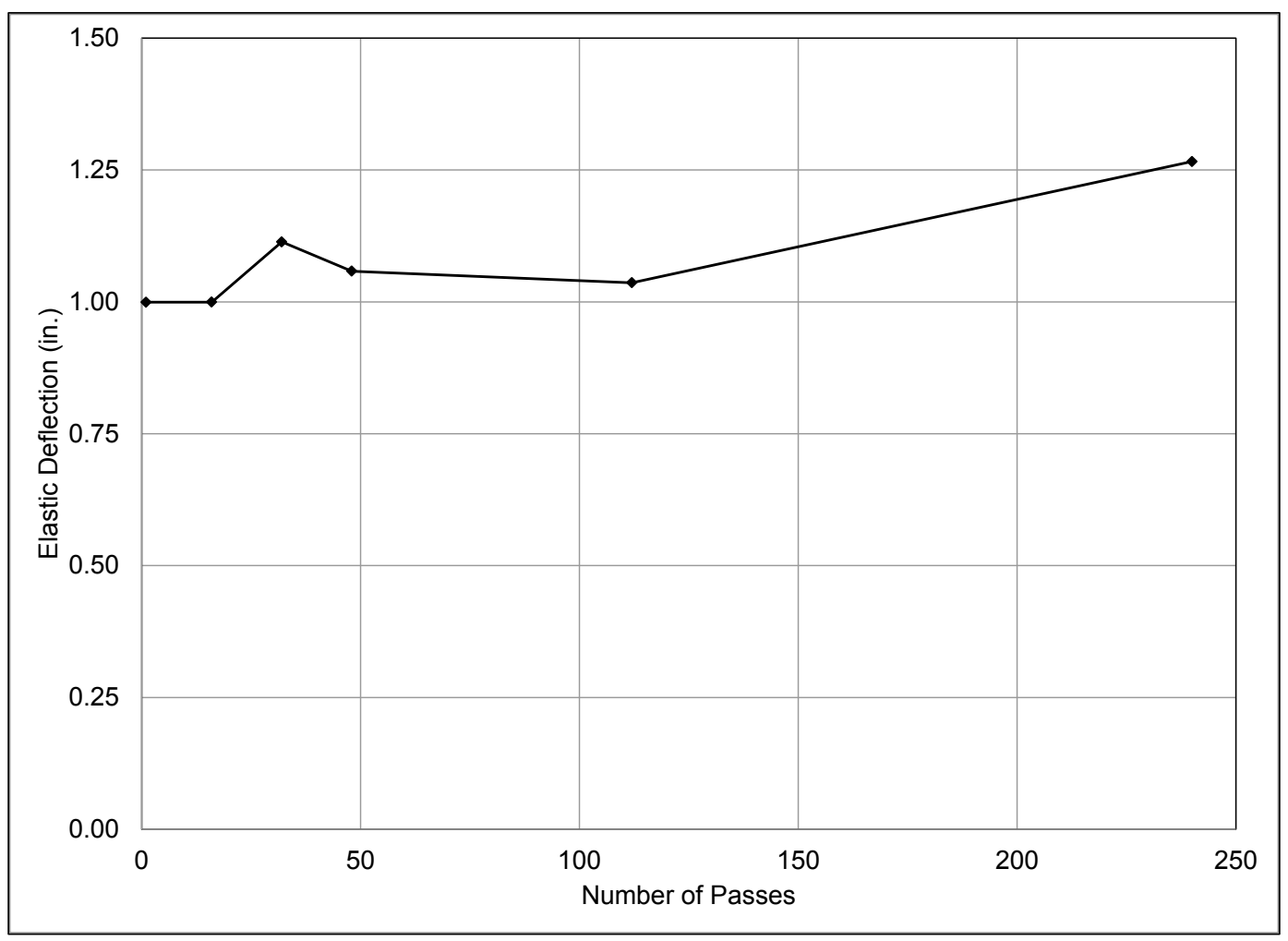

\subsection{Earth pressure cell data}

Examples of the data collected for each EPC are shown in Figures 85 through 92. Each of the F-15E item examples represents approximately 16,000 data points collected by the EPCs during passes 1 through 10 of F${ }_{15} \mathrm{E}$ traffic. Each of the $\mathrm{C}-17$ item examples represents approximately 18, ooo data points collected by the EPCs during passes 1 through 12 of C17 traffic. For the F-15E examples, each of the large peaks in these graphs represents one pass by the load cart. The smaller peaks in Figure 85 represent the drive wheels of the load cart prime mover, which were easily detected by EPC F1 since its location was offset $3 \mathrm{ft}$ from the centerline. Similar response can be seen in Figure 86 by EPC F2 and Figure 87 by EPC F3. For the $\mathrm{C}-17$ examples, each pair of large peaks represents a single pass of the load cart, since the six-wheel gear has two load carrying axles. The smaller peaks represent the drive wheels of the load tractor. The wander pattern used during trafficking is evident from the peaks' increase as the load cart moved toward the gauge location in the center and their decrease as the load cart moved laterally away from the gauge. During the test, EPCs $\mathrm{C}_{3}, \mathrm{C}_{4}, \mathrm{C}_{2}$, and $\mathrm{C}_{1}$ in the $\mathrm{C}-17$ item malfunctioned after pass 168 , 168,784 , and 1,215 , respectively. 
Figure 85. Measured data for EPC F1, passes 1-10.

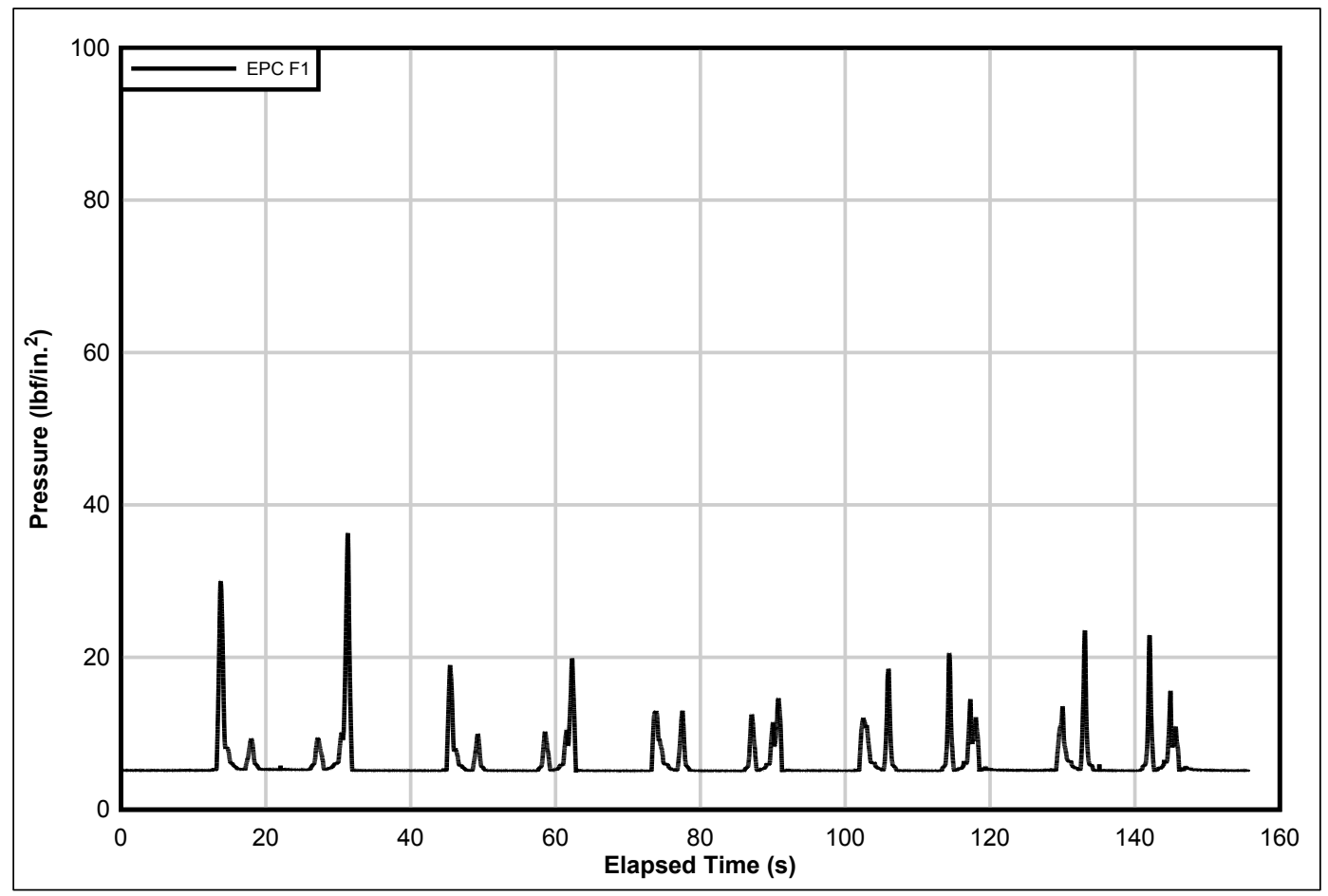

Figure 86. Measured data for EPC F2, passes 1-10.

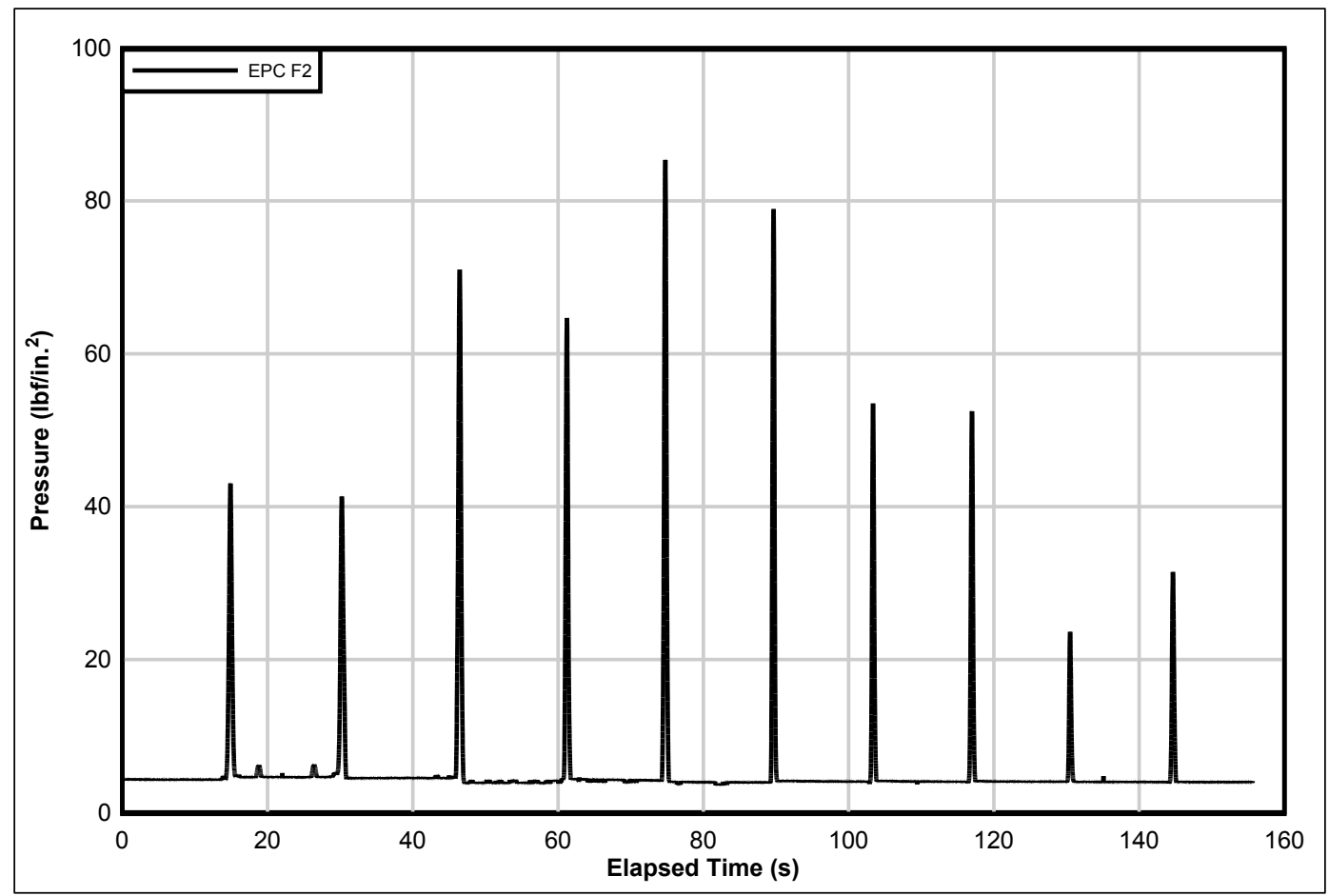


Figure 87. Measured data for EPC F3, passes 1-10.

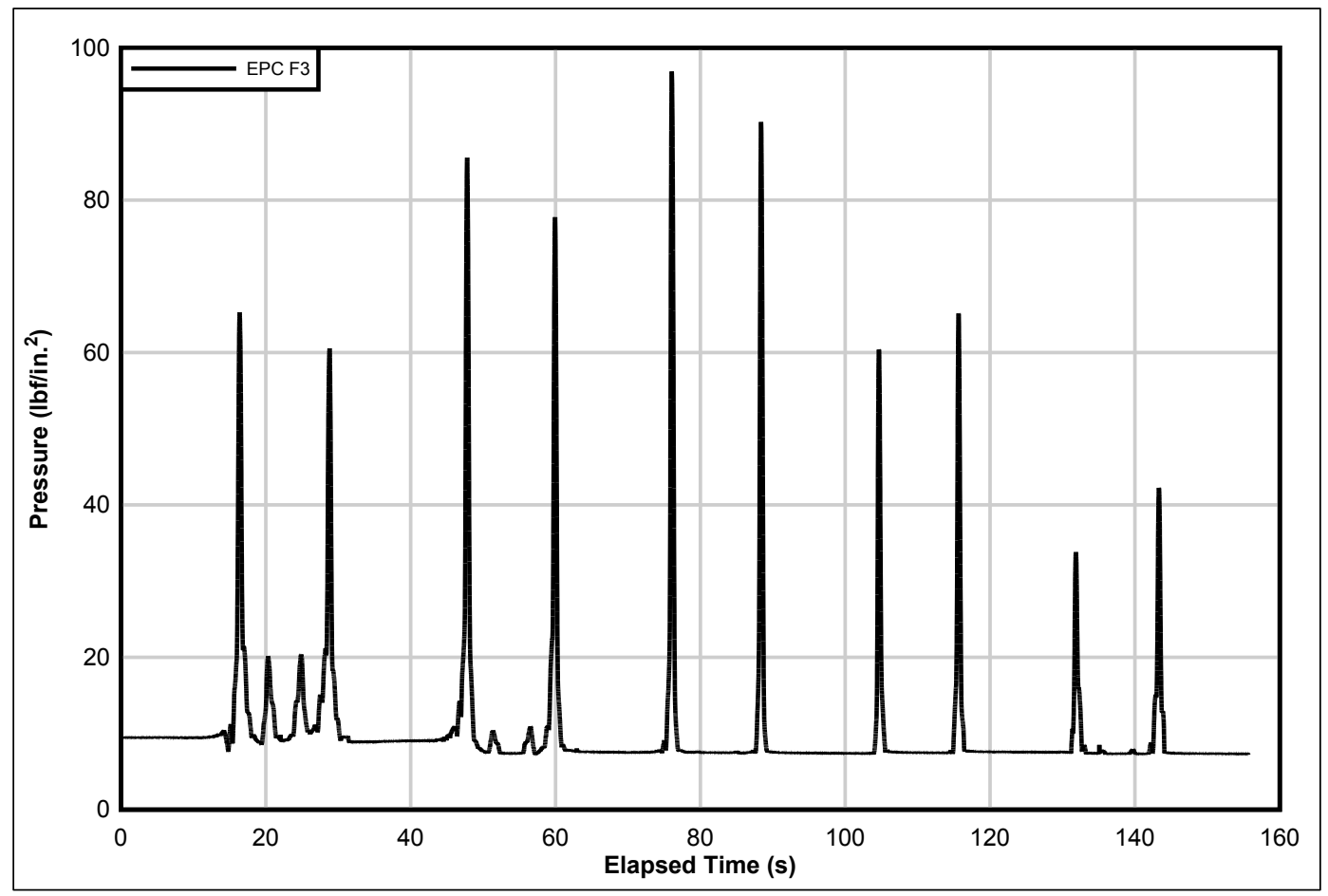

Figure 88. Measured data for EPC F4, passes 1-10.

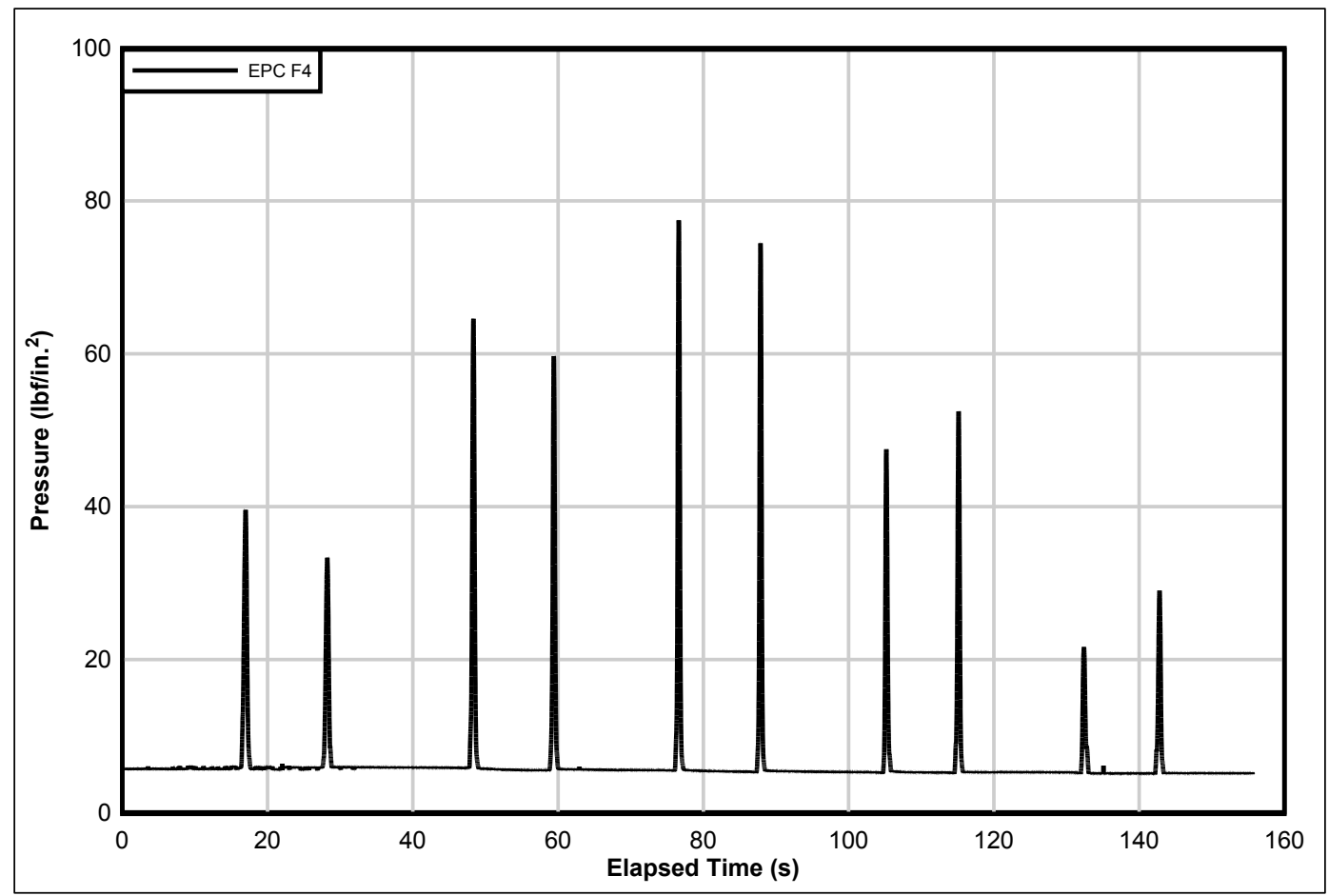


Figure 89. Measured data for EPC C1, passes 1-12.

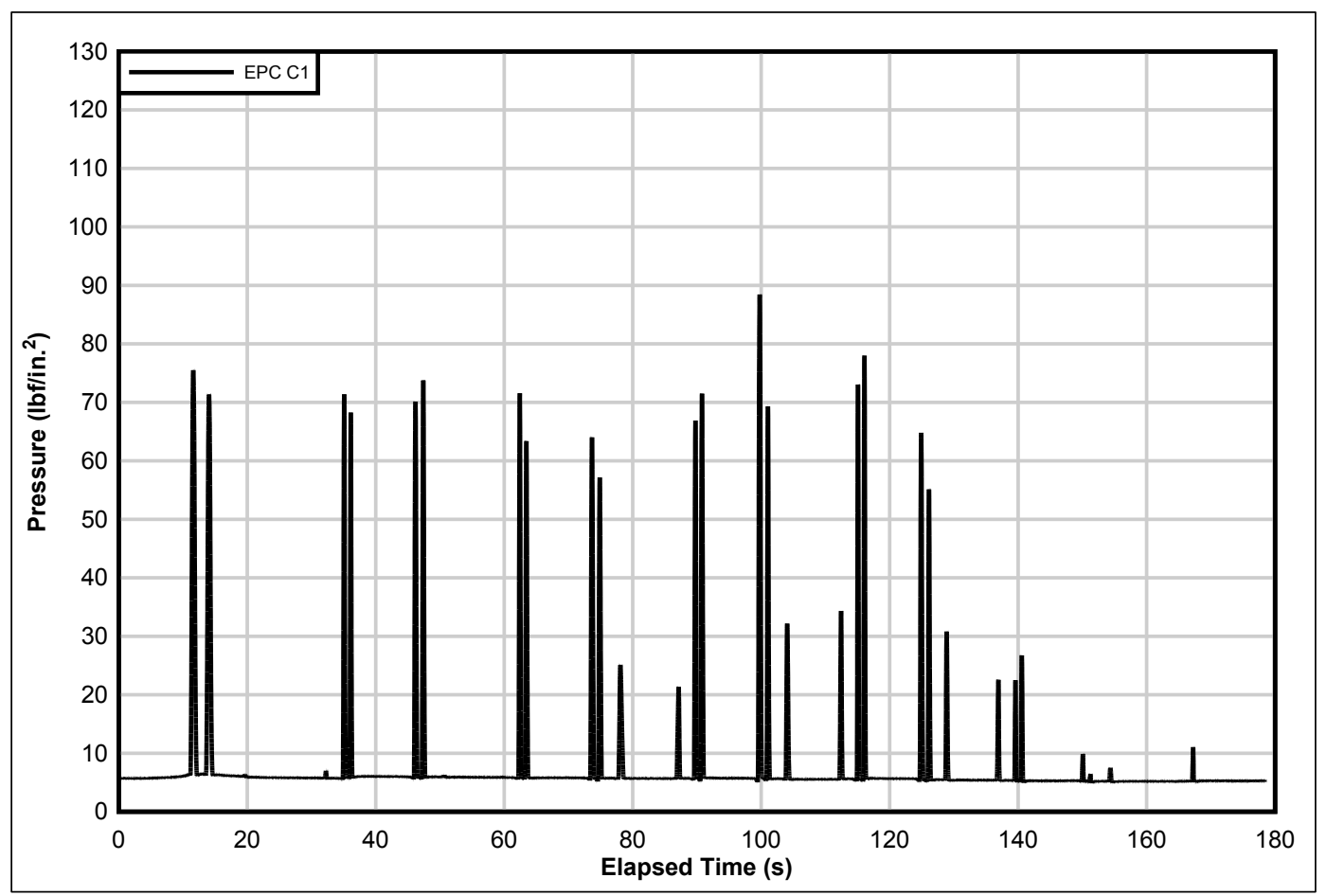

Figure 90. Measured data for EPC C2, passes 1-12.

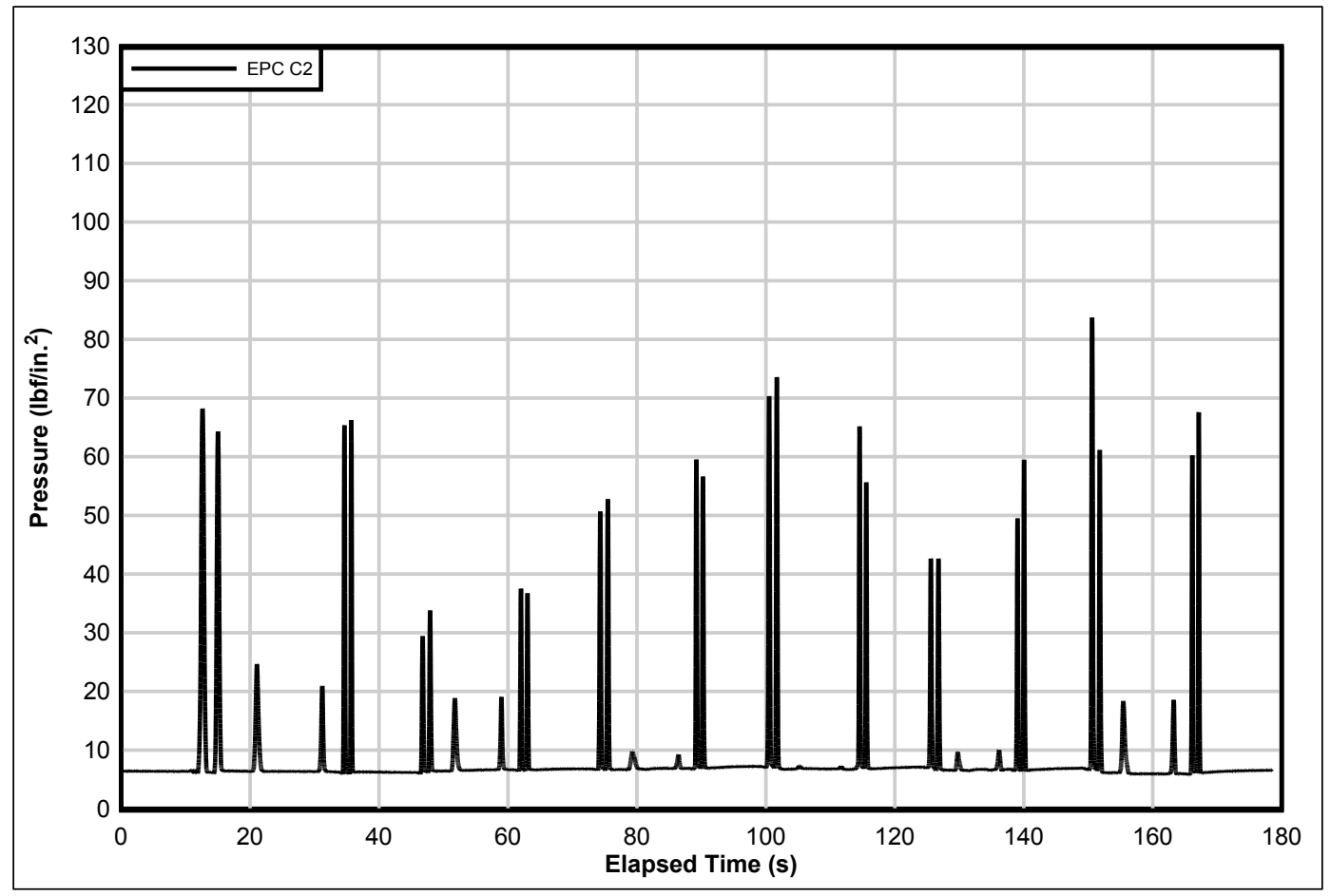


Figure 91. Measured data for EPC C3, passes 1-12.

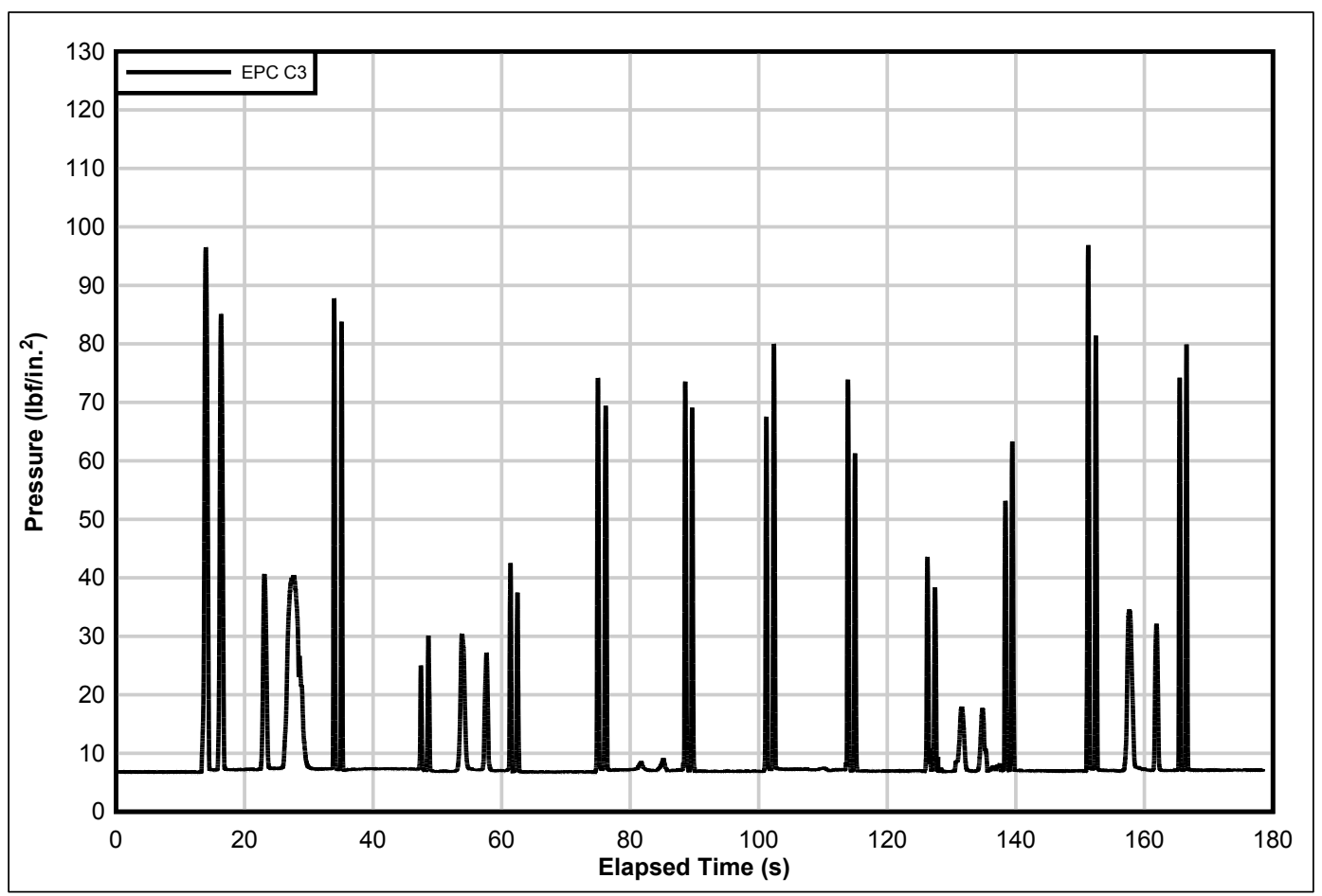

Figure 92. Measured data for EPC C4, passes 1-12.

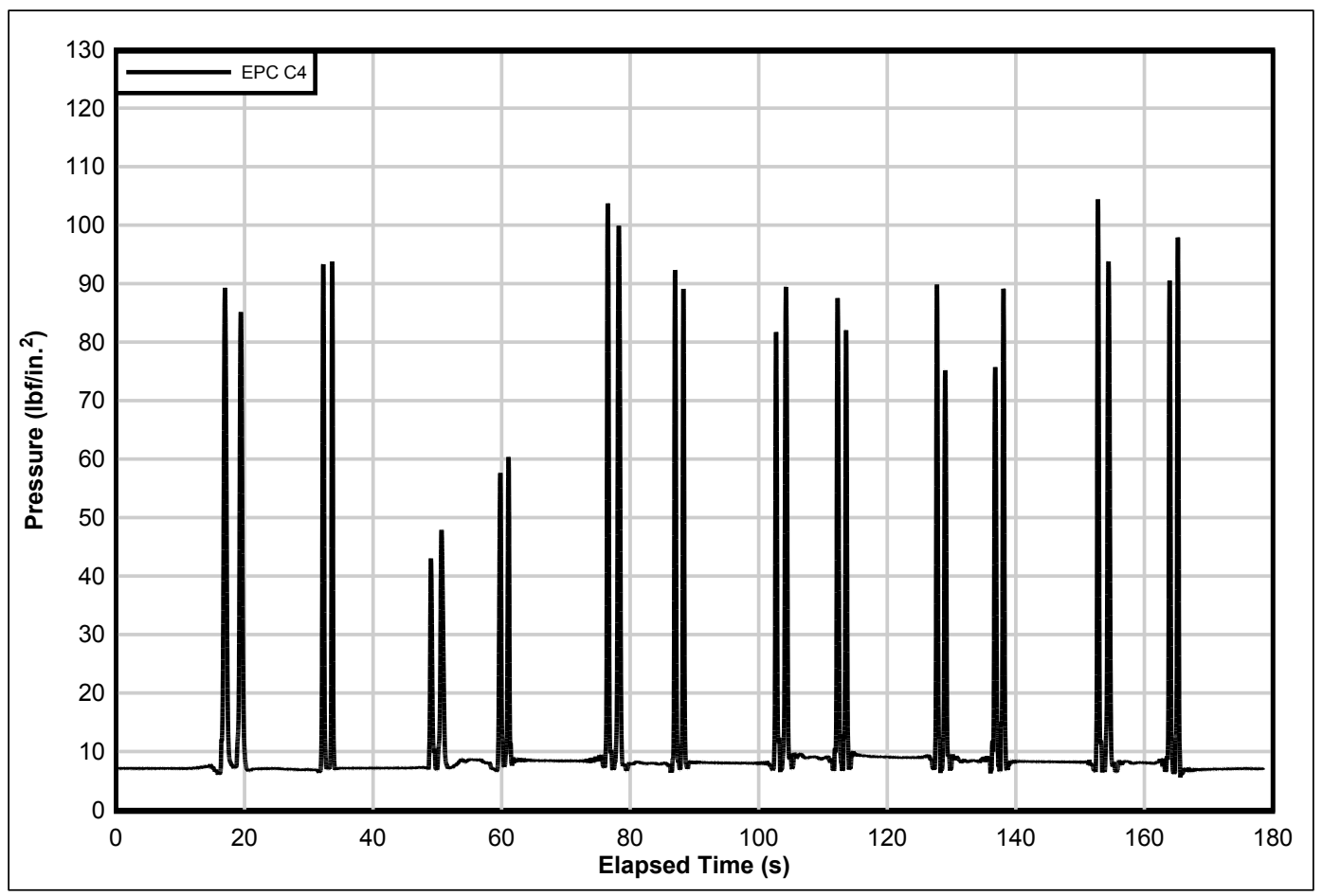

The horizontal distribution of pressures can also be inferred from the examples of the raw data. For example, Figure 86 illustrates the pressure response during the first 10 passes of a complete wander pattern 
(16 passes). Trafficking started in an outside lane and worked laterally across the traffic area. The first two peaks depict an EPC response of about $42 \mathrm{lbf} / \mathrm{in}^{2}{ }^{2}$ as the load cart traveled back and forth in a lane located about $18 \mathrm{in}$. from the traffic centerline. The third and fourth peaks represent the load cart traveling in a traffic lane adjacent to the center, with a distance of about $9 \mathrm{in}$. from the centerline. Pressure values recorded for these two passes were approximately $70 \mathrm{lbf} / \mathrm{in} .^{2}$. The fifth and sixth peaks represent the load cart traveling down the center lane with pressure values measuring approximately $80 \mathrm{lbf} /$ in. $^{2}$. The pressure values recorded in the entire data set are included in Appendix A and Appendix B.

Figures 93 and 94 are graphical summaries of the maximum normalized pressure values measured throughout traffic for the F-15E and C-17 items, respectively. These summarized data have been normalized to only show the influence of the load cart on the subgrade by removing the effects of soil overburden pressure. Table 19 summarizes the range of maximum normalized pressure values for each of the EPCs throughout the test.

Figure 93. Summary of normalized maximum pressure for the F-15E item.

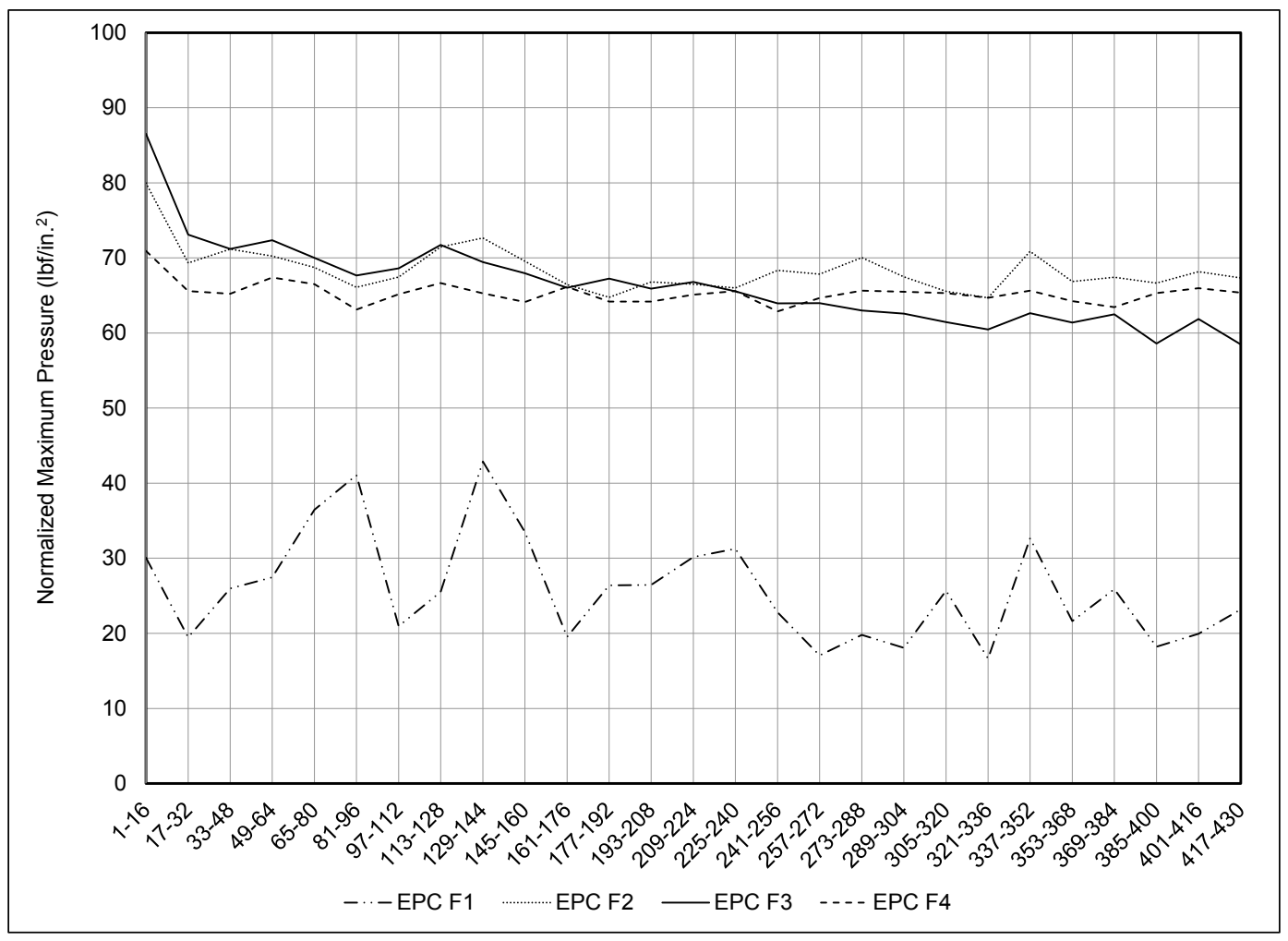


Figure 94. Summary of normalized maximum pressure for the C-17 item.

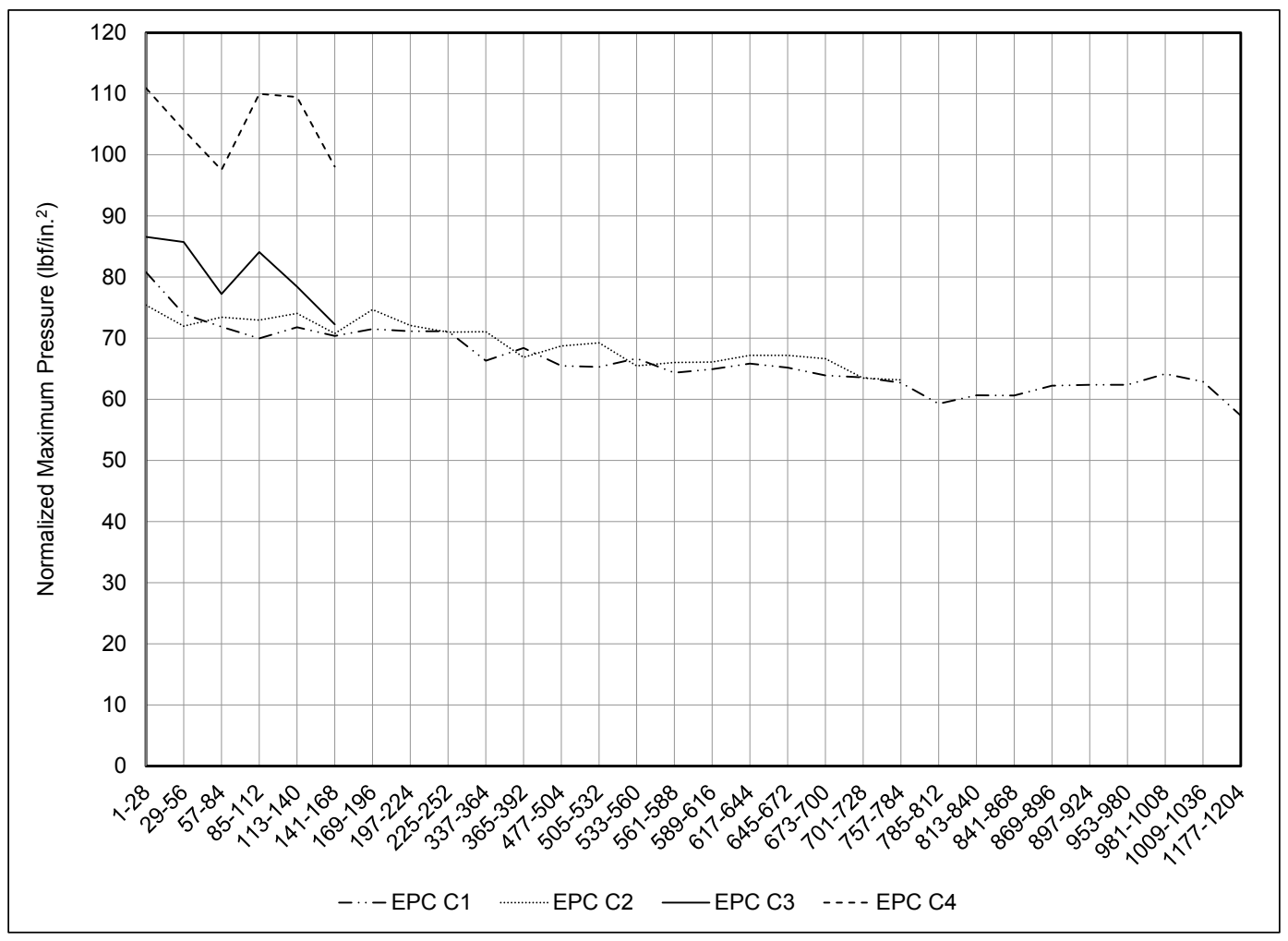

Table 19. Maximum normalized pressure ranges during each test.

\begin{tabular}{|l|l|l|l|l|}
\hline $\begin{array}{l}\text { Test } \\
\text { Item }\end{array}$ & EPC & $\begin{array}{l}\text { Pass number EPC } \\
\text { malfunctioned }\end{array}$ & $\begin{array}{l}\text { Range in maximum } \\
\text { pressure (lbf/in. }{ }^{2} \text { ) }\end{array}$ & $\begin{array}{l}\text { Average maximum } \\
\text { pressure (lbf/in. }{ }^{2}\end{array}$ \\
\hline \multirow{5}{*}{ F-15E } & F1 & - & $17-43$ & 26 \\
\cline { 2 - 5 } & F2 & - & $65-80$ & 68 \\
\cline { 2 - 5 } & F3 & - & $58-87$ & 66 \\
\cline { 2 - 5 } & F4 & - & $63-71$ & 65 \\
\hline \multirow{4}{*}{ C-17 } & C1 & 1,215 & $57-81$ & 66 \\
\cline { 2 - 6 } & C2 & 784 & $63-75$ & 69 \\
\cline { 2 - 5 } & C3 & 168 & $72-87$ & 81 \\
\cline { 2 - 5 } & C4* & 168 & $98-111$ & 105 \\
\hline
\end{tabular}

*questionable results

For the F-15E item, the maximum pressures values for EPCs placed under the centerline were similar in value and generally remained constant throughout the test. EPC F1, placed $3 \mathrm{ft}$ offset from the centerline and centered under a male/female joint, recorded lower pressure values compared to the other EPCs and showed no clear, general trend (i.e., increasing, decreasing, or constant) in pressure readings throughout traffic. 
For the $\mathrm{C}-17$ item, the maximum pressures measured by EPCs $\mathrm{C} 1$ and $\mathrm{C} 2$ were similar in value throughout the test. $\mathrm{EPC} \mathrm{C}_{3}$ malfunctioned after 168 passes, but measured slightly higher values than EPCs $\mathrm{C}_{1}$ and $\mathrm{C} 2$. Maximum pressures measured at EPC $\mathrm{C}_{4}$ were higher than in other areas and varied between 98 and $111 \mathrm{lbf} /$ in. $^{2}$ until it malfunctioned after 168 passes.

\subsection{Strain gauge data}

Example plots of the strain gauge raw data for the $\mathrm{F}-15 \mathrm{E}$ and $\mathrm{C}-17$ items are shown in Figures 95 and 96, respectively. Figure 95 represents the response from the first ten passes of $\mathrm{F}-15 \mathrm{E}$ traffic from a gauge installed on the upper underlap of Panel B73. Each of the positive peaks represents tensile strains, and the negative peaks represent compressive strains. Each of the ten passes can be associated with a measured peak. Since the distributed traffic pattern began on the east side of the gauge location, the gauge did not measure significant tensile strains during the first two passes. The data set validates that the load moved to the west side of the joint on pass seven, where there is a shift to compressive strains that decrease in magnitude as the load moves further from the gauge. The changing magnitude of the peaks was caused by the wander pattern used to simulate a normal distribution of traffic over the test section. The higher peaks indicate that the load cart was located adjacent to the strain gauge.

Figure 96 represents raw data collected for the first 12 passes of the 6wheeled C-17 load cart from a strain gauge mounted on the lower overlap rail of Panel B49. Each pass is indicated by two large peaks and one small peak, representing the two main axles of the $\mathrm{C}-17$ and the drive axle of the scraper engine used to pull the simulator, respectively. Since the distributed traffic pattern began on the east side of the gauge location, the gauge did not measure significant tensile strains during the first four passes. The data set validates that the load moved closer the joint on pass six, where there is a baseline shift indicating permanent deformation and large compressive strains. The magnitudes of the peaks when the load is on the west are observed to be higher, which is expected, since the gauge was mounted on a panel west of the centerline. The changing magnitude of the peaks is an indicator of the wander pattern associated with the load cart; however, the pattern is not as obvious when compared to that of the F-15E load cart, since the multiple-wheel C-17 simulator distributes the load over a larger area. 
Figure 95. Strain gauge data for F-15E item, SG B73-F2, passes 1-10.

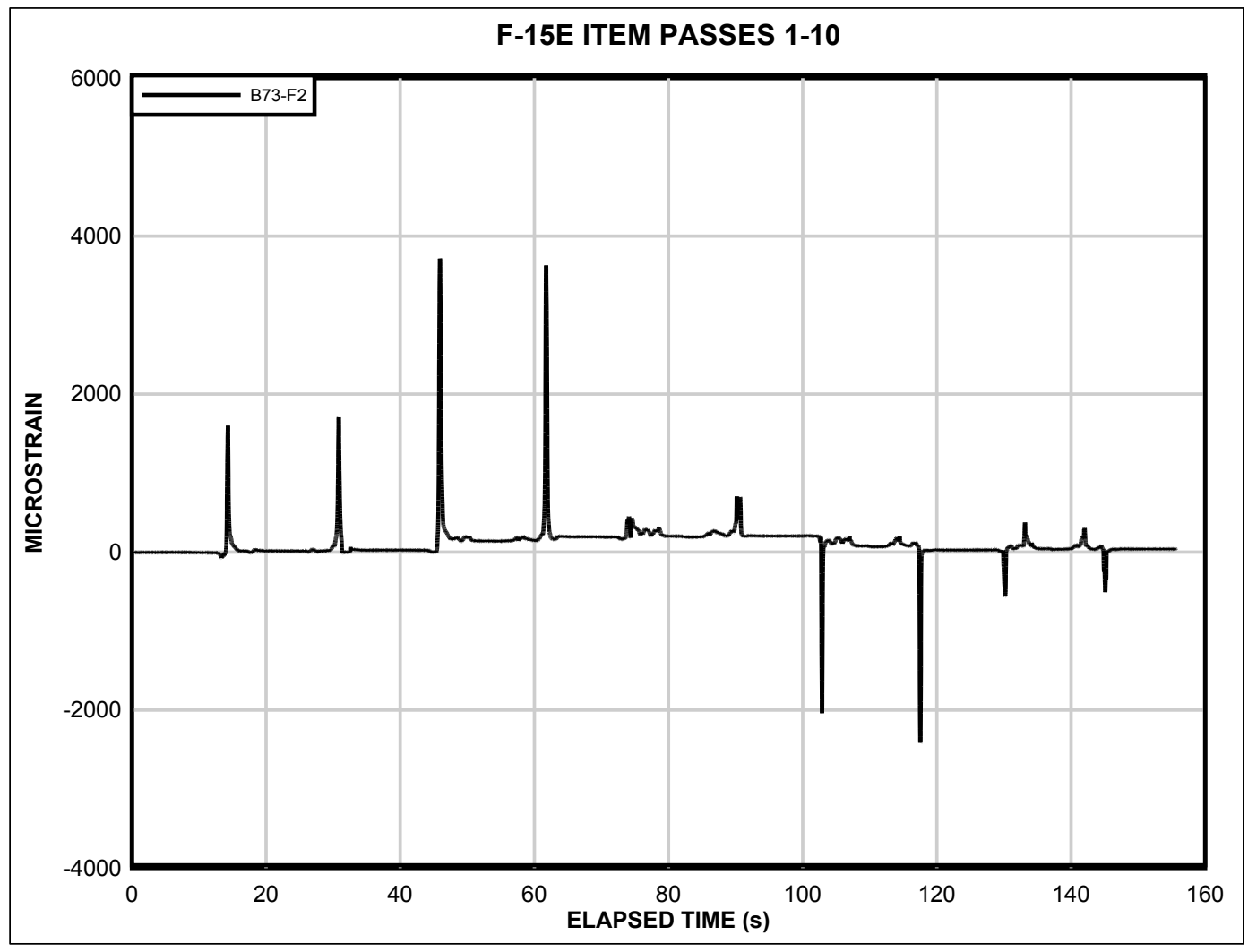

Figure 96. Strain gauge data for C-17 item, SG B49-F1, passes 1-12.

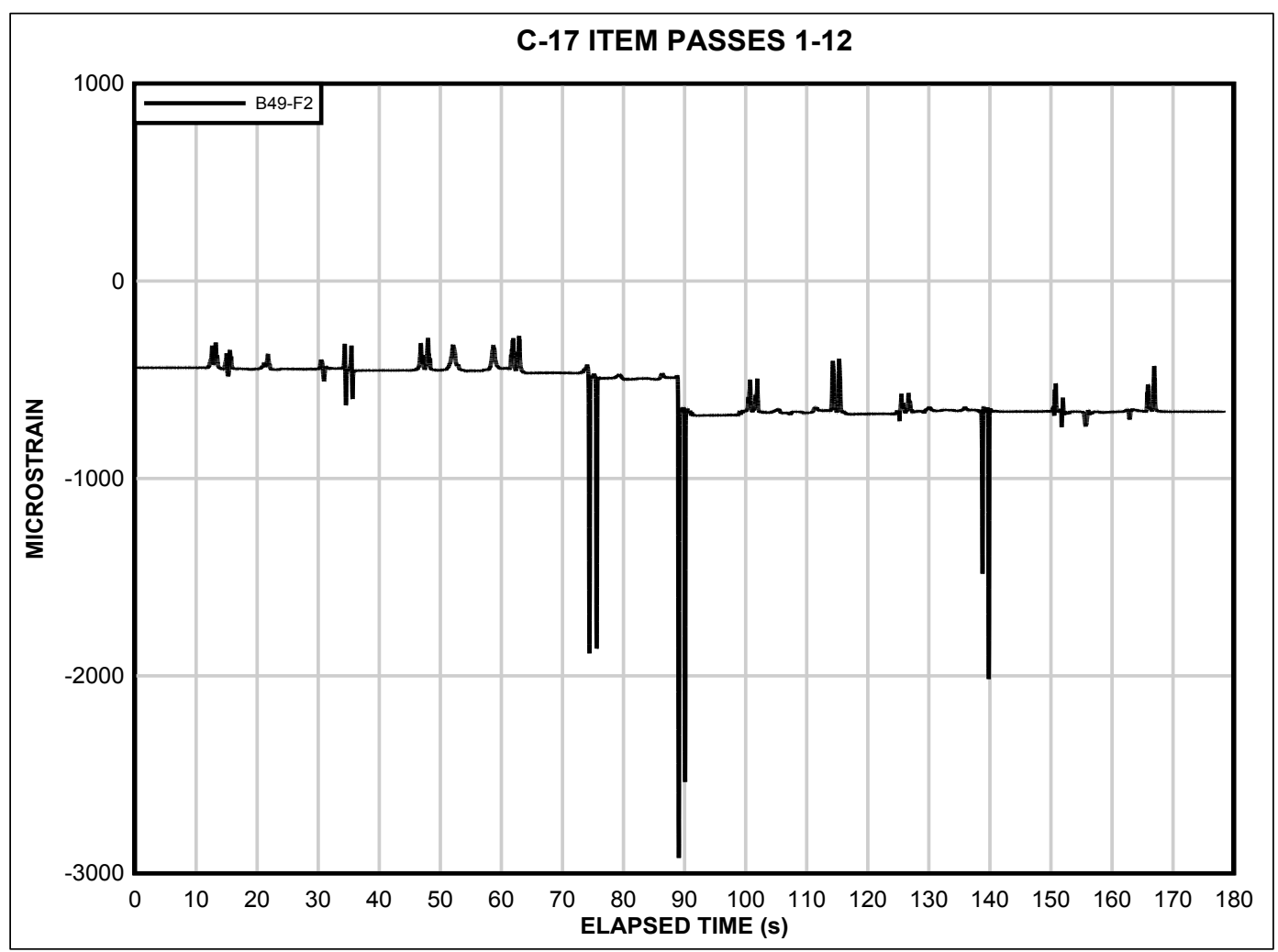


From the raw data, the maximum tensile strains and the absolute value of the maximum compressive strains were captured for each gauge throughout traffic and are reported in Figures 97 through 108. Each of these plots shows data for joining panels in each test item. Data reported for panels in the $\mathrm{C}-17$ item were baselined due to initial strain offset. This was not done for gauges in the $\mathrm{F}-15 \mathrm{E}$ item, since all were set to zero strain at the beginning of the test. The full data set is archived at the ERDC and may be made available upon request.

In the $\mathrm{F}-15 \mathrm{E}$ item, instrumented panels did not fail; therefore, measured strain could not be linked to a rail failure. The rate of accumulation of compressive strains was greater than tensile strains. At the end of the test, compressive strains were predominant.

For the $\mathrm{C}-17$ item, Figures 107 and 108 show that gauges B59-F1, -F2, and -F3 all failed to return usable data between 505 and 672 passes. Visual observations reported failure of Panel B59 at 784 passes; however, the strain gauge data may be an indicator that failure at panel B59 occurred earlier than noted, or that high strains may have destroyed the gauges prior to complete breakage of the upper underlap rail. The same can be observed for panels B71 and B48. Failure of the lower overlap rail of B71 was noted when the panel was removed from the subgrade surface. The strain data show that B71-F1 malfunctioned during pass interval 335-504, and B71-F2 eventually malfunctioned during pass interval 1,009-1,168. The rail may have slowly cracked until it broke completely after 1,009 passes, or high strains measured at B71-F1 may have the destroyed the gauge prior to actual breakage of the rail. Panel B48 was noted to have failed at 1,308 passes when the upper underlap rail broke, but strain data (Figures 105 and 106) indicate gauge failure before visual observations. Most likely, the gauge failures are directly linked to mat breakage. 
Figure 97. Max tensile strain at F-15E item panels B73 and B74.

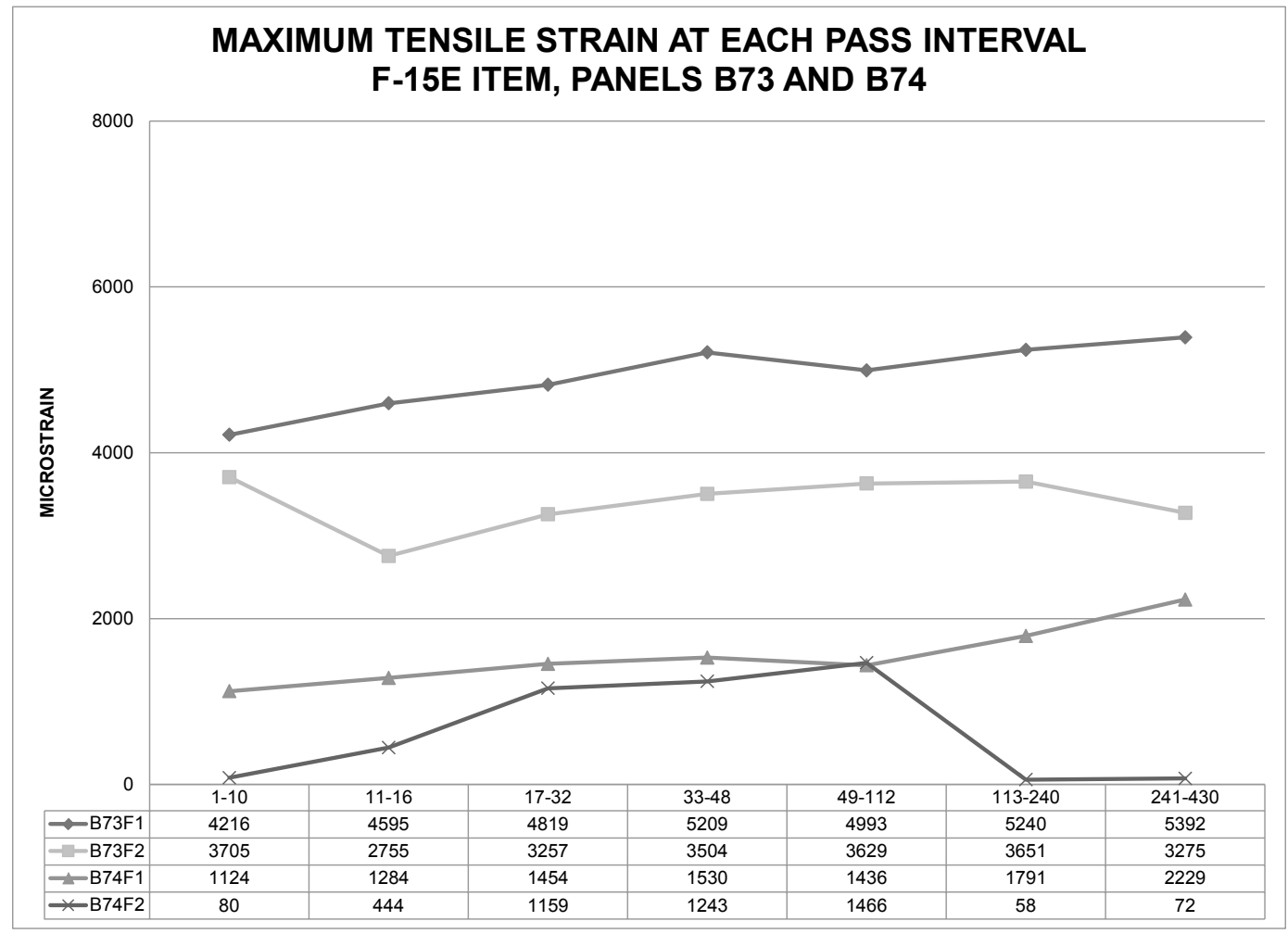

Figure 98. Max compressive strain at F-15E item panels B73 and B74.

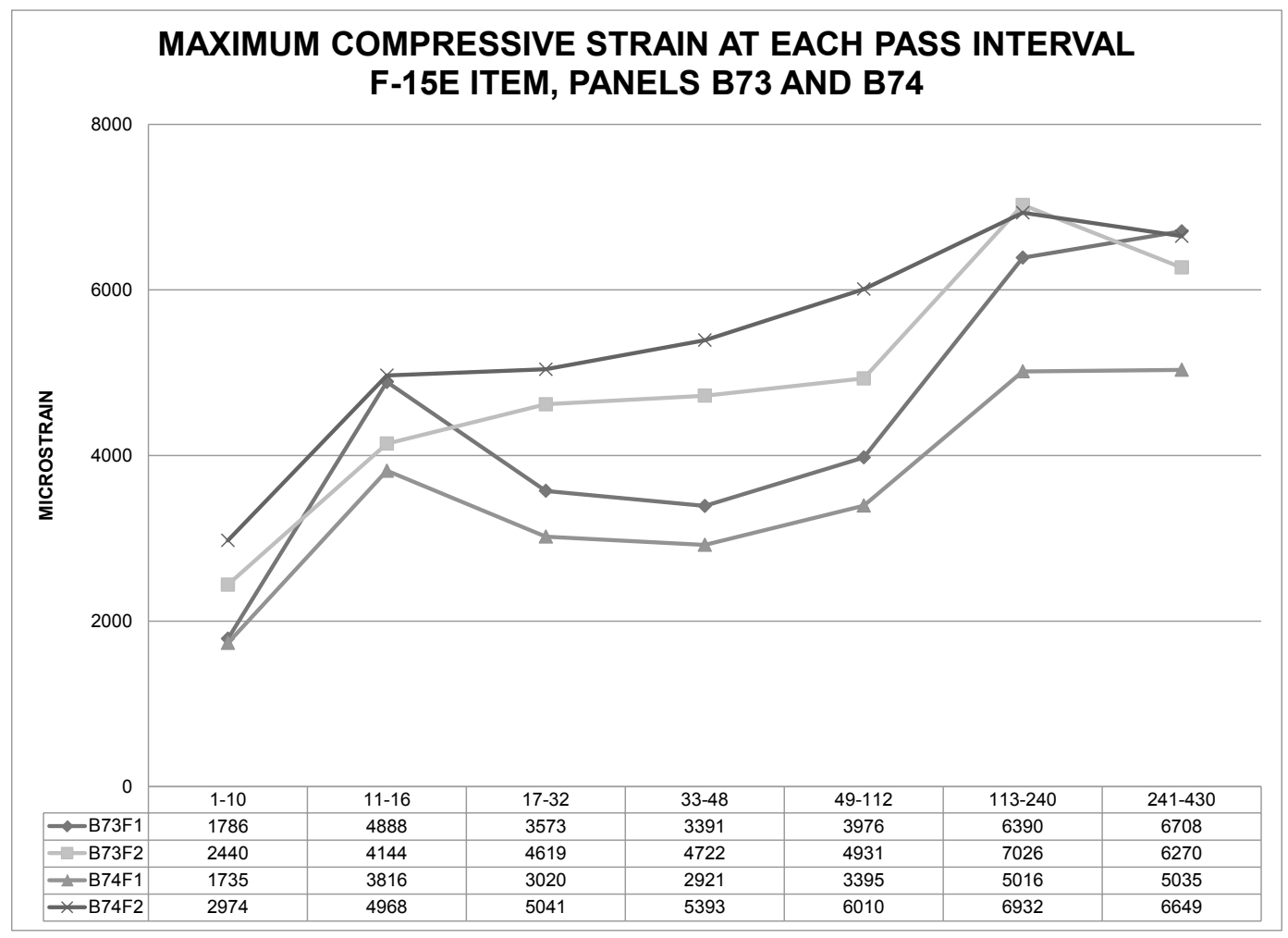


Figure 99. Max tensile strain at F-15E item panels B51 and B60.

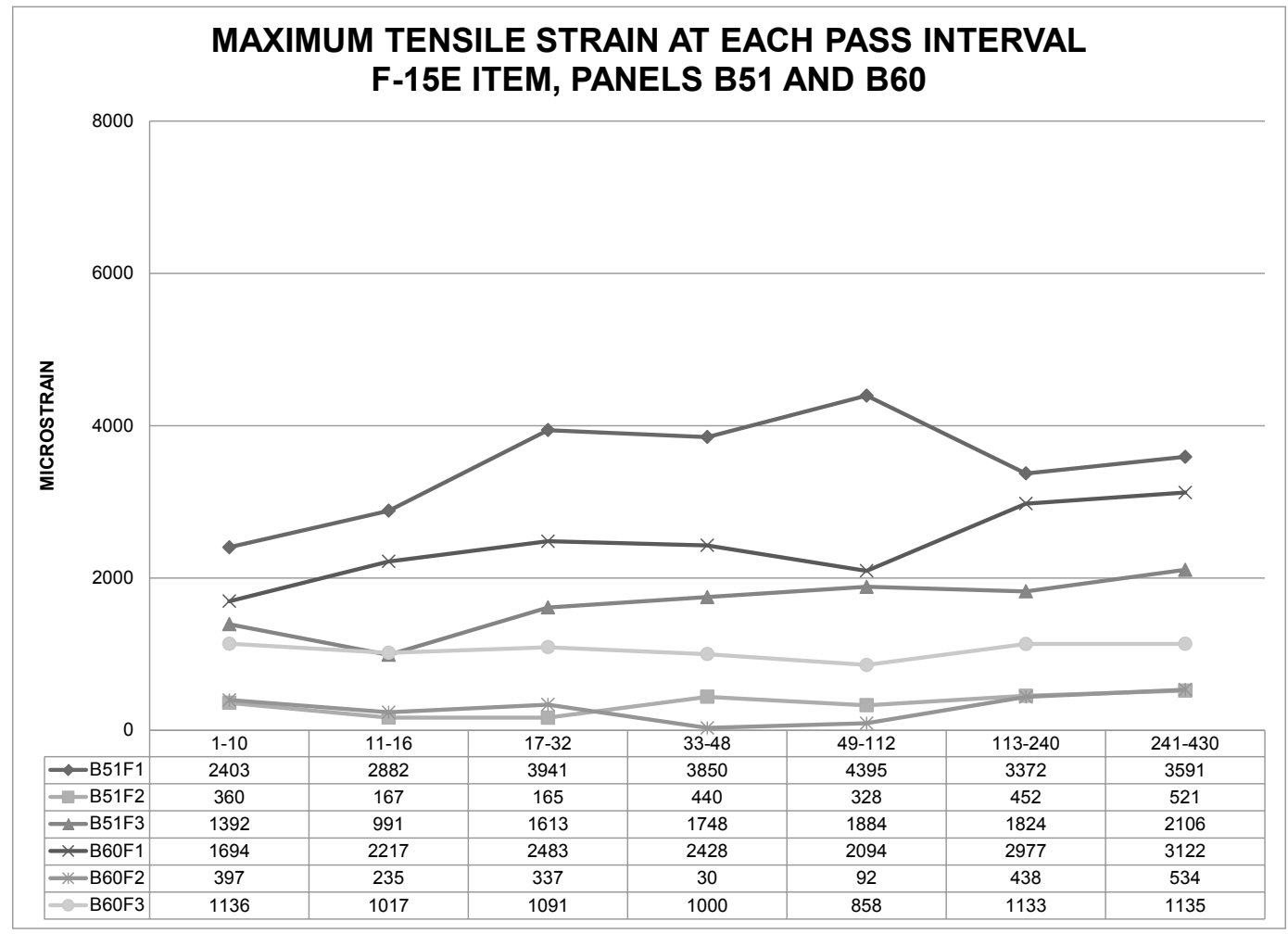

Figure 100. Max compressive strain at F-15E item panels B51 and B60.

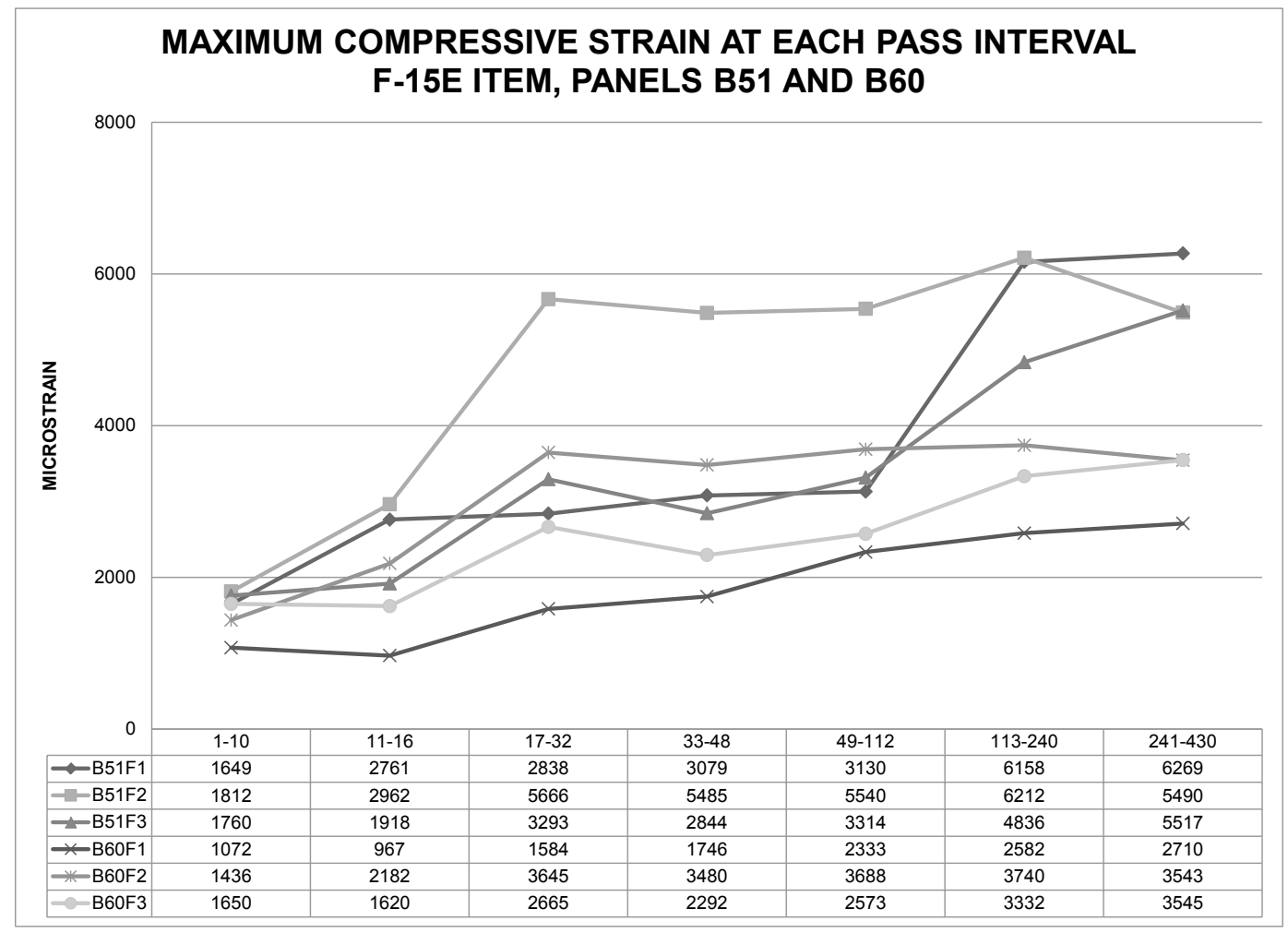


Figure 101. Max tensile strain at F-15E item panels B62 and B63.

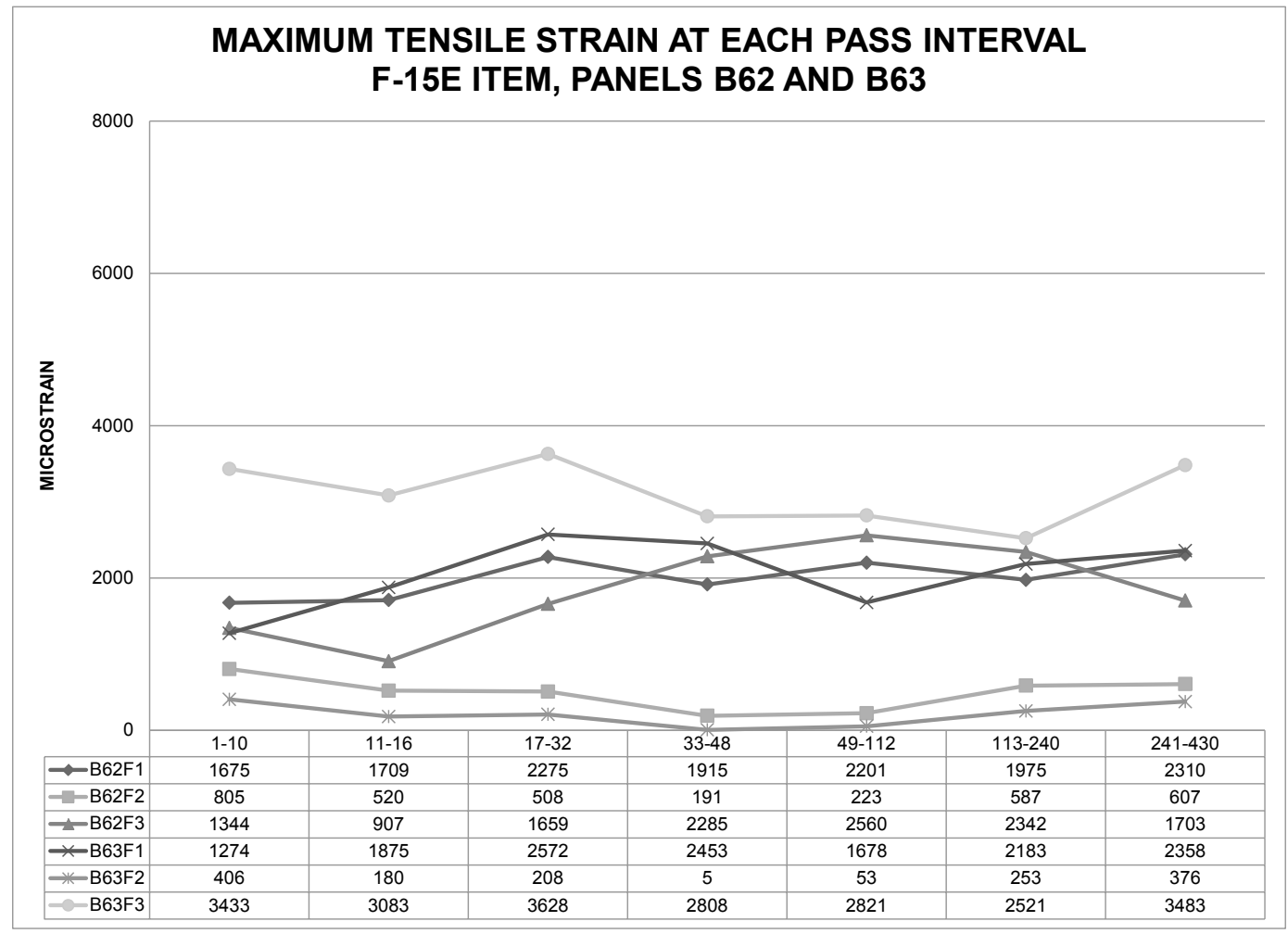

Figure 102. Max compressive strain at F-15E item panels B62 and B63.

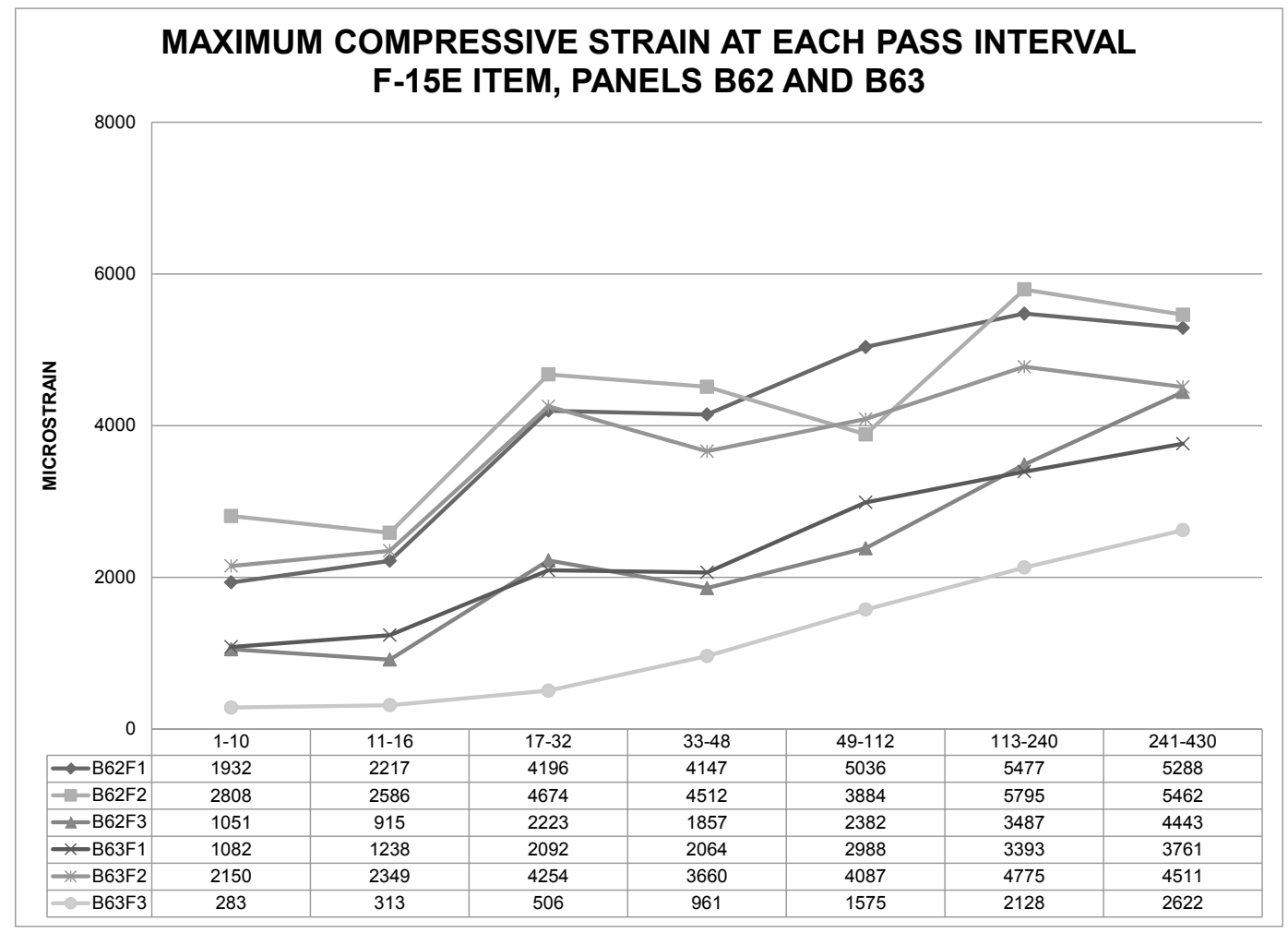


Figure 103. Max tensile strain at C-17 item panels B70 and B71.

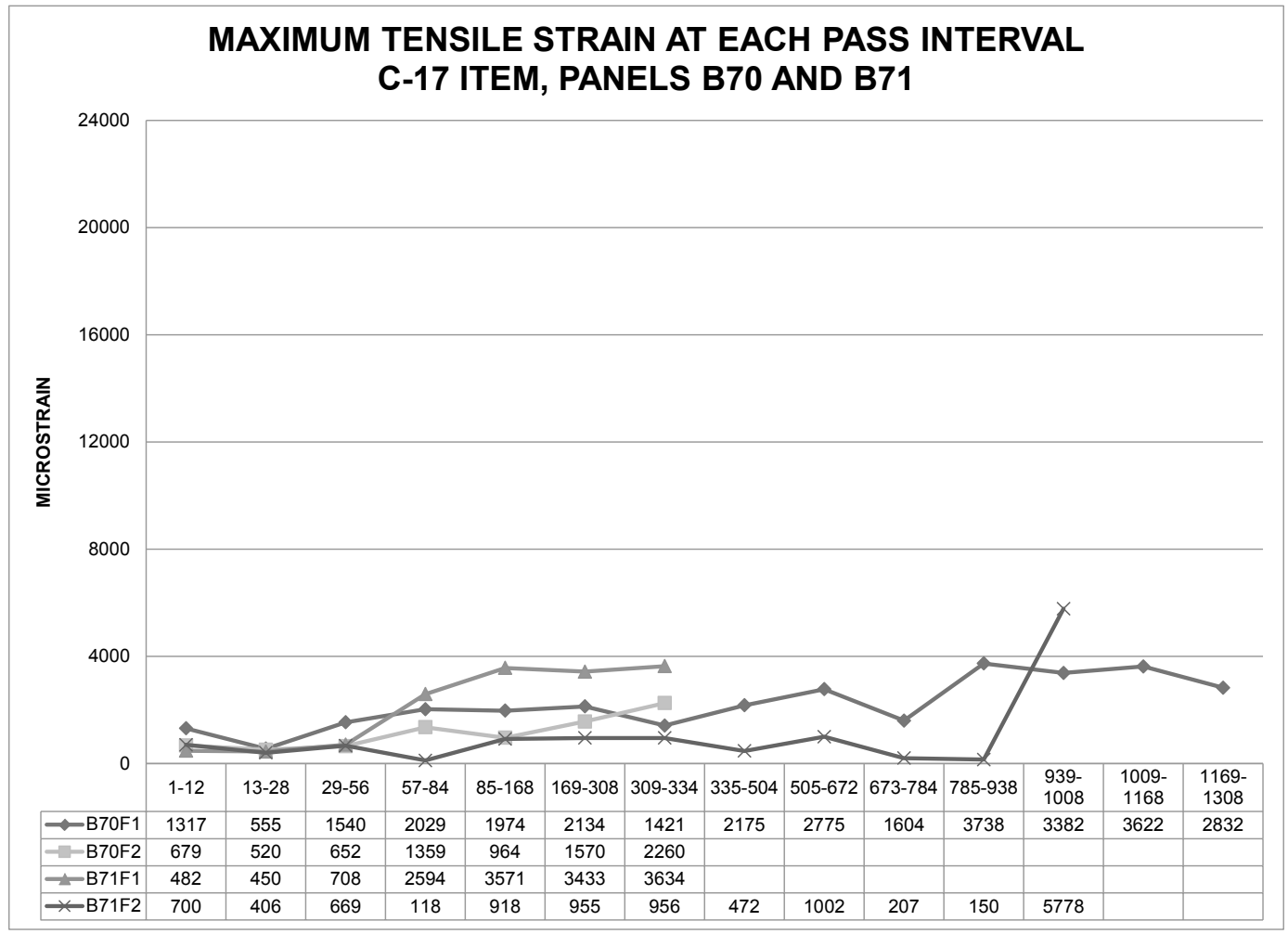

Figure 104. Max compressive strain at C-17 item panels B70 and B71.

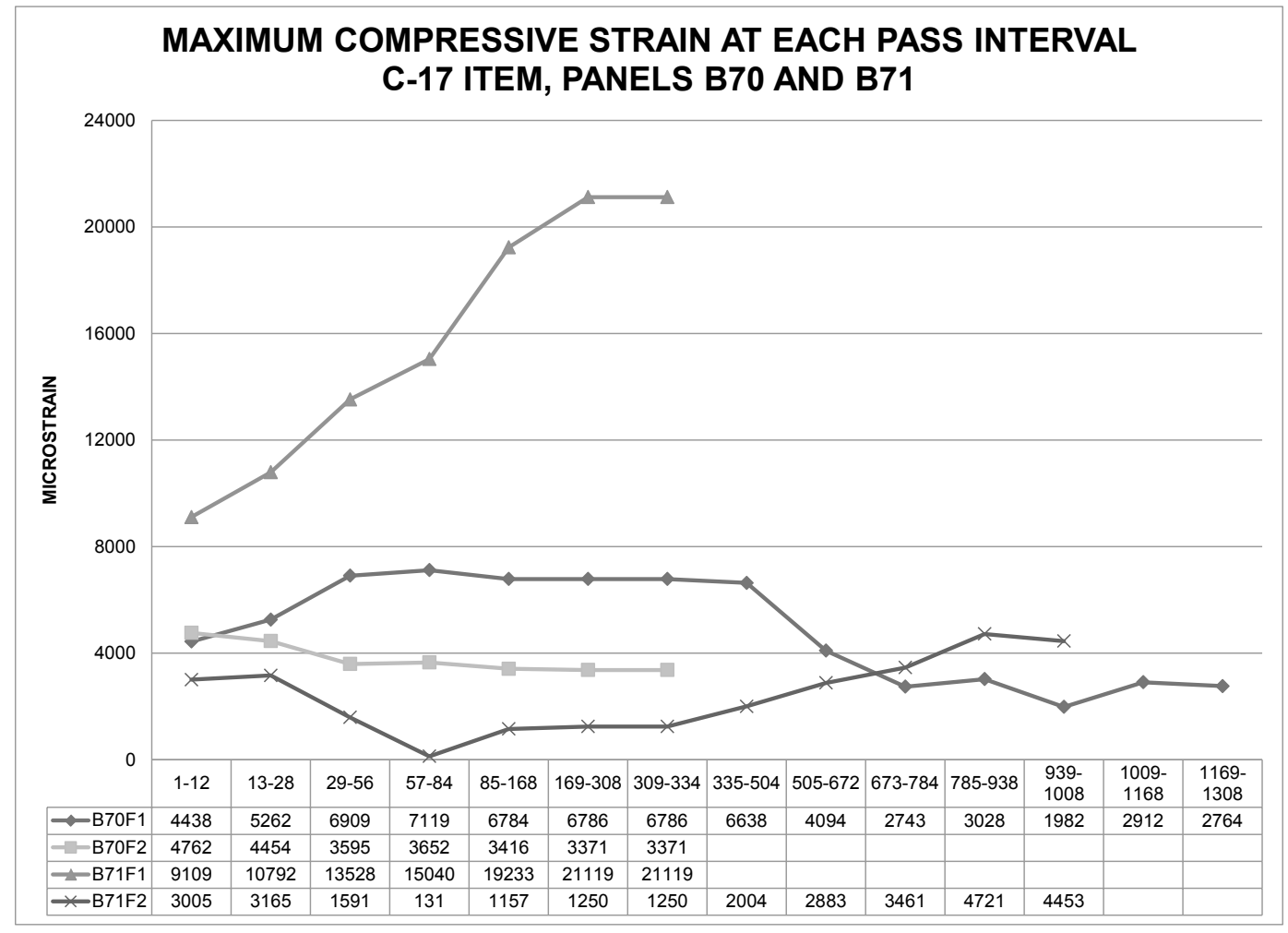


Figure 105. Max tensile strain at C-17 item panels B48 and B49.

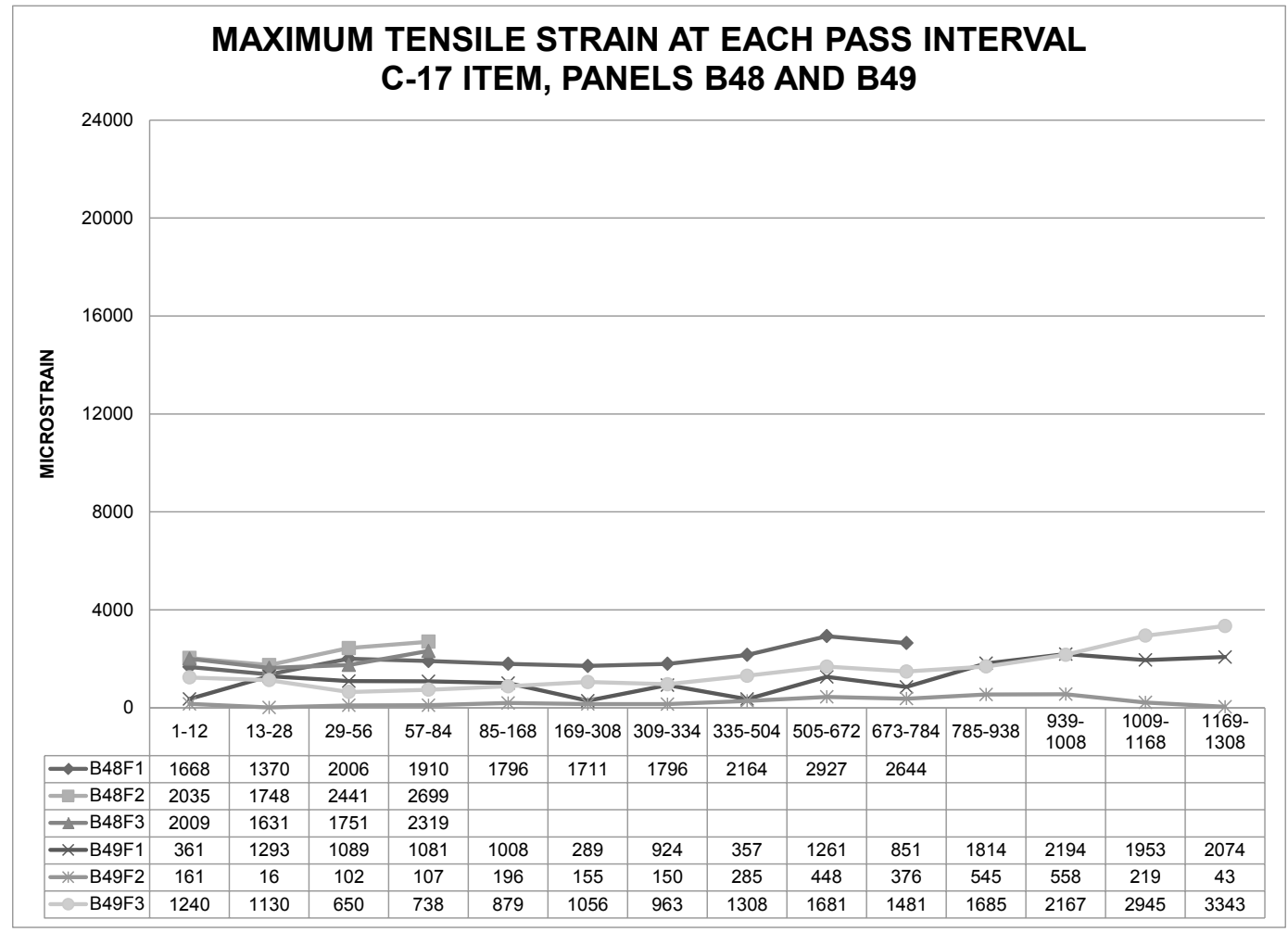

Figure 106. Max compressive strain at C-17 item panels B48 and B49.

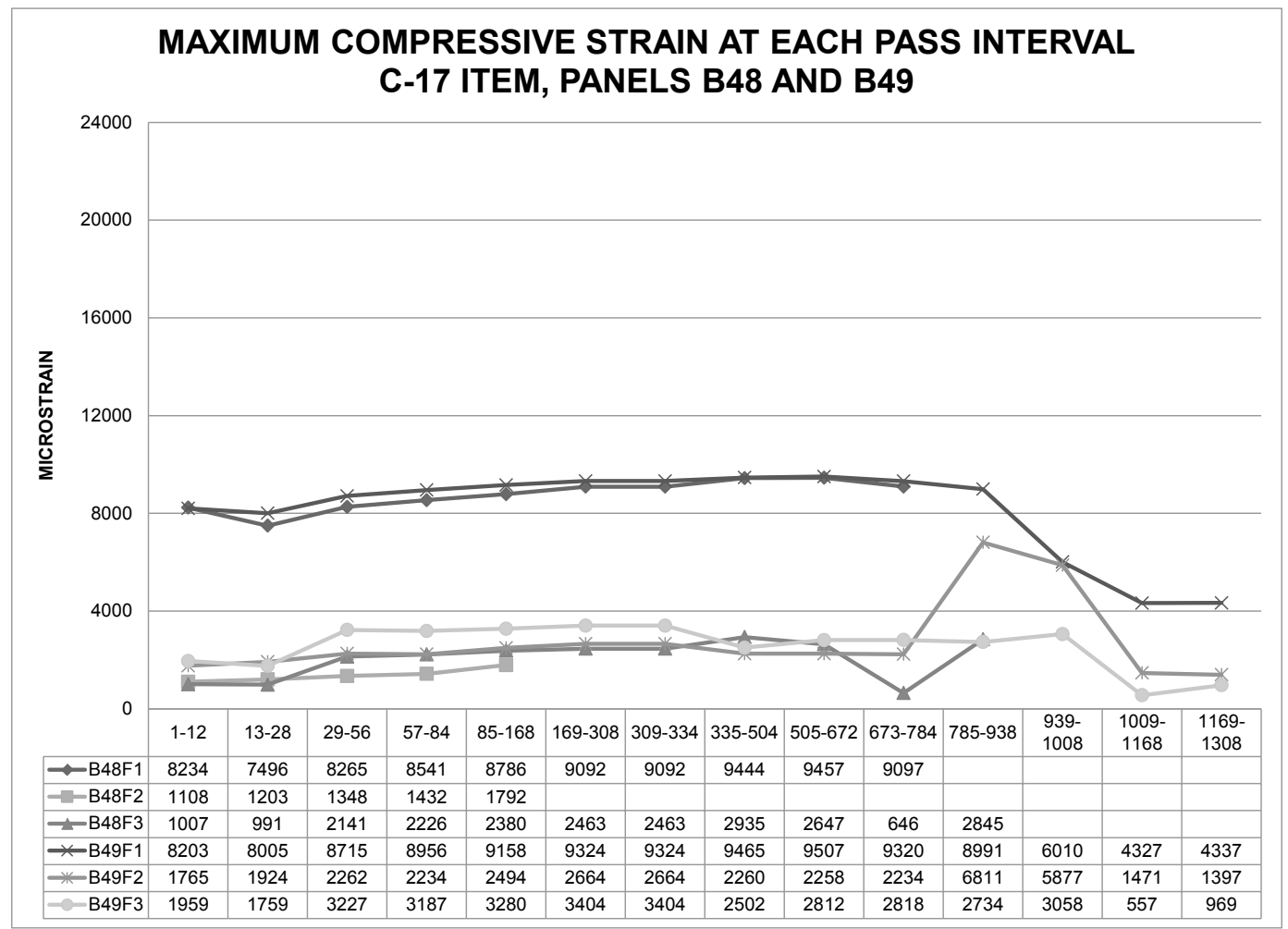


Figure 107. Max tensile strain at C-17item panels B52 and B59.

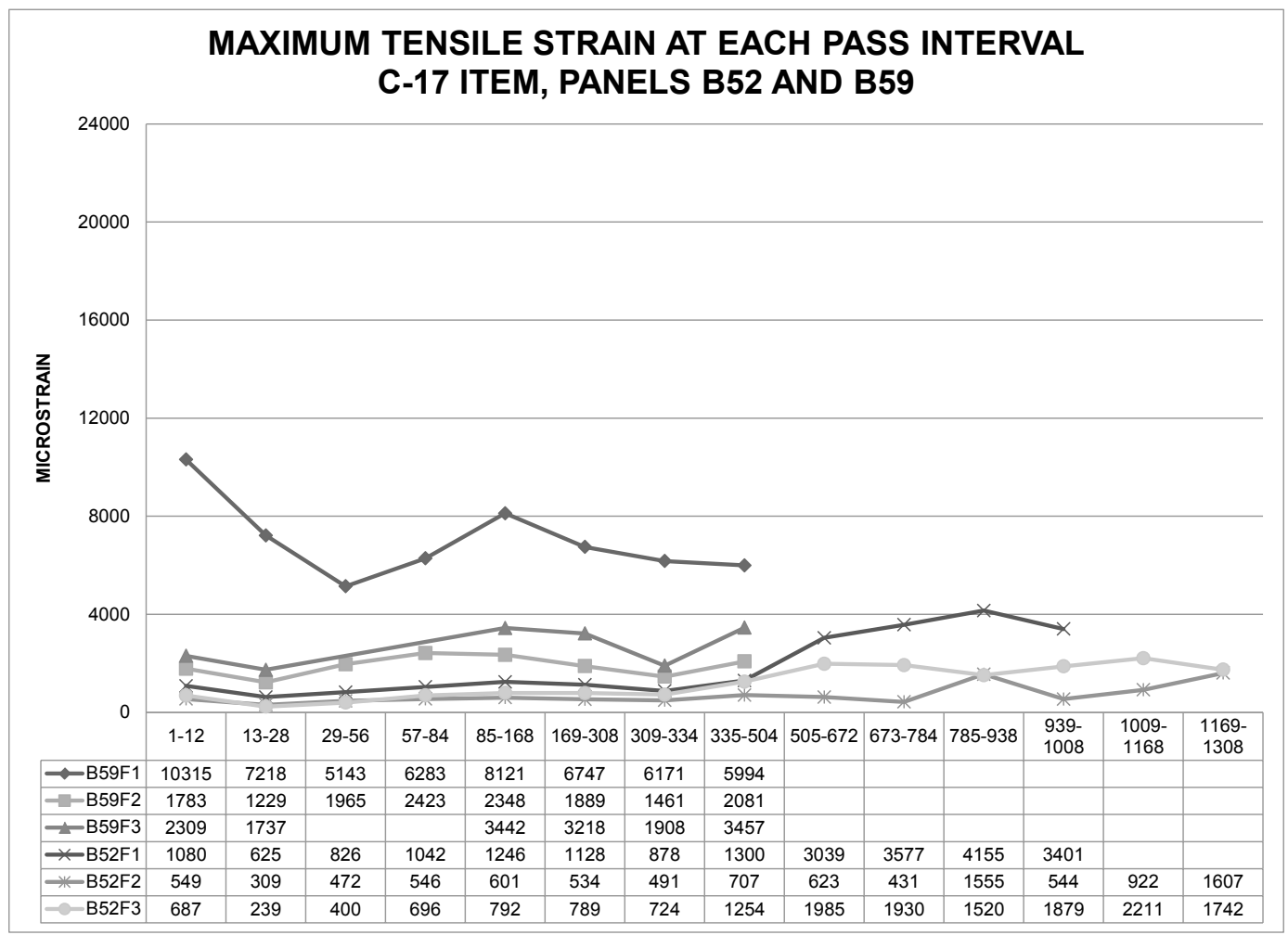

Figure 108. Max compressive strain at C-17item panels B52 and B59.

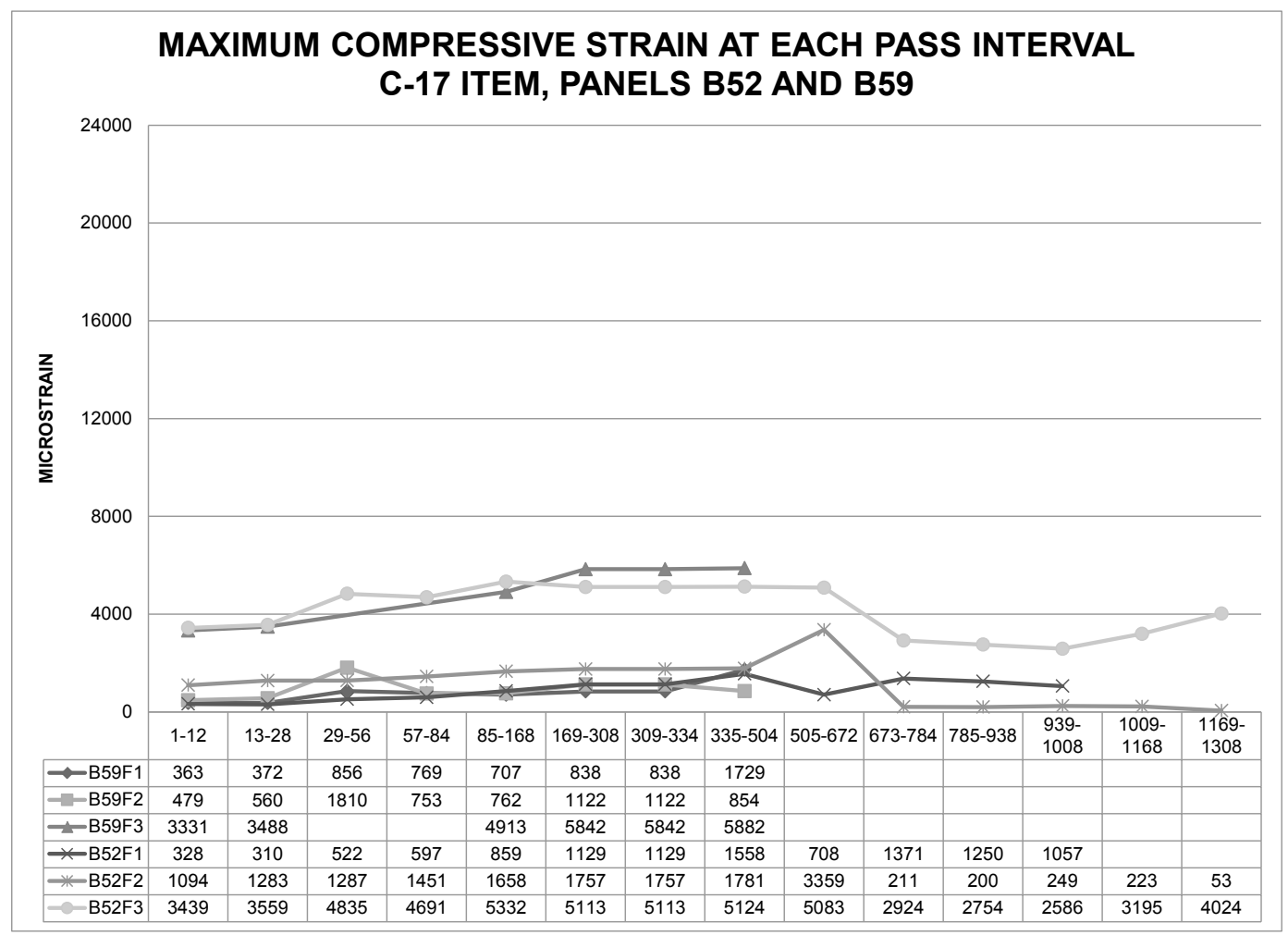




\section{Analysis of Results-Brickwork Pattern on Voided Subgrade}

\subsection{Mat breakage}

The F-15E-V test item was trafficked until 322 passes were completed. The test item did not fail by mat breakage or permanent deformation, but trafficking was concluded due to severe tire hazard in the lane. All damage (mostly corner curls and minor cracking) and the failure at panel B40-1 were typical and similar to that observed by Rushing and Tingle (2007), Rushing and Torres (2007), Rushing et al. (2008), Rushing and Mason (2008), and Garcia and Rushing (2013) in AM2 when trafficked over weak subgrade conditions. Although rail failure occurred in a new panel, most damage was observed in panels that were refurbished. As shown in Figure 44, at the end of the test, ten refurbished panels were documented to have been damaged, whereas only five new panels were noted to have damage. Upper underlap rail failure occurred because of stress concentrations located in the corner of the locking bar insertion slot at the interface with the smallest cross-sectional area of the rail. Cyclic loading caused a crack to incubate in the described location and then propagate along the end connector until the rail completely separated from the panel.

The expectation was that either panel B37-2 or B38-2, which had the joint directly above a void, would fail at their connection. However, the only evidence of a differentiable effect of the void was higher tensile and compressive strain measurements at the upper underlap rail of B37-2 than at any other instrumented rail (except B37-1F1). Tensile and compressive strains appeared to be high in panels B40-2 and B41-2, which were located between the largest voids ( $\mathrm{V}_{1}-\mathrm{C}, \mathrm{V}_{3} \mathrm{~W}$, and $\left.\mathrm{V}_{3} \mathrm{E}\right)$; however, only minor damage was noted in panel B41-2. An assumption was made that this was most likely attributed to the original condition of B41-2 (refurbished), and not necessarily with the existence of larger voids near the joint, because no damage was noted at connecting panel B40-2 (new). More than ten panels had damage at the end connection; however, not all were at or near voids. A clear difference was not observed in the extent of damage in panels near voids compared to panels located further from voids. Although trafficking was not continued to failure, it seems that the existence of voids in the traffic lane did not significantly affect the performance of the mat when 
compared to results reported by Rushing and Tingle (2007), where AM2 was also tested over a CBR of 6 .

\subsection{Permanent deformation}

\subsubsection{Centerline profile}

The centerline profiles for the post-traffic subgrade and the surface of the mat were analyzed to determine whether the roughness criterion was exceeded. The values were 0.54 in. and $0.16 \mathrm{in}$. for the subgrade and mat surface, respectively, and were below the 1.25-in.-deep maximum value established for roughness for F-15E aircraft traffic. Therefore, the system performed adequately to prevent excessive roughness from occurring along the profile. Similar behavior was also documented in previous brickwork pattern tests over a CBR of 6 (Rushing and Tingle 2007; Rushing and Torres 2007).

\subsubsection{Cross sections}

The permanent deformation on the subgrade, the loaded mat surface, and the unloaded mat surface were 0.64 in., 0.50 in., and 0.31 in., respectively. The failure criterion of 1.25 in. was not exceeded. Therefore, the system performed adequately to prevent excessive roughness from occurring prior to failure by mat breakage. In previous tests over a CBR of 6 using the brickwork pattern, deformation limits were exceeded around 1,500 passes (Rushing and Tingle 2007). The authors reported a deformation of approximately $0.28 \mathrm{in}$. on the unloaded mat surface after 384 passes. When comparing deformation at around the same pass level ( 2300 passes), the system performed similarly when placed on a voided subgrade.

\subsection{Elastic deflection}

The elastic deflection measurements were the sum of the gap between the bottom surface of the mat and the top surface of the subgrade when the mat was unloaded (elastic deflection of the mat) and the elastic deflection of the subgrade. The elastic deflection generally remained constant throughout the traffic test at approximately 1.0 in. Previous tests demonstrated an increase in elastic deflection as the test progressed. Since trafficking was stopped after only 322 passes, the limited number of data ranges evaluated may not have been sufficient for a similar trend to develop. However, Rushing and Tingle (2007) reported deflection values that averaged about 0.9 in. after 384 passes, further evidence of similar 
AM2 mat performance when placed on a voided and non-voided subgrade. The constant measurements obtained from this test seem to indicate that the distance between the mat and the subgrade stayed relatively constant, and that the mat surface moved downward with the permanent deformation in the subgrade.

\subsection{Strain gauge readings}

Analysis of the data from this test showed that the gauges performed as designed, and the measured strains appeared to be reasonable. Compressive strains appeared to be greater than tensile strains and controlled the failure of the rail at panel $\mathrm{B} 4 \mathrm{O}-1$. The gauge data were able to validate the pass number at which the panel failed by sorting through the data and counting the pass where malfunction was evident. Compressive strains increased throughout traffic and were elevated before failure of the gauges occurred. A summary of the maximum strain measured in the F-15E-V item is reported in Figures 109 and 110. Compressive and tensile strains measured by gauge B37-2F1 reached maximums that exceeded values reported for most other panels. This is likely associated with the existence of void V-F beneath the joint of B37-2 and B38-2. There appeared to be no pattern as to whether strains were higher in refurbished panels or in new panels, even though damage was more prevalent in refurbished matting. Other than panel B372, a clear trend that linked strain measurements to void sizes near instrumented panels was not observed throughout the test item. An identical test is planned with an array of panels that are all new, in addition to tests with alternate pattern arrangements other than the brickwork pattern. Once all data have been collected, an in-depth analysis of the strain behavior for the different patterns will be conducted. 
Figure 109. Summary of maximum tensile strain measured in F-15E-V item.

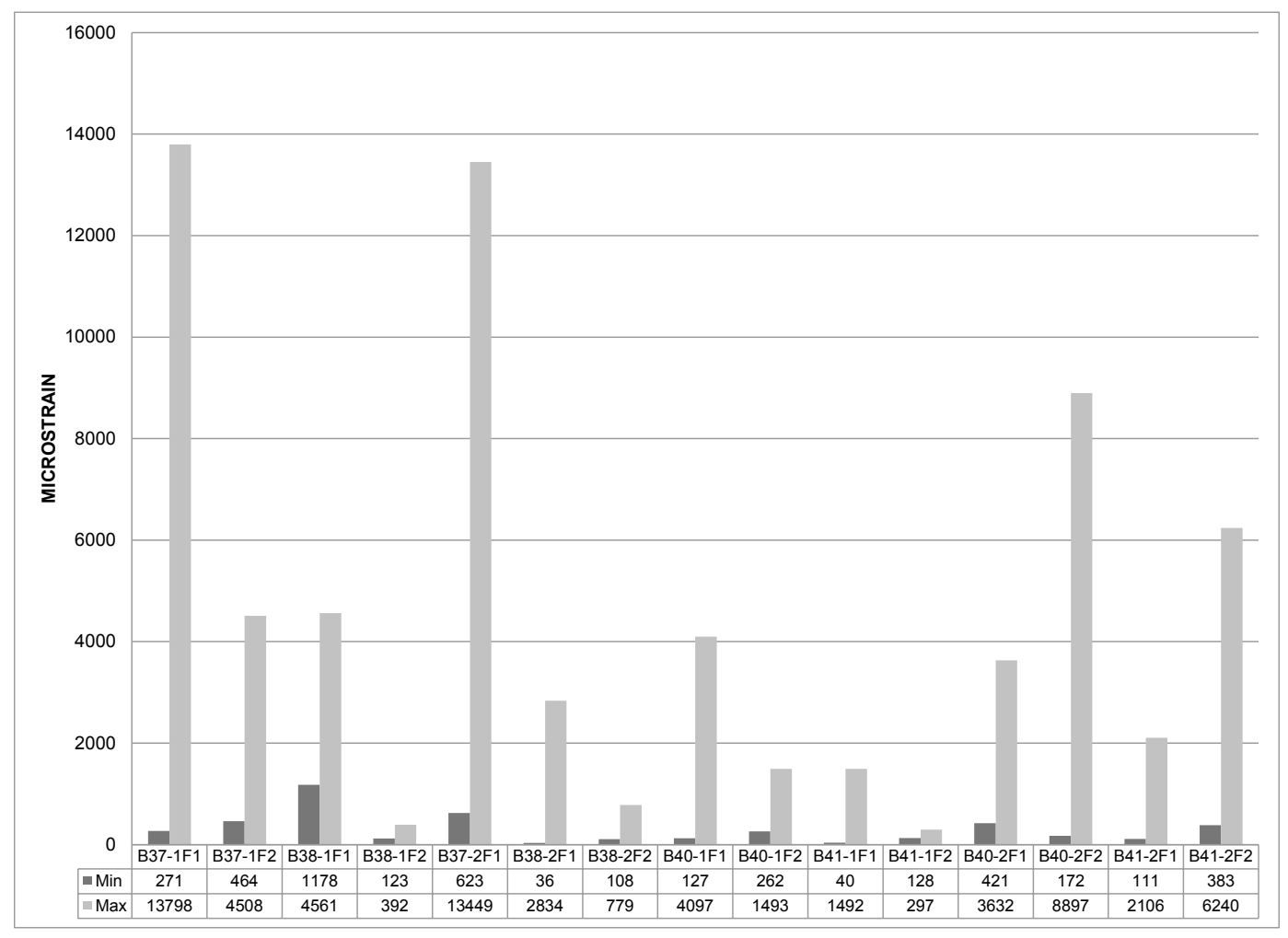

Figure 110. Summary of maximum compressive strain measured in F-15E-V item.

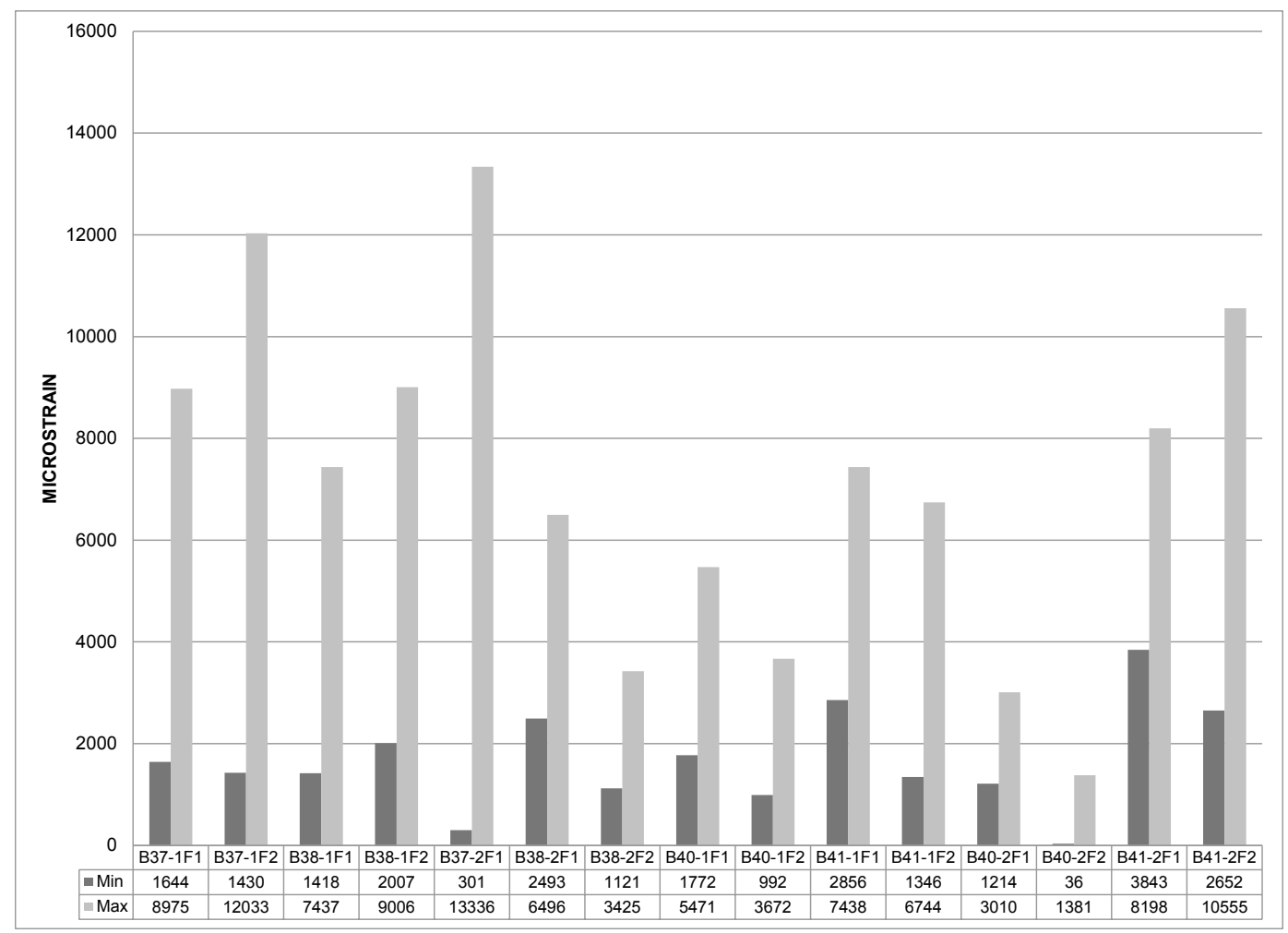




\section{Analysis of Results-Brickwork Pattern}

\subsection{Mat breakage}

\subsubsection{F-15E item}

The F-15E test item sustained 430 passes of simulated F-15E aircraft traffic with two panel failures (both refurbished panels) caused by detached end connectors. This same failure mechanism has been documented by Rushing and Tingle (2007). Damage generally noted included corner curls, top skin cracking, and cracking below the top flange of the female hinge, which is typical damage reported by Rushing and Tingle (2007), Rushing and Torres (2007), Rushing et al. (2008), Rushing and Mason (2008), and Garcia and Rushing (2013) in AM2 when trafficked over weak subgrade conditions. Damage was noted in both new and refurbished matting, but was more prevalent in refurbished mats. At the end of the test, eleven refurbished panels were damaged, and only four new panels were damaged. The extent of damage in refurbished panels was also to a greater degree, with longer cracks noted at the end connectors when compared to new mats. Failure of the end connectors also occurred in refurbished mats. Panel 89 was confirmed to be an older version of AM2 due to the location of the weld and the lack of inserts.

Since trafficking was not taken to failure, as a result of severe tire hazards in the traffic lane, a direct comparison of the pass level at failure cannot be established with results reported by Rushing and Tingle (2007) and Rushing and Torres (2007). However, Rushing and Tingle (2007) achieved 2.5 percent mat breakage after nearly 400 passes, and 5 percent mat breakage after nearly 1,300 passes. Failure of the test item occurred after 1,500 passes. In this test, 5 percent mat breakage was reached after 430 passes, indicating that failure by mat breakage would likely have occurred before 1,500 passes were reached. As expected, the conclusion can be made that the operating life of AM2 refurbished matting (especially older designs of AM2) is diminished as a result of previous fatigue history.

\subsubsection{C-17 item}

The $\mathrm{C}-17$ test item was trafficked until 1,308 passes were completed, and the failure point was reached due to mat breakage. At the end of the test, ten panels had failed, eight of which failed at either the lower overlap 
(5) or upper underlap (3) rail. Of the ten, six panels were new and four panels were refurbished. Similar modes of failure have been documented in previous tests of AM2 Mod 5; however, the majority of failures have historically been upper underlap rail failures with only a few lower overlap failures. The cause of the change in the predominant mode of failure is unknown, but is assumed to be linked to the unknown traffic history of the refurbished panels in the lane. Two of the five panels with this failure mechanism were refurbished mats, and one of the three new panels was joined with a refurbished mat. Panel B71 in particular was two-piece AM2, which has not been produced since the mid 1960's. Two holes drilled on the surface at the end connector for tie down were noted.

One refurbished panel failed due to top skin cracking along one of the vertical stiffeners. This mode of failure has not been observed by recent investigations under the same traffic conditions (Rushing and Tingle, 2007), but similar damage was noted by Garcia et al. (2014a and 2014b) when AM2 Mod 5 was tested over a high strength subgrades under F-15E traffic. Since this is not a common failure mechanism for the conditions of this test, the mat breakage was most likely associated with the unknown history of the panel. One refurbished panel that appeared to be AM2 Mod 5 failed at the weld of the end connector. A failure of this type is not common under $\mathrm{C}-17$ traffic in soft soil conditions and is assumed to be attributed to the unknown traffic history of the panel. Damage that did not reach failure, such as cracking near the top or bottom flange of the female hinge and at the weld of the end connector, was noted to be prevalent in refurbished panels, a further indicator of the higher rate of deterioration of mats already used in the theater or for other purposes (e.g., training).

Rushing and Tingle (2007) reported failure of AM2 Mod 5 under C-17 traffic over a CBR of 6 after 1,500 passes. When comparing the pass level at failure, it seems that the existence of refurbished matting did not significantly affect the performance life of AM2. However, the previous discussion shows evidence that distinct modes of failures can occur in older versions of AM2 and panels with unknown traffic history. A likely explanation is that airfield matting performance under simulated $\mathrm{C}-17$ traffic is normally controlled by deformation instead of fatigue damage, mostly because the multiple-wheel gear carries a larger, more distributed load. 


\subsection{Permanent deformation}

\subsubsection{Centerline profile}

The centerline profiles for the post-traffic subgrade and the surface of the mat at various traffic intervals were analyzed to determine whether the roughness criteria were exceeded.

\subsubsection{F-15E item}

The maximum values for the subgrade and mat surface were $0.84 \mathrm{in}$. and 0.17 in., respectively, and are below the 1.25-in.-deep maximum value established for roughness for F-15E aircraft traffic. Therefore, the system performed adequately to prevent excessive roughness from occurring along the profile. Similar behavior was also documented in previous brickwork pattern tests over a CBR of 6 (Rushing and Tingle 2007; Rushing and Torres 2007).

\subsubsection{C-17 item}

The values for the subgrade and mat surface were $0.90 \mathrm{in}$. and $0.52 \mathrm{in}$., respectively, and were below the 3.0-in.-deep maximum value established for roughness for C-17 aircraft traffic. Therefore, the system performed adequately to prevent excessive roughness from occurring along the profile after 1,308 passes. Similar behavior was also documented by Rushing and Tingle (2007) when the authors tested AM2 in the brickwork pattern over a CBR of 6.

\subsubsection{Cross sections}

The permanent deformation on the subgrade, the loaded mat surface, and the unloaded mat surface was analyzed to determine whether the deformation criteria were exceeded.

\subsubsection{F-15E item}

The permanent deformation on the subgrade, the loaded mat surface, and the unloaded mat surface after 430 passes was 0.75 in., 0.65 in., and 0.44 in., respectively. The failure criterion of $1.25 \mathrm{in}$. was not exceeded. Therefore, the system performed adequately to prevent excessive roughness from occurring. In previous tests over a CBR of 6 using the brickwork pattern, deformation limits were exceeded around 1,500 passes. 


\subsubsection{C-17 item}

The permanent deformation on the subgrade, the loaded mat surface, and the unloaded mat surface were 3.06 in., 2.72 in., and 1.67 in., respectively, after 1,308 passes. The failure criterion of 3.0 in. was exceeded on the subgrade; however, since the subgrade deformation was determined after the mat panels were removed, the number of passes at which the 3 -in. rut was developed could not be determined and was assumed at 1,308 passes. This further verifies the sensitivity of airfield mats to subgrade failure when subjected to simulated C-17 operations. Rushing and Tingle (2007) reported the same behavior after 2,520 passes were applied and 3.25 in. of deformation were measured on the subgrade surface.

\subsection{Elastic deflection in the F-15E item}

The elastic deflection measurements generally remained constant during the first 100 passes at about $1.10 \mathrm{in}$. and then increased to $1.25 \mathrm{in}$. at 240 passes. Previous tests demonstrated this behavior, where an increase in elastic deflection was noted as the test progressed. Assuming that the elastic deflection of the subgrade remained nearly constant throughout traffic, the increase in the total elastic deflection of the mat and subgrade indicates that the air gap beneath the mat increased as deformation occurred in the subgrade surface.

\subsection{EPC readings}

\subsubsection{F-15E item}

The EPC data obtained during trafficking show the stresses measured in the subgrade 3 in. below the surface. Maximum pressure ranges for each instrument are reported in Figure 93 and Table 19. As expected, pressure values measured at the offset location were on average at least $40 \mathrm{lbf} / \mathrm{in}^{2}{ }^{2}$ lower than pressure measured under the centerline. Similar maximum pressure values measured by instruments under the centerline are good indicators of the individual, connected panels working and moving as a uniform system. Rushing and Tingle (2007) installed EPCs at depths of 12 in., 30 in., and 54 in. As expected, maximum pressure values reported by the authors were lower than those measured in this test at $3 \mathrm{in}$. below the surface, with maximum pressure measured at 12 in. below the surface being in the range of about $35 \mathrm{lbf} / \mathrm{in} .^{2}$ to $45 \mathrm{lbf} / \mathrm{in}^{2}$. 
EPC data were collected to capture additional information for the development of models that more closely predict stresses underneath a matting system installed over a representative subgrade. Gonzalez and Rushing (2010) provided a detailed analysis of initial modeling efforts using Layered Elastic Analysis (LEA) for a variety of matting systems tested in full-scale, including AM2. LEA analyses were performed for each mat system reported by the authors by using the composite modulus of elasticity of each mat system. To determine the composite modulus, Gonzalez and Rushing (2010) used measured deflections from an in-air full-panel 4-point bending test described by Berney et al. (2006). The measured deflections of each mat under known applied loads were backcalculated using a two-dimensional (2-D) finite element implementation of the Mindlin plate theory. The composite modulus of the AM2 system was found to be approximately $3,970,000 \mathrm{lbf} /$ in. $^{2}$. Using the calculated modulus of elasticity for AM2 (or any other system tested) and an approximate modulus related to the CBR of the subgrade, the pressure values at any depth could be predicted using a LEA computer program, WinLEA.

Although the model provided some improvements, Garcia et al. (2012), Garcia et al. (2014a and 2014b), Rushing and Mason (2008), Rushing et al. (2008), and Rushing et al. (2011) were able to prove that LEA is not a useful method for capturing the effect of matting systems over the subgrade. They demonstrated this through a comparison of predicted values determined using LEA to pressure values measured during a test, where discrepancies were noted in the measured and predicted values, especially near the surface of the subgrade. The authors attributed this to the inability of LEA to account for the variability in stiffness along joints. Regardless, both measured and predicted values showed that the most critical area underneath the mat is near subgrade surface. This is further verified with the information captured in this test 3 in. below the centerline of the subgrade, with pressure ranges at least $20 \mathrm{lbf} /$ in. $^{2}$ higher than those measured by Rushing and Tingle (2007) at the 12-in. depth. Any improvements to the upper layers of the subgrade directly under the mat would increase the mat system performance even if the underlying layers remained much weaker.

\subsubsection{C-17 item}

The EPC data obtained during trafficking show the stresses measured in the subgrade 3 in. below the surface. Maximum pressure ranges for each 
instrument are reported in Figure 94 and Table 19. Similar pressure was measured by EPC C1 $3 \mathrm{ft}$ offset from the centerline and EPCs $\mathrm{C}_{2}$ and $\mathrm{C}_{3}$ under the centerline. This makes sense, since the load cart centers at the location of EPC C1 during the first few passes of each traffic interval. The multiple-wheel gear is also able to spread the load over an area large enough that will cause a similar response at instruments just $3 \mathrm{ft}$ from the centerline. This information gives further evidence of the ability of the mat to work as a uniform system rather than individual panels performing separately. EPC $\mathrm{C}_{4}$ under the center of a panel recorded much higher pressure responses throughout traffic when compared to the other EPCs. This was unexpected, since Rushing and Tingle (2007) reported similar values for EPCs placed at $12 \mathrm{in.} \mathrm{both} \mathrm{under} \mathrm{joints} \mathrm{and} \mathrm{under} \mathrm{the} \mathrm{center} \mathrm{of}$ panels. Average pressure at the 12-in.-depth was $50 \mathrm{lbf} /$ in. $^{2}$, a difference of at least $50 \mathrm{lbf} / \mathrm{in} .^{2}$ to the pressure measured at 3 in. The opinion of the authors of this report is that $\mathrm{EPC} \mathrm{C}_{4}$ reported values that are not dependable, which may be a result of improper placement or discrepancies with the gauge itself. Evidence that supports this is the malfunction of EPC $\mathrm{C}_{4}$ after 168 passes.

EPC data was collected in the $\mathrm{C}-17$ item to capture additional information for the development of models that more closely predict stresses underneath a matting system installed over a representative subgrade. Gonzalez and Rushing (2010) attempted similar efforts to those described for F-15E loads (6.4.1). Garcia et al. (2012), Garcia et al. (2014a), Rushing and Mason (2008), and Rushing et al. (2008) were able to prove that LEA is not a useful method for capturing the effect of matting systems over a subgrade. The discussion in section 6.4.1 regarding the discrepancies with pressure values predicted using LEA when compared to actual measured pressure during $\mathrm{F}-15 \mathrm{E}$ traffic tests closely resembles issues also encountered with measurements predicted for $\mathrm{C}-17$ traffic tests.

\subsection{Strain gauge readings}

\subsubsection{F-15E item}

Analysis of the data from this test showed that the gauges performed as designed, and the measured strains appeared to be reasonable. Panels with instrumented end connectors did not have mat breakage; therefore, failure of a panel could not be linked to measured strain at a particular location. Generally, the data suggest that tensile strain can remain relatively constant throughout the test. Compressive strains tend to 
accumulate, shown by the positive slope in Figures 98, 100, and 102. A summary of the strain measured throughout the test for each gauge is reported in Figures 111 and 112. There appeared to be no trend as to whether strains were higher in refurbished panels or in new panels. When compared to the data reported for the F-15E-V item (Figures 109 and 110), tensile and compressive strains were overall much lower in the F-15E item than that measured on a voided subgrade.

An identical test is planned with an array of panels that are all new. Alternate layout pattern tests are also planned, with all new matting. Once all data have been collected, an in-depth analysis of the strain behavior for the different patterns will be conducted.

\subsubsection{C-17 item}

Instrumented panels with rail failures were B59, B71, and B48. For each of these panels, breakage of each rail was noted after strain gauges were reported to have malfunctioned. The data suggests that either 1) the rails failed before visual observations of the surface could confirm mat breakage, or 2) high strains may have destroyed the gauges prior to complete breakage. Regardless, it is evident from the strain data that compressive strains in B59, B71, and B48 were larger than in other instrumented panels, which is useful for linking some value of compressive strain to crack initiation at the rails. A summary of the strain measured throughout the test for each gauge is reported in Figures 113 and 114. There appeared to be no trend as to whether strains were higher in refurbished panels or in new panels.

An identical test is planned with panels all from new production lots. Additional tests will be conducted on alternate layout patterns for arranged direct comparison of strains and number of passes to failure. Once all data have been collected, an in-depth analysis on the strain behavior for the patterns will be conducted to further improve understanding of the fatigue behavior or the AM2 joint system. 
Figure 111. Summary of maximum tensile strain measured in F-15E item.

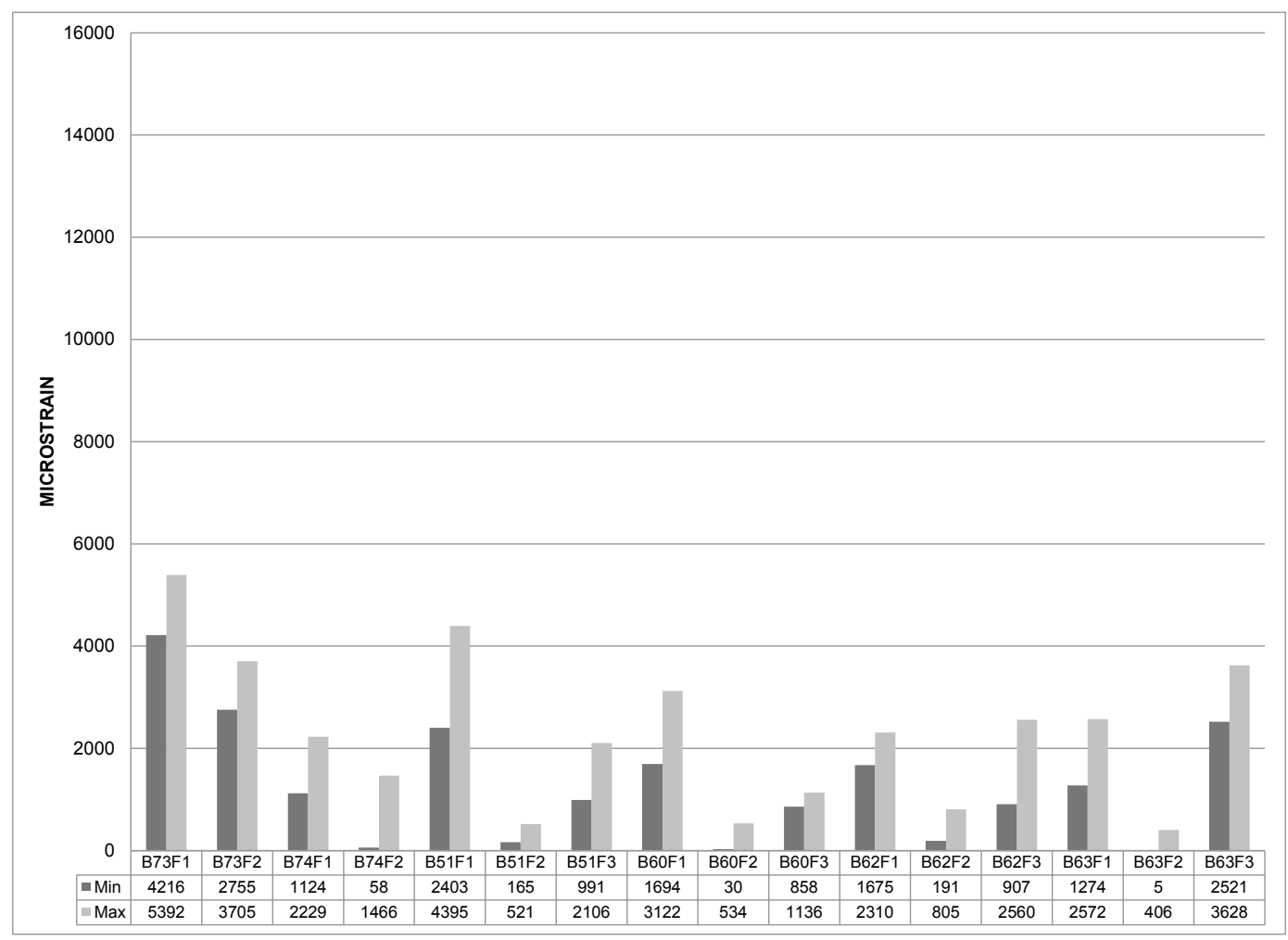

Figure 112.Summary of maximum compressive strain measured in F-15E item.

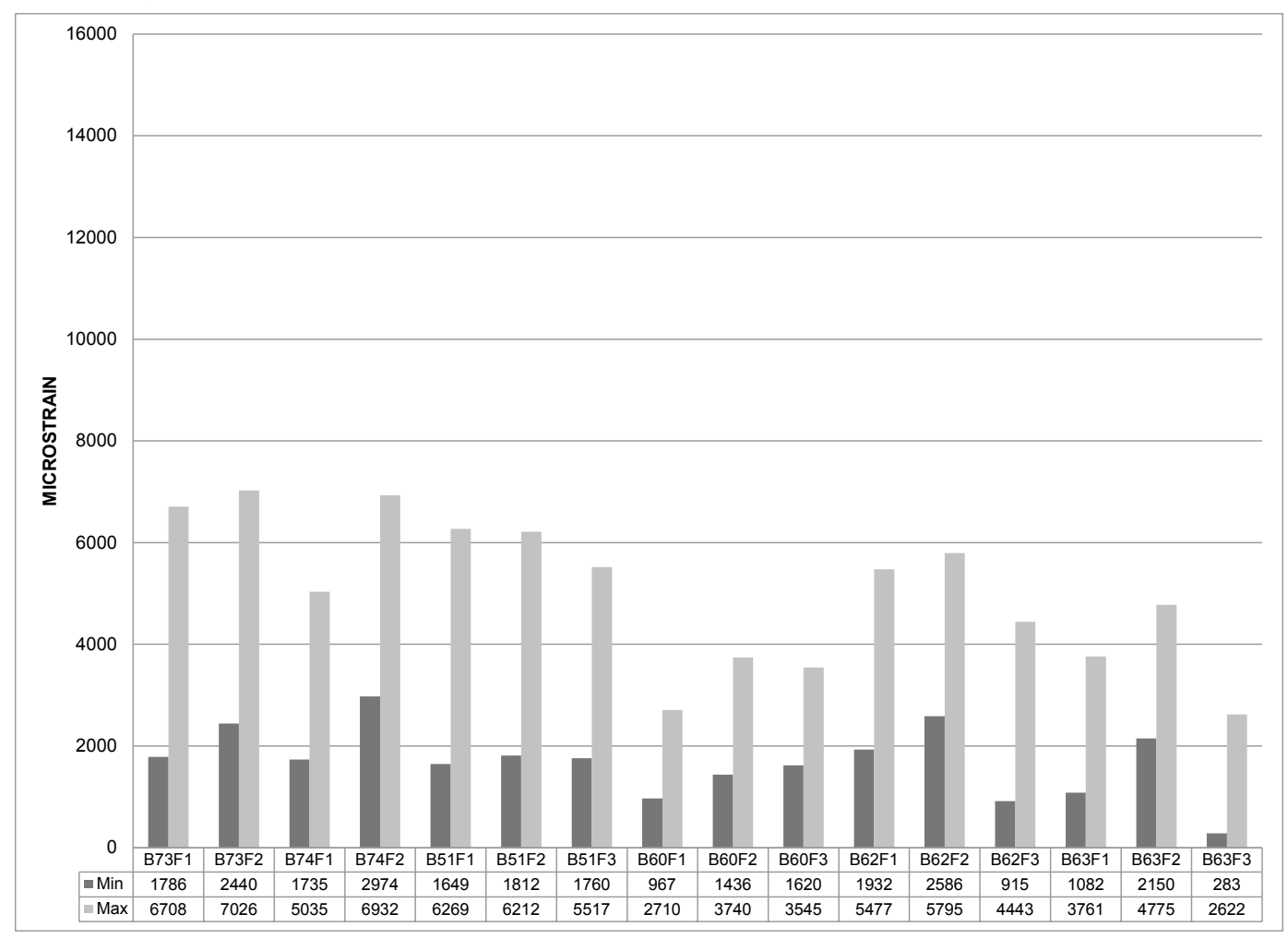


Figure 113. Summary of maximum tensile strain measured in C-17 item.

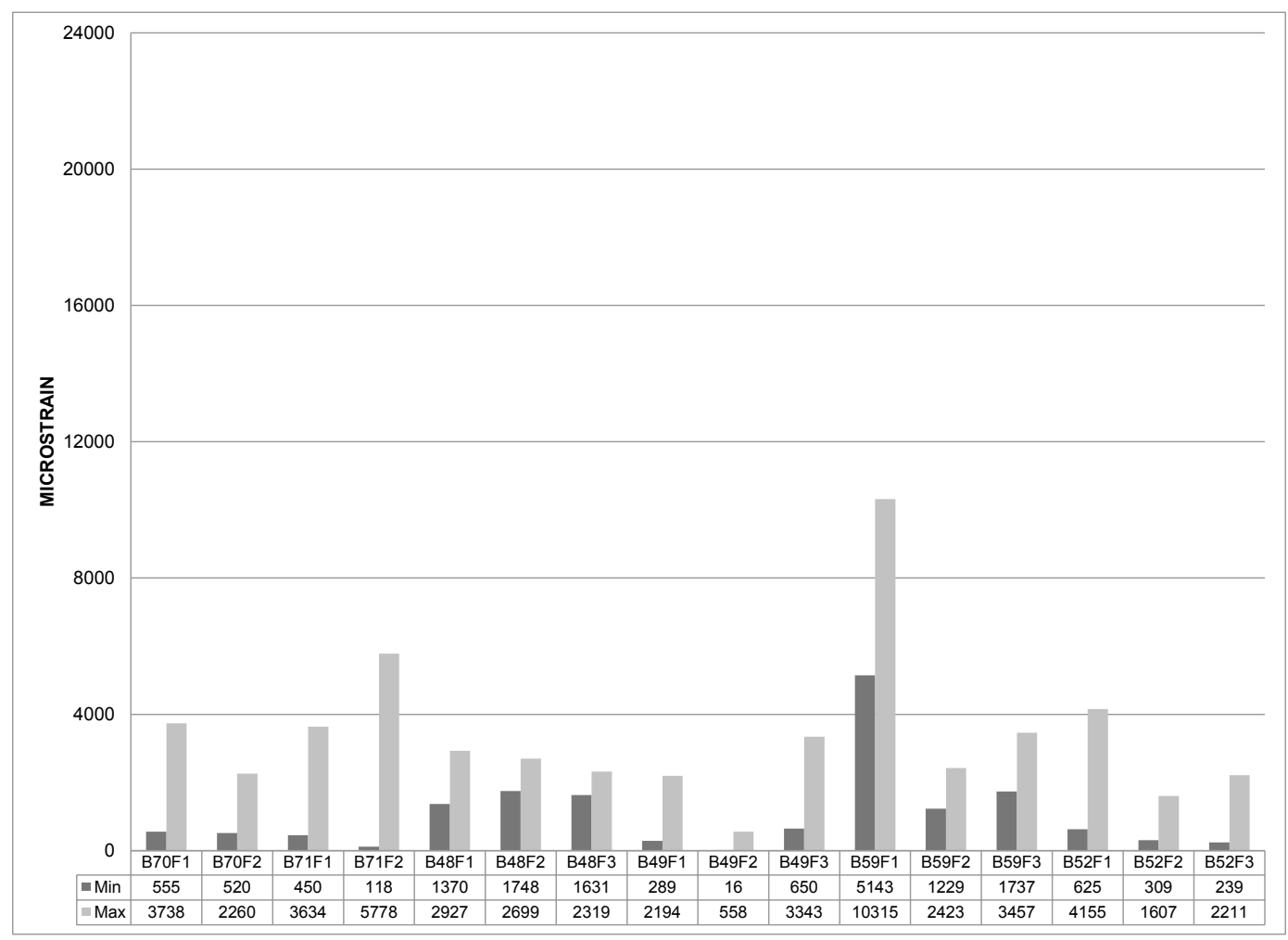

Figure 114. Summary of maximum compressive strain measured in C-17 item.

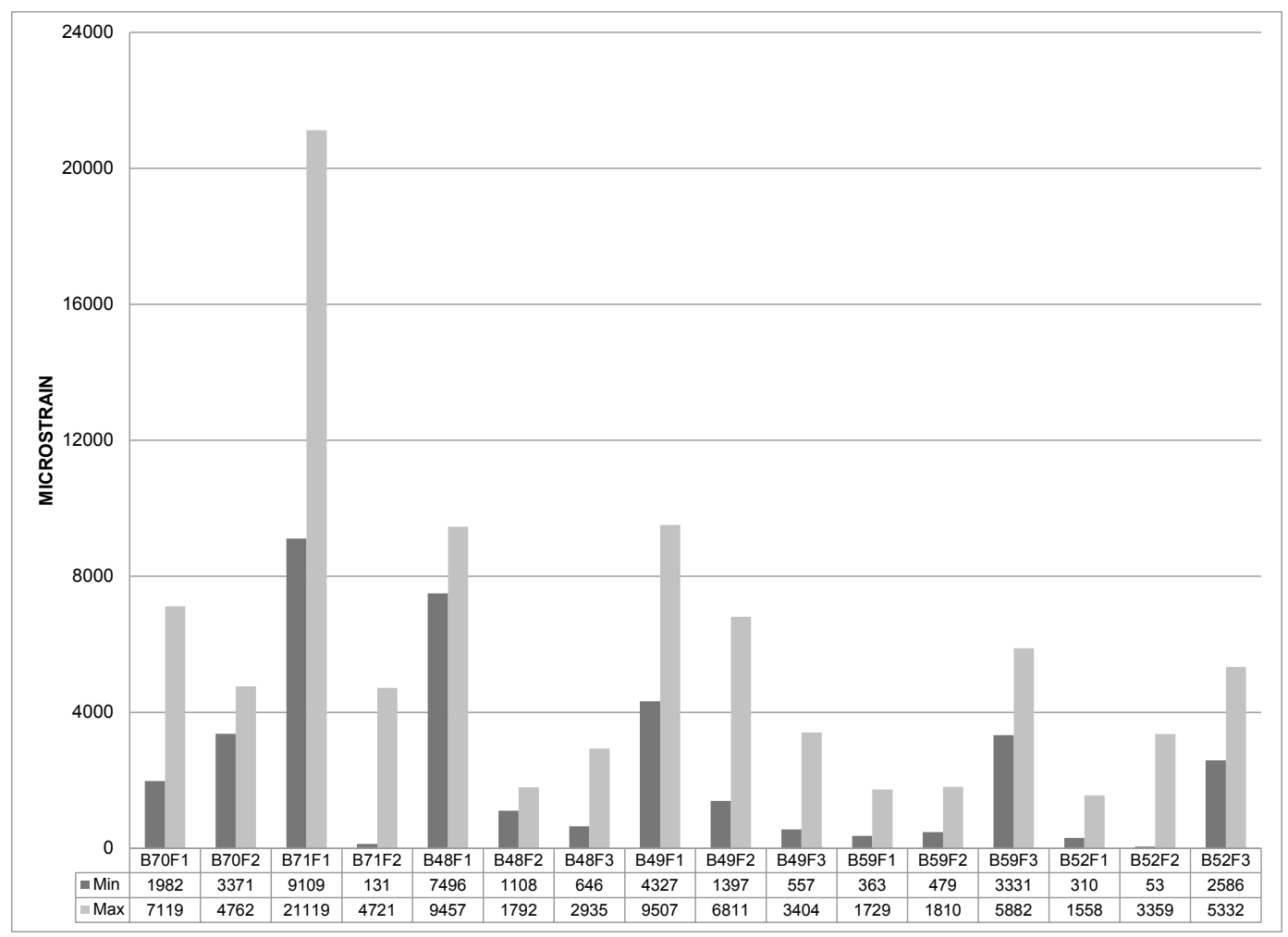




\section{Conclusions and Recommendations}

\subsection{Conclusions}

The objectives of the effort described herein were to evaluate the NAVAIR AM2 brickwork pattern with new and refurbished matting over a voided and non-voided subgrade with a CBR of 6 . Two individual sections of matting were tested consecutively. The first consisted of one item with the mat placed over a subgrade with voids and subjected to simulated F-15E traffic in two lanes centered $4.5 \mathrm{in}$. either side of the centerline of the excavated voids. The second section consisted of two items, one for simulated F-15E traffic applied in a normally distributed pattern and the other for simulated $\mathrm{C}-17$ traffic applied in a normally distributed pattern. Permanent deformation and mat breakage were monitored, and strain data were recorded continuously. The results from the test section were compared to those documented in previous tests where AM2 Mod 5 was installed in a brickwork configuration (Table 2). The information obtained from this evaluation will be used to determine operational limitations when a voided subgrade is encountered and when refurbished AM2 matting is used.

The following conclusions were derived from accelerated traffic testing of the AM2 airfield matting system conducted in October - November 2012:

- The AM2 brickwork pattern with refurbished matting, when placed on a subgrade with voids, was able to sustain 322 passes before the first panel failure occurred. Although higher strain measurements were recorded over a voided subgrade (F-15E-V item) than over a uniform subgrade ( $\mathrm{F}-15 \mathrm{E}$ item), the existence of voids of different sizes underneath the mat panels did not appear to affect the performance of the mat systems. Mat damage was prevalent in refurbished mat panels.

- The AM2 brickwork pattern with refurbished matting, when placed on a uniform subgrade, was able to sustain 430 passes of simulated $\mathrm{F}-15 \mathrm{E}$ traffic before failure of two refurbished panels. The test item was not taken to failure. However, when a direct comparison is made at the same pass level to the results reported by Rushing and Tingle (2007), the extent of mat breakage was greater in refurbished panels. Therefore, the existence of refurbished AM2 matting, particularly older 
versions of AM2 (prior to Mod 5), in an assembled AM2 surface accelerated the rate of failure of the installed system.

- The AM2 brickwork pattern with refurbished matting, when placed on a uniform subgrade, was able to sustain 1,308 passes of simulated C-17 traffic before failure due to mat breakage. The existence of refurbished matting did not significantly reduce the performance when compared to results of identical tests with new AM2 Mod 5. This is likely attributed to the general behavior of AM2 and other mat systems when subjected to simulated C-17 operations, which are typically more sensitive to subgrade permanent deformation than mat fatigue. Different modes of failure were noted in refurbished mat panels.

- The strain gauges placed on areas of high stress concentrations of the upper underlap and lower overlap end connector rails functioned as designed to monitor strains during trafficking. Initial data analysis showed that the gauge responses correctly followed the expected load paths. Strain magnitude varied depending on the location and position of the aircraft simulator. Compressive strains were generally higher in magnitude for panels that failed at the connection. For the $\mathrm{C}-17$, the magnitude of compressive strain reached as much as 21,000 microstrain. For the F-15E, strains reached 7,000 microstrain on a uniform subgrade and nearly 14,000 microstrain on a voided subgrade.

\subsection{Recommendations}

Based on the airfield mat evaluations described herein, the following recommendations are provided:

- Although the existence of voids on the subgrade surface did not appear to affect the performance of $\mathrm{AM} 2$, the criteria established by NAWCADLKE-MISC-48J200-0011 (Naval Air Warfare Center 2006), although conservative, should continue to be used to avoid unexpected damage to the mat.

- The results of the test described herein validate the expectations of the authors that the performance life of the AM2 system is reduced when refurbished panels are used for surfacing airfields. It is recommended that these panels be closely monitored in the field to avoid successive early failure of connected panels. 


\section{References}

ASTM International. 2008. Standard test method for determination of water (moisture) content of soil by microwave oven heating. Designation: D 4643-08. West Conshohocken, PA.

ASTM International. 2009. Standard test method for use of the dynamic cone penetrometer in shallow pavement applications. Designation: D 6951. West Conshohocken, PA.

ASTM International. 2010. Standard test method for in-place density and water content of soil and soil-aggregate by nuclear methods (shallow depth). Designation: D 6938-10. West Conshohocken, PA.

Berney, E. S., W.D. Hodo, and Vera J.A. 2006. Determination of unit section modulus for finite element modeling of matting systems. ERDC/GSL TR-06-10. Vicksburg (MS): U.S. Army Engineer Research and Development Center

Garcia, L. T. and T. W. Rushing. 2013. AM2 sand subgrade sensitivity test. ERDC/GSL TR-13-10. Vicksburg, MS: U.S. Army Engineer Research and Development Center.

Garcia, L., T. W. Rushing, and Q. S. Mason. 2012. Evaluation of webcore prototype AMX mat system. ERDC/GSL TR-12-14. Vicksburg, MS: U.S. Army Engineer Research and Development Center.

Garcia, L., T. W. Rushing, and Q. S. Mason. 2014a. AM2 25 CBR subgrade sensitivity test. ERDC TR-14-7. Vicksburg, MS: U.S. Army Engineer Research and Development Center.

Garcia. L. , T. W. Rushing, B. A. Williams, and C. A. Rutland.2014b. AM2 100 CBR subgrade sensitivity test. ERDC TR-14-37. Vicksburg, MS: U.S. Army Engineer Research and Development Center.

Gonzalez, C. R., and T. W. Rushing. 2010. Development of a new design methodology for structural airfield mats. International Journal of Pavement Research and Technology 3.3 (2010): 102-109.

Naval Air Warfare Center. 2006. Expeditionary airfield AM2 mat certification requirements. NAWCADLKE-MISC-48J200-0011. Lakehurst, NJ: Naval Air Warfare Center, Aircraft Division.

Rushing, T. W., and J. S. Tingle. 2007. AM2 and M19 airfield mat evaluation for the rapid parking ramp expansion program. ERDC/GSL TR-07-5. Vicksburg, MS: U.S. Army Engineer Research and Development Center.

Rushing, T. W., and N. Torres. 2007. Prototype mat system evaluation. ERDC/GSL TR07-29. Vicksburg, MS: U.S Army Engineer Research and Development Center. 
Rushing, T. W., and Q. S. Mason. 2008. AM2 15 CBR subgrade sensitivity test for the rapid parking ramp expansion program. ERDC/GSL TR-08-25. Vicksburg, MS: U.S. Army Engineer Research and Development Center.

Rushing, T. W., N. Torres, and Q. Mason. 2008. AM2 1O CBR subgrade sensitivity test for the rapid parking ramp expansion program. ERDC/GSL TR-o8-13. Vicksburg, MS: U.S. Army Engineer Research and Development Center.

Rushing, T. W., L. Garcia, and Q. S. Mason. 2011. Large-scale 6-CBR prototype mat system evaluation for the AMX program. ERDC/GSL TR-11-37. Vicksburg, MS: U.S. Army Engineer Research and Development Center.

Rushing, T. W., L. Garcia, and Q. S. Mason. 2012 Evaluation of faun aluminum mat systems. ERDC/GSL TR-12-32. Vicksburg, MS: U.S. Army Engineer Research and Development Center.

Rushing, T.W., L. Garcia, J.S. Tingle, P.G. Allison, and C.A. Rutland. 2014. AM2 3-4 alternate lay pattern evaluation. ERDC/GSL TR-14-38. Vicksburg, MS: U.S. Army Engineer Research and Development Center.

U.S. Army Engineer Research and Development Center. 1995. Standard test method for California Bearing Ratio of soils in place. Designation: CRD-C 654-95.

Vicksburg, MS: U.S. Army Engineer Research and Development Center. 


\section{Appendix A: EPC data for F-15E item}
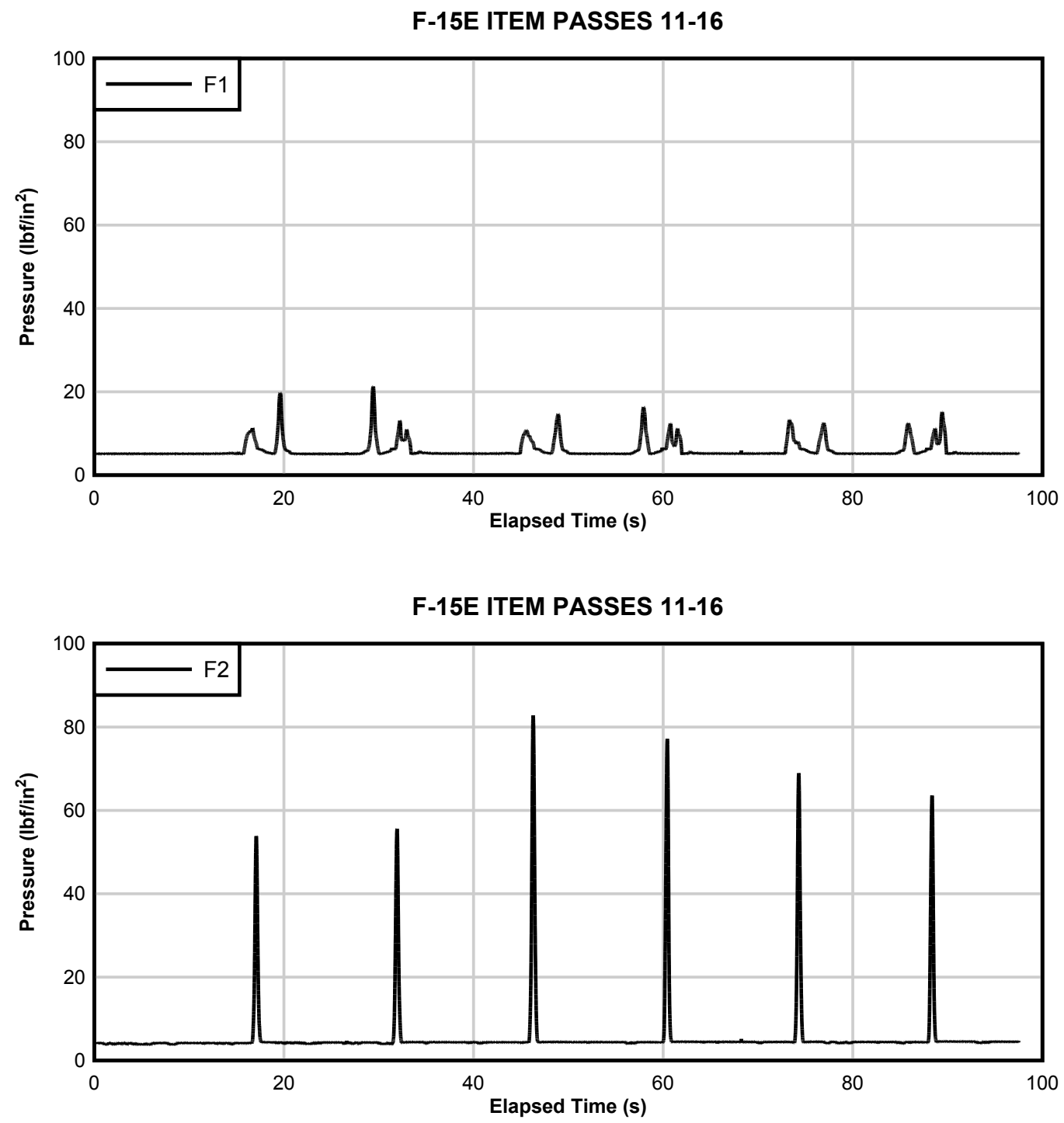
F-15E ITEM PASSES 11-16

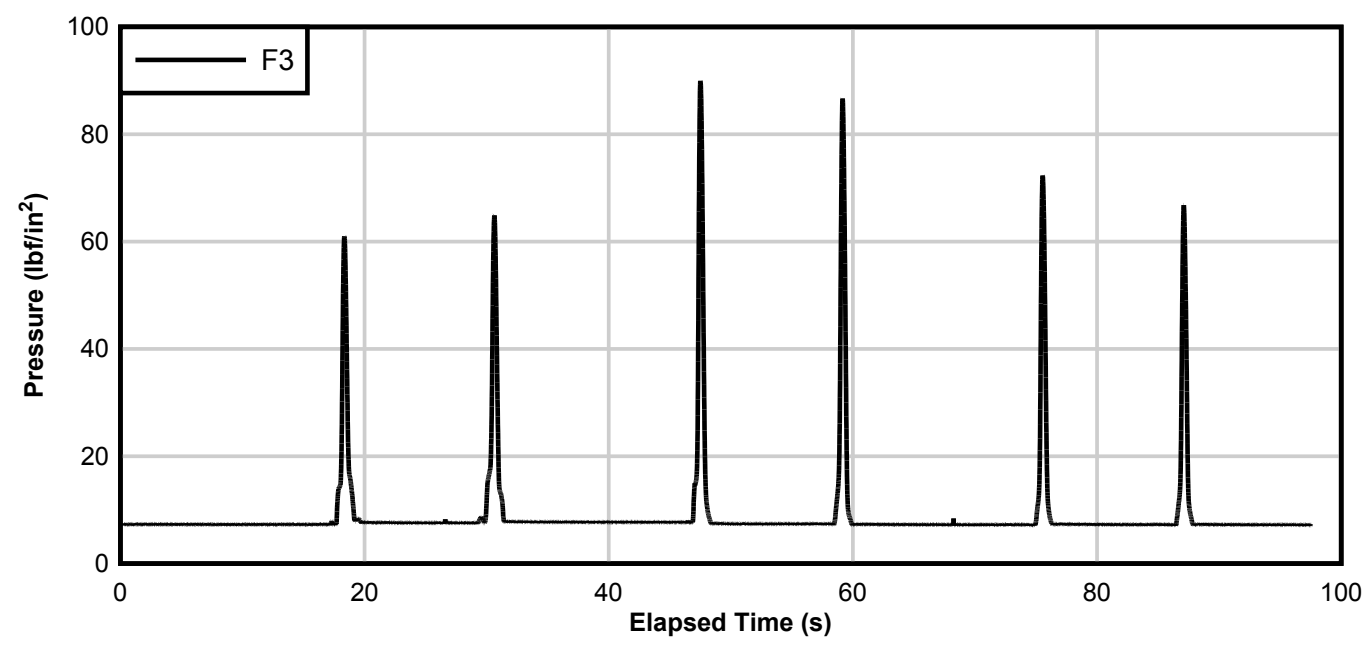

F-15E ITEM PASSES 11-16

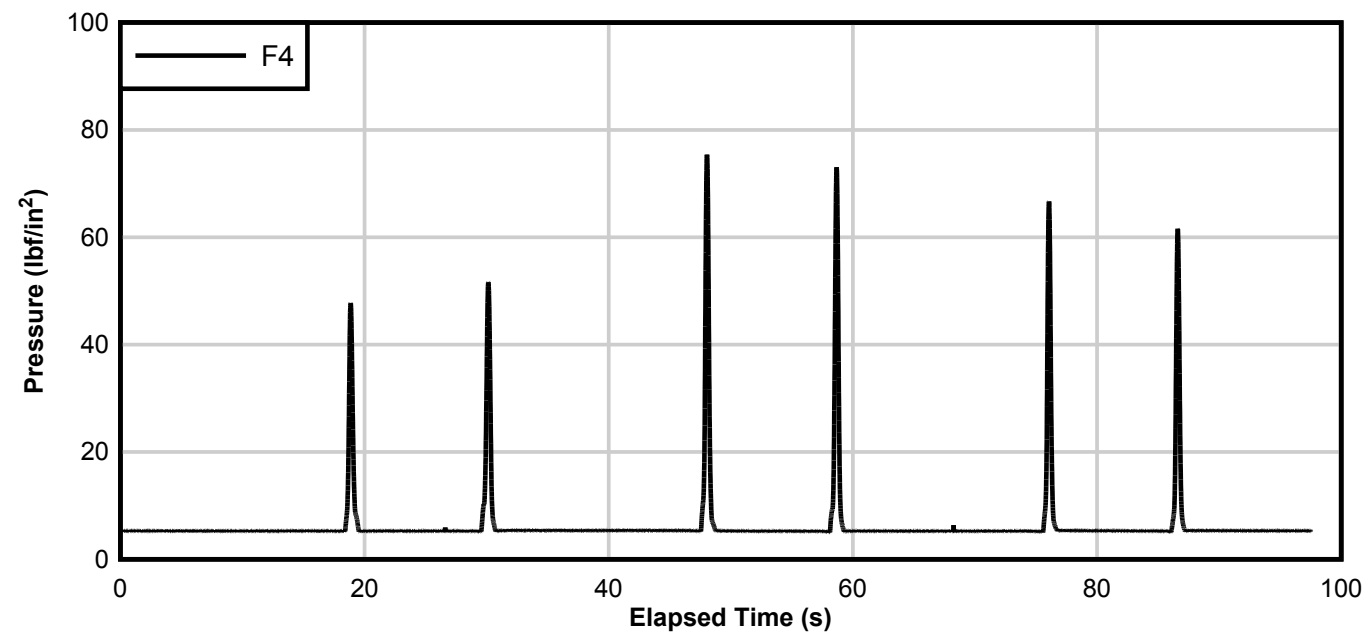

F-15E ITEM PASSES 17-32

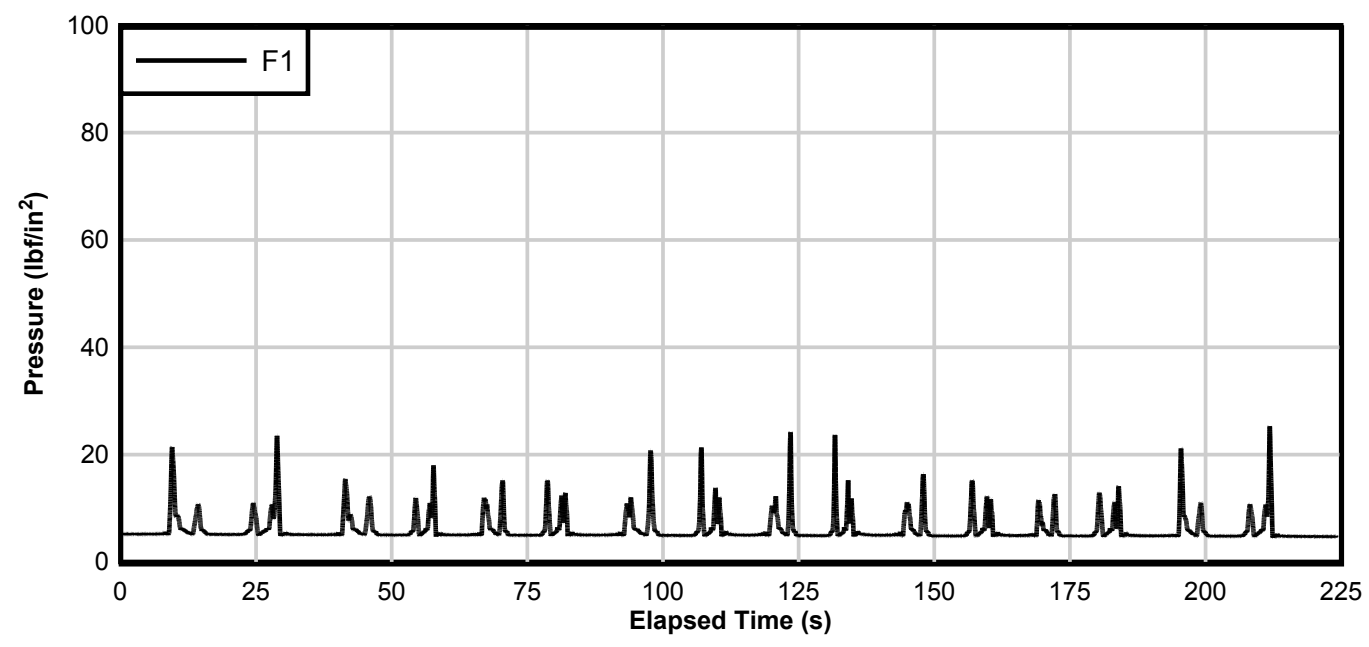


F-15E ITEM PASSES 17-32

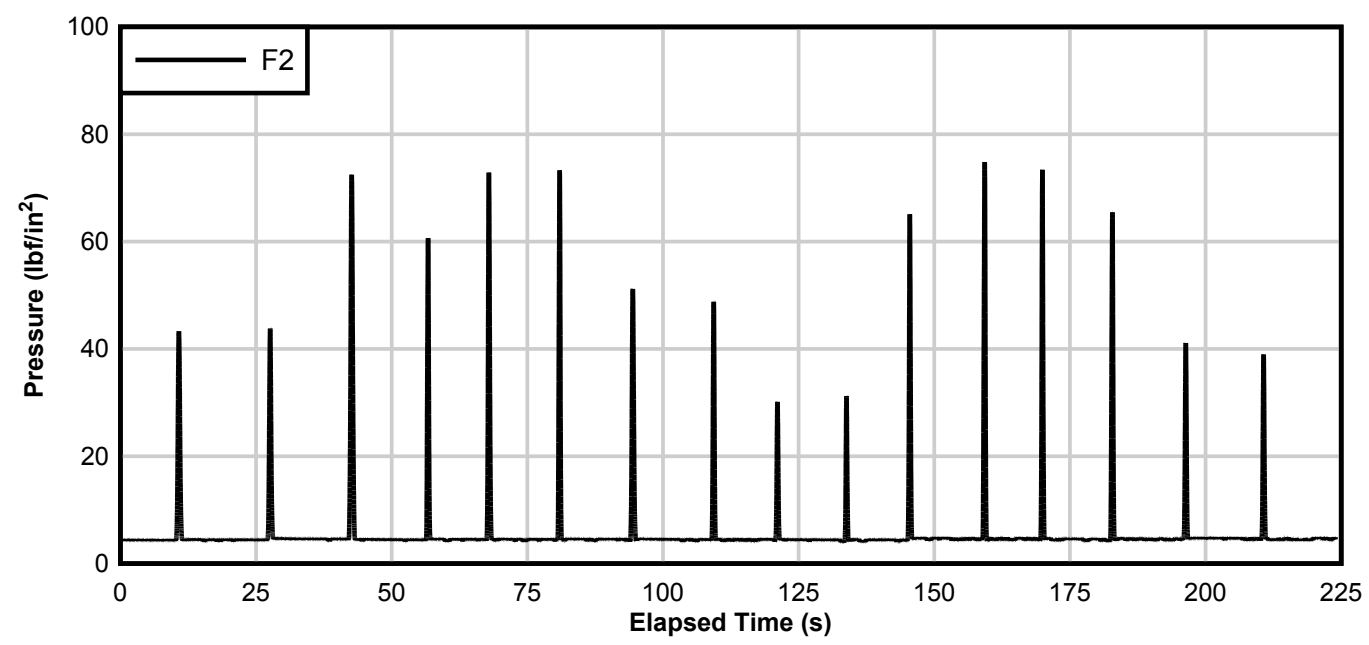

F-15E ITEM PASSES 17-32

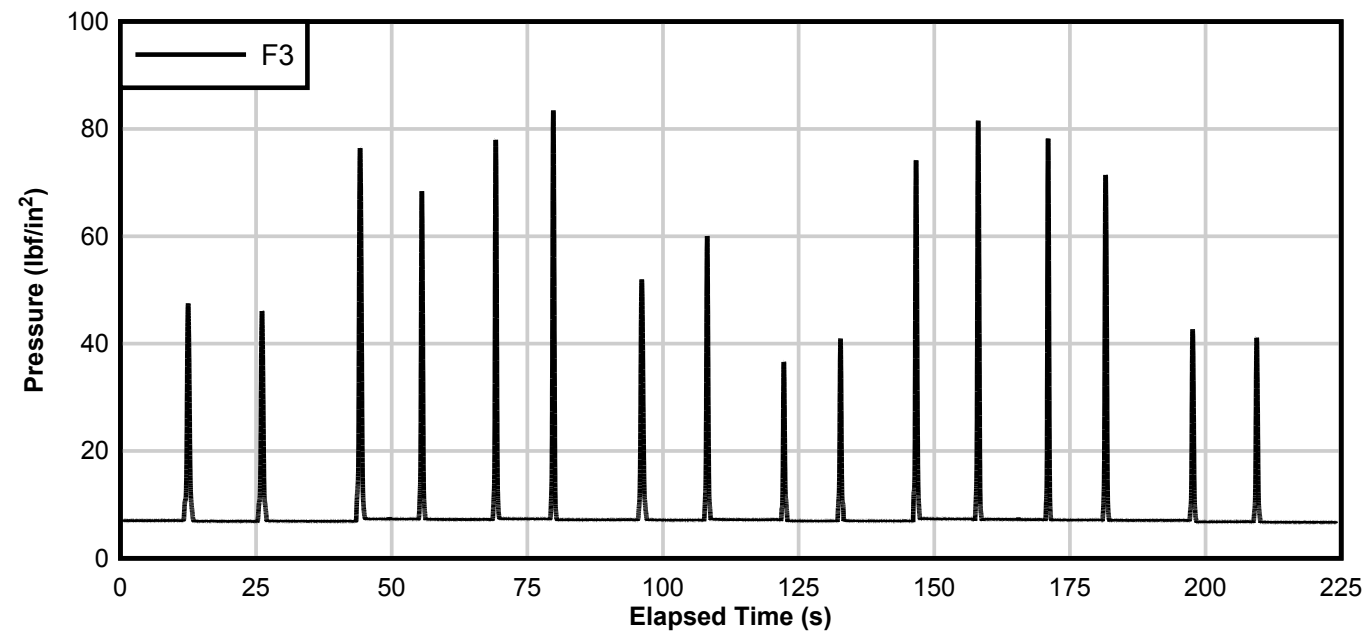

F-15E ITEM PASSES 17-32

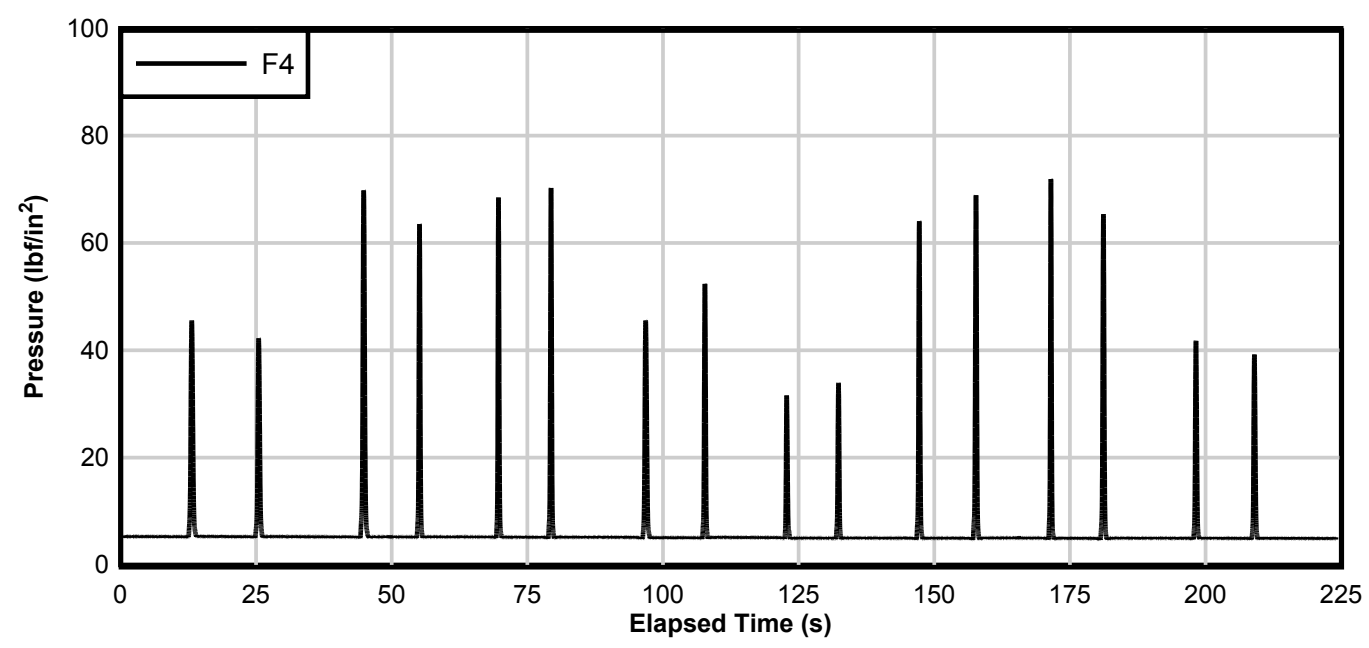


F-15E ITEM PASSES 33-48

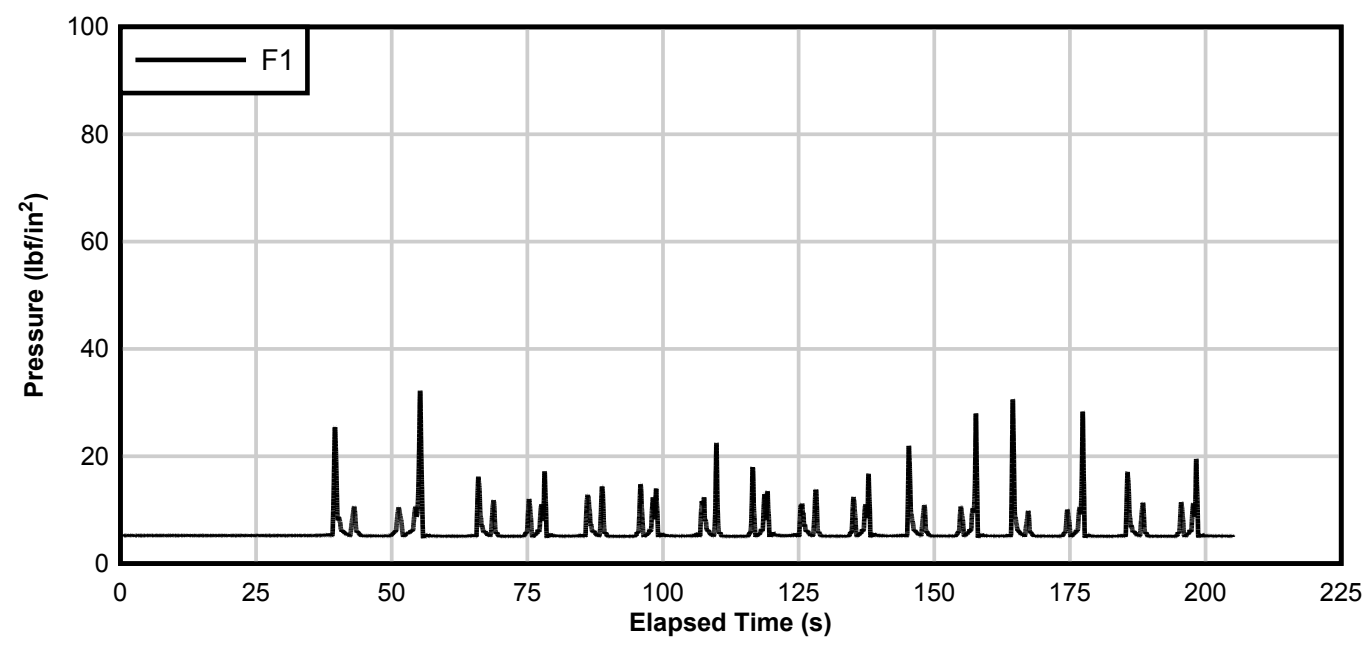

F-15E ITEM PASSES 33-48

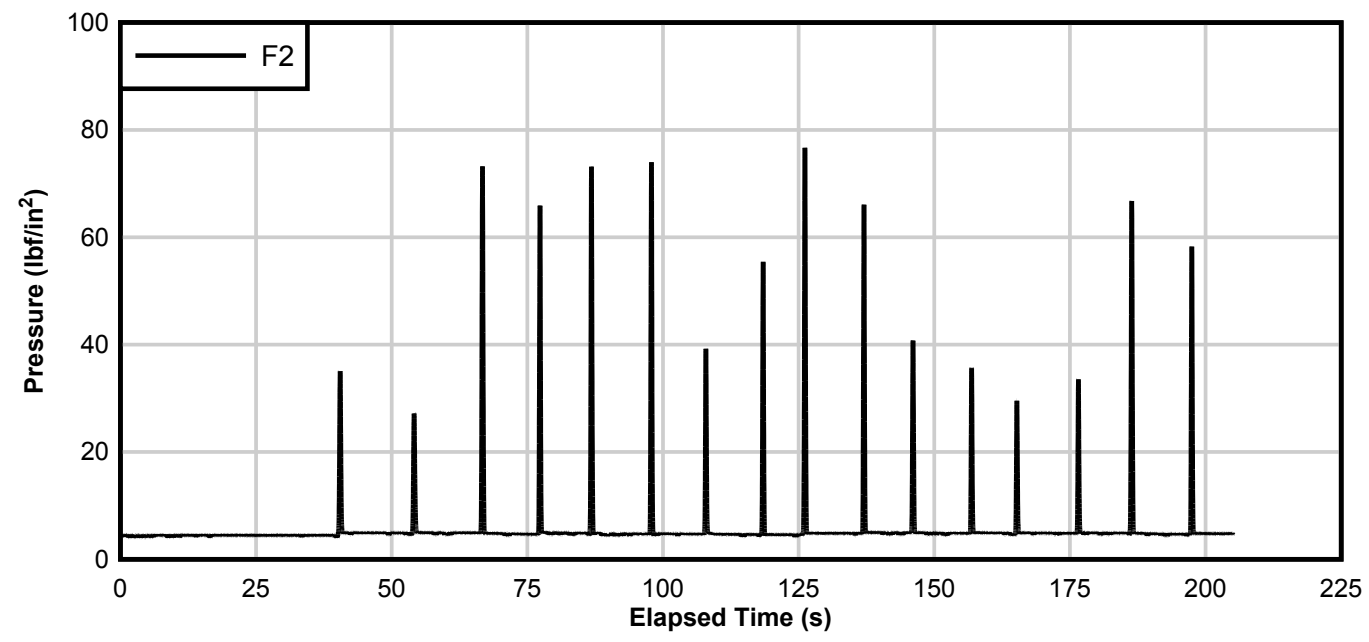

F-15E ITEM PASSES 33-48

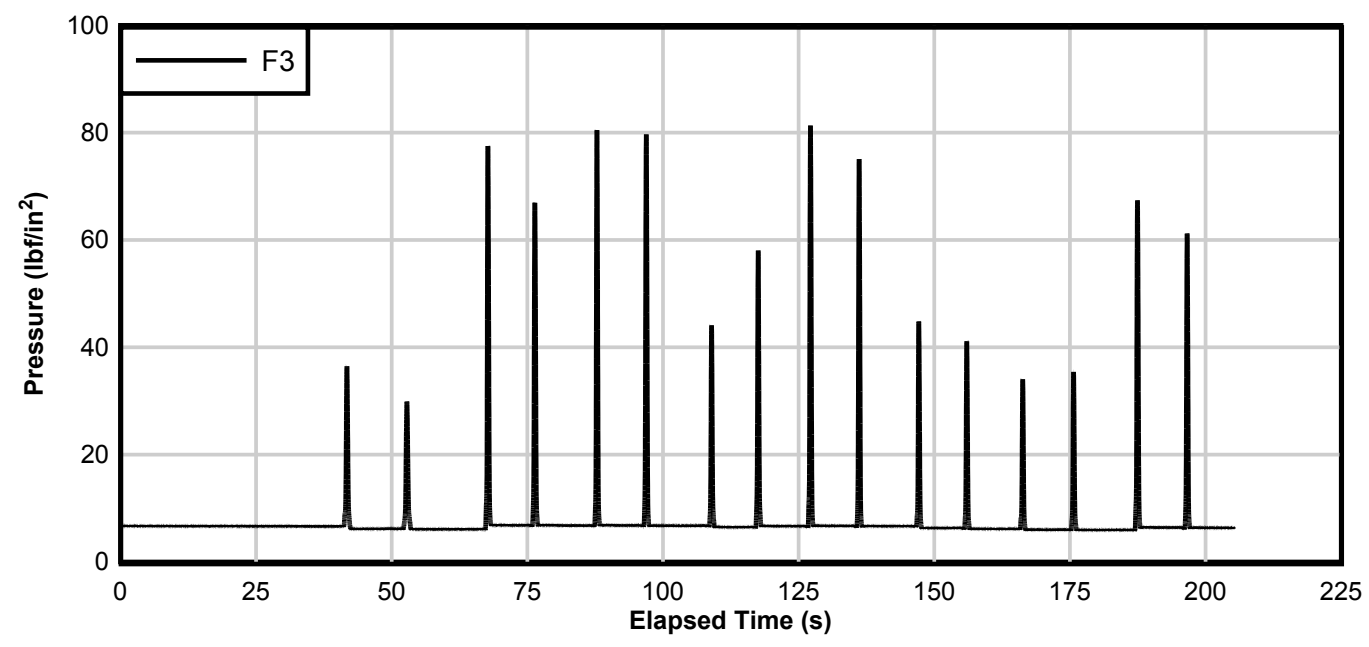


F-15E ITEM PASSES 33-48

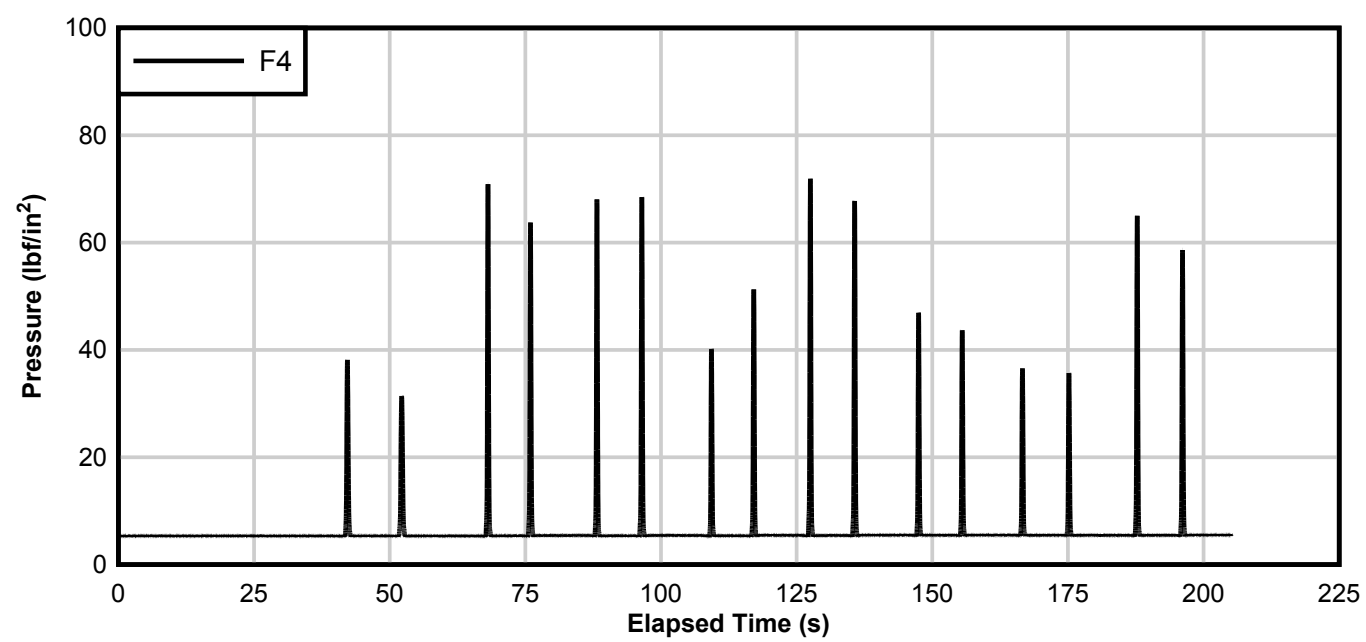

F-15E ITEM PASSES 49-112

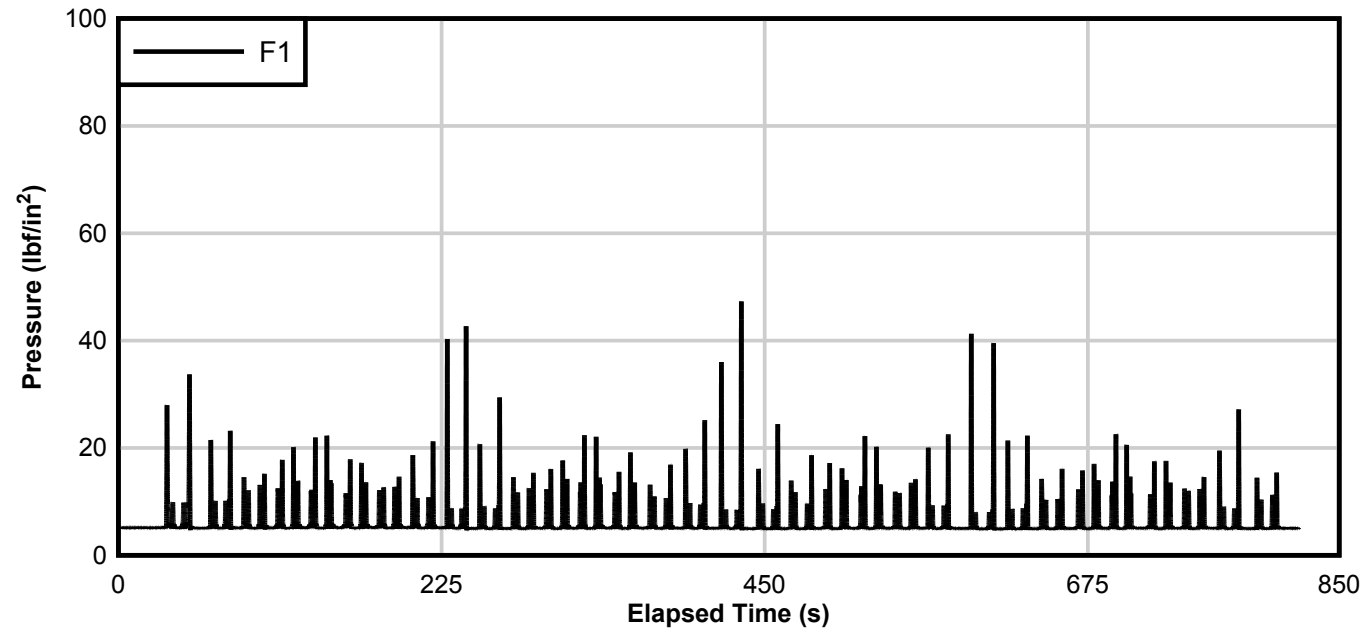

F-15E ITEM PASSES 49-112

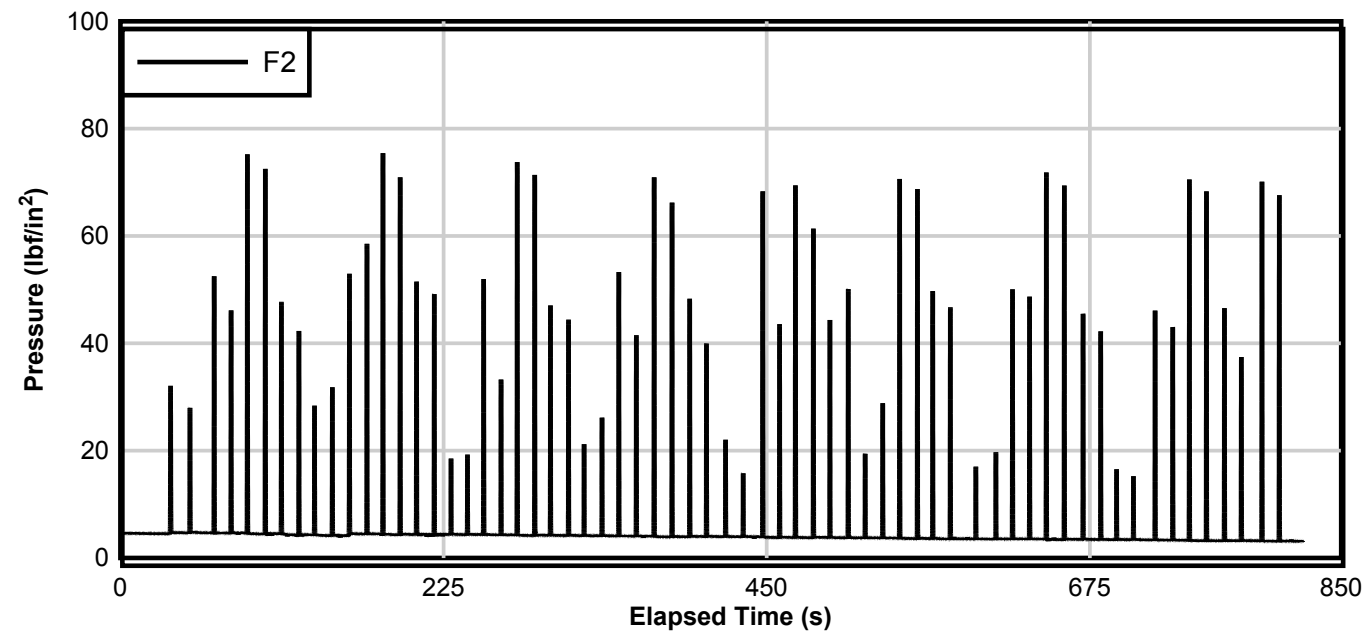


F-15E ITEM PASSES 49-112

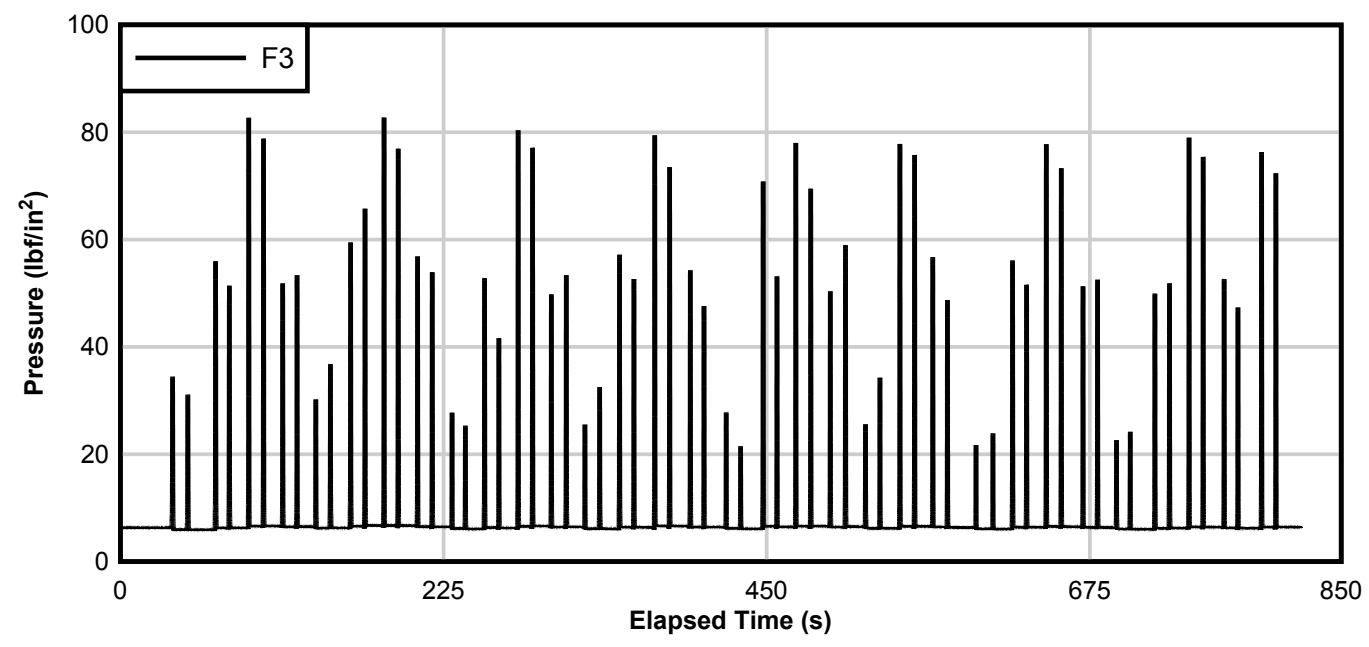

F-15E ITEM PASSES 49-112

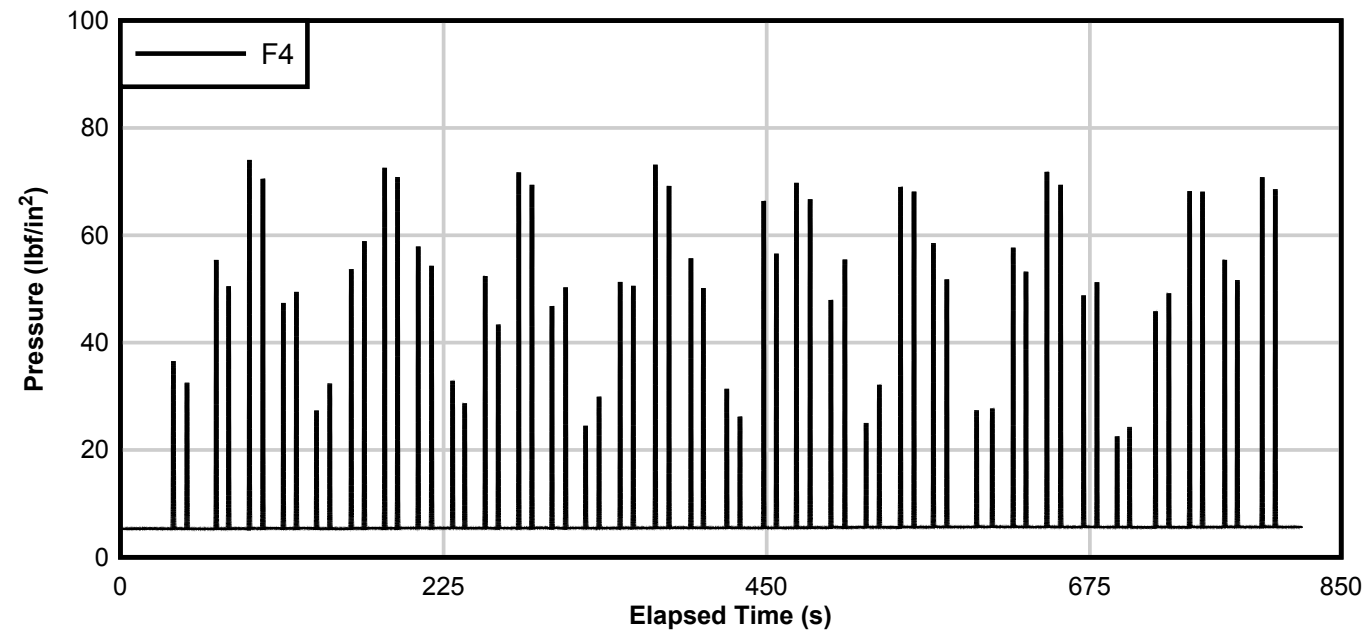

F-15E ITEM PASSES 113-240

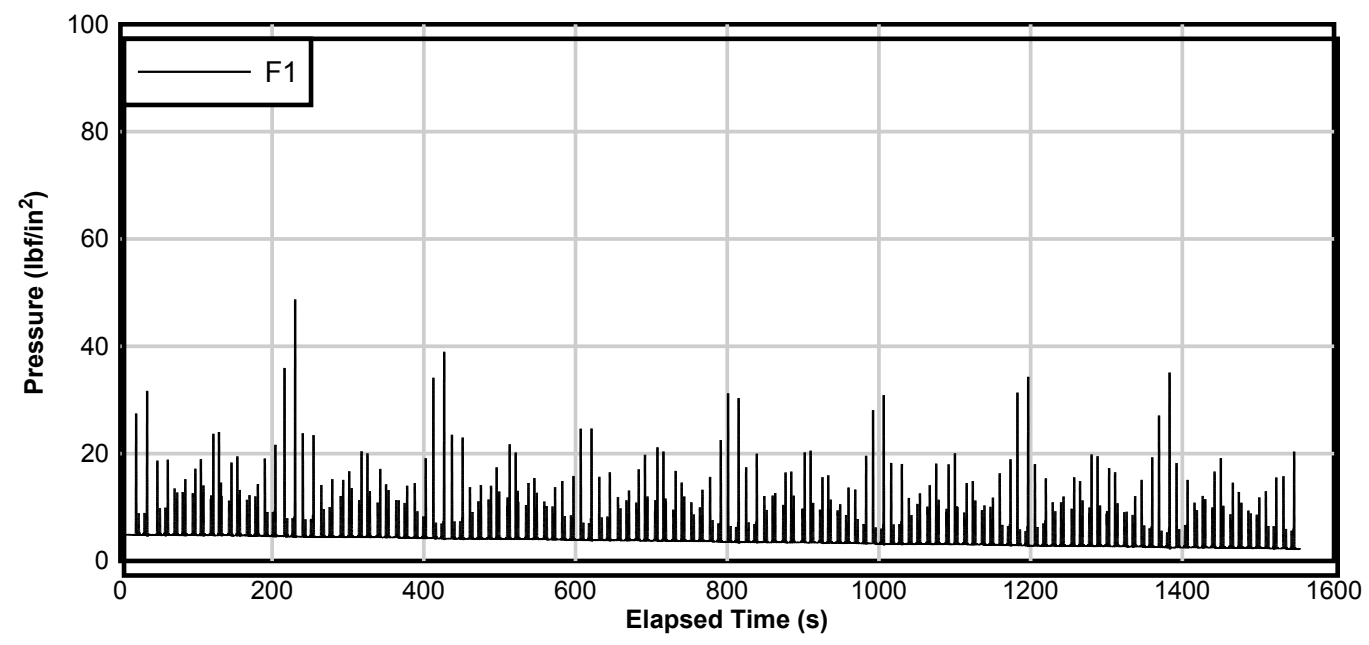


F-15E ITEM PASSES 113-240

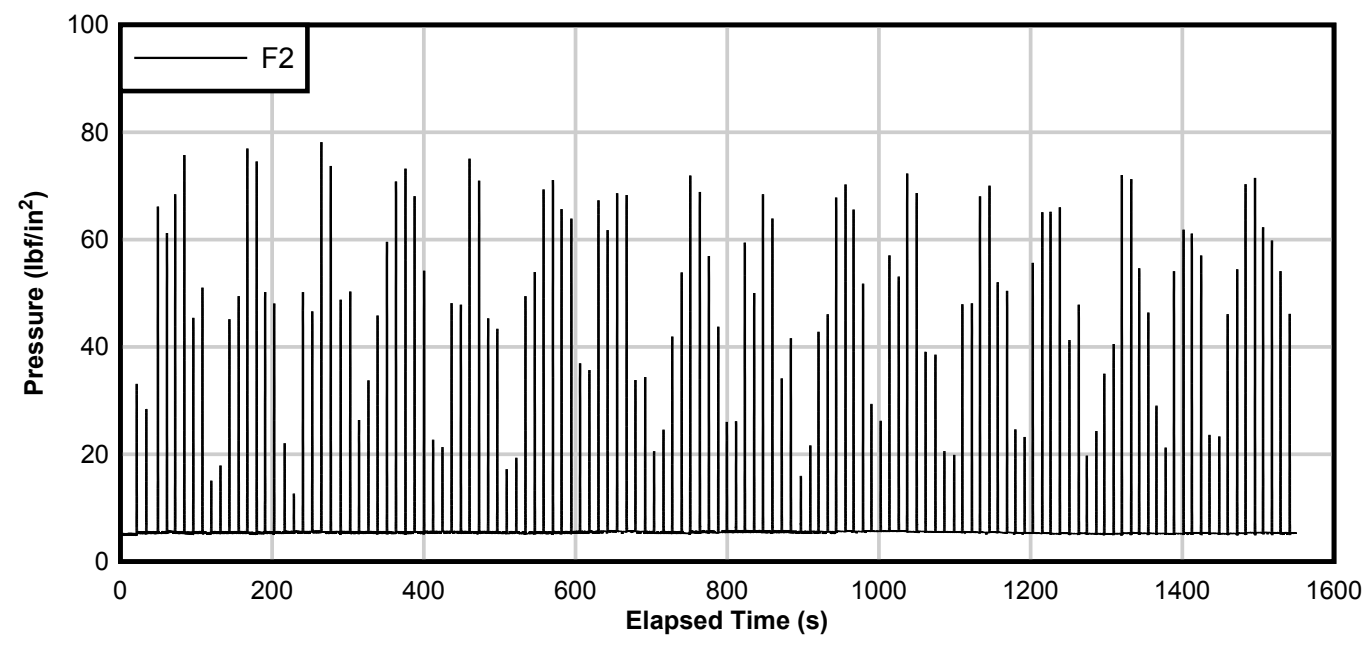

F-15E ITEM PASSES 113-240

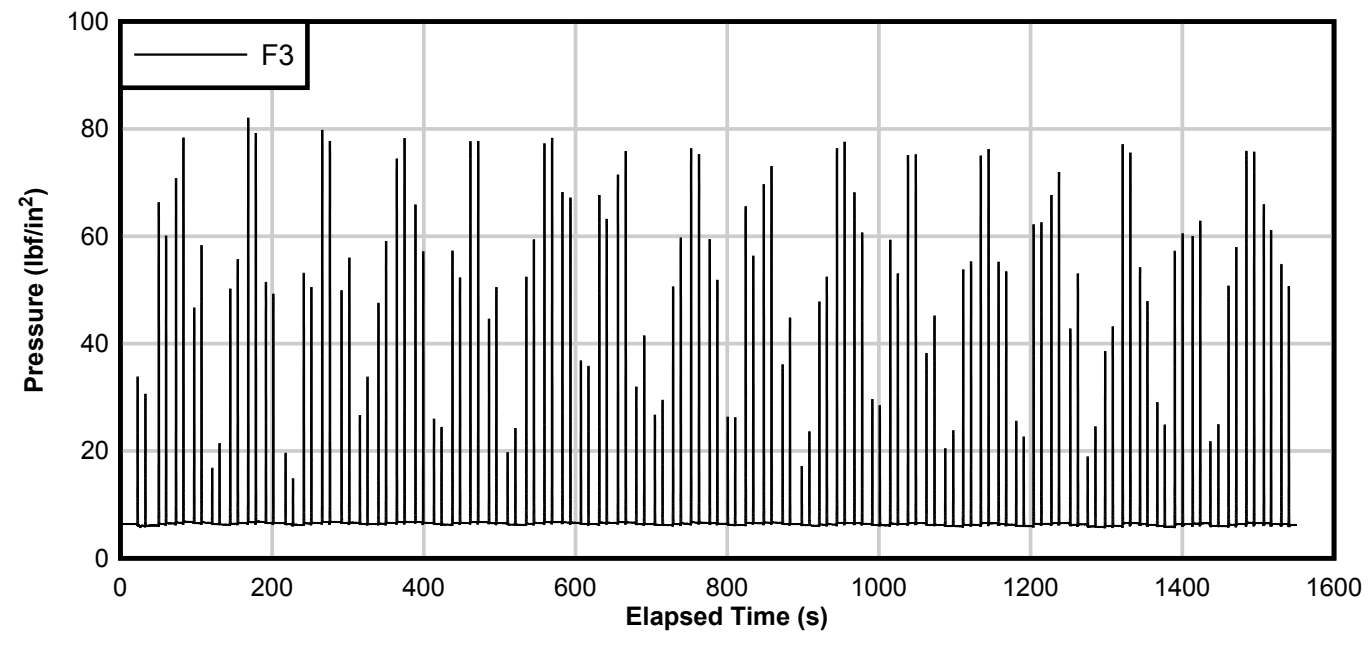

F-15E ITEM PASSES 113-240

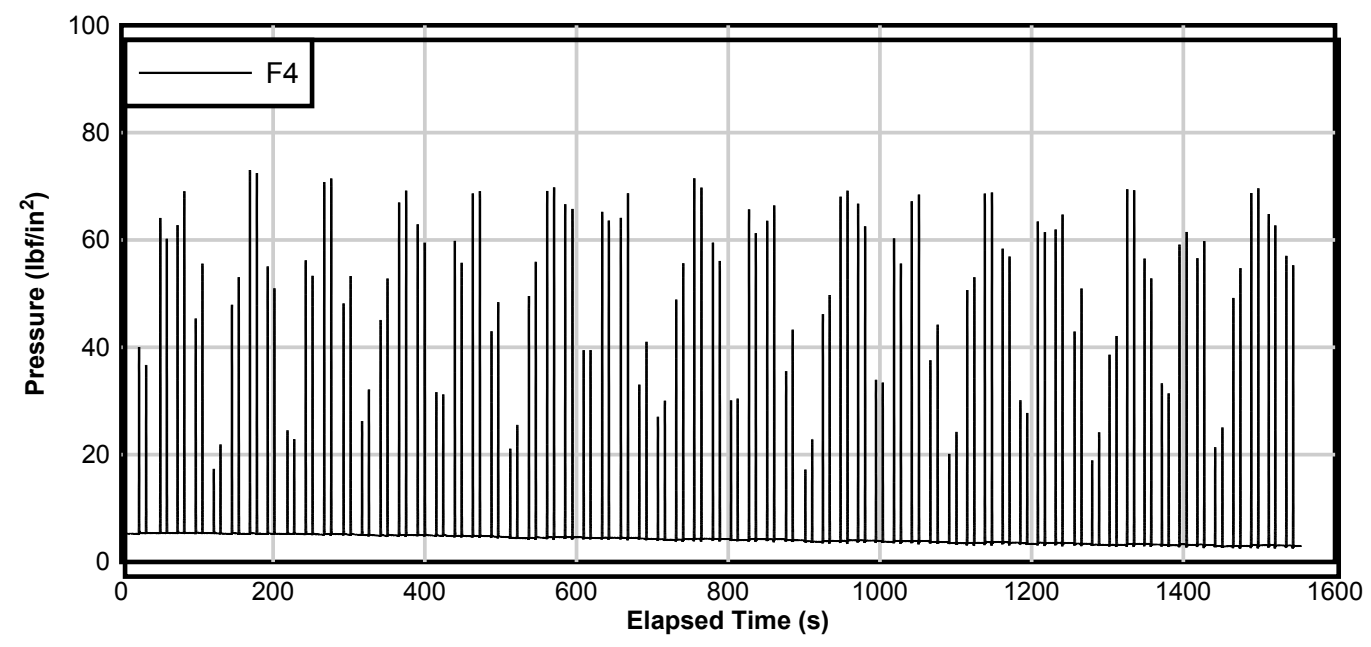




\section{F-15E ITEM PASSES 241-430}

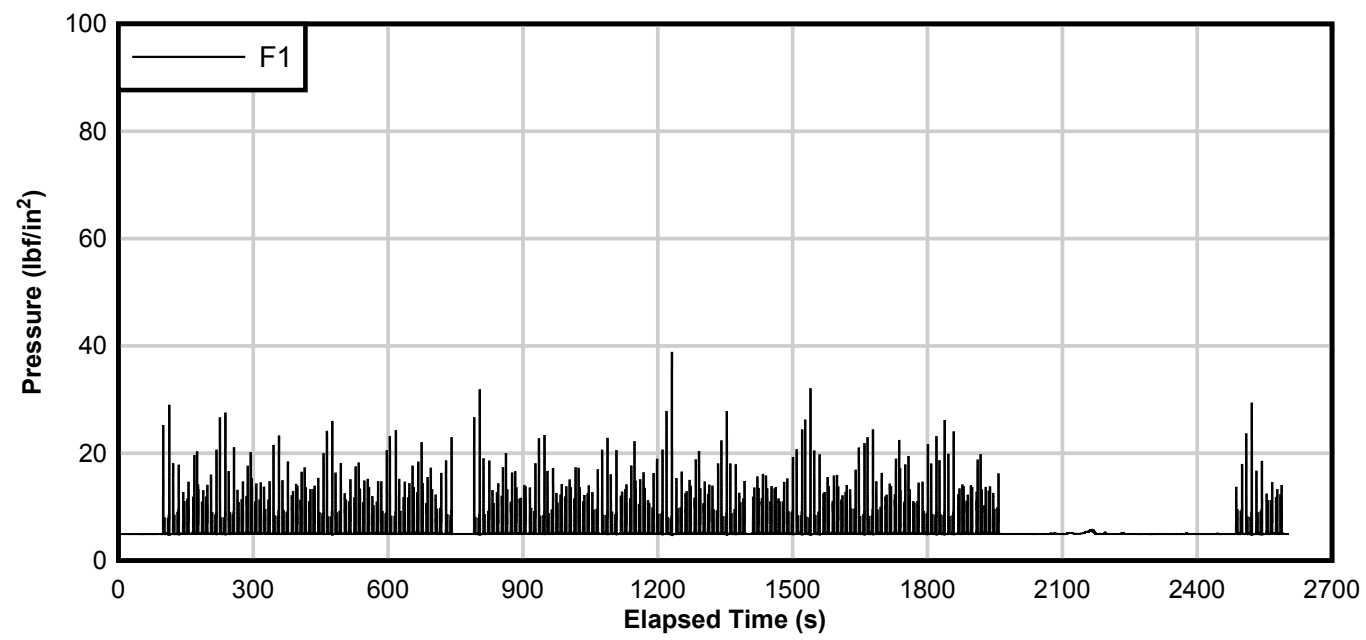

F-15E ITEM PASSES 241-430

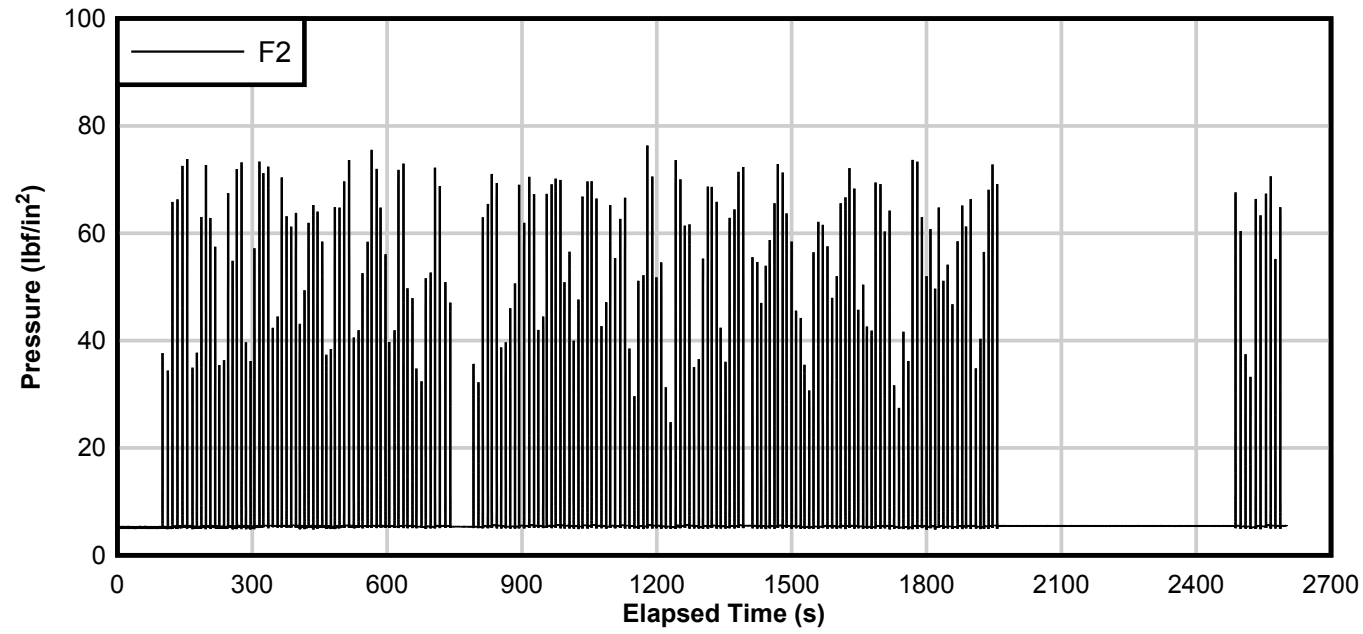

F-15E ITEM PASSES 241-430

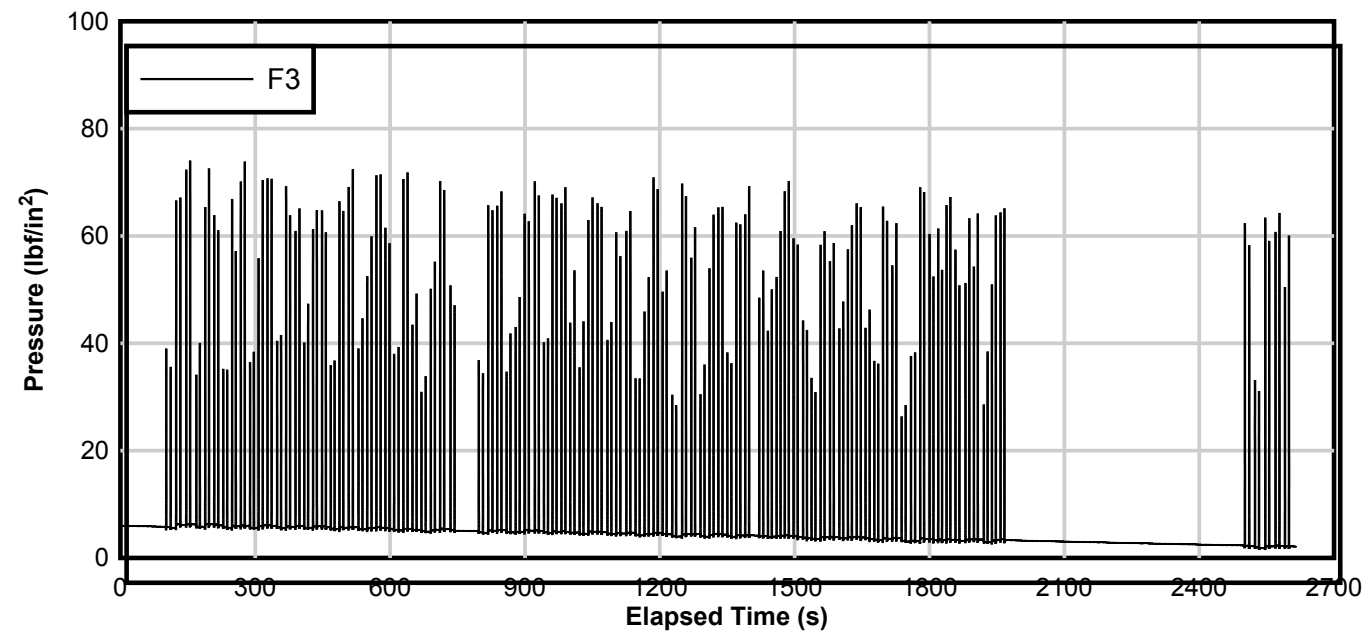




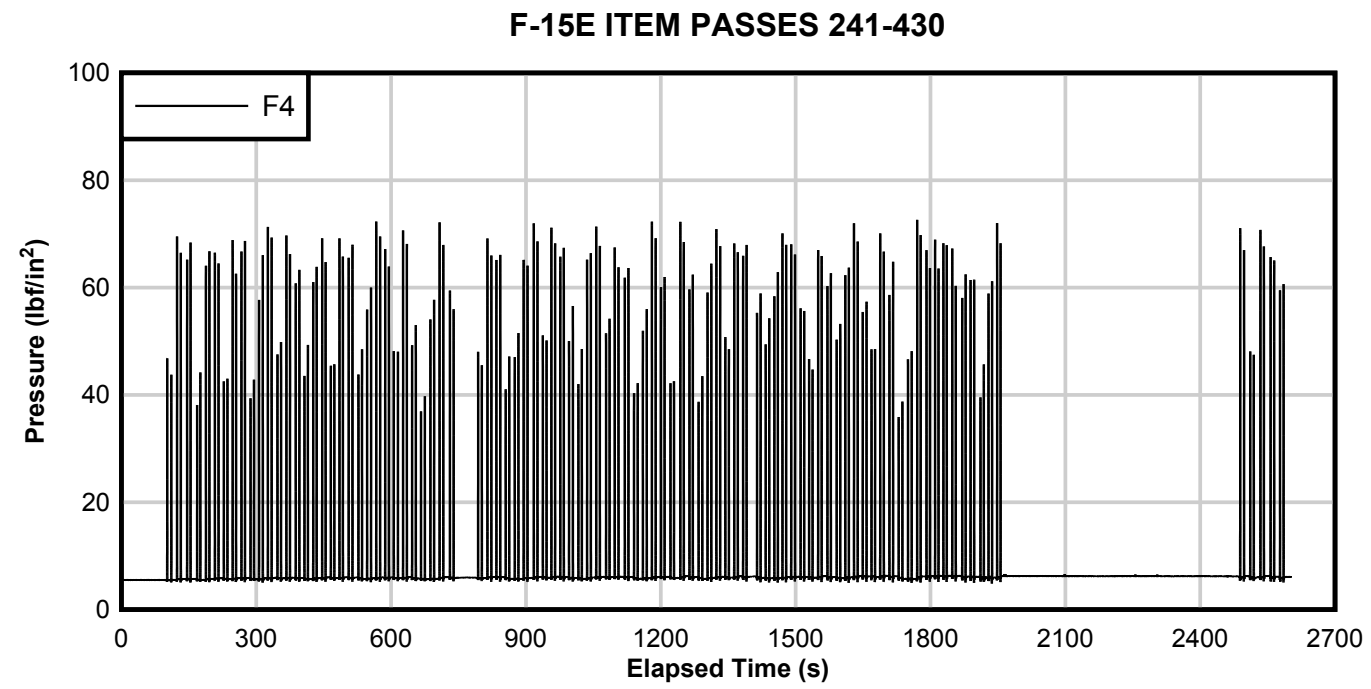




\section{Appendix B: EPC data for C-17 item}
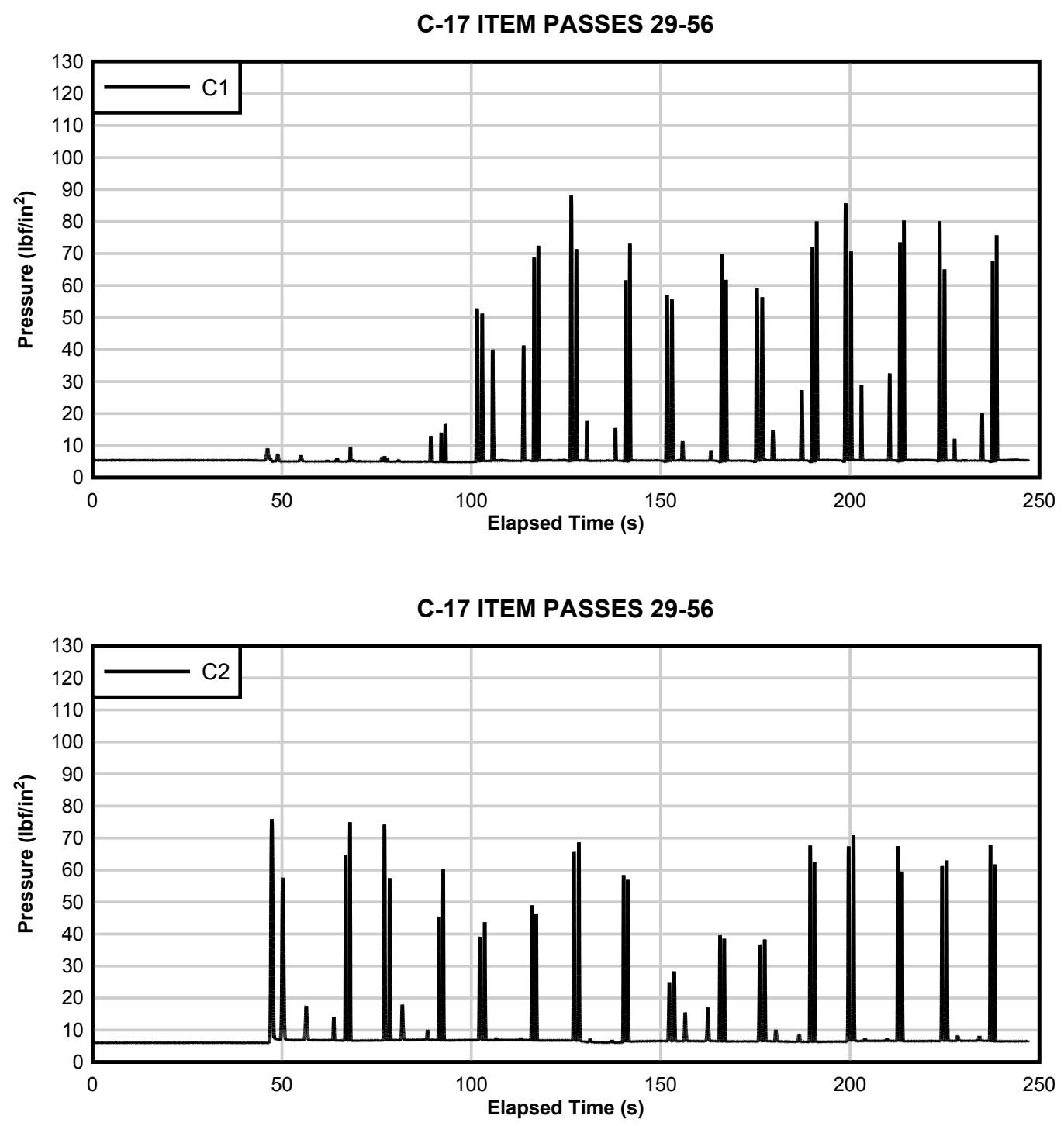


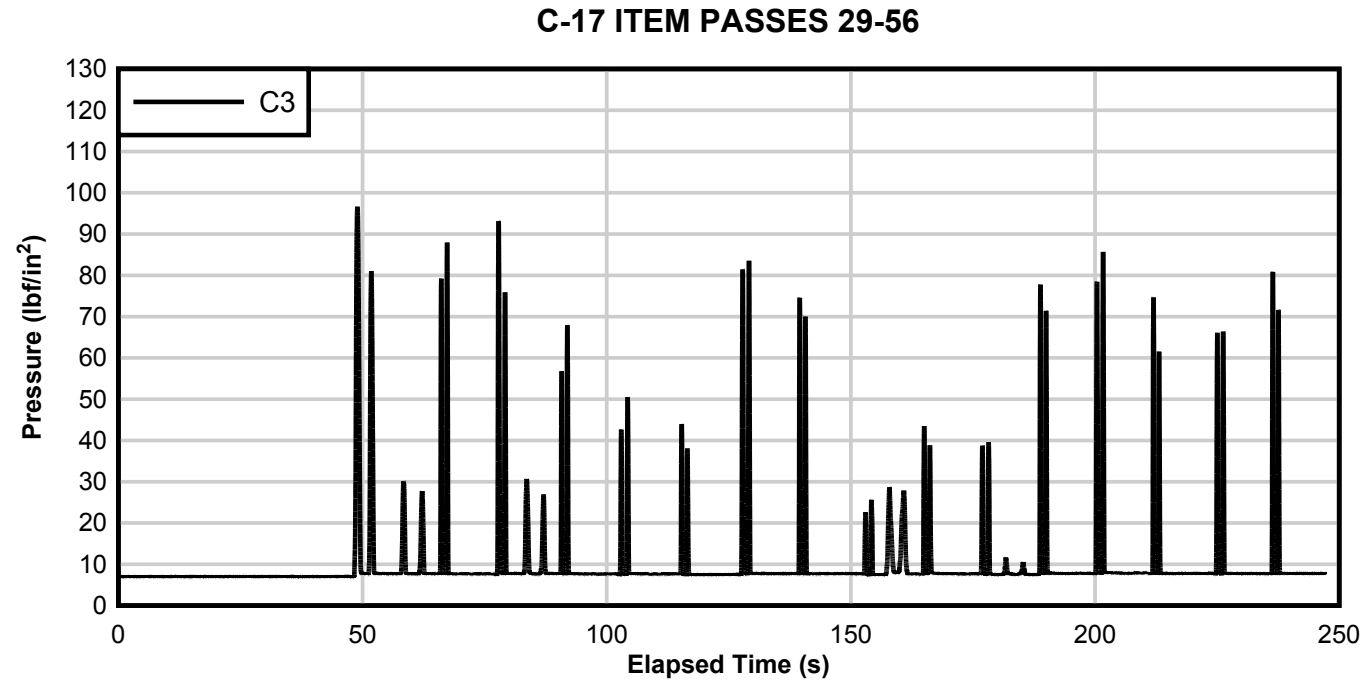

C-17 ITEM PASSES 29-56

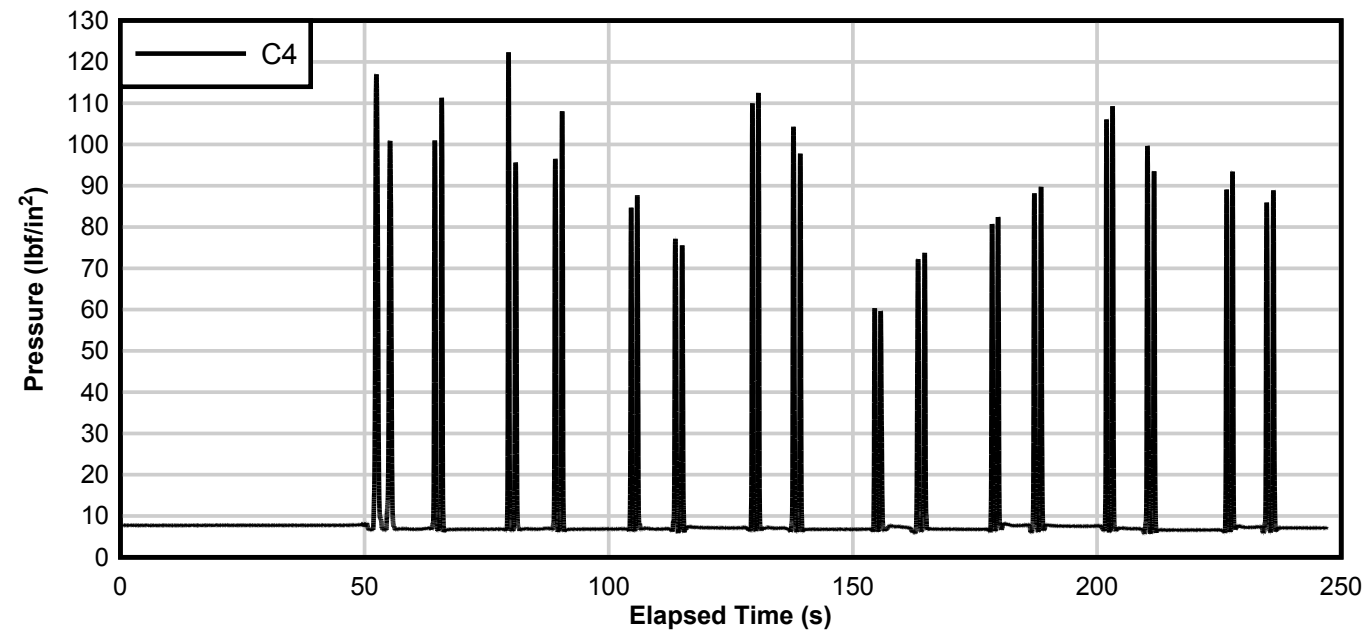

C-17 ITEM PASSES 29-56

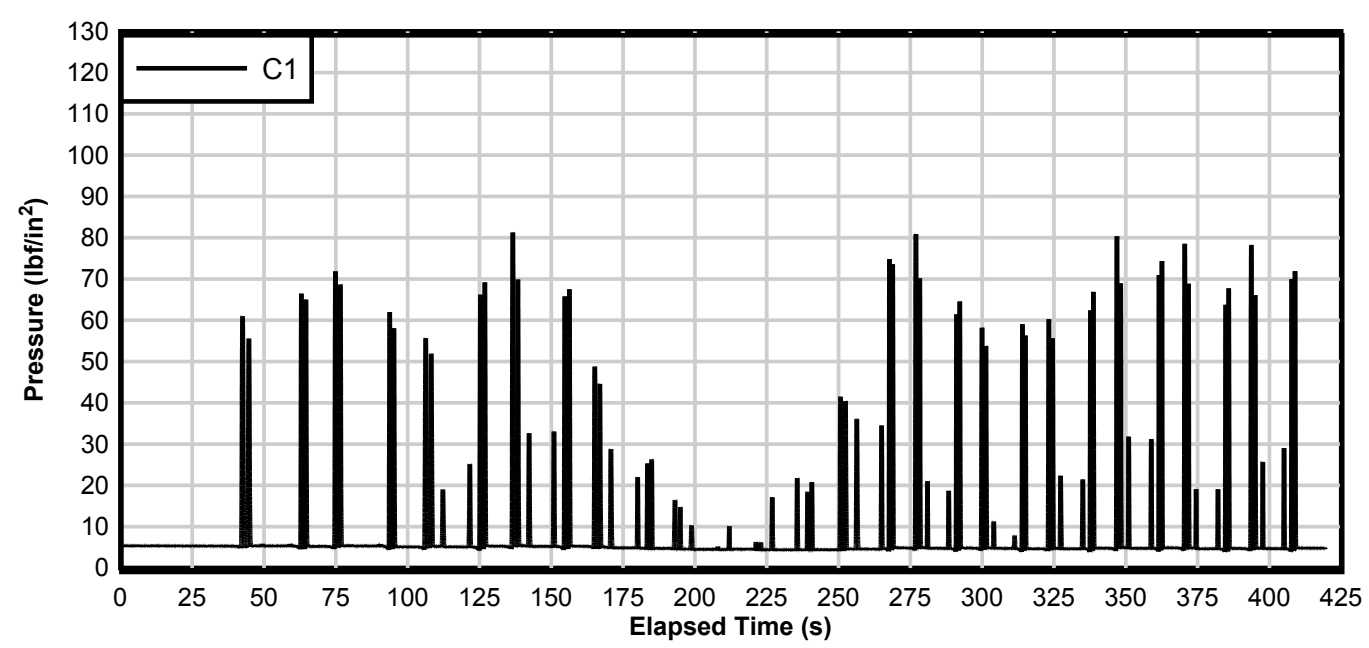




\section{C-17 ITEM PASSES 29-56}

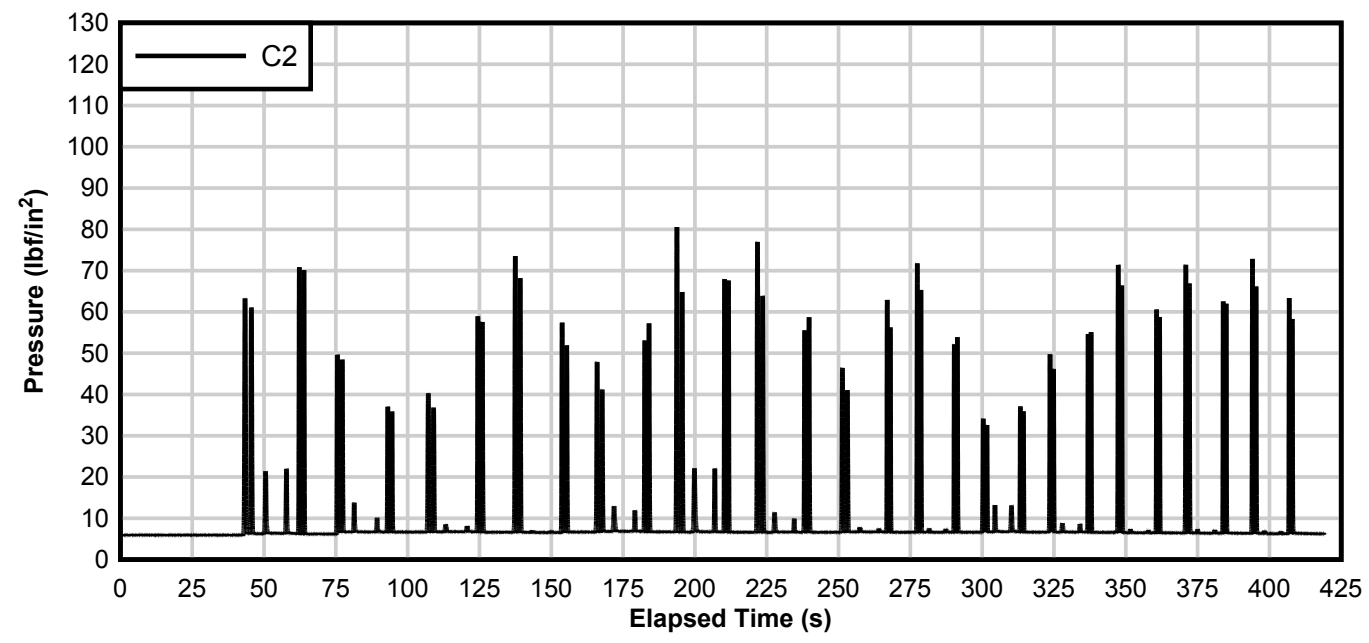

C-17 ITEM PASSES 29-56

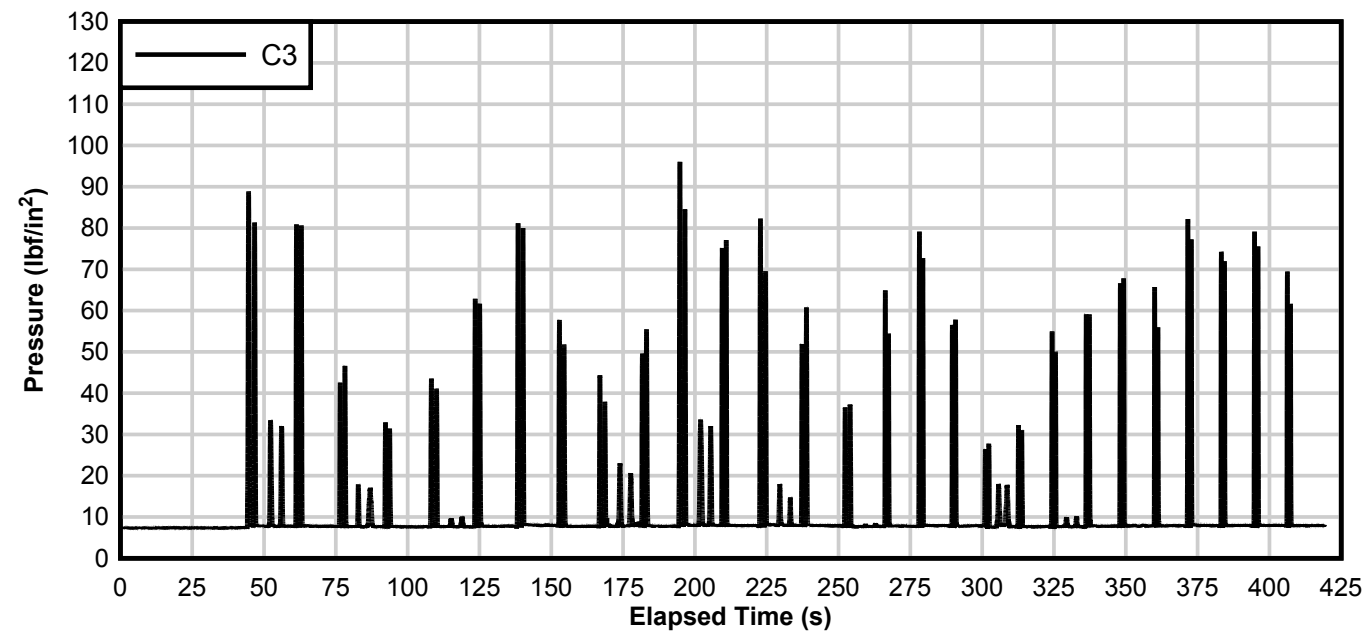

C-17 ITEM PASSES 29-56

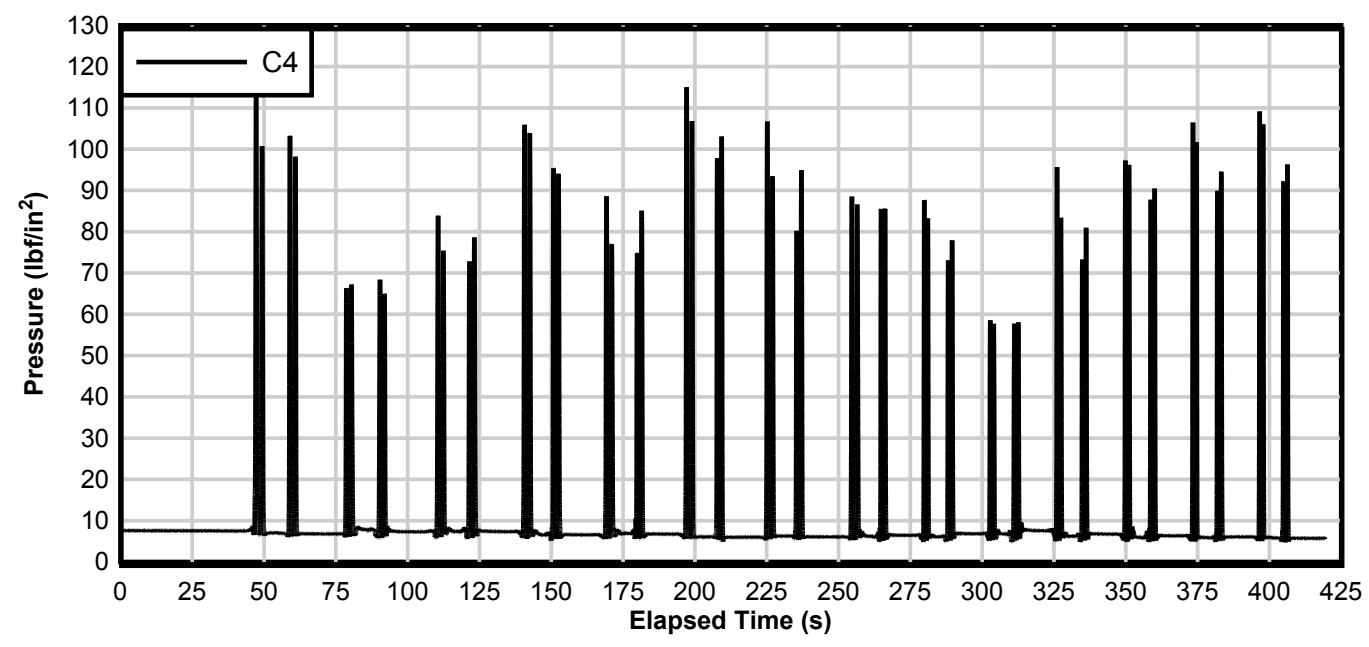



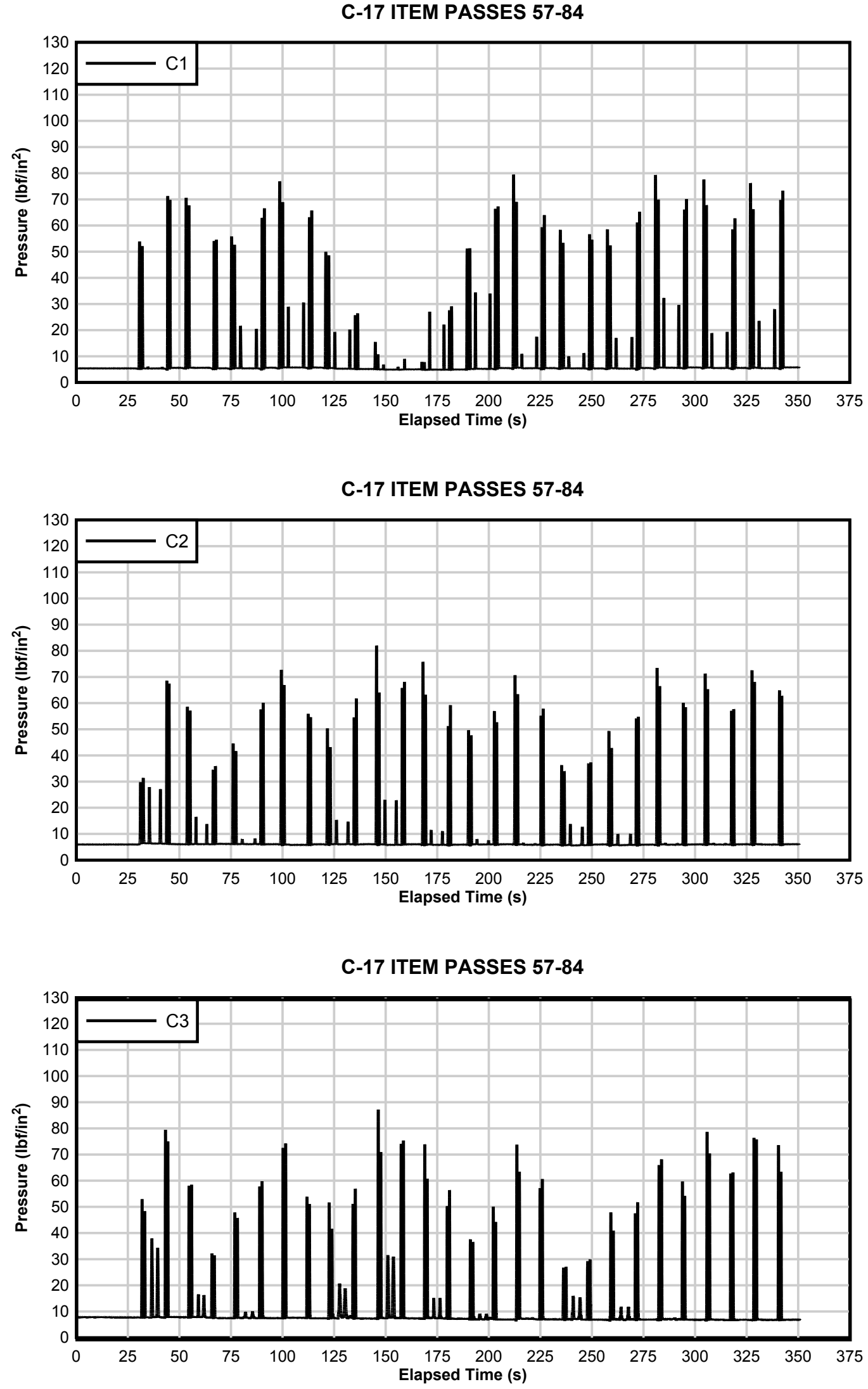


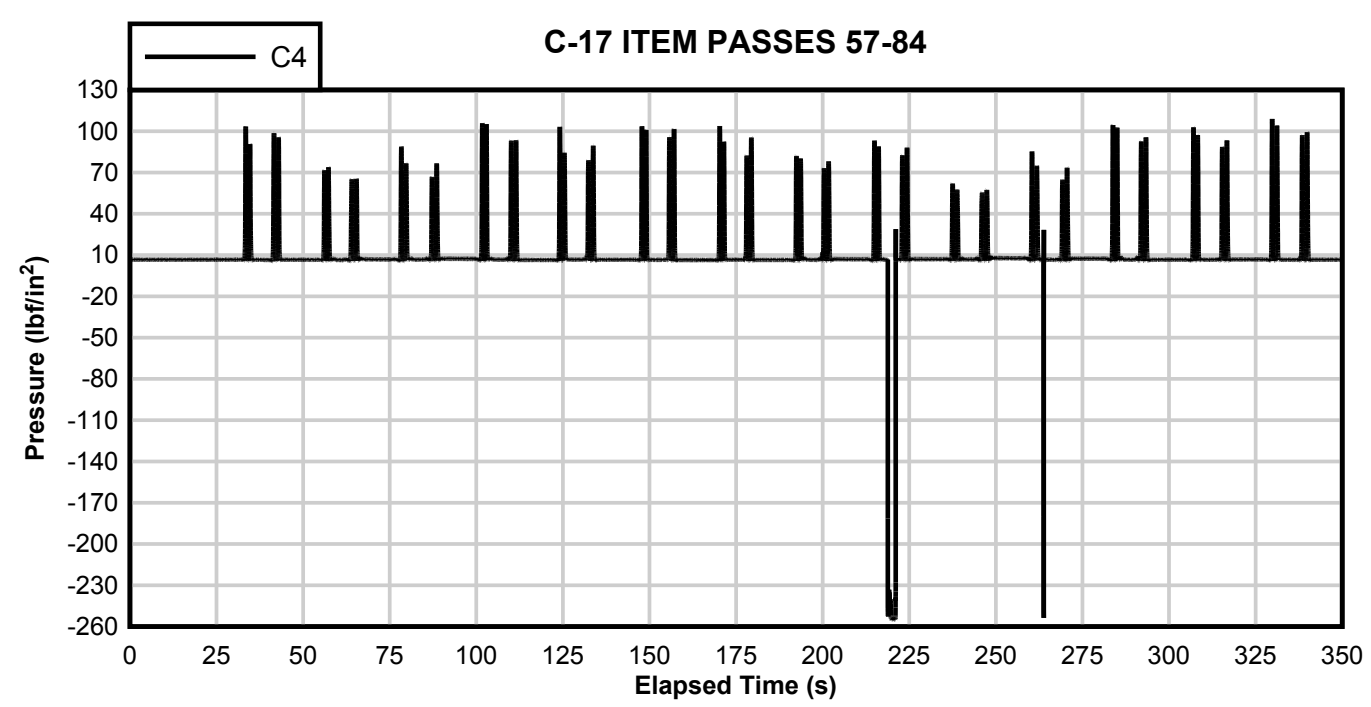

Note: $\mathrm{C}_{4}$ over-ranged in two instances.

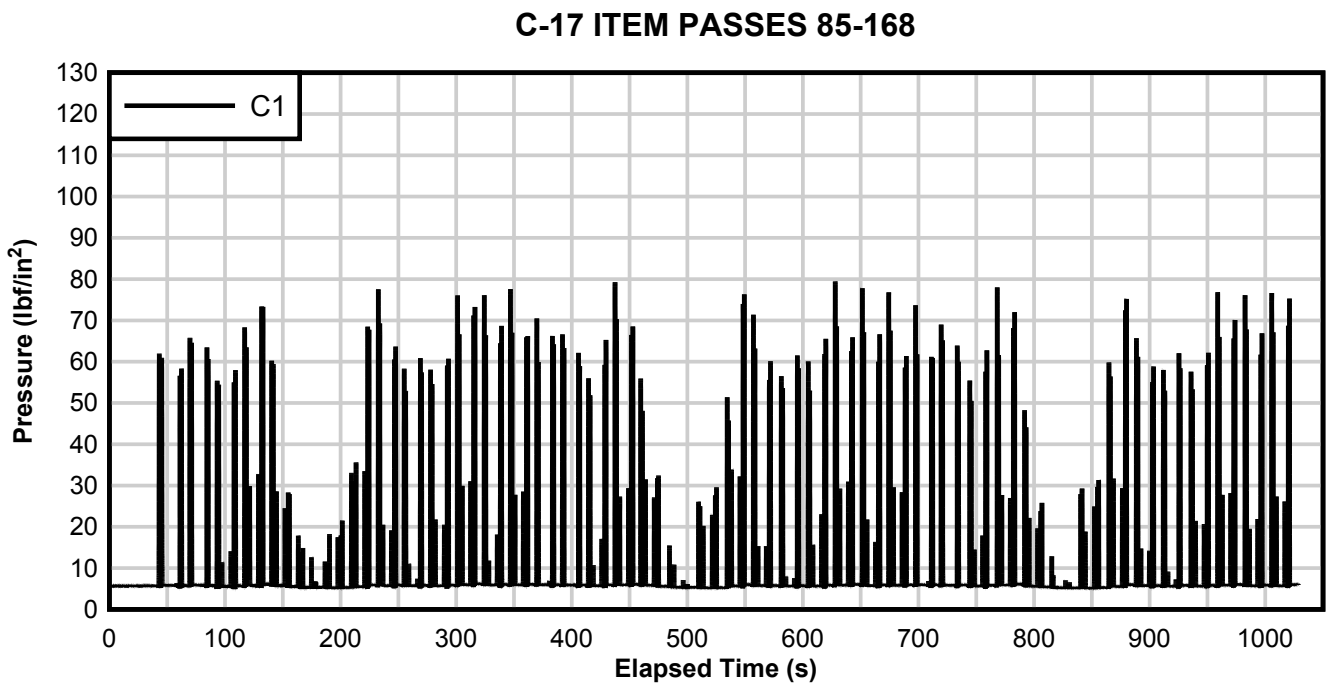



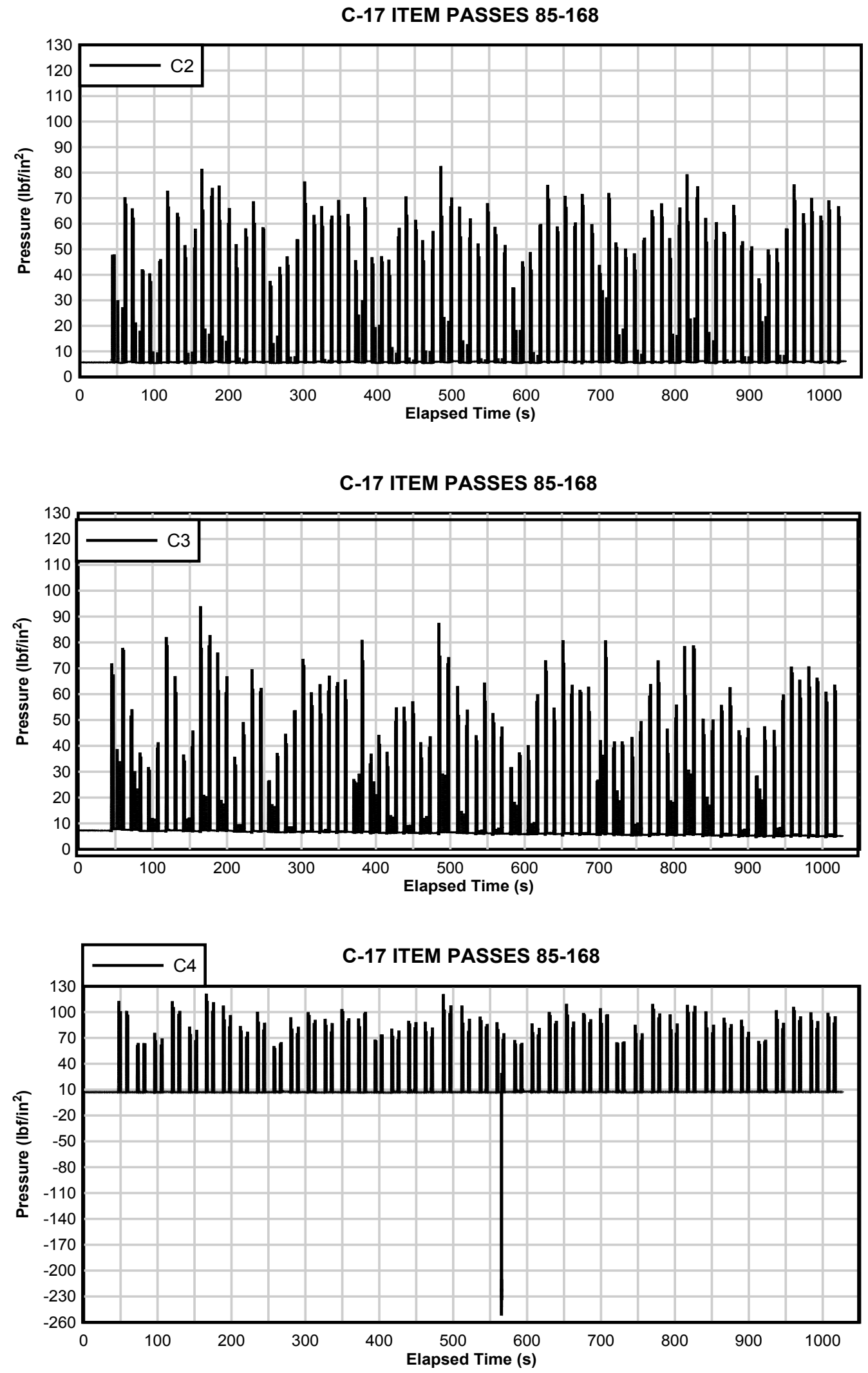

Note: 44 over-ranged in one instance. 


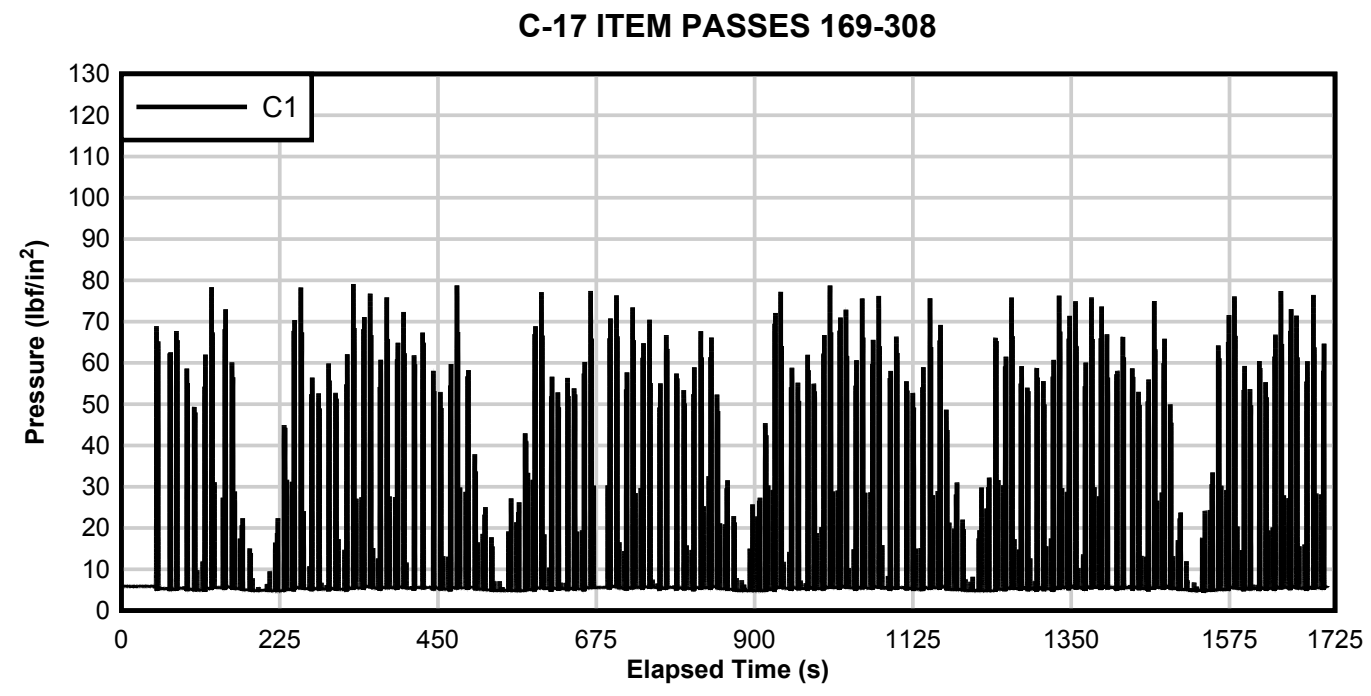

\section{C-17 ITEM PASSES 169-308}

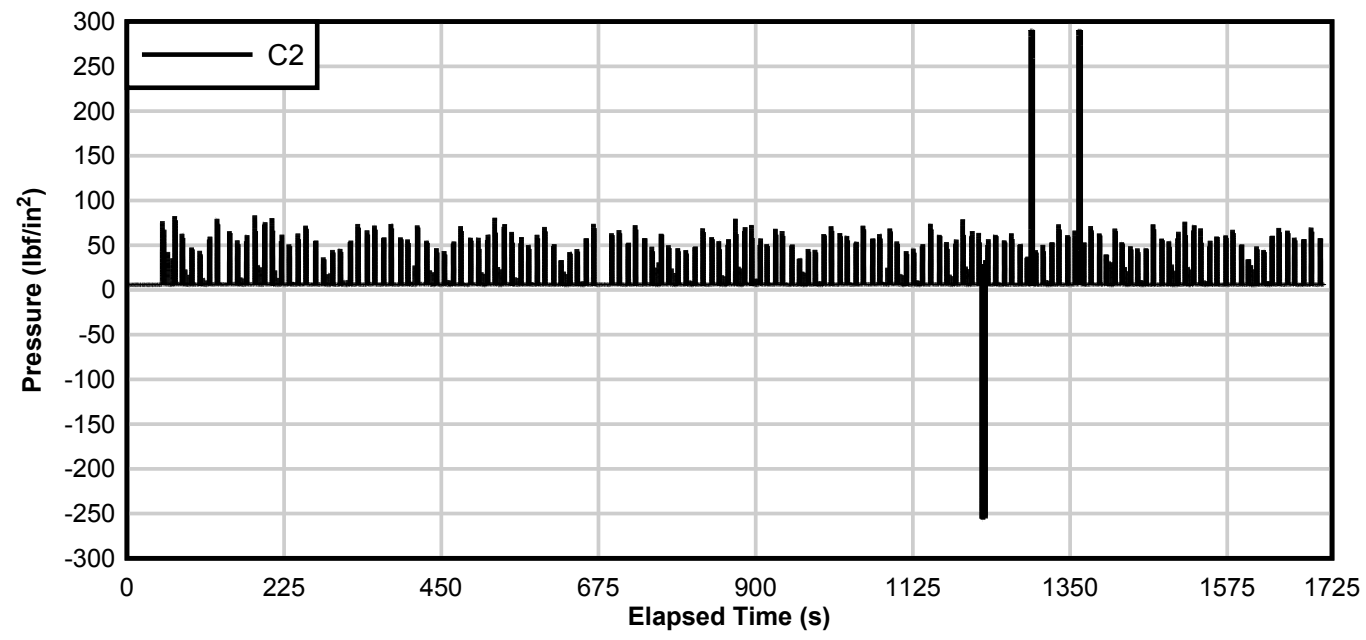

Note: C2 over-ranging in three instances. This data was not reported 


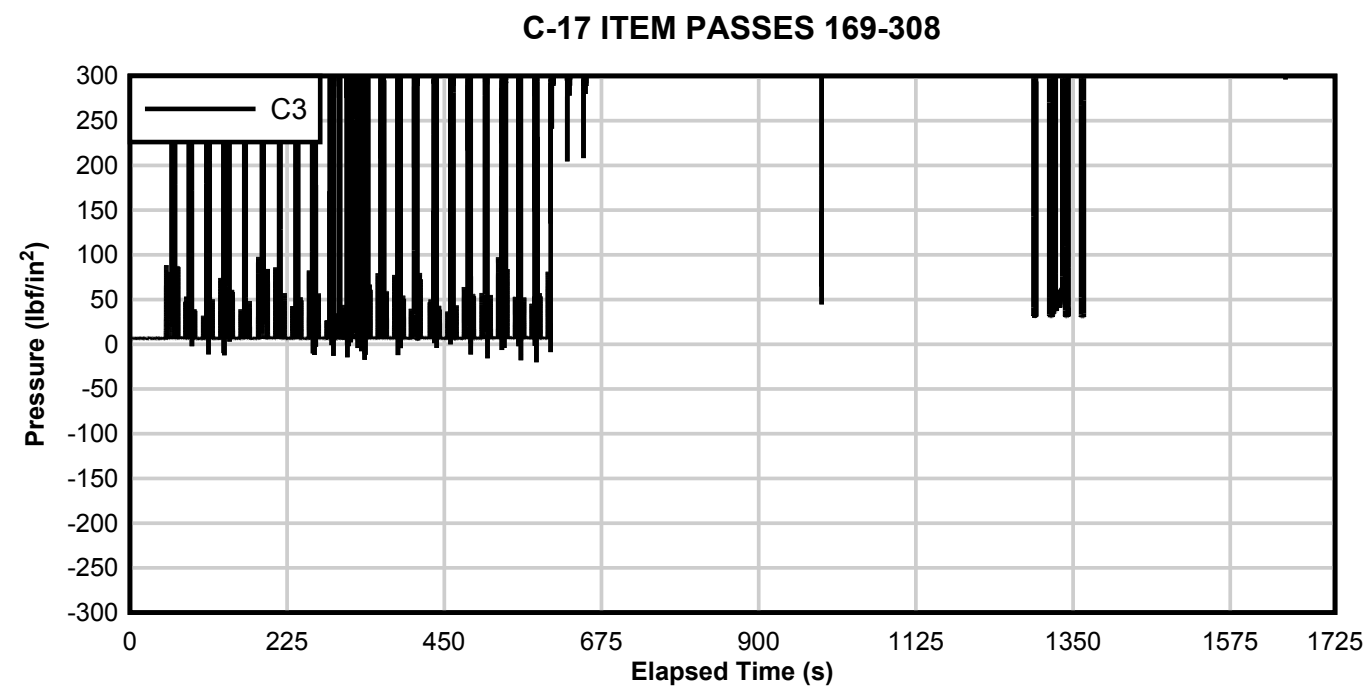

Note: C3 malfunctioned. Did not report usable data after pass 168 .

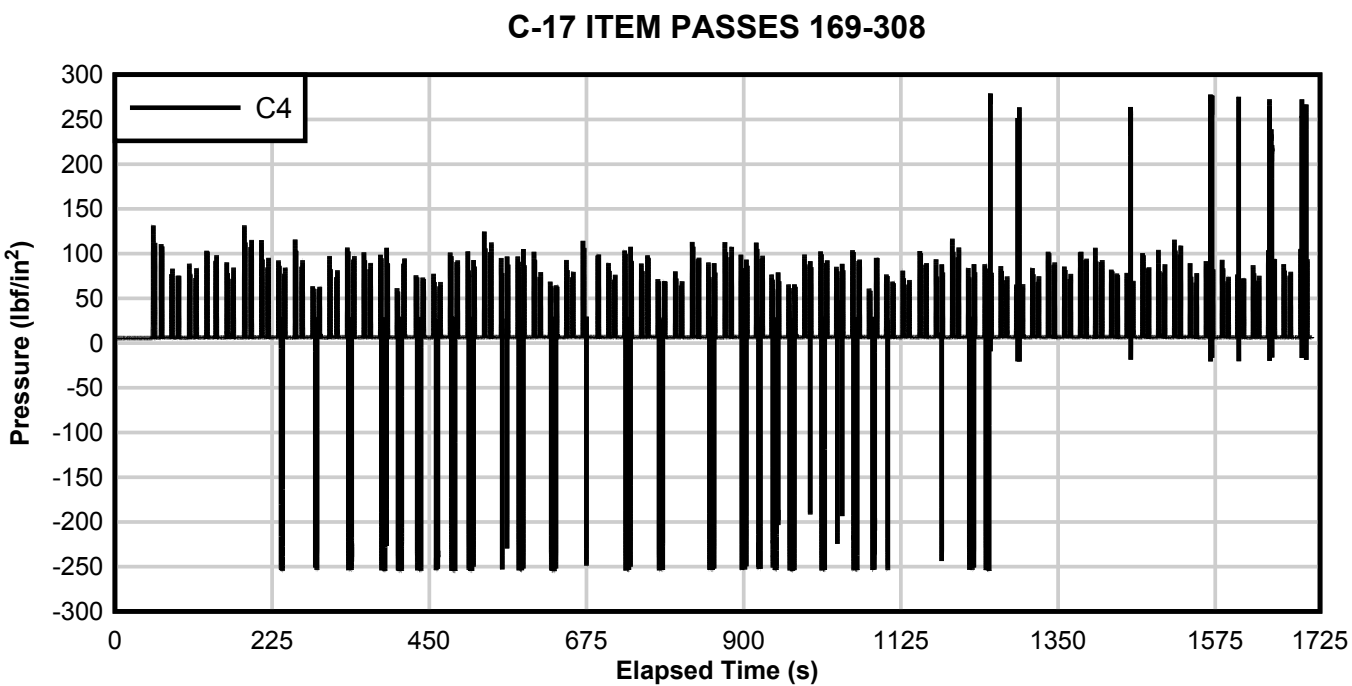

Note: C4 over-ranging. Data not usable after pass 168. 

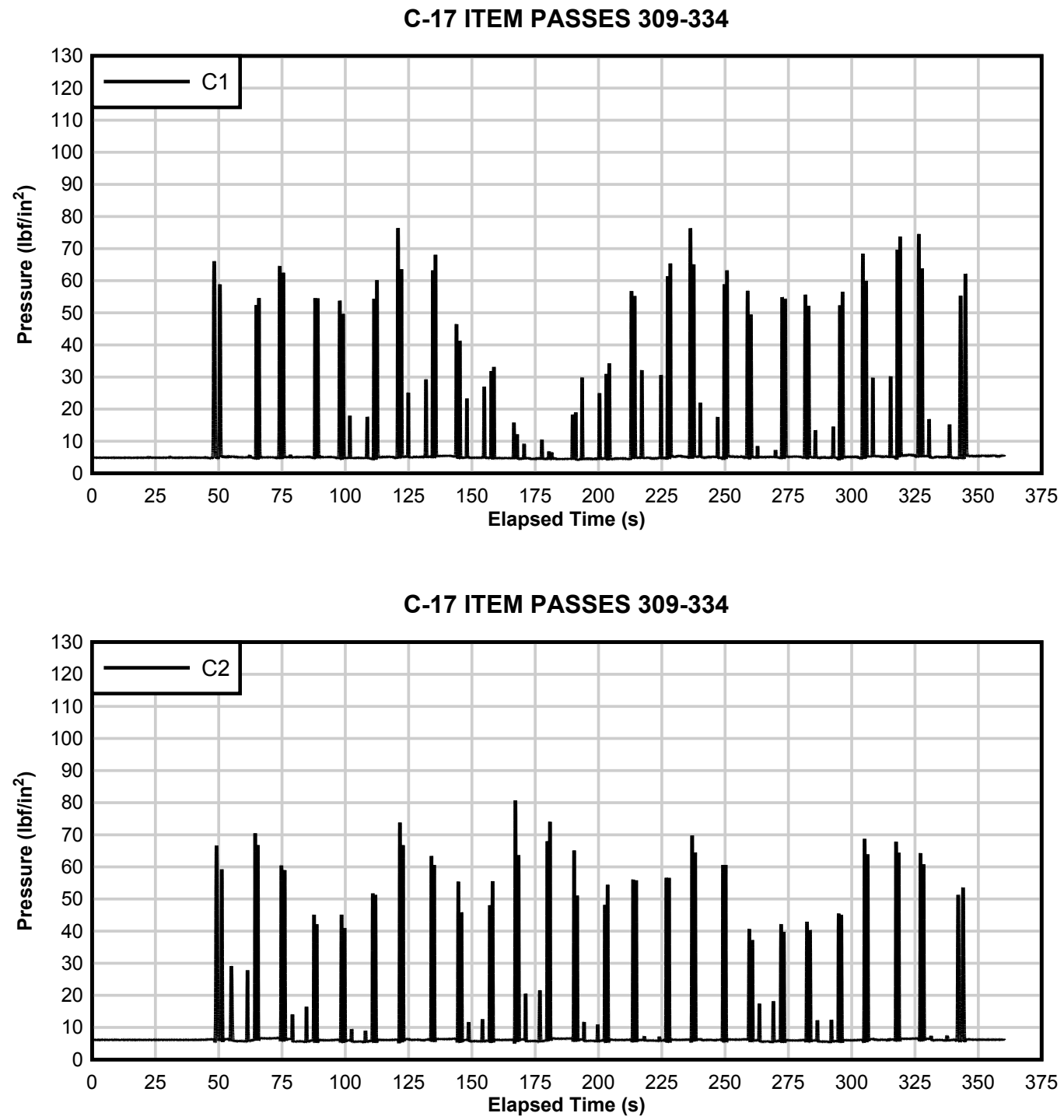

C-17 ITEM PASSES 309-334

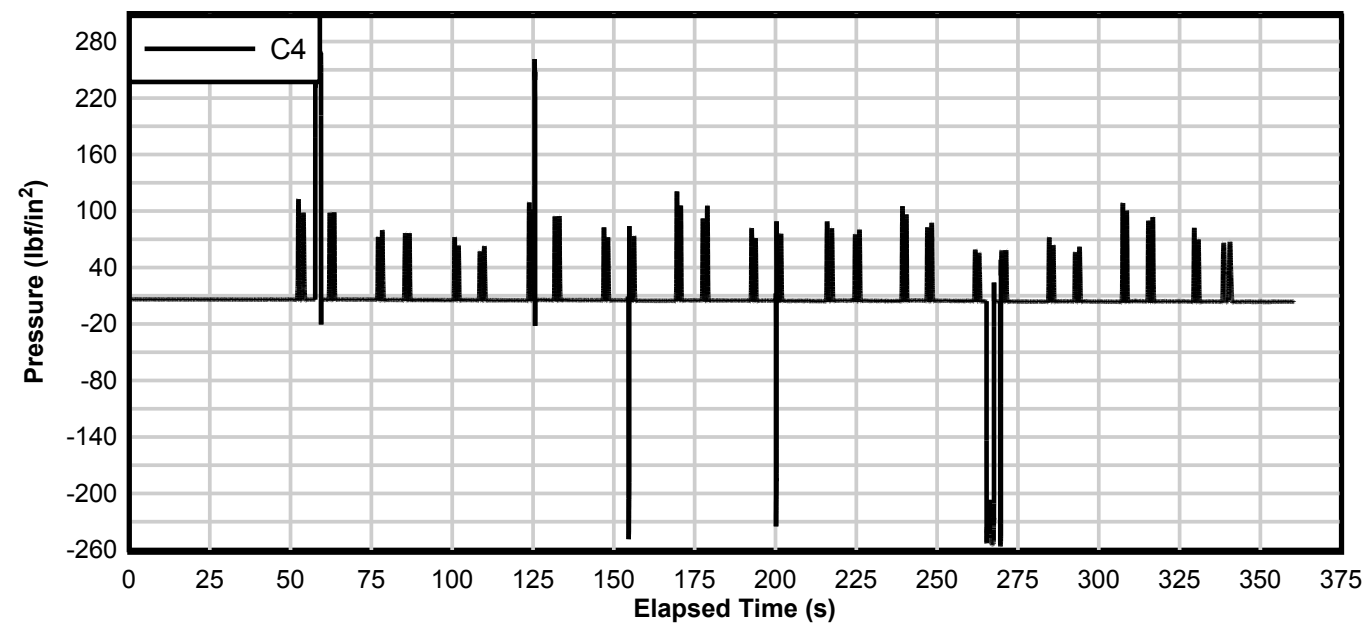




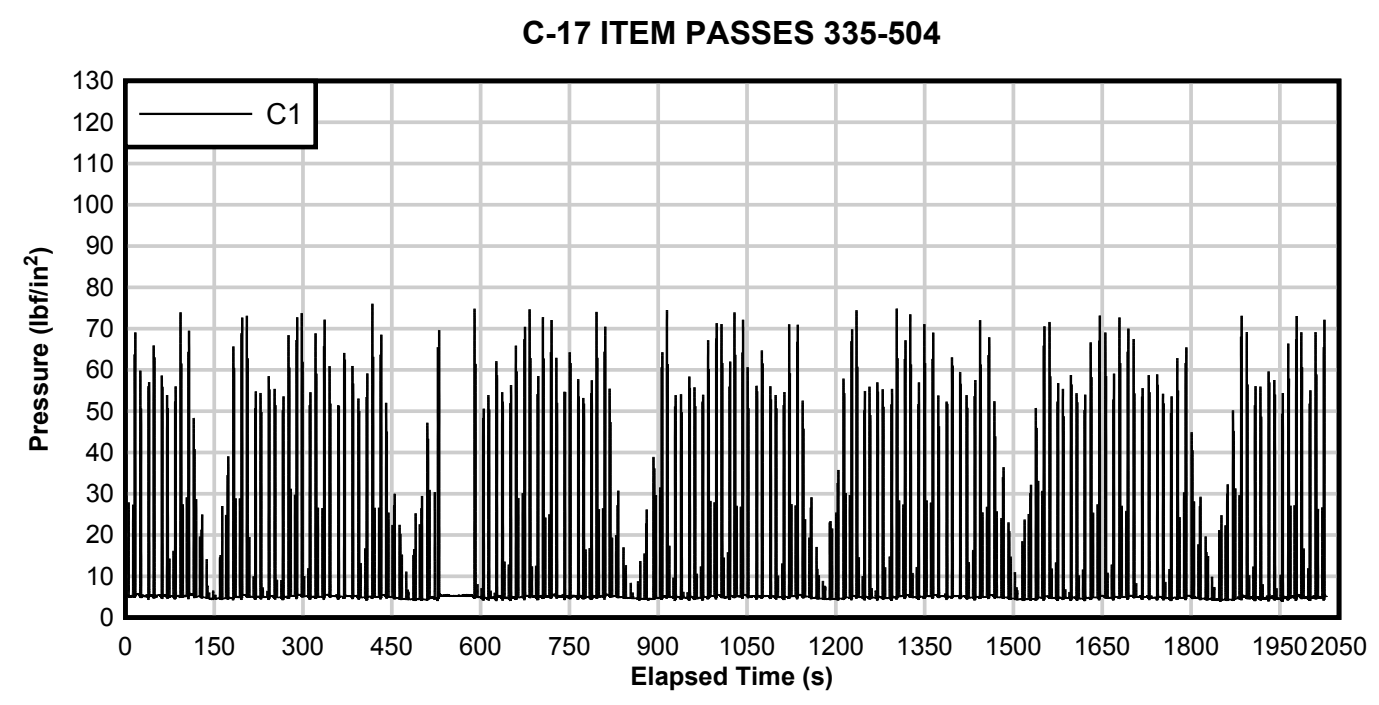

\section{C-17 ITEM PASSES 335-504}

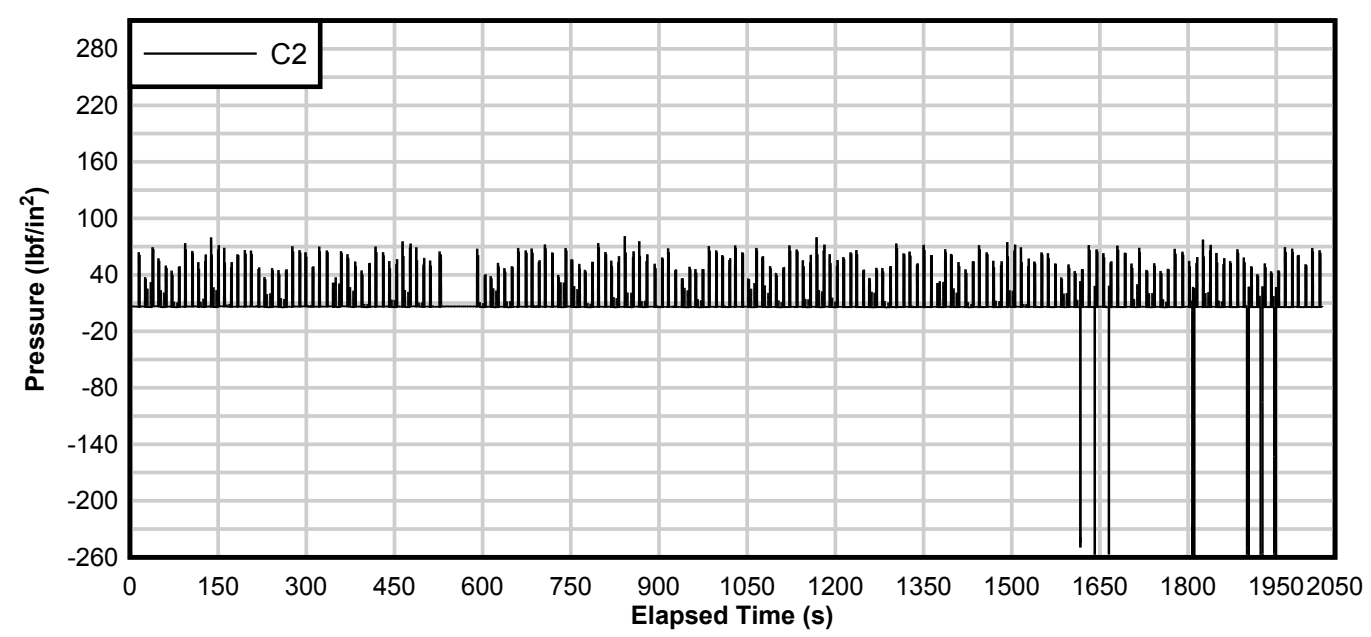

Note: C2 over-ranging during some intervals. This data was not reported 


\section{C-17 ITEM PASSES 335-504}

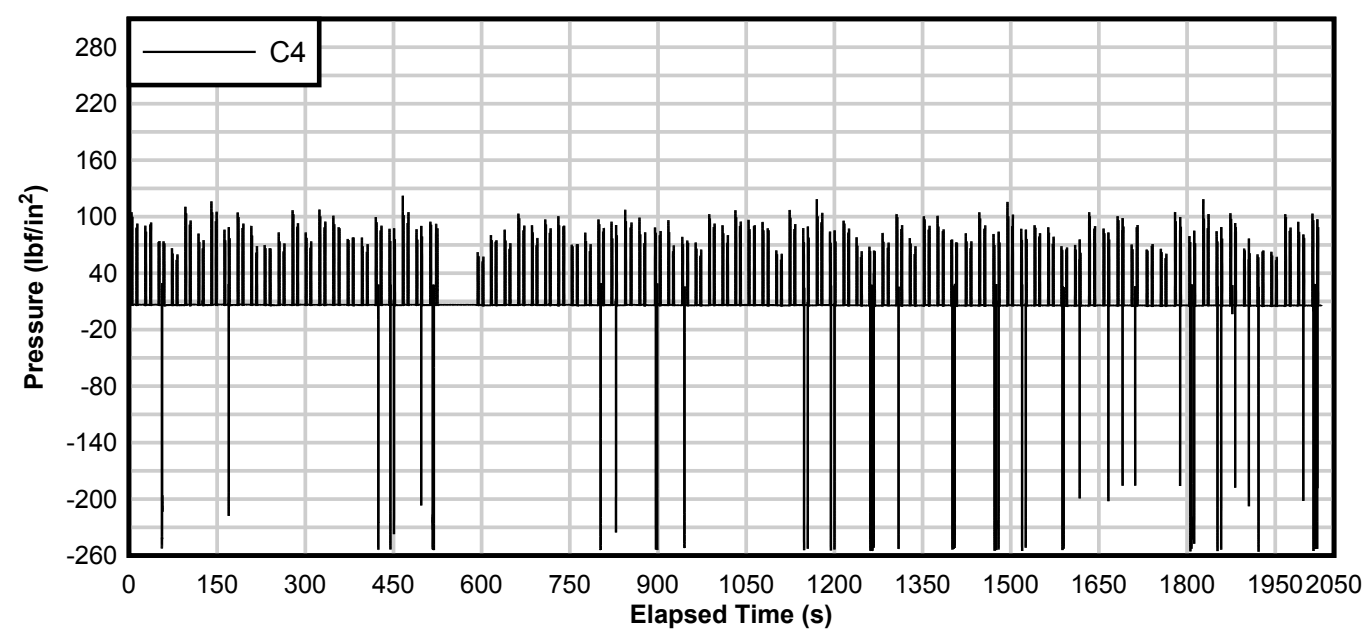

C-17 ITEM PASSES 505-672

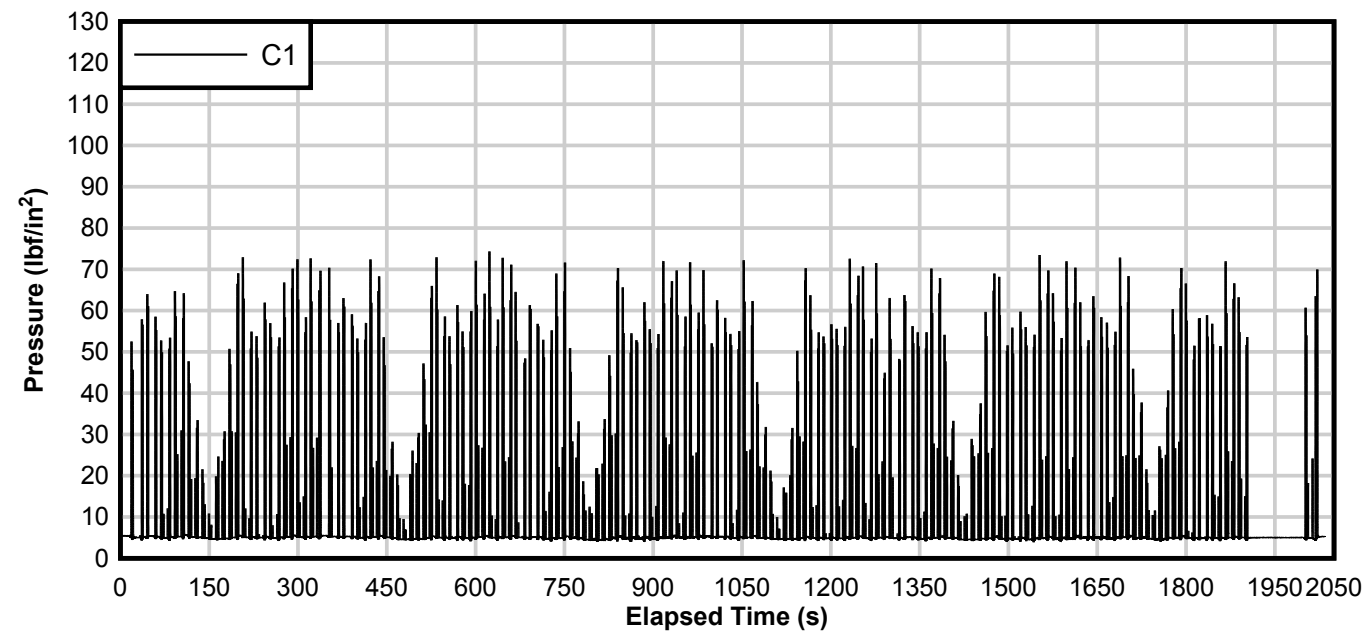

C-17 ITEM PASSES 505-672

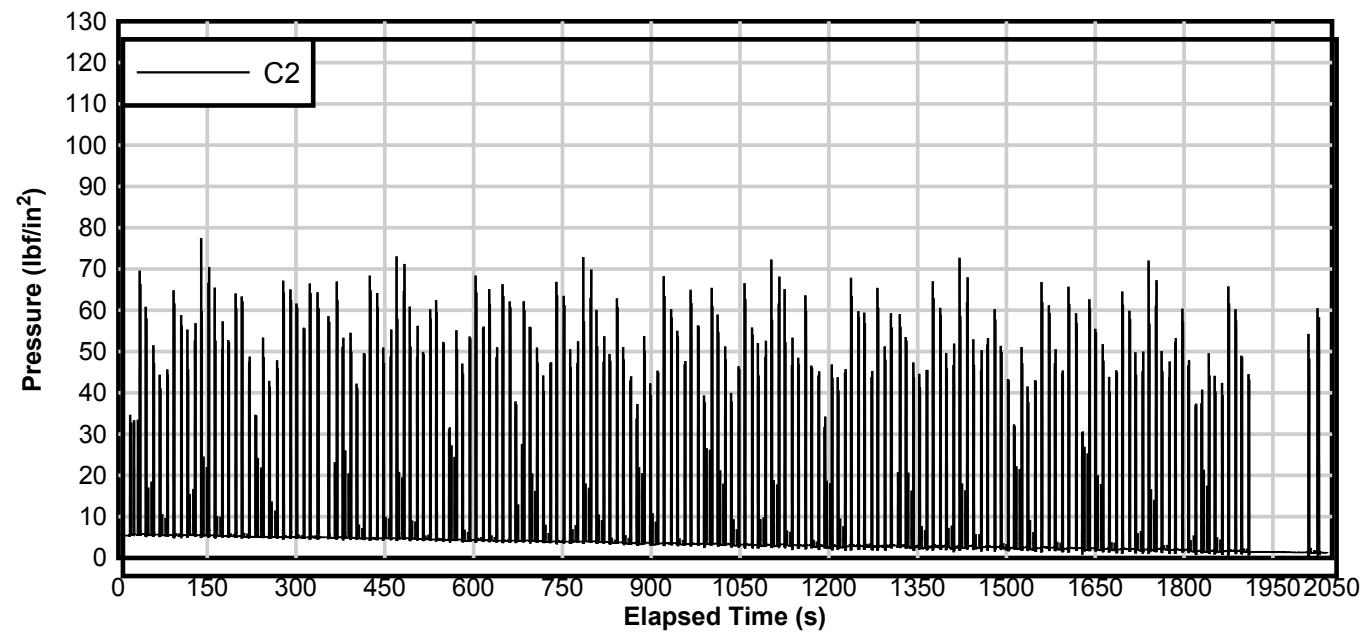




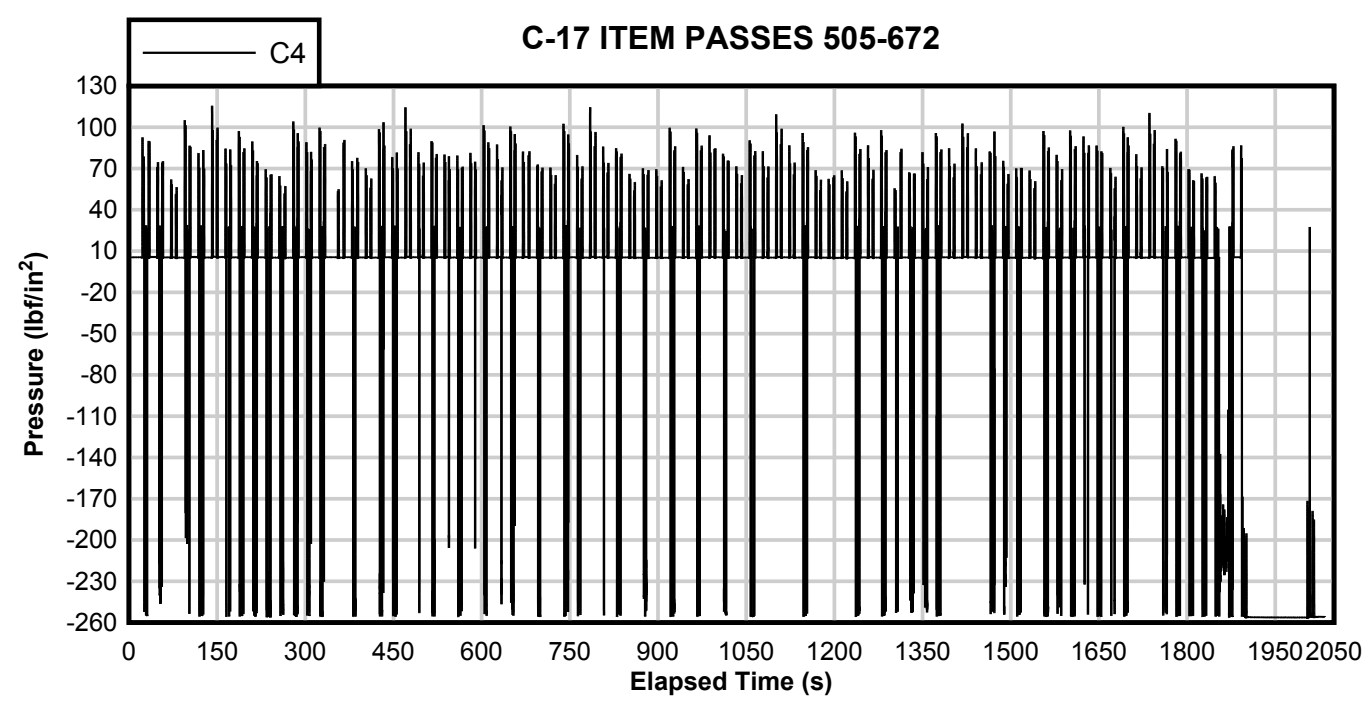

C-17 ITEM PASSES 673-784

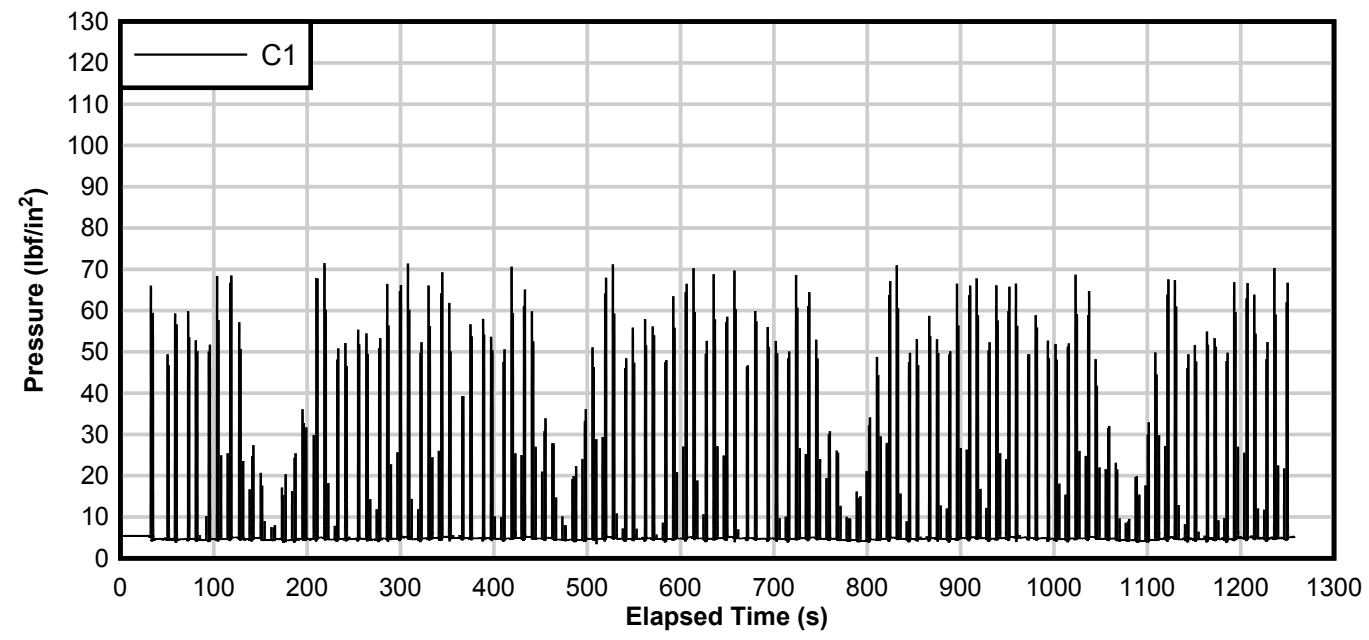

C-17 ITEM PASSES 673-784

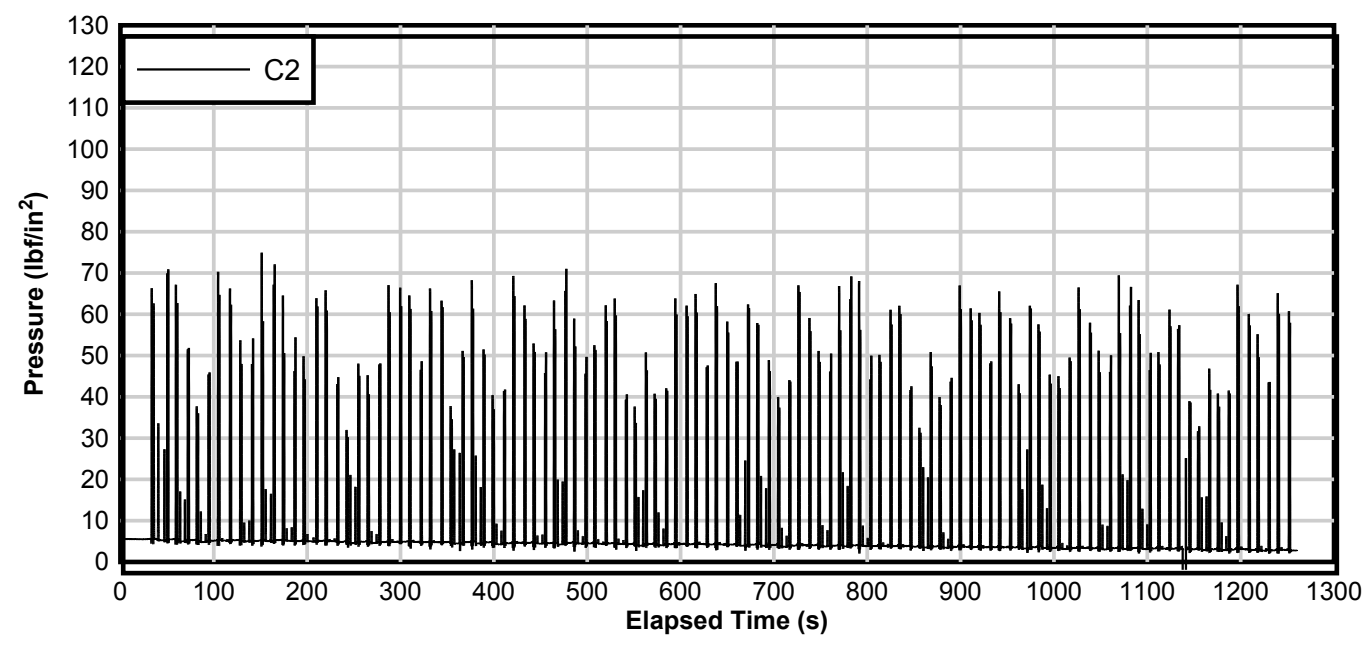




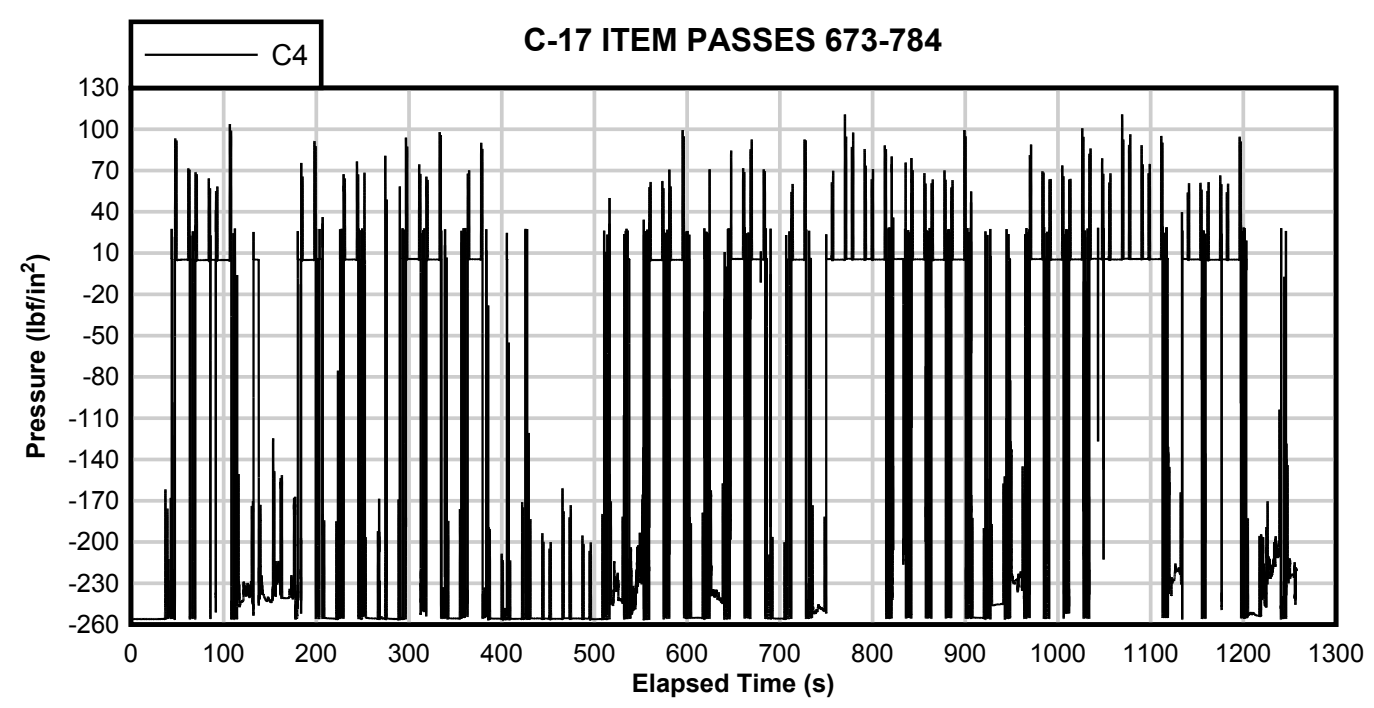

Note: Complete malfunction of $\mathrm{C}_{4}$ after pass 672.

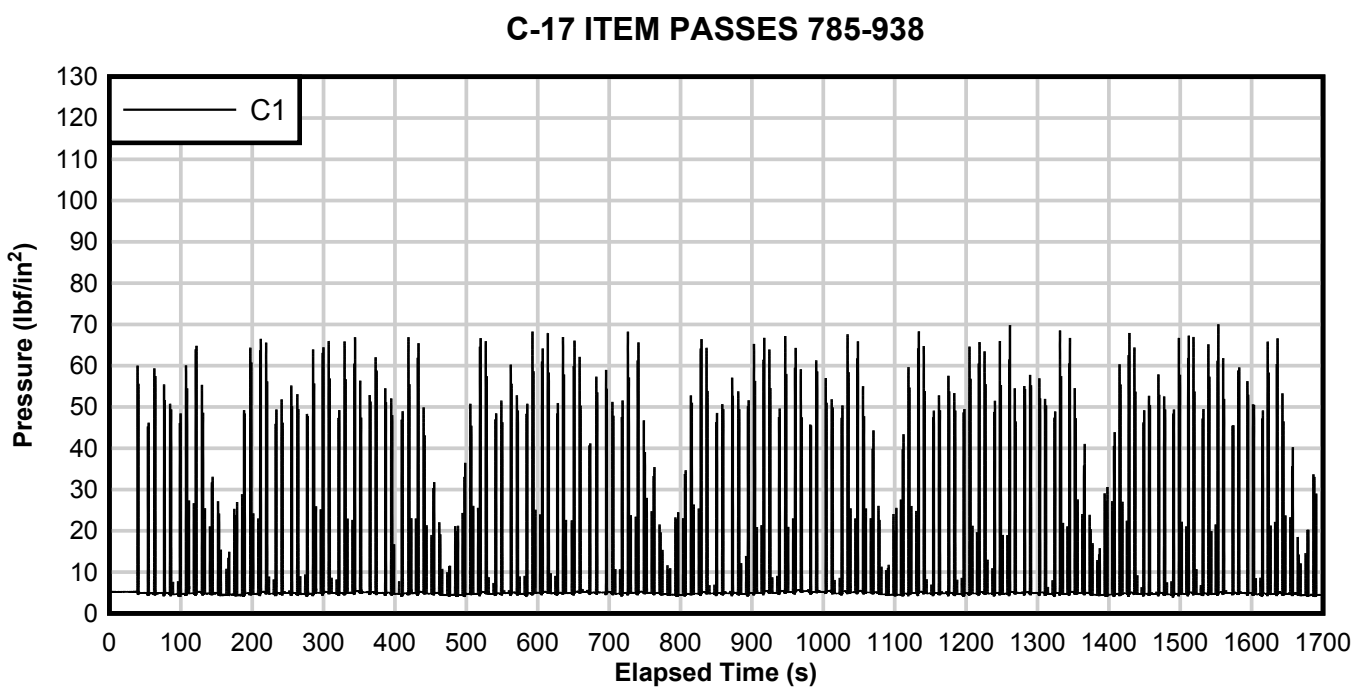




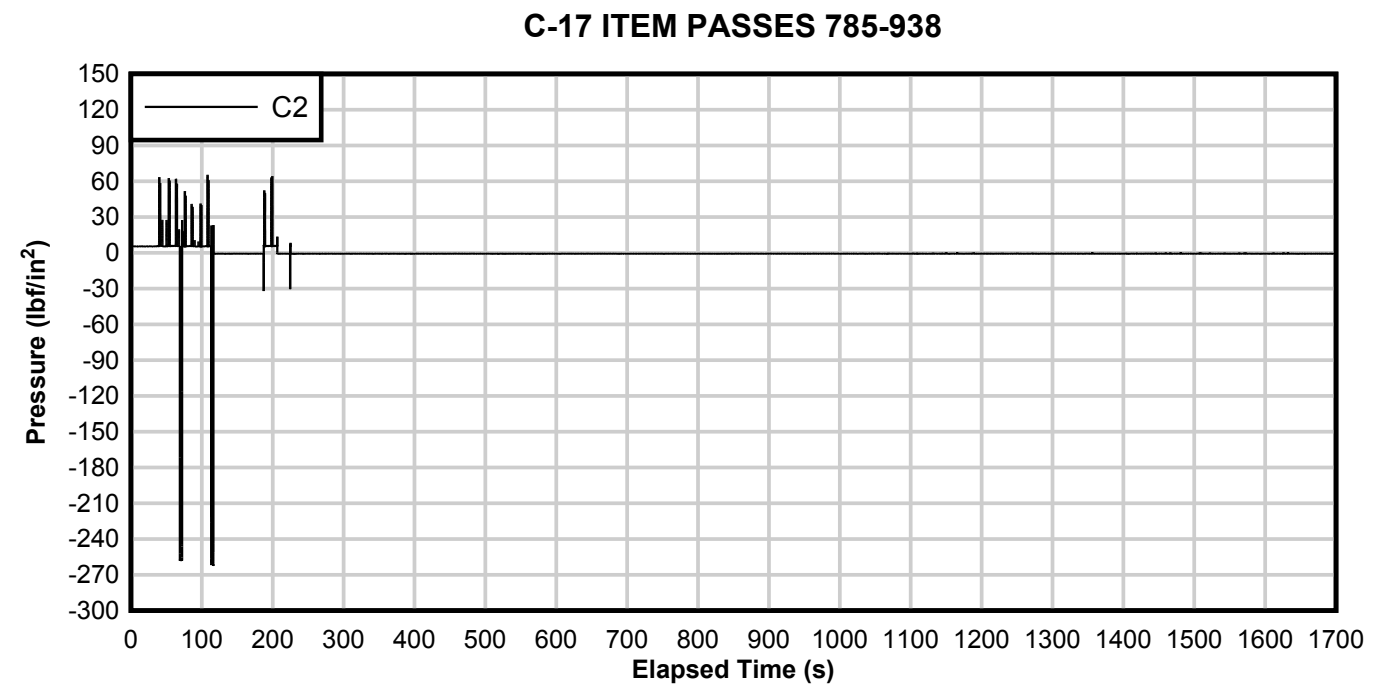

Note: Complete malfunction of $\mathrm{C} 2$ after pass 784

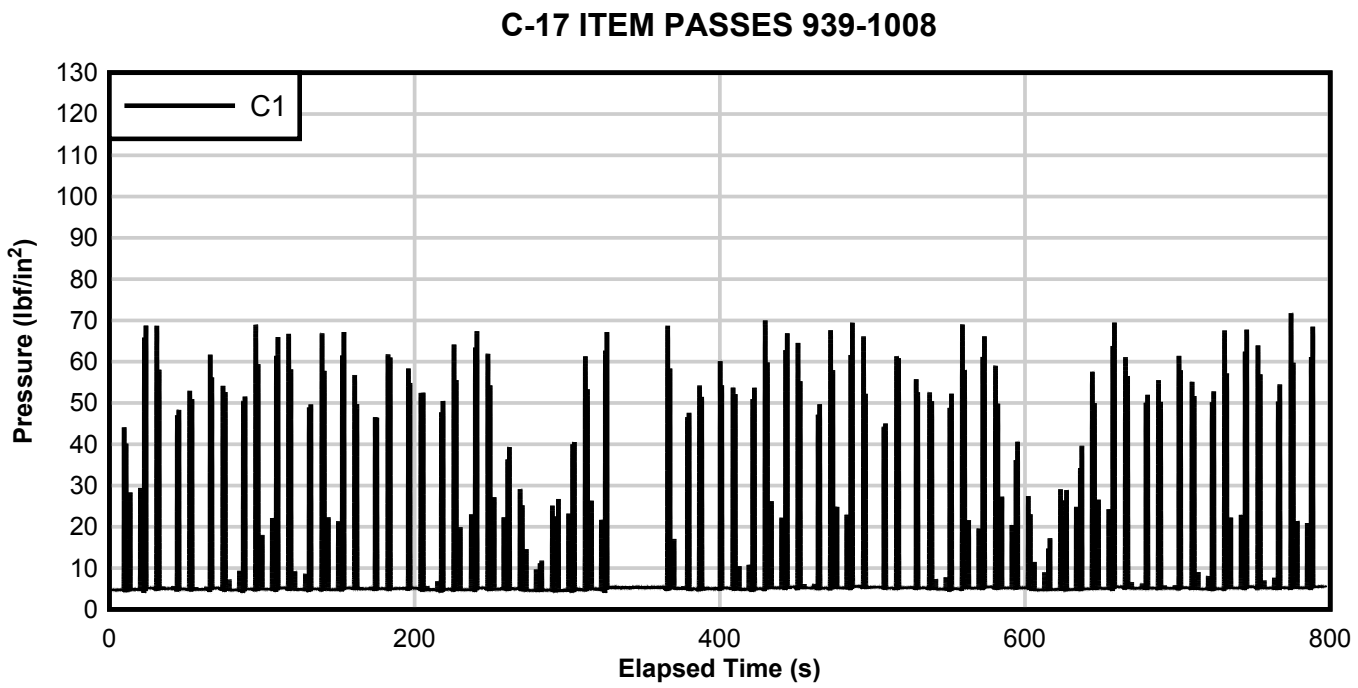




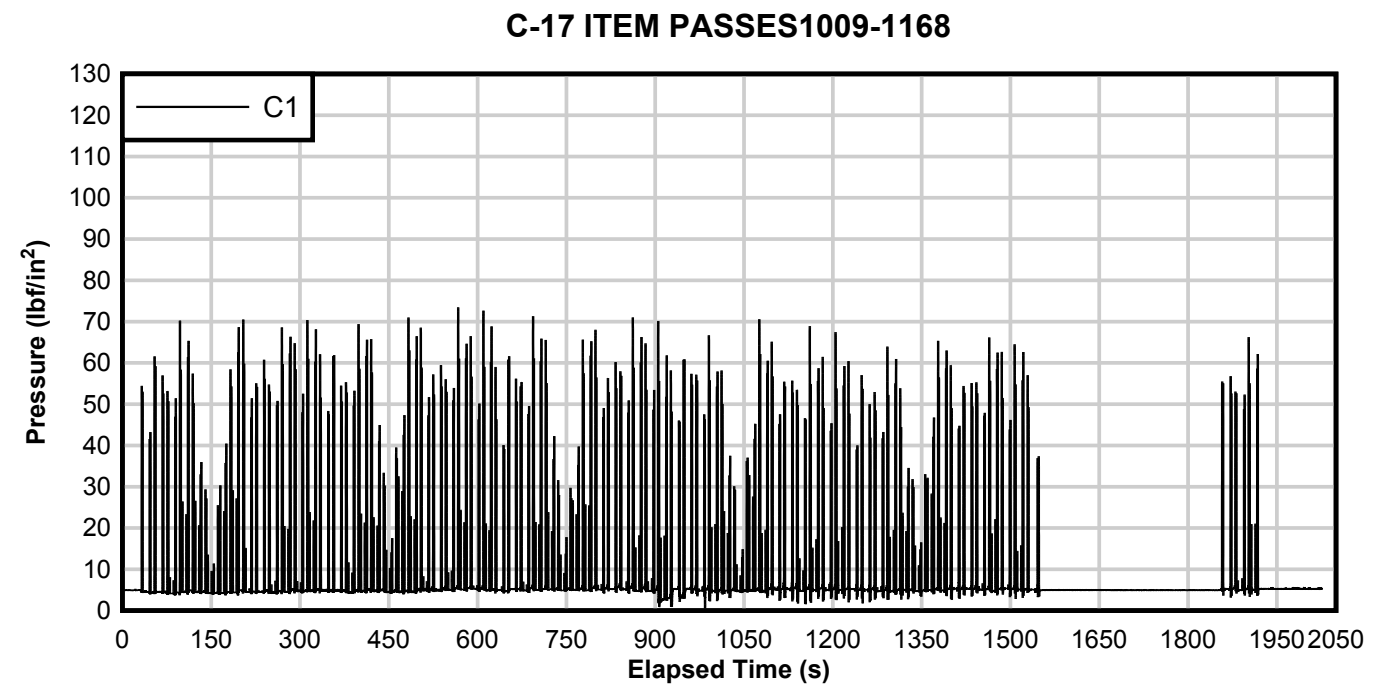

C-17 ITEM PASSES 1169-1215

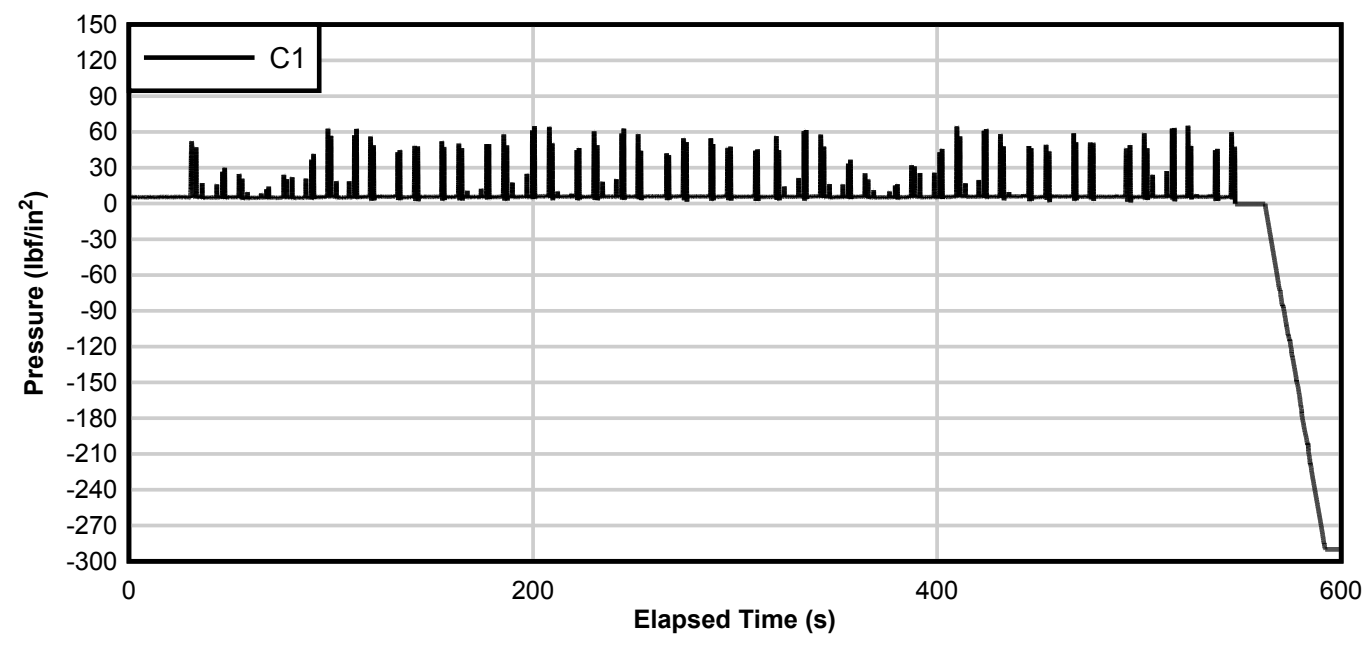

Note: Complete malfunction of $\mathrm{C} 1$ after pass 1,215 . 


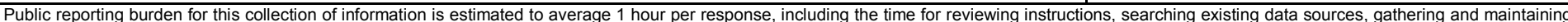

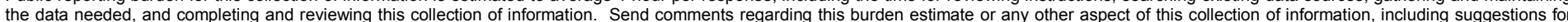

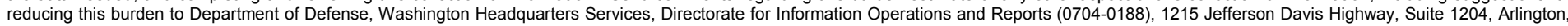

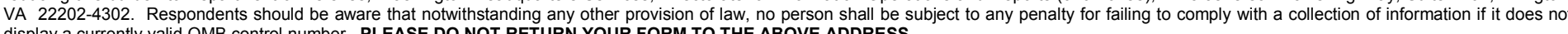
display a currently valid OMB control number. PLEASE DO NOT RETURN YOUR FORM TO THE ABOVE ADDRESS.
1. REPORT DATE (DD-MM-YYYY)
August 2015

AM2 Brickwork Pattern Evaluation with Refurbished Matting

\section{TITLE AND SUBTITLE}

3. DATES COVERED (From - To)

5a. CONTRACT NUMBER

5b. GRANT NUMBER

5c. PROGRAM ELEMENT NUMBER

5d. PROJECT NUMBER

5e. TASK NUMBER

5f. WORK UNIT NUMBER

8. PERFORMING ORGANIZATION REPORT NUMBER

ERDC/GSL TR-15-30

U.S. Army Engineer Research and Development Center

Geotechnical and Structures Laboratory

3909 Halls Ferry Road

Vicksburg, MS 39180-6199

9. SPONSORING / MONITORING AGENCY NAME(S) AND ADDRESS(ES)

Headquarters, Air Force Civil Engineer Center

Tyndall Air Force Base, FL 32403-5319
10. SPONSOR/MONITOR'S ACRONYM(S)

11. SPONSOR/MONITOR'S REPORT NUMBER(S)

\section{DISTRIBUTION / AVAILABILITY STATEMENT}

Approved for public release; distribution is unlimited.

\section{SUPPLEMENTARY NOTES}

\section{ABSTRACT}

The U.S. Marine Corps established different lay patterns to assemble AM2 mat expanses that can be used to form aircraft operating surfaces. The brickwork configuration is the traditional installation pattern and has proven to provide improved load carrying capability of the system. For several years, the U.S. Army Engineer Research and Development Center conducted full-scale testing of the brickwork pattern using new AM2 Mod 5 matting acquired directly from the manufacturer. Several years ago, the Naval Air Systems Command (NAVAIR) implemented a refurbishment program to restore AM2 panels after these have been in service in an effort to reduce frequent large procurements of new AM2 Mod 5. Since AM2 is made from aluminum and has an indefinite service life, many earlier versions, such as two-piece and Mod 4, still remain in the fleet and can be found in refurbished bundles. The efforts of the test program discussed in this report focused on evaluating an AM2 surface that combined both new AM2 Mod 5 panels and AM2 refurbished panels to provide insight on the life expectancy of refurbished panels as compared to new panels. In addition, NAVAIR subgrade void criteria were tested to determine the effect a voided subgrade will have on the structural integrity of AM2. This report provides test results for each evaluation and discussions comparing their performance to previous tests conducted under similar conditions.

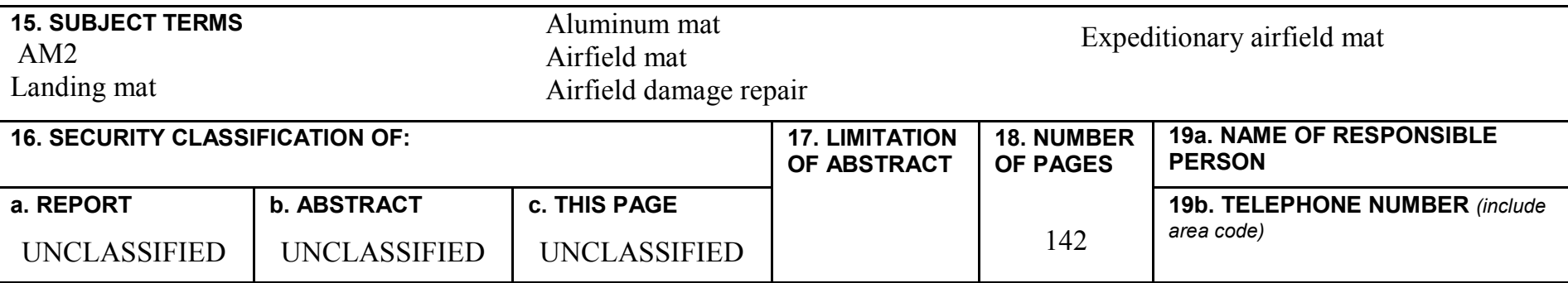

